\title{
MAPPING HOME: LITERARY AND FILMIC REPRESENTATIONS OF MULTI-SCALAR DWELLING
}

\author{
by \\ Aleksandra Bida \\ Master of Arts, Jagiellonian University, Krakow, Poland, 2007 \\ Bachelor of Arts, McGill University, Montreal, Canada, 2005
}

A dissertation presented to

Ryerson University and York University

in partial fulfillment of the

requirements for the degree of

Doctor of Philosophy

in the Joint Program in

Communication and Culture

Toronto, Ontario, Canada, 2014

(C)Aleksandra Bida 2014 


\section{Author's Declaration}

I hereby declare that I am the sole author of this dissertation. This is a true copy of the dissertation, including any required final revisions, as accepted by my examiners.

I authorize Ryerson University to lend this dissertation to other institutions or individuals for the purpose of scholarly research.

I further authorize Ryerson University to reproduce this dissertation by photocopying or by other means, in total or in part, at the request of other institutions or individuals for the purpose of scholarly research.

I understand that my dissertation may be made electronically available to the public. 
Mapping Home: Literary and Filmic Representations of Multi-scalar Dwelling Aleksandra Bida

Doctor of Philosophy in Communication and Culture, 2014

Ryerson University and York University

\begin{abstract}
In this dissertation, I investigate the overlapping individual, relational, and social scales of home in contemporary literary and cinematic texts, drawing on Martin Heidegger's writing on dwelling (as the essence of being human), Zygmunt Bauman's concept of liquid modernity (particularly the commitment avoidance that its "fluidity" fosters), and Jacques Derrida's work on hospitality (both the welcoming and hostile social practices that this term encompasses). I explore these ideas and scales of home in international and multi-medial texts, which include Mark Z. Danielewski's House of Leaves (2000), Neil Gaiman's Neverwhere (television series and novel 1996, graphic novel adaptation 2007), M. Night Shyamalan’s The Village (2004), Nicolas Dickner's Nikolski (2005, trans. 2008), Lars von Trier's Dogville (2003), and Wolfgang Becker's Good Bye, Lenin! (2003). My corpus of texts demonstrates that a traditional understanding of home as a distinct location is incompatible with the realities of liquid modernity, and, moreover, sheds light on new modes of constructing home as a composite of locations and scales - a complex, multi-scalar, geocultural map of identity and belonging. Together, these texts show a dual pattern that makes visible the need to rethink the notion of home: an inclusive map of home on various scales helps home-makers to integrate the various places and people who populate their understanding of home, while the inability to conceive of home in this multifarious way nurtures social fissures, conceptual homelessness, and even psychoses. My main objectives are to challenge neutral, utilitarian conceptions of space, place, and home, and to demonstrate the possibility of what Heidegger calls "poetic dwelling" in liquid modern times and an increasingly inhospitable, market-driven social landscape.
\end{abstract}




\section{Acknowledgments}

I want to thank the amazing scholars and teachers who have been exceptionally generous with their expertise and time. Monique Tschofen, my supervisor, has been an exemplary mentor-(re)teaching me how to write through her incisive feedback and how to teach by sharing advice and modelling engaged teaching at every turn. I am grateful to Susan Ingram for not only supporting the development of this project but her warmth and encouragement in general, and I am particularly thankful that Jonathan Rollins helped me see the value in this work early on and for his many insights along the way. I also want to thank Asha Varadharajan for her astute feedback and helping me see the possibilities of traditional as well as new paradigms of thinking about theory.

I would also like to express my appreciation to the non-academic thinkers who have played a large role in my ability to undertake and finish this work: my mother, Iwona, for helping me feel at home in roughly a dozen corners of the world, decades of patiently listening and fruitful discussion, as well as the genes of calm perseverance that I might one day more fully nurture; my sister, Veronika, for being smarter than I am in most things but not yet noticing this; and old friends, scattered across the globe, who have kindly listened to and read my ramblings and offered enduring sighs as well as ramblings of their own.

This project would not have been possible without the support of the Ontario Graduate Scholarship program as well as Rogers Doctoral Fellowship grants. It would also not have been possible without the remarkable texts that it has been my pleasure to re-read and re-watch. Finally, I would like to express my thanks to the people who keep the Communication and Culture program working in and across two very different universities as well as Ryerson University's Department of English for being such a welcoming place during my time as a doctorial student. 


\section{Dedication}

Pracę tę dedykuję mojemu dziadkowi i mojej babci, Jerzemu i Alicji Wilińskim, którzy pokazali mi, że dom to idea, która przetrwa inwazje, wojny, przesiedlenia i prześladowania polityczne.

Przetrwa nawet wtedy, gdy dzieci przeprowadza się na drugi koniec kraju lub świata.

I dedicate this work to my grandparents, Jerzy Wiliński and Alicja Wilińska, who have shown me that home transcends invasion, war, resettlement, and political oppression. It even transcends children moving to the other side of the country or the other side of the world. 


\section{Table of Contents}

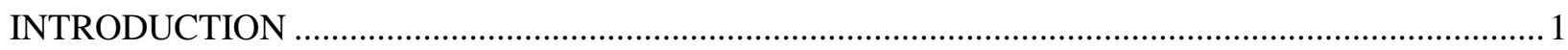

PART I: Home on an individual scale and the philosophy of learning to dwell ............................. 15

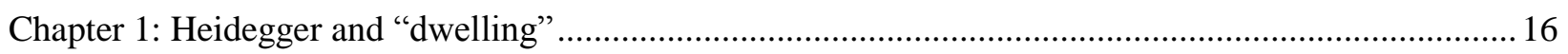

Introduction: dwelling, the process that defines us as human beings .................................................22

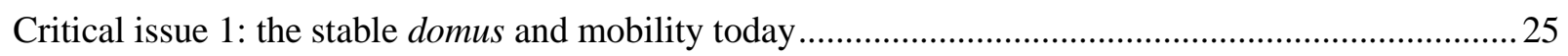

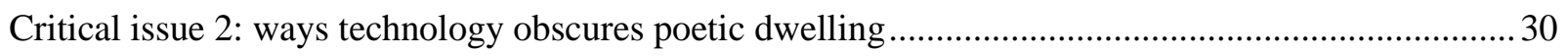

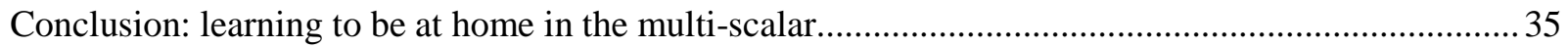

Chapter 2: The labyrinthine home in Mark Z. Danielewski's House of Leaves ......................................... 42

The labyrinthine home as "the state of dwelling" ........................................................................4 47

The issue of mobility: isolation, knowledge, and the labyrinth ...................................................51

The issue of technology: recording and reflecting (on) home …...................................................57

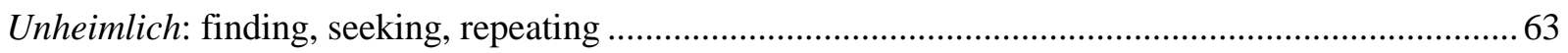

Chapter 3: Homecoming in Neil Gaiman's Neverwhere ….................................................................. 70

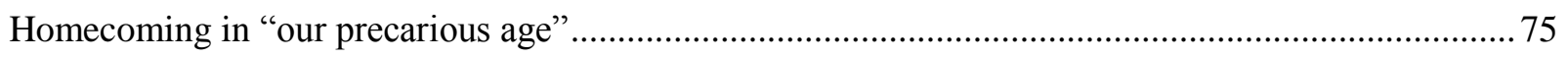

The issue of mobility: poetic images in London Below …................................................................. 79

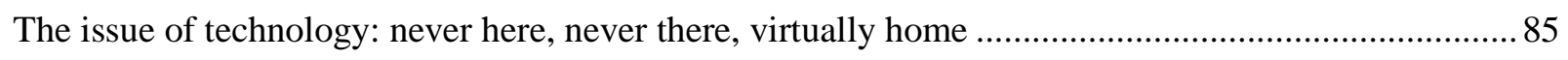

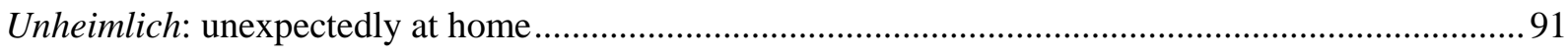

PART II: Home on an interpersonal scale and the economics of mobility ....................................97

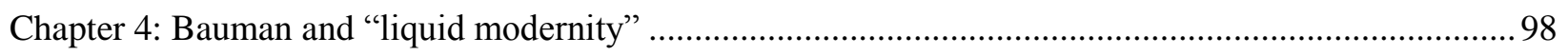

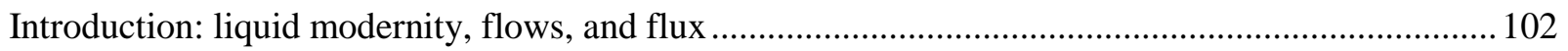

Critical issue 1: commodification and "shopping around" for home.............................................. 107

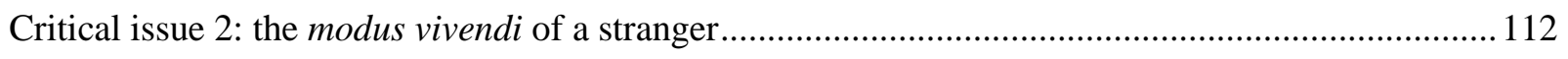

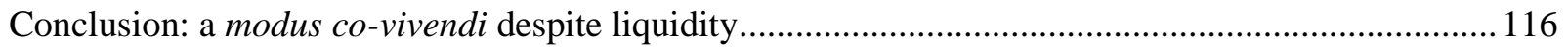

Chapter 5: "Roots" and stability in M. Night Shyamalan's The Village .............................................. 121

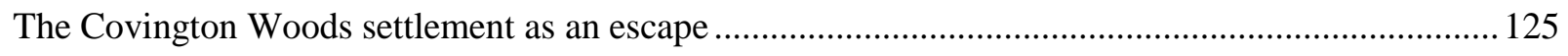

The issue of commodification: buying stability in a liquid modern world ...................................... 129

The issue of strangers: "those we [actually] don't speak of" .......................................................... 134 
The gated community as an unsustainable "ideal" 138

Chapter 6: "Routes" and mobility in Nicolas Dickner's Nikolski. 144

Uprooting nostalgia in liquid modernity . 149

The issue of commodification: mobile identities, garbage, and memories... 152

The issue of strangers: pirates, passersby, and "Applied Nomadology" 158

The liquid modern home as a complex map 165

PART III: Home on a social scale and the politics of (hostile) hospitality. 170

Chapter 7: Derrida and "hostipitality" 172

Introduction: deconstructing hospitality 176

Critical issue 1: designating "guests". 181

Critical issue 2: the scales and politics of home 185

Conclusion: recovering home through "hostipitality" 190

Chapter 8: Welcome as house arrest in Lars von Trier's Dogville . 196

Public and private hospitality in Dogville. 199

The issue of guests: "giving" Grace "place" (and keeping her in it) 204

The issue of scales: invisible walls and the social order of Dogville....... 210

Home or not: a failure to conceptualize the multi-scalar home 215

Chapter 9: "Home safe" in spite of hostility in Wolfgang Becker's Good Bye, Lenin! 220

Public and private histories in Good Bye, Lenin!. 224

The issue of guests: "giving place" in an imagined home 229

The issue of scales: inside out and outside in 234

Mapping the multi-scalar: rooms, neighbourhoods, cities, worlds .239 CONCLUSION 244

Bibliography 261 


\section{INTRODUCTION}

...the text [is] habitable, like a rented apartment.

- Michel de Certeau

All too often home is defined by nostalgic whimsy, childhood memories, or patriotic rhetoric, yet this construction remains weighty, emotionally and politically loaded. In her novel, Kartography, Kamila Shamsies gestures towards the crux of this issue: "Who among us has never been moved to tears, or to tears' invisible counterparts, by mention of the word 'home'? Is there any other word that can feel so heavy as you hold it in your mouth?" (63). The importance of the idea of home, I argue, stems from its links to the construction of personal and communal identity. Cultural geographers Alison Blunt and Robyn Dowling point to the way in which "people's senses of themselves are related to and produced through lived and imaginative experiences of home" (24), yet the relation of home to identity remains largely undertheorized. David Morley in his standout text, Home Territories, begins a much needed analysis of the impact of ways in which we make, leave, and transform not only physical but conceptual homes. Morley focuses on the larger "territories" possible through communication technologies, and also covers related notions of belonging, the distribution of privacy, the evolution of comfort and domesticity, as well as homelessness in a materially "home-centred culture" (26) in which full citizenship implies property ownership or owning literal "roots." His overview suggests some of the ways in which home permeates identity as well as innumerable dimensions of society, and raises important question regarding how we understand identity, society, and their interrelationships in the twenty-first century. My contribution to this emergent discourse is to examine the rich imaginary landscapes of contemporary literary and cinematic texts in order to build on the sparse but incisive multidisciplinary scholarship on the ontology of home and what I call the process of 
"home-making" (in which a gender-neutral "home-maker" quite literally "makes" him or herself at home). I look at a series of literary works and films, hailing from the US, Canada, England, Denmark, and Germany around the turn of the twenty-first century, arguing that they illuminate the stabilities and mobilities through which home not only mediates but also integrates an individual's diverse experiences of belonging in different locations as well as on different scales - from the intimate "household" to the more abstract "homeland" and beyond. My analysis shows that self-concept is deeply tied to constructions of home in a mobile and global age through an epistemological link between "knowing oneself" and being able to map "one's place(s) in the world."

One reason this idea is so vital is that home makes visible the constructed nature of the divisions between space/place as well as public/private. How we understand these two sets of terms has many socio-political ramifications since such categorizations shape cultural mores and social norms regarding privacy and isolation, as well as levels of control or forms of agency in "making" home. Conventional understandings of space and place suggest that the former is an objective geographic concept while the latter is a subjective construction of lived experience, but this dichotomy has been perceptively re-evaluated, notably by geographer Doreen Massey, who claims that space is always in process and created through interrelations and plurality (9). Massey challenges the idea that space can be neutral, and my analysis of theoretical and creative texts similarly undermines the notion that the space, place, and idea of home can be neutral as a fully exchangeable structure or location, only internalized through nostalgic memories. The public/private distinction that home makes visible mirrors the issues of space/place. In fact, the category of the public aligns with space (as an objective sphere) and the private with place (through subjective experience). I will show how literary and filmic texts can collapse the 
public-private binary by depicting everyday experiences of the liminal role of home, which is both privately and publicly constructed through the experiences of restricted and communal spaces or places. In the following chapters, through my analysis of the personal, interpersonal, and social scales of home, I develop new ideas about the ways in which home problematizes a firm distinction of public/private and space/place since home signifies connections to spaces imbued with publicly and privately inscribed meaning. Furthermore, by highlighting the visceral, multi-sensory memories and associations aggregated by "home-makers" through this conceptual nexus of stability and mobility, I examine the ways in which cultural texts demonstrate the centrality of home to both self-concept and communal identities.

\section{Identity and homogeneity: one "home sweet home" does not fit all}

The specific works that I treat here are in many ways representative examples of an emergent discourse in North American and European literature, film, visual arts, philosophy, as well as in public discourse. They engage with but also destabilize the kinds of nostalgic ideas about homes that grew out of the Romantic era. Rootedness and belonging, Heimat, as well as idealizations of nature and nationalisms took their shape under particular social and historical circumstances and yet persist despite the fact that the realities of the contemporary hyper-mobile world create very different sets of experiences. When authors and filmmakers undertake the project of rethinking home-where it begins, where it ends, what it feels like, what it does and does not do, what it can and cannot do- they interrogate naturalized modes of understanding our "corner" of the world and what an individual role is in constructing it or conceding to outside

forces. Authors and filmmakers are able to unpack some of the intricate complexities of issues that include urbanization, settlement, and immigration; the manifold effects of transit and 
communications technologies, which facilitate a composite sense of home; the cultural logic of global market capitalism and its fetishization of impermanence and interchangeability; the complexities of personal and collective allegiances; the boundaries between public and private; the weight of history and the (false) promises of unequivocal progress and universal freedom in the new millennium. Furthermore, by constantly keeping the human subject's experience in the foreground, authors and filmmakers are able to present what is at stake with these various factors in ways that by themselves philosophy, cultural geography, cultural studies, and other disciplines cannot. In a broad sense, the works that I analyze in this dissertation foreground the economic disparities and personal struggles that have been overshadowed by the social discourses that proclaim freedom and prosperity in an era of "global" citizenship and belonging, and as such, can be considered as critical responses to the scholarship in the 1990s that celebrated postmodernism's multiplicities and a relativism that exacerbated an emphasis on the benefits of change, flows, and uncertainty. Ultimately, what can also be discerned when authors, filmmakers, and other artists undertake the project of rethinking how to think about home, is the modelling of new ways of reflecting on—even dwelling on—dwelling, in concert with some of the central thinkers of the twentieth century.

By mapping and analyzing the home-making processes in Mark Z. Danielewski's House of Leaves (2000), Neil Gaiman's Neverwhere (television series and novel 1996, graphic novel adapted by Mike Carey and Glenn Fabry 2007), M. Night Shyamalan's The Village (2004), Nicolas Dicker's Nikolski (2005, trans. 2008), Lars von Trier's Dogville (2003), and Wolfgang Becker's Good Bye, Lenin! (2003), I show how flexible some twenty-first century notions of home are. My texts investigate the problems of working within old frameworks or traditional conceptions of a singular, static home. Moreover, these works demonstrate how home, instead of 
being an antiquated idea or needless tether, can remain a formative space and become an integrative anchor amidst the global flows of people, products, and ideas. The metaphor of an anchor, like a suitcase or any metonymy for mobility, is too singular and explicitly tangible to suggest the expansive reach of the idea of home, and I will show through my close reading of exemplary, allegorical homes that home can be conceived more comprehensively as a kind of map. To this end, I reconstruct the partial maps of home of key protagonists as they navigate the psychological, material, and social experiences of tangible home spaces as well as myriad intangible dimensions. Together, my primary texts show a dual pattern which makes visible the need to rethink notions of home: the inclusive map of home on various scales helps home-makers to integrate the various places and people who populate their understanding of home, while the inability to conceive of home in this multifarious way nurtures social fissures, conceptual homelessness, and even psychoses.

In linking home to individual and communal identity, I build on the claims of theorists like Stuart Hall and Iris Young who describe identity as something that remains in process. I draw on Hall's sense of "identity as a 'production', which is never complete, always in process, and always constituted within, not outside, representation" (222). The idea of home is a part of this production, embroiled in the complexities of representation. What is even more salient for a discussion of home is Hall's claim that "identities are the names we give to the different ways we are positioned by, and position ourselves within, the narratives of the past" (225). This "positioning," I contend, is in part articulated through the locations and links that are claimed by an individual or assumed by others as that individual's home. Cultural identities, as "the unstable points of identification or suture, which are made, within the discourses of history and culture," according to Hall constitute "[n]ot an essence but a positioning" (226). For me, to conceive of the notion of home as a 
map — one that is immersive, multi-dimensional, and multi-scalar-offers a means of contextualizing such a positioning. My primary texts test and reject the notion of home as originary "essence" and depict the processes of characters who are positioned by external forces but also potentially claim a level of agency in that positioning.

Another important link to identity that my texts illustrate is the role of others in the construction of a personal identity, a notion which Young describes as "always in process" since "our selves are constituted by differing relations with others" (140). I suggest that positioning and relations are two defining characteristics of home-making and their combined resonance is the reason that I focus on a geocultural sense of home — not only a lived space or personally constructed place but both. The idea has far-reaching psychological and social impact, and even though it increasingly seems to be "valued" as an economic asset, home is always essentially political. These many dimensions of home are reasons why I agree with Young's claim that "[d] espite the real dangers of romanticizing home [...] there are dangers in turning our backs on home" (154). These dual dangers, I argue, are looming and affect not only the individual (my focus in Part I) but also community (my focus in Part II), social norms (my focus in Part III), and any conception of global responsibility to others as well as the world in general (my focus throughout, particularly through considerations of commodification and the ethical dimensions of hospitality and home).

Because home is not a homogeneous construct, one of my aims is to show that conceptualizations of what home looks and feels like are expanding as new modes of home-making infiltrate cultural narratives and the popular imagination. The essentially limiting conventional imagery of home has been shaped in many ways by various forms of art, including paintings (from European country landscapes to Edward Hopper's porches, windows, and houses), 
literary icons and Hollywood classics (such as Anne of Green Gables or The Wizard of Oz), and even globally re-broadcast American sitcoms that habitually open with wide or close-up shots of the comfortable houses in which most of the action takes place (examples include The Brady Bunch in the 1970s, The Cosby Show in the 1980s, or Full House in the 1990s). By the end of the twentieth century, urban life made a more direct mark on the imagery of home. New literary sub-genres such as urban fantasy emerged and more cityscapes inserted the high-rise as not only place of business but a possible home space. This is not to say that apartments did not previously figure in art but that the apartment once signaled a convenient or unavoidable temporary home. Only with the prominence of the city did it emerge with some frequency as an acceptable kind of home space in itself. For instance, in the internationally popular sitcom Friends and Hollywood films that distinctly take place New York, characters choose this iteration of home in lieu of a more traditional home space. I suggest that such a shift in representations of home indicates that our sense of which structures, spaces, and landscapes qualify as appropriate depictions of home is culturally and historically contingent, and continually evolving. Furthermore, this shift speaks to the growing challenges as well as possibilities of mapping unstable, heterogeneous, and more flexible homes.

Methodology: reading into the practices of owning, renting, and imagining home This work makes comparisons between works from different nationalities, produced in different visual and print media, and so in that sense, it is comparatist, but my goal is not to perform a medium-specific nor a cross-cultural analysis. I take up the texts I selected here because they each engage in an inquiry into the most pressing issues about home in the present. In doing so, they pose certain sets of questions and find means to respond to them in ways that result in 
startlingly tropes and images as well as recurring ways of representing the stakes of their questions. The work I am doing, then, is partly exegetical and partly philosophical because I try to demonstrate how two cultural texts can engage in and be engaged in a dialogue with philosophy. My approach to analyzing the notion of home takes as a starting point Michel de Certeau's observation that "the text [is] habitable, like a rented apartment" (xxi). In fictional homes, readers are not invited as guests who are then bound by a host's rules but enter as spectral "renters" who are offered access to a home-maker's narrative of complex beliefs, circumstances, and histories. ${ }^{1}$ I take the opportunity to "inhabit" texts—which are not only metaphorical apartments but specific rooms, buildings, streets, and the larger regions that they are a part of — in order to uncover some of the intricacies of not just a physical space marked by its economic value and urban or national affiliation, but a complex network of material realities, socio-political forces, interpersonal relations, as well as personal dreams and disenchantments. The protagonists' experiences of testing or renting while home-making, and not-quite-being-at-home, yet continuing to map home are the thematic links that bring together my corpus of psychologically and sociologically complex, formally innovative, and epistemologically diverse works. These texts contend with, and in some cases depict the successful rejection of, an archaic notion of home which is allotted by birthplace, familial or ethnic legacy, and other uncontrollable circumstances. Instead, home is imagined in many of these works as a dynamic map that can be shaped and scaled by home-makers - a representation of identity that links places in adaptable ways in order to accommodate change over time. For example, House of Leaves examines the labyrinth as a metaphor for this map, Neverwhere uses the London tube to map an actual underground London,

${ }^{1}$ In "The World and the Home" Homi Bhabha similarly discusses "the House of Fiction" (141) as a means of understanding the world, while also valuably highlighting the impact of mobility on this "House" by focusing on "the uncanny literary and social effects of enforced social accommodation, or historical migrations and cultural relocations" (141). 
The Village depicts a precisely isolated tract of land that is created specifically not to exist on maps in the outside world, Nikolski explicitly suggests a complex map for its nomadic protagonists' understanding of home, Dogville boldly outlines the structures of its eerie town in chalk, and Good Bye, Lenin! seamlessly maps private and public histories inside post-Wall Berlin.

In order to address the fact that maps and homes have very particular connotations and standards for what they should look or feel like, I adopt another claim from de Certeau and, as a way of invalidating these expectations, I seek to explore the "subtle art of 'renters' who know how to insinuate their countless differences into the dominant text" (xxii). My corpus is not made up of works that strictly align with dominant narratives of home — such as eventually returning from an arduous odyssey or clicking red shoes because a wonderful home has merely been taken for granted — but it prominently depicts diverse kinds of home-makers who insinuate their "countless differences" into the expectations of home, albeit with varying results. My analysis of each novel and film focuses on the ways that characters insinuate their experiences of home into the dominant, culturally ingrained, Western imagery—most often of a slanted roof and proverbial white picket fence in a boundlessly welcoming community. Yet, even if a home-maker (like Will Navidson in House of Leaves, the elders in The Village, and Grace in Dogville) insists on procuring such an icon of "home sweet home-ness," I argue that the idea remains one part of the complex, multi-scalar map of home which already includes previous homes on various scales and the formative impact of these - whether the impact invites a level of nostalgia of happier times or the repression of trauma. Although the homes and home-makers in my primary texts do not represent an international breadth of experiences, they do encompass a spectrum of different subject positions, from unwilling to inadvertent to overzealous home-makers (such as Richard Mayhew in Neverwhere, the protagonists in Nikolski, and Alex in Good Bye, Lenin!, respectively). In some 
cases these home-makers flounder, unable to commit to rethinking home or to insinuate their differences into the construction of their conceptual home, but in other cases they illustrate Martin Heidegger's notion of "learning to dwell" by seeking to build (to both construct and preserve) their own kind of home, one that I suggest must be composite and multi-scalar.

The term "multi-scalar," which I first encountered in Blunt and Dowling's Home, signals the overlapping influences of various social and physical scales, and so is particularly well suited to complement the postmodern sensibilities of my corpus and the fragmentation as well as multiplicities which influence how home can be constructed. These postmodern sensibilities include seeking to "de-naturalize some of the dominant features of our way of life" which are "made by us, not given to us" (Hutcheon 2). Rather than viewing home as "natural" or unalterable, the home-makers in my primary texts contend with and in some cases embrace the postmodern characteristic of being "certain of its uncertainty" (Butler 2). In Part II, I investigate uncertainty as a trait of Zygmunt Bauman's concept of consumption-centered "liquid modernity"—which he contrasts with production-centered "solid modernity" - in order to challenge the kinds of "stability" that home requires. My primary texts undermine and even usurp the comfort of certainty as characters attempt to rethink their expectations of and engagements with home in postmodern or, more specifically, liquid modern times. In many cases they learn to embrace a higher level of uncertainty because it frees them from the limitations of a predetermined origin as home. The question of certainty and stability additionally relates to a postmodern "suspicion to the notion of origins" (Sheehan 20) which is also essential for rethinking home, especially when combined with an understanding of postmodern endings as "thorny and recalcitrant" (Sheehan 20). In my analysis I show that my primary texts undermine the limiting associations and melodrama of home as a natural origin and inescapable end, and I suggest that this is a first step in opening up the 
idea of home to new kinds of personal mobilities, global flows, and forms of social organization.

\section{A multi-scalar paradigm: metaphysics, relations, and social norms}

I could not presume to discuss all possible configurations of conceptual homes or their meanings. Instead, through my analysis of my primary texts I seek to add to recent scholarship on home by not only turning to important philosophical and sociological ideas but examining the insights that they offer regarding the idea of home in the twenty-first century. In order to reframe the distinctions of space/place and public/private in relation to the idea of home and to ground my analysis of literary and cinematic works, I draw on three of the thinkers about home that I deem the most significant over a half century, looking at Martin Heidegger's writing on dwelling, Zygmunt Bauman's on liquid modernity, and Jacques Derrida’s work on hospitality. I begin with Heidegger's post-war essay "Building Dwelling Thinking," in order to trace the rupture that the fallout of World War II affected regarding associations of home as a safe place, particularly through the imminent dangers to "home" and "homeland" that were instilled in citizens on both sides of the Atlantic during the Cold War. Bauman's notion of liquid modernity offers me a critical framework of modern socio-political and economic systems, and it helps me show the continued effects on notions of home that new kinds of uncertainties and risks — not due to physical attacks but blows from the "invisible hand" of global capitalism and its unpredictable economic flows - continue to shape home-making norms and practices. Derrida's later work on hospitality additionally serves as a way to think about dwelling in a broader international context of increased short and longer term migration. My main objective is to demonstrate the possibility of what Heidegger calls "poetic dwelling" in liquid modern times and to challenge neutral, utilitarian conceptions of space, place, and home. I do this by highlighting the diversity of experiences of 
home and what it means, as well as the imagery and emotional connotations of home in postmodern, genre-crossing works that each present multiple perspectives of home spaces on intimate as well as larger scales. I seek to provide a paradigm for thinking of home as a dynamic, multi-scalar construct that is not only amenable to modern mobility and connectivity but the nexus of mediating these cornerstones of globalization.

The notion of home is marked by paradox and these three theorists address this in important ways: Heidegger addresses being stable yet unsettled through the term unheimlich (literally, un-home-like), Bauman discusses liquid modernity as a dialectic with solid modernity, and Derrida coins "hostipitality" in order to explore the hostile as well as welcoming nuances of hospitality. The notion of a multi-scalar home supports contradictions, and the idea of home that I theorize from my primary texts - a conceptual, labyrinthine cartography that is partially a palimpsest and partially blank canvas — offers a way of re-imagining home in ways that surpass Gaston Bachelard's "integrative space," bell hooks' "site of resistance," or a place marked by what Agnes Heller calls “geographic monogamy” (or promiscuity). Rather, my concept of home accounts for the reality that home is shaped by a multitude of possible combinations of these relations in addition to many others. In the following chapters, I will show why the question of home needs to be rethought and re-evaluated as an important conceptual tool for self-concept and social bonds in spite of but also through mobility in an increasingly "fluid" era. In order to illustrate the far-reaching impact of conceptions of home on identity and belonging, I present close readings that show why a traditional understanding of home as a distinct location is incompatible with the realities of liquid modernity, and, moreover, that make visible new modes of constructing home as a composite of locations and scales: a complex, multi-scalar, geocultural map of identity and belonging. 
I organize my dissertation through scales—-the individual, interpersonal, and social—and in each of my three parts I first introduce the theoretical issue and follow that with critical examinations of texts through the lens of that theory. In each of these parts, the first text I analyze grapples with obsolete models of home as a space of isolation, while the second work investigates new possibilities of thinking of home as a means of discovery or exploration. I begin my examination of the individual scale of home with Danielewski's House of Leaves because this novel poignantly examines many of the fears and traumas that the ideal of one "home sweet home" inherently fosters. I pair this multi-modal novel with a work that began as a BBC mini-series, was turned into a novel, then into a graphic novel, and even staged, because Gaiman's Neverwhere mitigates these same fears through an emphasis on individual agency in constructing home and by redefining the boundaries, networks, and nodes that could constitute a map of home. In the second part's analysis of the relational or interpersonal scale, I begin with Shyamalan's The Village, a film that depicts the impossibility of isolating home from global flows and controlling the idea of home for others. The linchpin is Dickner's Nikolski, a novel that-in counterbalance to The Village - uses navigation emblems and metaphors to illuminate the relevance of understanding places, and specifically home, through mobility. In the final part, I focus on the social scale of home and open with von Trier's Dogville, a film which depicts the dire consequences of a rigid social conception of home through delineations of who may or may not claim it as "theirs." Finally, I conclude with Becker's Good Bye, Lenin! because, in offering an incisive look into the interpersonal and social nuances of defining home, this film demonstrates the deeply personal but also always political significance of the idea across geocultural scales. Unlike Dogville, my final text reveals that economic hardship and social tensions need not invalidate the freedom and agency of engaging with the construction of home, a process mired with hostility as well as 
hospitality—or what Derrida refers to as "hostipitality." Through their diverse depictions of the process of home-making and the idea of home, all of these texts emphasize inclusion, exploration, and adaptation, over older models of exclusion, isolation, and stagnation. In doing so, they demonstrate the socio-political implications as well as possibilities of rethinking home before it truly regresses into a quaint, nostalgic notion. 


\section{PART I: Home on an individual scale and the philosophy of learning to dwell}

When you find yourself prisoner of such a vast horizon, when the shore slips away and the criss-crossing paths on the beach lead to just one house, always the same, with its single huge window, its castaway eye, the only thing left is to unknot, one way or another, the cord that's choking you. You can't pretend anymore.

- Pascale Quiviger, Breakwater House

The house my father left behind in Fargo, North Dakota, was never really a house at all. Always, instead, it was an idea of itself. A carpenter's house. A work in progress $[\ldots]$ in blueprint; in different stages of design or repair.

- Johanna Skibsrud, The Sentimentalists 


\section{Chapter 1: Heidegger and "dwelling"}

In this chapter, I begin my project of rethinking the role of home as a composite fulcrum of personal and social identity by looking at the idea from the smallest, most intimate scale in order to offer insights into the conception of home at the level of the individual or "home-maker." I seek to unpack the role of the individual in mediating the barrage of external socio-cultural visions and versions of how home has been and can be conceived of, and I will build on this work in Parts II and III when I turn to consider the larger communal and social scales of home. Part of my work in this dissertation is intended to contest contemporary theory's fixation with globalization, technological flux, and postmodern multiplicity-ideas that have historically nurtured the notion of homelessness as a conceptual answer to the nationalistic rooting that marked much of the twentieth century. Because I argue that a sense of a national homeland (and, increasingly, homelands) is a part of the multi-scalar conceptualization of home, neither a defining nor an irrelevant element of the idea, I investigate the motivations and outcomes of conceptual homelessness through a dialogue of theoretical and creative texts. I seek to undermine the efficacy of the aura of freedom attributed to postmodern homelessness by suggesting that its costs outweigh its benefits and, much in the same way that home (as a national, ethnic, or hereditary space) once was, it is now the idea of homelessness that is romanticized in problematic ways.

In order to bring yet another alternative to the table which demonstrates the anchoring and integrative possibilities of the idea of home in a social world characterized by mobility and technological mediation, I turn to Martin Heidegger's notion of dwelling, which he characterizes as a process of physical as well as metaphysical home-making. Heidegger's ideas about 
conceptual homelessness and the "calculative thinking" of technology offer a cogent warning regarding the dangers of commodifying the world, and so I take up his argument that art and more "meditative thinking" can still foster dwelling by examining two innovative texts in chapters two and three which illustrate in contemporary contexts the possibilities for connecting to but not being limited by home - in other words, a balance that I argue is inherent to Heidegger's concept of dwelling. Mark Z. Danielewski's House of Leaves (2000) incisively engages with the problems of dwelling as landscapes change through continual flux, and Neil Gaiman's Neverwhere (novel and television series 1996, graphic novel 2007) investigates possible solutions or means of adapting to the fluidity of a mobile and digital era. Both Danielewski and Gaiman offer skeptical approaches to the trope of "home sweet home" but, even more importantly, depict the ways in which dwelling still plays an important role in not simply where but how we engage with the world around us.

I begin with philosophy because the discipline allows me to focus on ideas about the ontology of home through larger existential questions that pertain to the individual: how one lives and what one sees as the good life, how one aligns living in a particular time and place with who one is or wishes to be, how such questions and their relations to a sense of home establish one's worldview, and so on. Another reason for starting with philosophy and Heidegger, in particular, is that "Heidegger's work provides us with perhaps the most important sustained inquiry into place to be found in the history of Western thought" (Malpas, Heidegger's Topology 3). In fact, much of the recent theoretical work on home (including Blunt and Dowling 2006, Morley 2000, and Young 1990) draws on a seminal essay by Heidegger called "Building Dwelling Thinking," which began as a talk at an architecture conference in 1951 and was first published in 1954. The core claim that Heidegger makes in the essay is that we do not pay attention to our place in and connections to the world and thus cannot meditatively think about the ways in which we live. His decision to not use 
commas in the title signals the symbiotic and diachronic relation he wants to establish between building, dwelling, and thinking — processes that define human existence as we venture to create, inhabit, and imagine our world. Heidegger's view of dwelling itself as a defining feature of human life and not merely a specific aspect or portion of our lives offers a way to think about home beyond associations to childhood, national connotations, as well as other ideals or forms of nostalgia. I draw upon Heidegger's work on the concept of dwelling in order to argue that the idea of home is the emblem and comprehensible result of dwelling; as such, it represents an anchor for identity and a means of actively engaging with and cultivating one's increasingly mobile and changing "place(s)" in the world.

Concerns about physical space, community, allegiances, and personal investments are all a part of what Heidegger is discussing when he uses the term $d$ welling, and the scope of this important philosophical means of understanding home is, I think, essential for reviving the significance of the role of home in an increasing mobile and unsettled age. I find the notion of dwelling that Heidegger proposes particularly insightful because of this larger scope, as the term is closely related to his project of refocusing Western thought on what he comprehensively calls Being $^{2}$ and away from a limited focus on human beings as objects that can be isolated from their contexts. Dwelling, as Heidegger explains in "Building Dwelling Thinking," is "the basic character of Being in keeping with which mortals exist" (158, original emphasis), and his claim that we should investigate how we exist in the world is an important proposition within the context of centuries of critical and scientific thought that - through Western metaphysics and technology — have obscured Being by systematically cataloging, categorizing, utilizing, and

${ }^{2}$ In German Dasein underscores the role of place more so than the common English translation by combing the verb "sein" (to be) with the adverb "da" (there). Jeff Malpas, for instance, highlights this nuance by translating Dasein as "being-there" instead of Being. 
maximizing efficiency. The effect of these practices and modes of thought is what Heidegger describes as "forgetfulness," a term that encompasses our forgetting that Being ultimately trumps smaller, quantifiable concerns. He also maintains that technological novelty can "reveal" Being to us if we notice the calculative emphasis on objects and convenience, yet when we do not see this, technology more often "conceals" Being through its quantified and systematic automation. The larger problem Heidegger raises, then, is that, in an increasingly technologically mediated world, quantity, ease, and the commodification of everyday life can continue to supersede an examination of Being, which requires more meditative than calculative thinking - in other words, a concern with qualitative questions rather than quantifiable answers. In chapters two and three, I uncover in two literary texts varyingly successful ways of addressing the growing problem of being able to dwell in a cultural context and economic system that favour substitutes and consumption. Neither text offers a formula for home but each considers new modes of home-making that stem from shifts from materially thinking about home to more self-reflective examinations of home that are distinctly suggestive of Heidegger's notion of dwelling.

In these first three chapters I use Heidegger's work to demonstrate how objectified worldviews and a technologically defined existence redefine home as a commodity, the main function of which is temporary shelter, status symbol, or investment. An understanding of home as the label for a type of commodity has been increasingly critiqued in popular works as well as recent scholarship on home. ${ }^{3}$ More than half a century after it was published, Heidegger's foundational text, more concerned with thinking and cultivating than physically planning and

\footnotetext{
${ }^{3}$ Examples of books on material culture include Daniel McGinn's House Lust (2008), Marjorie Garber's Sex and Real Estate: Why We Love Houses (2000), as well as Lauren Greenfield's documentary The Queen of Versailles (2012), while scholarship includes Domicide (2001) by J. Douglas Porteous and Sandra E. Smith, Peeking Through the Keyhole (2002) by Avi Friedman and David Krawitz, and The Ideology of Home Ownership (2008) by Richard Ronald.
} 
constructing, is a foundational text which, I suggest, works to effectively reframe our understanding of the diverse experiences of people immersed in myriad forms of mobility (physical, wireless, or otherwise). Indeed, since the technological advances and post-war uprootedness that inspired "Building Dwelling Thinking," the problems which Heidegger uncovered regarding the idea of home have only been exacerbated through hyperconsumerism, planned obsolescence, and a popularized belief in economies of perpetual growth, all of which make his work on dwelling even more relevant today.

In much of his later work, Heidegger proposes that art and engaged personal investment can "poetically" open up what the convenience of technology and commercialism have increasingly limited. Art, he suggests, can do this specifically through "poetic images" that are able to expand or reframe our understanding by presenting something with an alien element or in an unfamiliar light. Later in this chapter, I examine what poetic images of home can reveal and then, in chapters two and three, I develop these ideas through an analysis of Danielewski's and Gaiman's texts. The conceptual homes in these works, I argue, illustrate the core notions of "Building Dwelling Thinking": the process of "learn[ing] to dwell" (159) and the poetic nature of dwelling itself. Each text does this by depicting in multifaceted ways the home-making of diverse characters as they are continually forced to reconfigure what is familiar and alien about their notions and experiences of home. The works combine depictions of urban and rural life at the end of the twentieth century with fantastical spaces that defy physics and conventional geographies. The fantastic elements allow the authors to allegorically explore the physical, temporal, and conceptual boundaries of the characters' sense of home through distinct "poetic images" of home. The works' fantastical and multimodal elements, lingering intertexts, shifts of perspective and re-mediations all offer a vibrant and adaptive vision of home without rejecting the usefulness of 
more traditional questions about rooting and belonging which home still orients.

My thesis in Part I is that the means of poetic dwelling that House of Leaves and, especially, Neverwhere reveal are not only feasible but in many ways necessary for maintaining a sense of stability and groundedness in an increasingly mobile and technologically-mediated world. In House of Leaves, Danielewski delves into the psychology of postmodern homelessness (particularly through the character of Johnny Truant) and the inability of consumerism to address such a state (evident through the unhappy experiences of the Navidsons in the house they so eagerly buy, thinking that it could somehow fix their personal problems). By offering deeply personal accounts of characters who explore physical and figurative places in a labyrinthine house that shifts and includes dead ends, Danielewski depicts learning to dwell as an exploration of a structure or environment that is always unknowable in some ways. In doing so, he divorces dwelling from simplistic expectations of a "home sweet home" as well as the haunting or trauma of an irrevocable bitterness that can fuel feelings of homelessness. In Neverwhere, Gaiman poses similar questions about homelessness and the commodification of home (through Richard Mayhew's failure to make a home in London after leaving his small Scottish hometown as well as the narrative's overarching theme of actual homelessness), but he also goes further in demonstrating the ways in which agency can bring about a revived sense of "making" home. Gaiman shows that the agency which his protagonist begins to claim is more fulfilling than the detachment and conceptual homelessness that he first embraced. Together, these two texts illustrate Heidegger's main claims about dwelling: that although we have adopted a purely utilitarian approach to home which results in an emotionally empty living space that conforms to the exigencies of functionality and efficiency, meditative thinking and greater investment in the possibilities that reside in the idea of home can lead to the construction of a personally meaningful 
home amidst—and even because of—increased mobility and technological mediation.

\section{Introduction: dwelling, the process that defines us as human beings}

For Heidegger, dwelling epitomizes being human and he frequently demonstrates the relevance of this concept by examining art. My analysis focuses on the essays in Poetry, Language, Thought, a collection of works that translator Albert Hofstadter notes "seem to be directly or indirectly concerned with art" (ix). Hofstadter is purposefully hesitant because, while these essays discuss aesthetics and literature, they are actually more concerned with how our relationship to art shapes our world and thinking. All of the essays in the volume explore Being through an opposition between art (experiencing a world of Being and thinking meditatively) and technology (cataloguing a world of objects and beings through calculative thinking). For instance, in "What Are Poets For?" Heidegger points to a shift in the ways that we categorize, particularly as the nature of technology "establish[es] itself" and "man becomes the subject and the world the object" (110). This kind of objectification of the world and its limiting focus on human beings in and of themselves - rather than as immersed in their physical and intellectual contexts (which Heidegger aligns with the "poetic" experience of art) — propagates a fragmented and utilitarian approach to existence. ${ }^{4}$ The distancing or remoteness of an increasingly fragmented, utilitarian approach to the world seems to offer clarity through order, but Heidegger argues that the "uniformity of production [...] destroys the realm from which any rank and recognition could possibly arise" (114). Instead, "[w]hat is constant in things produced as objects merely for

${ }^{4}$ Heidegger offers an example of such objectified life when quoting from a letter by Rainer Maria Rilke about the shift in our relation to objects from "infinitely more intimate" to "empty indifferent things, sham things, dummies of life" (110-1, original emphasis, cf Breife aus Muzot 335 ), and this example is particularly relevant for a relation to home spaces, as "intimate" and personally meaningful or "indifferent" products. 
consumption is: the substitute" (127). A world of substitutes - including replaceable houses and other abodes - strips away the intimate understanding of the experiences that can make up the personal, composite idea of home. So, although Heidegger's notion of dwelling suggests a singular concept (each individual or home-maker's collection of thoughts and experiences), it is notably changeable and adaptive, as his insistence in "Building Dwelling Thinking" that we "must ever learn to dwell" (159) indicates.

Particularly significant for the notion of dwelling as a means of reviving engaged home-making is its link to meditative thinking, which Heidegger contrasts to the calculative thinking of an increasingly technological age. In the simplest terms, calculative thinking is quantitative and seemingly objective, while meditative thinking is qualitative and self-reflexive. Although both types of thinking are necessary, Heidegger warns that the former is increasingly eroding and replacing the latter. In his "Memorial Address," published in Discourse on Thinking, Heidegger explains that calculative thinking "computes ever new, ever more promising and at the same time more economical possibilities" while meditative thinking "contemplates the meaning which reigns in everything that is" (46). The latter seeks unequivocal answers while the former favours rethinking, multiple possibilities, and unexpected relations that reveal a larger whole. What Heidegger calls calculative thinking nurtures a drift towards ease, profit, or trends and fosters a culture of disposable and replaceable connections and investments, while dwelling and meditative thinking support a means of mooring experience and integrating it in a more representative manner that speaks to the qualitative nature of lived experience.

Drawing on the foundational claims in the essays of Poetry, Language, Thought and most especially from "Building Dwelling Thinking," I suggest that the conceptual home includes the experiences as well as beliefs through which we remain connected to places which are, in turn, 
formative to identity. In order to underscore the fundamental ties that people have to their immediate environment, he examines the etymology of dwelling by comparing bauen (building) to wohnen (dwelling). Heidegger's concept of building, like meditative thinking, foregrounds the home-maker's agency in engaging with the idea of home by constructing and preserving, rethinking and reframing it. For Heidegger, building is what mediates dwelling by providing edifices, not only through construction but also cultivation and preservation. Furthermore, this building encompasses a form of claiming, specifically in the sense of acknowledging a responsibility to care for and maintain a place. Without cultivation constructions crumble, decay, and disappear - this is also happening to building itself, which Heidegger suggests we have not cultivated with the consequence that "[t]he real meaning of the verb bauen [to build], namely to dwell, has been lost to us" (144). That loss grows as our technological world becomes increasingly designed around a need to discard rather than cultivate. Even though dwelling in Heidegger's sense is maintained through change and forms of growth, it is irrevocably opposed to replaceability. Heidegger explicitly equates "ich bin" (I am) with "I dwell" (145), and by describing the meaning of both "I am" and "I dwell" as "[t]he way in which you are" (145), he emphasizes the links between who we are and how we live, which must incorporate where we live. These links cannot be quantified or replaced, and I will show this in my investigations of the connections of who, how, and where one can "be" in my primary texts' depictions of contemporary home-making practices.

The deep interconnections between Being, dwelling, building, and thinking that Heidegger writes about offer a comprehensive conception of home, not as something that can be static but an idea that remains tied to mutable lives, both through the agency required to "think for the sake of dwelling" and a fundamental acknowledgment of the need to "ever learn to dwell" (159). In this 
sense learning, I suggest, is a process that must to a large extent be self-reflexive and involve an active agent. This agent, the home-maker, navigates through her own sense of home with its geocultural nuances. This navigation in turn sustains the metaphysical process of learning to dwell, which is comprised of the more mundane acts of home-making as well as larger existential questions. For Heidegger, dwelling is an active pursuit that requires different kinds of creation: a combination of building as construction and as cultivation. The limiting of dwelling to tangible

production - through calculative or technological thinking — is problematic because "dwelling is never thought of as the basic character of human being" (146) but only as "the activities of cultivation and construction" (146, my emphasis). Ultimately, dwelling is not something we do because we might as well or because it is convenient to live somewhere, inhabit a space, establish a community, and be at home. These are all activities that we undertake because, essentially, "we are dwellers" (146, original emphasis), regardless of the historical period and its technological innovation. Dwelling is how we exist and in "Building Dwelling Thinking” Heidegger implores that we again think about that existence through how we dwell-by discovering whether we dwell thoughtfully, deliberately, functionally, ignorantly, superficially, or otherwise. He argues for the continual need of thinking about home and it is this sentiment that I continue to explore in the following sections and, then, in my analysis of my primary texts, as both literary works incisively address two of the issues that seem to form obstacles to Heidegger's sense of dwelling and the stability of a conceptual home: mobility and technology.

\section{Critical issue 1: the stable domus and mobility today}

In order to address some of the perceived gaps in Heidegger's articulation of home through the notion of dwelling, I want to briefly shift to criticisms that Heidegger's work receives, 
particularly a view that his notion of dwelling attempts to turn back clocks and reifies ways of settled living and rooting that are associated with the past. In "The Dark Side of Domus" Neil Leach argues that Heidegger's idea of dwelling cannot accommodate the mobilities and flux of modern life. For Leach, domus, Latin for home, is an idea that is unsuitable for our mobile age because of its stable or settled nature. Yet, if Heidegger is said to romanticize "roots" and settlement, then Leach does the same with "routes" and mobility. For instance, his examples of Gypsies and Jews as people not rooted "to the soil" (33) exaggeratedly suggest that nomadic people are literally perpetually wandering, when, in fact, these examples include very distinct senses of "rooting to the soil" in specific regions. Leach similarly mirrors Heidegger's personal preference for rural life — a penchant that Albert Borgmann calls "Heidegger's affirmative provincialism" (141) — with his own preference for the city. Reading Heidegger's preferences into the idea of dwelling is not something I seek to undertake and, in fact, the primary texts which I analyze in the upcoming chapters break down problematic assumptions regarding the positive nature of both rural placidity and urban anonymity by incorporating the destructive as well as formative elements of each.

At the heart of Leach's criticism of Heidegger's notion of dwelling is the fact that, unlike Heidegger, Leach positively views a sense of home as a replaceable commodity meant to facilitate mobility. Home, Leach explains, has "been largely redefined as property, so that what was once a stable point of origin has become a commodity, exchangeable in the marketplace-located within a price range, if no longer constrained by place — but, arguably, there has also been a shift in the way in which we relate to the world" (37). The assertion that home was "once a stable point of origin" is itself problematic considering the histories of colonization and other forms of forced as well as voluntary migration resulting from natural or man-made disasters and subsequent living 
conditions. Leach describes the crux of the current problem with the meanings of home as well as the consequence of this redefinition. The way "we relate to the world" certainly shifts with commodification but while Leach's essay implies a positive shift, the negative impact of viewing the world as a resource is a more convincing issue in these circumstances. I suggest that a price-range cannot adequately describe the psychological, geocultural, as well as socio-political meanings of home. However, Heidegger's notion of dwelling can still address these dimensions of home because the concept focuses not merely on a material commodity but on important personal nuances as well as socially constructed modes of inhabiting space. He explains that " $[\mathrm{t}] \mathrm{he}$ relationship between man and space is none other than dwelling" (155), and to feel at home - rather than feeling homeless — we must think about and build dwelling, this relation that makes any meaningful conception of home possible and not a specific, potentially predetermined shelter or commodified dwelling space.

Leach's position does relate several important points in regards to the potential constraints of home by being wary of the political rhetoric of origins and stressing the importance of mobility in constructions of identity, but other more compelling analyses of dwelling maintain that modernity and mobility affect rather than erase the potential of dwelling poetically. In his book Heidegger and the Thinking of Place, Jeff Malpas, for instance, points out that "it is a mistake to see the notion of dwelling as tied to some pre-modern mode of life-not only does it render the concept itself superficial, but it also constitutes a superficial reading of what Heidegger has to say about it" because, as a "topological mode of being that belongs to human being" (67), dwelling encompasses any and all historical periods. Similarly, when Brendan O’Donoghue discusses Heidegger's notion of homecoming as "poetic remembrance," he claims that it is not a "revivalist nostalgia for an ancient or past sense of 'home,' but the anticipation of new possibilities of home 
hitherto unforeseen or unimagined" (371). Like Malpas, he stresses that Heidegger does not argue for stagnation or regression. Moreover, by understanding homecoming as a kind of "unceasing venture" (371), O'Donoghue highlights the continually changing ways of making and being at home that are inherent to Heidegger's dwelling as well as the engagement that Heidegger warned is increasingly obscured by the speed as well as ease with which technology allows us to replace or renege rather than reflect or re-engage. Heidegger himself is explicit about the general context of his example, explaining that his "reference to the Black Forest farm in no way means that we should or could go back to building such houses; rather, it illustrates by dwelling that has been how it was able to build" (158, original emphasis). In other words, the idea that poetic dwelling was possible does not indicate that we should attempt to replicate anything but that we can take away the knowledge that since dwelling could once cultivate an engagement with and "build" home places, then we can seek to dwell by constructing and cultivating places in our current contexts and circumstances.

I want to suggest that a view of domus or rooting as inherently flexible — since homes change and roots grow, shift, and can be transplanted—is central to Heidegger's notion of dwelling. Moreover, I argue that dwelling is not only possible but increasingly needed amidst rampant mobility since it offers an anchor in a world of flows. Because of technological innovation, migration suggests significantly more frequent and diverse forms of mobility today than when Heidegger theorized dwelling: these moves are not only local or global, short-run or long-term, but can also be characterized by sporadic or consistent returns as well as patterns that more quickly reflect and adapt to political and economic circumstances. This is the context in which I argue that poetic dwelling is still being overlooked, not because the idea is incompatible with the times but because it is inconvenient in the midst of consumerism and the characteristics of 
what Zygmunt Bauman calls "liquid modernity" (which I will examine in more depth in chapter four). Leach seeks to distance himself from the notions of dwelling and rooting, claiming that Heidegger's "evocation of the soil, this call for a 'situated' architecture, can be read as an evocation for the Heimat, for the homeland" (31). While this is an important point in light of the ways that the notion of home has been used in nationalistic discourse, especially in Germany, the ideas of "soil" and "land" are not inherently nationalistic. "Roots" as well as "home" are not intrinsically tethered to a political ideology; rather, as mobile terms, they can and have been used in service of and against a rhetoric that co-opts or amplifies nationalistic inflections. ${ }^{5}$

Reflection on and a re-engagement with place — not merely a formative childhood home or an abstract national construct but the impact of every scale of home-are the two requirements of poetic dwelling that Heidegger argues we have become increasingly careless about. Pieter Tijmes succinctly reminds us of the danger of replacing and reneging home in Heidegger's overarching claim that "without their own home humans cannot flourish" (209). Although Tijmes specifies "their own home" (209, my emphasis), this does not demand a deed or legacy but emphasizes the sense of claiming that Heidegger implicitly foregrounds in his discussions of "building" as not merely constructing but also preserving and cultivating. This "own home" is not a literal, monetary, or historical claim of ownership since Heidegger is adamant in "Building Dwelling Thinking" that "the real plight of dwelling does not lie merely in a lack of houses" (159, original

${ }^{5}$ Leach is critical of a speech called "Homeland" that Heidegger gave for the seventh centenary of his hometown of Messkirch. Yet, in the speech, abstract belonging and a smaller region that Heidegger feels an affinity to are the foci. Along these lines, the translator of the speech, Thomas Frankin O'Meara, explains in his introduction that, "Heideggerian homeland involves two dimensions: the reality of the place of a person's home and origins, and their effect upon his existence" (232). Heidegger's highly problematic connection to the Nazi Party can, of course, insert nationalistic meanings to "roots" and "home." I address some of the serious problems of social constructions of home which oppress or seek to replace and control personal constructions when I turn to politics and the social scale of home in Part III. 
emphasis). Instead, Heidegger claims that "as soon as man gives thought to his homelessness, it is a misery no longer" (159, original emphasis), suggesting that reflection is a starting point for deciding what kinds of home may be needed as well as wanted. The protagonists of House of Leaves and Neverwhere demonstrate Heidegger's claim, not in "eureka" moments but in gradual shifts in how they think of home as a process of "building" rather than a destination, and this shift, I suggest, serves to initiate their emergent desire to learn to dwell. Heidegger suggests that the main impediment to revitalizing our sense of dwelling and engaging with the idea of home is technology, or, more specifically, calculative (or technological) thinking. I examine this claim in the following section and then again in my analysis of my primary texts through various characters' initial disenchantment, apathy, and automatized lifestyles.

\section{Critical issue 2: ways technology obscures poetic dwelling}

In this section, I will examine the impact of technology and technological thinking on dwelling before turning to the possibilities of poetic dwelling in an increasingly technological age. Heidegger's mid-century observations regarding technology are still vital since the technological or calculative thinking that became commonplace in the twentieth century has arguably become the norm of the twenty-first. In his introduction to Poetry, Language, Thought, Hofstadter points out that Heidegger "is thinking always of the opening up of the possibility of authentic human existence — of a life in which man does not merely go on blindly, writhing in the grip of a basically false meaning of being [...] but rather a life in which man truly $d w e l l s "$ (xiii, original emphasis). The alternative is what Hofstadter calls the "vicious automata of self-will" (xv). This opposition of "authentic" and "automaton" offers a nuanced binary which showcases the difference between, on the one hand, a fuller conception of home as places and ideas that are capable of affecting a sense 
of personal "authenticity," and on the other hand, the utilitarian view of home as an object or machine that is replaceable and not capable of changing us as we "use" it. Importantly, Heidegger does not vilify technology through its potentially dehumanizing automation. ${ }^{6}$ What he does is champion poetic dwelling while remaining suspicious of the increasingly thoughtless immersion and technologically influenced thinking of the twentieth century.

Just as critics who understand dwelling as a concept that hinges on going backwards to mythic "good old days," critics of Heidegger's view of technology suggest that regression underlines Heidegger's wariness of increasing technological immersion. A contradiction that emerges from his critique of Western metaphysics is that Heidegger focuses on dwelling even though the house is a prominent symbol in the tradition he wants to reject. This is a problem which, for me, signals that even as its iconic physical structure changes shape (from Victorian to Colonial to townhouse or apartment), the idea that the house represents is not something that can be eliminated because, as Heidegger points out, humans are, foremost, "dwellers" (146). Mark Wigley critiques the overlapping emphasis of the house by suggesting that rather than "dismantle the house" as a thematic concept of Western metaphysics, Heidegger "advocates a return to it...in order to take refuge from the modern — which is to say technological — age of representation that is condemned inasmuch as it produces a generalized "homelessness"' (100, my emphasis). This reading reiterates concerns that Heidegger's ideas are regressive. However, what Wigley suggests about the house offering "refuge" also does not strictly align with Heidegger's concept of dwelling which, as I argue, is used in a much more complex way in his work than the Western symbol of a house as idealized shelter and refuge. In fact, the acts of building that Heidegger describes do not facilitate escape since they imply connectedness to surroundings rather than being set apart.

${ }^{6}$ In "Question Concerning Technology" he suggests that we neither "push on blindly with technology" nor "curse it as the work of the devil" (330). 
I want to suggest that technology is an important way in which we access and connect to surroundings and so, while the house or home (as emblem of dwelling) might offer a repose from an increasingly global economy and technological work environment, it might be just as full of technology itself. The distinction that Heidegger is stressing is that that the house/home/dwelling helps us to think about how we are engaging with the world, and certainly not escaping the world because this would be a move towards thoughtlessness. Critics like Wigley and Leach are right to stress the immense role that technology and technological mediation play in our lives both directly and indirectly. However, overemphasizing the ways that technology affects lifestyles and practices suggests that rather than "dwellers" we are simply "technology users." Leach, for instance, claims that "[u]ltimately we even begin to constitute our identity through technology" which "can lend us our lifestyles, lend us our identities" ("Forget Heidegger" 53). Heidegger is wary of just such an assimilation of technology: people who are defined by the technology they use (technology as the agent that "lends" in Leach's description) and by the modes of thinking that this technology transforms into automated habit.

Following Heidegger, I argue that home, the fulcrum of dwelling, cannot be flattened and limited to a mechanical category that suggests human mastery and predicable outcomes because our connections to place cannot be adequately distilled in such ways. The commodification that threatens ideas of home today is exemplified in the thought of the architect Le Corbusier, who criticizes the "cult of the home" (13) and famously calls the house "a machine for living in" (95). His choice of language offers the antithesis of Heidegger's thoughts on dwelling by foregrounding the technological rather than emotional and symbolic aspects that make up the image, idea, and feeling of being at home. Heidegger observes that home is increasingly understood as a machine but suggests that this is, in fact, a mounting problem. Rather than planning a better or more 
efficient "machine," he entreats us to think about all the ways that this kind of calculative thinking begets an individually and socially crippling notion of dwelling and belonging. Self-concept is stifled in a machine home with a focus of quantitative outcomes and efficiencies rather than qualitative personal meanings and co-inhabitation. In his discussion of how technology obstructs dwelling, Tijmes refers to Hannah Ardent's point "that modern science and technology remove us further from ourselves" (211), and this effect on the individual further suggests that a home as "machine for living in" perpetuates distance rather than connection. Nonetheless, Le Corbusier's perfunctory approach to home as object and implement pervades contemporary thinking through the disposability and external "upgradability" of home as a commodity on a market.

An engagement with dwelling can counter the ways in which technological thinking supports practices that emphasize the convenience, utility, and exploitation of calculative thinking. Mark Wrathall points out that according to Heidegger "[t]echnology creates a world within which only resources can show up; dwelling, by contrast, establishes a space in which human being can once again reclaim its essence" (109). Malpas more specifically explains that for Heidegger technological transformation is "a challenge, an affront even to what it means to be human - the essential character of human life as dwelling is contradicted and obscured by the representation of the human in terms of consumption, productivity, preference, and utility" (Heidegger and the Thinking of Place 67). Malpas' precision here in referring to four more specific concerns rather than discussing technology abstractly is especially relevant for a discussion of home because these are the new foci of home when it is understood as a commodity: home is consumed and rated according to productivity, preference, and utility rather than a bigger picture of other qualitative personal and social concerns. Both Wrathall and Malpas place dwelling —as "essence" and "essential character of human life," respectively—at the forefront of mitigating the disconnect 
from places and people that technology and calculative thinking foster. Technology for Heidegger is in itself neither good nor bad and Robert Sinnerbrink fruitfully elaborates that technological modernity "harbours both destructive and liberating possibilities" (92, original emphasis) which need to be more deeply investigated in everyday life. Sinnerbrink concludes with the rather cynical assertion that "the technological reduction of human and non-human beings to exploitable resources continues apace, no matter how poetically we dwell" (94), but I suggest that, much like the view of technology as a saving grace, a disparaging view also undermines our agency (and dwellers and home-makers) in creating and adapting technology as well as facilitating the ways in which it changes us. There is more optimism in Heidegger's writing on the convenience, utility, and exploitation of technology than in Sinnerbrink's conclusion. Heidegger proposes that in the face of increasing technological mediation, the "plight of dwelling" needs to be "considered and kept well in mind" (159) in order to begin confronting this problem—this plight—and, in this light, Sinnerbrink's "no matter how poetically we dwell" implies a "how much" or quantifiable concern that suggests calculative thinking where meditative thinking is needed.

In "The Origin of the Work of Art" Heidegger uses the notion of "attentive dwelling" (24) to describe the necessarily agential nature of dwelling and his discussion of different kinds of objects in light of attentive dwelling illuminates the material as well as conceptual characteristic of home as something that we, as home-makers, help create and define. He compares "the handmade and the factory product" (57), calling the former a work and the latter equipment, and this distinction is vital to home if we can understand the idea as an intimate "creation" or a multifaceted space "handmade" in a particular way by an individual, rather than a standard product manufactured by socio-cultural and market trends. A work of art and Heidegger's concept of poetic dwelling rely on the uniqueness of human creation and Heidegger values both on account of 
their ability to center or anchor us. We are increasingly denied conceptual or philosophical centres in a more mobile and quickly changing world, and the lack of anchors is an impediment to attentive dwelling as well as a reason that rethinking home- - as an anchor and conceptual centre - is imperative. Borgmann argues that "Heidegger points us to the kinship of centering practices in a sacred world" (141), and, for me, the "centering practices" that Borgmann refers to can remain open to ways of connecting or centering that are old or new as long as they include attentive construction rather than automatic replication. The poetic image is a concept that foregrounds centring amidst flux and Heidegger proposes it as a means of helping us to meditatively think since it offers not only the familiar (the naturalized and expected) but also new, alien elements that spur us to rethink not simply what we do but how we do things. In terms of Heidegger's distinction between the handmade and factory product and a work or equipment, a poetic image is an original and not merely a stock representation. In the following section, I outline the ways in which poetic images of home are vital to poetic dwelling by offering insights into how we can, in fact, dwell poetically in an era deeply defined - constrained but also liberated — by technology.

\section{Conclusion: learning to be at home in the multi-scalar}

My overall aim in examining home on the individual scale is to demonstrate that the personal contexts and changing places that Heidegger's concept of dwelling can describe fit into the multi-scalar paradigm of home which I proposed in the introduction. In other words, even though the process of learning to dwell is intimate and occurs at the level of the individual, it includes feeling at home in the world as well as in the households, communities, and societies of which each home-maker's "world" is comprised. Richard Capobianco offers an illuminating 
example of the largest scale of home by exploring Heidegger's understanding of existence itself as home, arguing that, ultimately, "becoming 'at home' in Being is the aim" (164). This wider sense of home is an important aspect of the scales that make up an individual's sense of home- from the specific, or what Gaston Bachelard calls our "corner of the world" (4), to humanity or being a so-called "citizen of the world." A broader understanding of "at homeness" is central to the concept of home; however, much like with the notion of being a "citizen of the world," it is counterproductive to romanticize and aggrandize home in ways that overshadow the very specific, personal connections that form the foundation of dwelling. In the previous sections, I discussed the relevance of dwelling and rooting in times of increased mobility and outlined Heidegger's argument regarding the ways in which dwelling can offer alternatives to an increasingly technological way of life and mode of thinking. I also gestured towards the idea that poetic images can help us to dwell poetically in the twenty-first century. Before I turn to examples of such poetic images in my primary texts, I want to expand on what the poetic image is and what it has to offer within the framework of Heidegger's thought on dwelling and the notion of home as unheimlich.

In addition to understanding home through many scales, I suggest that a comprehensive understanding of home must be informed by what it is not or through moments when the expectation of "at homeness" are not met. This paradox of home and homelessness is encapsulated in the German word unheimlich, which literally means "not-home-ly" or "not-at-home(ness)" and also connotes unfamiliarity. The term is important in psychological discourse through the famous essay by Sigmund Freud ${ }^{7}$ but also in Heidegger's work through his insights into conceptual homelessness. The richness of this German term lies in its infusion of the not-home-ly (un-heim-lich) into the sense of home (Heim) and the familiar (heimlich) in a way that the most

7 Translated as "The Uncanny," Freud's essay draws heavily on literary analysis and the fantastic yet is concerned with familiarity in general rather than the familiarity of home. 
common English translation, uncanny, or the negative of "homely" do not. Capobianco, for instance, makes a point of translating Heidegger's use of the word as "unsettled" or "unsettledness" (156), and I think that this choice is particularly important for reaffirming the significance of stability and mobility in Heidegger's concept of dwelling and the construction of home. If the unheimlich nature of dwelling is understood as a kind of "unsettledness," then learning to dwell can be identified as a process of or movement towards settling rather than a familiarity with settlement in and of itself. Since we are not born intrinsically belonging somewhere in any decidedly permanent way, such a process does not demand an end or even delineate a clear beginning and thus can offer an expansion of the conventional notion of home as distinct location.

What Heidegger seeks to underscore in his work on dwelling is that the "unsettled," unheimlich facet of home is exacerbated by the rise of calculative thinking, which cripples our ability to engage with home, think meditatively, and strive to dwell. Capobianco explains that the "truly unsettling" thing for Heidegger "is not the vast array of technologies, but rather our being unaware of what is shaping and forming and dominating our times, and this is the sway of calculative thinking" (167). In Capobianco's words, meditative thinking "is open to the 'mystery' of the coming to be and ceasing to be of all things" (167), and he makes the important point that such openness does not replicate an "old rootedness" in which Heidegger claims "human beings dwelt meditatively" but, more realistically, can facilitate a "new rootedness" (167). Calculative thinking, on the other hand, cannot replace the reflection that "making" a home or dwelling requires, yet this mode of thought of statistics, projections, and quantifiable analytics is increasingly taking up the space and time that could be directed towards reflections on meanings and Being, rather than outcomes and objectified beings. Heidegger proposes dwelling as a concept 
through which we can investigate questions regarding the relation of where and who we are-questions that today increasingly touch on which allegiances we transfer and which we sever or leave behind, as well as how such choices redefine self-concept, belonging, and a sense of our "place" in the globalizing world. Adam Sharr points out that places can allow "dwellers to identify a centre, or maybe multiple centres, to their lives" (70), and this centering aspect, which I discussed earlier and also refer to as the ability of home to anchor identity, is crucial amidst the growing consumerism that privileges "new and improved" mobilities, technologies, and means of consumption. In contrast to the material aspects of home that are emphasized in abundant glossy shelter magazines and real estate as well as decorating television programs, innumerable conceptual homes are imagined through art. For Heidegger "imaginary places, lost places or places not yet visited might be as immediate as actual tangible locations" (Sharr 64) such places exemplify the poetic images through which Heidegger suggests we can still learn to dwell. The fictional and imaginary infuse alien elements into common experience in ways that challenge conventional practices and naturalized social norms, in these ways facilitating our attempts to learn to dwell in changing circumstances.

Ultimately, Heidegger's project is a reminder to think about how we live-something that cannot be divorced from where we live and which places we maintain links with. The essays in Poetry, Language, Thought highlight that Being is increasingly concealed through what Hofstadter describes as "the artificialities of the modern imprisonment of man in a culture dominated by the will to power and the technical-technological brain" (xviii). Heidegger does not suggest a move back in time and in "Building Dwelling Thinking” he clearly frames his actual aim: "Enough will have been gained if dwelling and building have become worthy of questioning and thus have remained worthy of thought" (158, original emphasis). He goes on to say that "[t]he 
next step on this path would be the question: what is the state of dwelling in our precarious age?" (158). This is the step that I want to take by looking at two texts which offer incisive examples of new, old, comforting, scary, and ever shifting kinds of contemporary homes. My primary texts do this through their depictions of realistic and recognizable but also fantastic poetic images of home. In "Poetically Man Dwells," poetic image as capable of showing "visible inclusions of the alien in the sight of the familiar" (223). The homes in my primary texts defy physics and conventional geographies, and their poetic images offer insights into the unheimlich nature of home—-both as "unsettled" in Heidegger's sense of the term but also with intimations of Freud's "uncanny," or finding something eerie and strange in what is familiar. Because "dwelling rests on the poetic" (212), the link that Heidegger suggests between dwelling and the poetic is foundational. In other words, the idea of home is always poetic, imagined, and meditative, and Heidegger further stresses the role of the conceptual home in the claim that "[p]oetic creation, which lets us dwell, is a kind of building" (213). By building dynamic, imagined homes my primary texts are able to challenge norms but also depict new possibilities of dwelling poetically and meditatively in an increasingly "calculative" age.

Jennifer Anna Gosetti fruitfully summarizes Heidegger's view of poetry as something capable of offering us "the echo of a lost, more essential engagement with the world" (57), and it is because of this "echo" that I turn to literature and film in this dissertation. As I proceed to my analysis of my primary texts, I examine metaphors and poetic images that convey such an "essential engagement" with the ideals embedded in notions of home that Heidegger points to. However, I also contend that, even though Heidegger is wistful, he is not simplistically nostalgic

${ }^{8}$ The essay's title is taken from a line in a poem by Friedrich Hölderlin: "Full of merit, yet poetically, man / Dwells on this earth" (216). For Heidegger the "on this earth" is significant because "[p]oetic dwelling flies fantastically above reality" (215) but is always rooted in our experience or a means of understanding reality. 
about the past, and so such engagement has not been literally lost in the past but is increasingly harder to uncover or maintain. Gosetti's "lost" engagement, then, can more precisely point to the loss of connections and personal investments that the idea of home no longer explicitly signifies. The possibilities of poetic dwelling are still present and iterations of such dwelling can be found in poetic images — even ones that are technologically mediated and produced (like the documentary film written about in House of Leaves) or attempts to dwell in urban spaces (such as the Londons depicted in Neverwhere). The "echo" in poetry—and in the multi-modal literary texts that I will analyze in chapters two and three — reminds us of an ideal that for Heidegger is encapsulated in the notion of poetic dwelling. My analysis of these texts will show that the problems of mobility and technology are manageable when dwelling is undertaken as an implicitly attentive process which demands reflection, continual learning, and a commitment to building as well as preserving the meaningful places through which we can dwell poetically.

In the following two chapters, I will examine the ways that dwelling and home are uncovered and recovered in, first, House of Leaves and, then, Neverwhere. These texts explore dwelling through a particular emphasis on the ways that we use technology and are used through it, as well as to what degree we may poetically dwell in spite of an increasing technological presence in our lives and a preponderance of calculative thinking in the socio-cultural norms of late capitalism. Both works illustrate the potential of Heideggerian dwelling by depicting growing and more meaningful levels of engagement with an environment through innovative, rather than regressive, kinds of rooting. In an era when globalizing and virtual worlds are framed not simply as change but as revolutionary progress, Danielewski and Gaiman acknowledge the effect that place still has on who we are and can significantly impact who we might become. Both House of Leaves and Neverwhere re-imagine and refract problematic, recalcitrant, and emergent conceptions of 
home at the turn of the century, inviting readers on journeys through labyrinthine homes and quests that require imaginative investments in conceptual homes. Most importantly, both texts build narratives around Heidegger's premise that dwelling is central and necessary, with each work demonstrating the many ways in which how we $d$ well makes us who we are. 


\section{Chapter 2: The labyrinthine home in Mark Z. Danielewski's}

\section{House of Leaves}

Mark Z. Danielewski's debut novel, published in 2000, asks what being "at home" can mean in the twenty-first century by investigating the social and psychological constructions of belonging that home signifies even in a highly mobile, globalizing, and technologically mediated era. The multi-modal and multi-layered novel includes descriptions of a documentary film about a family reconnecting after moving into a house, (pseudo)academic analysis of the film, diary-like footnotes, as well as poems, letters, images, and text formatted in ways that challenge conventional, linear reading. Additionally, the central house in House of Leaves contains an "inner" house, a space that is impossibly large, windowless, dark, shifting, and at times seemingly doorless. Like physically adjacent rooms or conceptual past residences, the narrative layers of the novel combine to offer a fuller picture of the construction of home through proximal and removed experiences of the house — or more precisely, the narrative of the house, its symbology, and psychological impact - as well as insightful reflections from divergent perspectives about the possibilities of home-making amidst technological flux, particularly as information is more easily disseminated but also more easily distorted.

The narrative layers of the novel include a film called The Navidson Record made by Will Navidson of his family's move to the central house on Ash Tree Lane (somewhere in Virginia), an academic manuscript of the same name about that film by the mysterious Zampanò, the incessant footnotes that Johnny Truant produces while compiling that manuscript from an old trunk full of fragments, additional notes by "The Editors," and visual as well as textual content in appendices. I 
argue that by offering a figuratively and formally labyrinthine text, the novel continually suggests that home, the idea at the centre of the intersecting narratives, is itself a labyrinth. This labyrinth home consists of physical residences and spaces as well as embellished or repressed memories that take on the sheen of nostalgia or the shadow of fear and loss. Danielewski's text raises timely questions about the ways in which such a fantastic house embodies the unheimlich nature of home as (un)settled as well as (un)familiar, and how as a poetic image it sheds light on dwelling. In the following sections, I will examine these questions and this poetic image by, first, investigating the relevance of the labyrinth metaphor for home and, then, exploring the significance of technological innovations in the reconstruction and re-mediations of the idea of home.

The layered plots of House of Leaves offer a complex critique of the extremes of, on one hand, limiting home to a particular location, image, or ideal and, on the other, reverting to feelings of homelessness in order to avoid contemplating the role of the idea of home in our lives. The novel opens with the character Johnny Truant's warning about the impact of this narrative house, advising readers to not continue reading because, like him, they will only uncover obsession and disappointment. In compiling Zampanò's manuscript from scattered notes—reconstructing a puzzle or a kind of labyrinth-Johnny becomes fixated on the home in the documentary about which Zampanò has written so eloquently and persuasively, even when a significant portion of his sources and citations are fictional. The old blind man, dead when Johnny is told about a trunk with this manuscript, was equally obsessed with a film which he may or may not have viewed and may or may not have completely made up. Johnny comments on these possibilities yet they do not dissuade him from continuing his editing as well as his editorializing in increasingly lengthy footnotes about his own life, his feelings of homelessness, and his thoughts on the mysterious house on Ash Tree Lane. 
In the documentary film that Zampanò analyzes, the Navidson family-Will, Karen, and their two kids-leave New York City and Will's jet-setting career as an internationally renowned photographer in order to move to Virginia and move on to his new project of documenting this move to small town America. After Will discovers that the house seems to be larger inside than outside, he grows obsessed with this new space, an "inner" house within his previously idealized home. Will contacts his estranged twin brother (Tom), a friend who is a geographer (Billy Reston), as well as a known explorer (Holloway Roberts) and his two crew members to come help chart the dark territory below his homestead. However, the space cannot be charted: markings and fishing line disappear, technology hardly functions, and the space seems to change at its own will— the explorers find small rooms and sometimes enormous caverns or stairwells. As these explorations become increasingly dangerous, Karen asks Will to stop but he-like Zampanò and Johnny — seems unable to put the mystery of the house aside. In his final trip into the "inner" house, Will gets lost and is nearing death when Karen ventures in to save him. In his manuscript, Zampanò divulges that the documentary closes with a shot of the family seemingly happy elsewhere, yet House of Leaves itself ends with Johnny set on finding the house. This ending underscores that, unlike the adult characters in The Navidson Record who all end up physically entering the fantastic space, Johnny-like readers of Danielewski's novel ${ }^{9}$ — only enters it conceptually, and the dual emphasis is crucial, I think, because through it Danielewski underscores the importance of the meanings and ideas of home in addition to the physical circumstances of shifting home spaces.

There is a significant amount of scholarship on House of Leaves, predominately focused on the combination of linked narratives and innovative layout which invokes connections to new

${ }^{9}$ Martin Brick argues that personal experience is the focus of the novel, going so far as to describe Johnny "as parallel to the reader" (np, original emphasis). 
media. Academic work on the book includes analysis of the text's digital influence (Hayles, Hansen) and more specific examinations of virtual networks and labyrinths (Pressman, Hamilton), intertexts (Evans, Belletto), the question of postmodern readership and authorship (Cox, Timmer), but also investigations of nihilism and the uncanny (Slocombe and Bemong, respectively). In addition to the impressive online forums dedicated to unraveling the novel's secrets, clues, real or misleading sources, and interpretive webs, there are two edited volumes on Danielewski's work-Mark Z. Danielewski edited by Joe Bray and Alison Gibbons, and Revolutionary Leaves edited by Sascha Pöhlmann. However, although critics often mention that the word "house" is always in blue (in the colour edition), establishing a connection to standard hyperlinks or blue screens, they do not investigate the conceptual and physical houses of the title. ${ }^{10}$ Only Rune Graulund explicitly underscores the importance of the house itself, claiming that "[t]he major points around which House of Leaves revolves are those very unhip themes of its title: house and text" (379). I will take up these two themes in a somewhat different manner, through the experiences of characters in relation to the house on Ash Tree Lane and by understanding the textual metaphor of the title (a house made of "leaves" of paper) as a symbol for the idea of home: a kind that labyrinth that individuals - like readers but as home-makers - help to create through continual exploration.

Drawing upon the abundant technologically-focused scholarship, I argue that House of Leaves offers an exploration of home and the evolving process of home-making amidst technological changes that produce more streams of information but also increase the convenience or ease of processing and even falsifying that information at the expense of the need to reflect on it.

${ }^{10}$ William Little mentions other connections to "house of blues" (195) and the phrase "out of the blue" (179), which comes up in the novel with some frequency. Although he does not elaborate on their relevance, both associations can be tied to the notion of home and its potential for trauma as well as catharsis of the unexpected or unplanned, respectively. 
According to Mark Hansen, "the novel insistently stages the futility of any effort to anchor the events it recounts in a stable recorded form" (602). However, as a published work in print, its narratives must be stable to some extent, despite often being contradictory, sprawling, and open to significant re-interpretation. This feeling of being unstable that Hansen picks up on, I want to suggest, results from Danielewski’s incisive consideration of postmodern conceptual homelessness as well as the "unsettled" or unheimlich aspects of home which Heidegger argues are intrinsic to the idea. Danielewski succeeds in showing that postmodern homelessness cannot quite describe reality since his innovatively unstable narrative and typographic strategies do not subvert the relevance of home but serve to mask the fact that at the core of his work is a stable (though shifting) home which dramatically affects the lives of his characters. Moreover, while Hansen's observation relates to many of the digital and seemingly mobile aspects of the book, I argue that the novel presents the house as an anchor rather than what Hansen describes as "stag[ing] the futility of any effort to anchor" (602). An anchor can shift or be moved across vast distances and so is not a completely rigid or permanent fixture. In the following sections, I will examine how the house on Ash Tree Lane and its "inner" house illustrate some of the costs and benefits of the anchoring role of home and, through this, the possibilities of Heidegger's notion of dwelling. Then, in turning to the depictions of technological mediation in House of Leaves, I argue that for Danielewski technology is not simply another means of perpetuating conceptual homelessness and making home unheimlich but something that can also offer new kinds of what Heidegger calls poetic images_-both familiar and alien - through which we can still learn to poetically dwell. 


\section{The labyrinthine home as "the state of dwelling"}

The term "labyrinth" is often linked to Danielewski's physical text (with its paths of footnotes, boxes, wandering lists, multiple fonts, augmented spacing, and so on) as well as the actual structure of the "inner" house through which Navidson and crew attempt to find their way. I suggest a third way in which the metaphor is entrenched in the novel: as a framework for exploring the notion of home itself. Explicating the dual theme of text and house that Danielewski embeds in his title, Jessica Pressman claims that "[t]he house is like a book: made of ink, it becomes a thing to be read and analyzed, navigated and referenced" (112). ${ }^{11}$ The point that the house is a metaphor for the text suggests a particular kind of cohesive yet compartmentalizing construct, one that I argue reflects new ideas about the labyrinthine nature of the idea of home. The structure does not produce mathematical solutions or geometric paths to reaching a pre-determined centre but serves as a means of seeking to learn by continuing to (re)locate, transpose, and know home.

Danielewski's "unsolvable labyrinth" (Hansen 627) or "mutable labyrinth" (Slocombe 103), I argue, additionally challenges the origin and end points of a labyrinth in order to focus on how moving through, remembering, seeking, and reflecting on home in this labyrinthine framework can shed light on identity in a time of diminishing spatial identity markers. The notion of home as an origin was once an identity marker but can no longer be conceived of as a permanently delineated beginning because of the social and technological change of physical, virtual, and social mobility. Danielewski undermines a traditional understanding of origins by consistently questioning and problematizing beginnings in his novel's polyphonic and

11 Will Slocombe similarly finds "not 'footnotes' but rooms within a house, sometimes empty (the blank boxes), sometimes full of people (lists of people such as the 'authors of buildings' section on page 121)" (97), and Martin Brick extends the book-house metaphor even further: "Danielewski's novel has rooms. [....] The reader might do well to imagine Truant telling his story in one room, Zampanò in another, and Navidson in yet another. The reader moves between these rooms, encountering the narratives in a fractured manner" (np). 
multi-modal narrative structure. ${ }^{12}$ In order to showcase shifts away from understanding home as (only) a beginning, the novel pushes readers, as Sudha Shastri claims, "to recognise the beginning and understand it anew" (89). In doing so, it investigates the temptations of seeking to find some quintessential "sweet" home - an ultimate origin or end — and illustrates the rich possibilities of a shifting idea because the metaphor of the labyrinth is able to sustain both the stability of being within a structure or context (a singular but composite idea of the home-maker) and the demands of mobility (making home by staying as well as leaving).

The labyrinth offers a fruitful expression of Heidegger's notion of learning to dwell through not only the act of wandering but also wondering, or reflecting on potentially circular, forked, or closed paths, and, through it, Danielewski theorizes a more contemporary sense of home. The "inner" house is not modeled after the stone structure made famous by the Greek myth but represents a dynamic, networked conception of space—-both physical and virtual. Throughout his text Danielewski presents a way of re-imagining the possibilities of Heidegger's notion of poetic dwelling and develops new ideas about Heidegger's architectural metaphors of building, constructing, and preserving by incorporating digital technology into the realm of making as well as maintaining the idea of home. This includes the cameras used to film the Navidson house as well as related video diaries and Johnny's use of the Internet to share the manuscript (the published book is marked as "2nd edition" because the first is Johnny and/or Danielewski's initial work circulated on the Internet prior to publication). The re-mediations of the text infuse the learning to dwell that Danielewski depicts with a postmodern outlook that not only questions beginnings but

12 That authorship can be contested for many or all the "authors" of the book adds to the ways origins are challenged in the book. The title pages include "Mark Z. Danielewski's" on the left page and on the right "House of Leaves // by / Zampanò // with introduction and notes by / Johnny Truant," proclaiming Danielewski's ultimate ownership but subverting his role as author. Even Johnny's institutionalized mother, Pelafina, has been suggested as a covert author, having made up even Johnny, a son who actually died in infancy. 
seeks to de-naturalize the ideal of home and embrace uncertainty to a manageable extent. The narratives that have been sutured and layers of different media that have been translated in this impressive book also offer an intimate sense of the re-mediations of technology that have become a part of everyday life as recorded images and sounds as well as transcripts and written documents are more accessible but also more easily altered, taken out of context, and misrepresented.

In her examination of labyrinths, cities, and cyberspace, Kristin Veel suggests that "the fixed walls of the traditional labyrinth have become porous" (167), and the word "porous" is similarly used by geographers Alison Blunt and Robyn Dowling to define home, which they describe as a "porous, open, intersection of social relations and emotions" (27). The notion of home in House of Leaves and the "inner" house itself suggest porous labyrinths that change and shift, not only in terms of spatial characteristics but in their meanings to those who venture in physically or through an imaginative leap that demands meditative thinking and reflection. An impediment to such a conception of home drawn out by the text is that while the possibilities of stability and safety are deeply embedded in ideas of home, loss and danger are more reluctantly accepted. Early in the documentary Navidson describes his intentions: "Settle in, maybe put down roots, interact, hopefully understand each other a little better. Personally, I just want to create a cozy little outpost for me and my family" (23). "Cozy" suggests heimlich (comfortable, homey), but in his exposition of this comment Zampanò focuses on the term that Navidson uses for his home, pointing out that "“outpost' means a base, military or other, which while safe inside, functions principally to provide protection from hostile forces found on the outside" (23). Navidson's use of the word is partially explained through his motivation for leaving the city to locate a safe or at least safer home and externalize the problems that the family had by blaming former circumstances or surroundings. The subtext of danger is also poignantly depicted with 
other members of the family. Karen is asked by her son, Chad, what he needs to do to become President and whether she would be his Vice President. She responds with a standard "study hard" answer and a kiss but it is unclear whether the last line of the exchange belongs to her or her son: "How about Secretary of Defense?" (61). This position explicitly foregrounds safety and the kind of outpost home that should be able to keep "cozy" things in while keeping anything alien and potentially dangerous out (I will further examine the lengths to which the search for safety can augment notions of home in my analysis of M. Night Shyamalan's The Village in chapter five and Lars von Trier's Dogville in chapter eight).

Like Navidson, Johnny idealizes an outpost kind of home. The apartment through which he isolates himself also fails Johnny, which suggests the integrative - and, as I argue, multi-scalar - nature of home and the idea that dwelling requires exploration and meditative thinking, rather than isolation and calculative thinking. Johnny writes that he "wanted a closed, inviolate and most of all immutable space" (xix), even though home can be none of these things. It cannot be permanently closed, it was never inviolate, and it cannot be immutable since it continually changes. Part of Johnny's need for stability can be attributed to the instabilities he experienced throughout his life - the death of his father, his mother's institutionalization, and abusive foster parents. Nevertheless, Johnny perpetuates this lack of stability by seeing home as a malevolent labyrinth of obstacles and setbacks rather than a space for investigating and integrating his memories and experiences. He becomes increasingly paranoid about being "alone in hostile territories" (43), until he is able to eventually move beyond this fear by fixating on something else. Johnny announces, “My plan's to leave tonight and take a southern route all the way to Virginia, where I hope to find that place, or at the very least find some piece of reality that's at the root of that place, which might in turn - I hope; I do, do hope — help me addrefs [sic] some of the awful 
havoc always tearing through me" (410). Johnny will likely encounter other "hostile territories" wherever he goes, but seeking to address the "awful havoc" that once immobilized him so profoundly signals this character's shift from calculative to more meditative thinking about home. Rather than reiterating that he has no (idyllic) home, Johnny begins to think of himself as a home-maker who cannot control yet can affect the places and ways through which he dwells. The labyrinths of House of Leaves illustrate, as I argue in the next section, that while a quintessential home does not exist, a complex and unheimlich home always under construction can fill its place—never complete but increasingly knowable.

\section{The issue of mobility: isolation, knowledge, and the labyrinth}

Before turning to my analysis of how the motif of the labyrinth informs conceptions of home through its emphasis on movement and discovery, I want to briefly examine the myth that is so deeply tied to the labyrinth and its initial home-maker, the Minotaur. Scholars of Greek mythology and the labyrinth recount that in the most basic and widely known version of the tale the Minotaur is the son of the Cretan king's wife and an ethereal bull. He is the hybrid but decidedly bestial threat that feasts on a yearly or multiple-year sacrifice of youths until Theseus, the son of another king, slays him. The Minotaur is conventionally denied a voice and agency as a grunting beast that awaits its prey, but newer interpretations interrogate the Minotaur's assumed complicity in the creation of the labyrinth (the idea that the violent creature needed to be contained) and the deaths associated with the ritual sacrifice. For example, the fact that the youths never re-emerged can be attributed to the complexity of the labyrinth itself. Even Edith Hamilton, in her popular book on mythology, specifies that "one would go endlessly along its twisting paths without ever finding the exit" (212, my emphasis), and in such a complex maze, the youths would 
succumb to exhaustion rather than be killed by the Minotaur. This complexity has become a focal point for new uses of the labyrinth metaphor that encompass not only movement through physical structures—-from confusing high-rises to complex cities—but also the "twisting paths" of cyberspace and the information age. The labyrinthine home both stresses and subverts the possibility of becoming lost, since mobility is not only a means of becoming lost but also finding new or lost paths and centres. Chapter 9 in House of Leaves, listed as "The Labyrinth" (540) in the appendix, highlights the role of mobility as inherent to home-making with telling epigraphs, the first of which is from Virgil: "Here is the toil of that house, and the inextricable wandering" (107). In this section, I argue that although the "inextricable wandering" depicted in House of Leaves can evoke a conventional "search" for home modeled after the quests of Odysseus and Dorothy Gale, it, more importantly, foregrounds the broader, meditative exploration of inextricable, mundane wandering — of leaving, returning, and through these common acts discovering more about dwelling and the idea of an increasingly labyrinthine, multi-scalar home that is my focus in this dissertation.

The labyrinth myth's solitary Minotaur figure offers insights into contemporary ideas of home, particularly on the individual scale, and in House of Leaves the Minotaur figure suggests a postmodern home-maker through his isolation and lack of commitment. Johnny Truant dreams about being the Minotaur, Zampanò delves into interpretations of the figure, and Navidson literally resembles the deformed, trapped being on his last exploration in the "inner" house. ${ }^{13}$ Throughout

13 Danielewski is not the only writer interested in the Minotaur in a reframed context. Jorge Luis Borges offers a similarly victimized Minotaur in "The House of Asterion" in Labyrinths; Steven Sherrill depicts a more humanized, everyday sort of beast in The Minotaur Takes a Cigarette Break; Victor Pelevin "upgrades" the figure as the hub of the mainframe of a cyber-labyrinth through a horned virtual reality helmet in The Helmet of Horror; and The Royal Opera created a new, distinctly postmodern opera about the myth in 2008 . Yet, while all of these Minotaurs shed light on the labyrinths of modern life, House of Leaves most incisively asks what 
the novel, Danielewski depicts labyrinth-homes and Minotaur-like home-makers, who much like the traditional beast, feel trapped and initially react passively to this feeling. He blatantly foregrounds the importance of the labyrinth in his book: in the color edition, text concerning the most iconic labyrinth and its enigmatic resident is bright red and in all of the editions, it is crossed out. Johnny claims to have "resurrected" these passages that Zampanò "tried to get rid of" (111), which suggests that the Minotaur cannot be so easily forgotten or erased from the labyrinth. These sections include speculations that rather than the progeny of the queen and a bull, the Minotaur was a deformed child that King Minos did not want to claim. Zampanò describes an obscure play which tells the story of the king's shame in his own genetic deformity rather than his wife's bestiality (if she lusted after a bull) or divinely orchestrated infidelity (if the gods came up with the infatuation to punish Minos). Similarly, the questions that Zampanò asks about the labyrinth inside the house include multiple possibilities: whether it "[c] onceals a secret? Protects something? Imprisons or hides some kind of monster? Or, for that matter, imprisons or hides an innocent?" (111). ${ }^{14}$ While Zampanò wants to classify the alleged son of Minos as victim rather than villain, Johnny, as well as characters in The Navidson Record such as Will's brother, Tom, and the invited explorer, Holloway Roberts, who enter the "inner" house, question the stability of strict villain or victim categorizations as they struggle with both in their identifications with the Minotaur.

In House of Leaves, the mythical story which enriches the labyrinth metaphor becomes a sprawling postmodern narrative of the monster and hero who both do and do not belong inside a space claimed or conquered by/for them. Danielewski meticulously weaves alternate possibilities

home is for the secluded Minotaur and the Minotaur-home-makers of an ever more virtual and globally linked age.

${ }_{14}$ The Minotaur in this last view mirrors the ungainly but oddly endearing Ludo from the 1986 film Labyrinth who, like a deformed child, is easily cast as a victim of outside forces instead of a violent brute that requires sacrificial youths. 
into his text as his characters experience the two central roles of the Greek myth: as trapped Minotaur and/or conquering Theseus. The three main "creators"-filmmaker Navidson, author Zampanò, and additional author, Johnny — are alternately trapped in confining spaces (Navidson at the mercy of the "inner" house and Zampanò as well as Johnny in their isolated apartments) and ready to conceptually explore the homes in the stories that they produce. ${ }^{15}$ This combination of entrapment and liberating reflection reveals an amalgamated Minotaur and Theseus: trapped, intruding, and (un)welcome in his "own" labyrinth of home. Additionally, two extreme examples of the labyrinth structure not simply categorizing and isolating but encouraging exploration come in the form of the troubling realizations of two of the documentary's secondary characters, Tom Navidson and Holloway Roberts. Zampanò writes that, while alone in the darkness of the inner house, Navidson's twin brother, Tom, was "referring to i[] as 'Mr. Monster"' (335). Johnny uses brackets for missing parts of the latter portion of Zampanò's manuscript, and this particular omission of the "t" leaves only the "i" to suggest that Tom is this monster, referring not to an "it" but to himself. Similarly, Holloway, the professional explorer who loses his grip on reality inside the house, repeatedly refers to a beast. Both Mr. Monster and the beast suggest the Minotaur inside the labyrinth as well as a connection to the alcoholic Tom and murderous Holloway themselves. In an even more personalized attempt to make this point, one of Zampanò's struck-out footnotes reads: "At the heart of the labyrinth waits the Mi[ ]taur and like the Minotaur of myth its name is [ ] ] (335). This time the missing "no" suggests "Mi" (me) and the blank space for the name asks readers to fill in their name. Along with Tom or Mr. Monster and Holloway or the beast, even the reader's name can fill in this blank and be or become the Minotaur, the "thing" for which the

15 Notably, Johnny's mother, Pelafina (who has been suggested as another or even the ultimate author of the story), is also isolated, sequestered along with her occasionally lucid confessional letters in the appendix and literally trapped since she wrote to her son from an insane asylum. 
labyrinth was created, the individual that defines and is defined by that creation.

In House of Leaves, introspection and encounters with narratives that mirror or deeply resonate with personal experience, on one hand, emphasize self-knowledge, and, on the other, emphasize the fact that the labyrinth, as N. Katherine Hayles suggests, is "a trope for incomplete knowledge" (792). The combined emphasis on self-knowledge and incomplete knowledge is not contradictory because dwelling, as a process of home-making, cannot demand completion but requires continued contemplation, building, and preservation. Danielewski illustrates this point as both the quest-seeking Theseus impetus and Minotaur-like isolation influence the ways in which Johnny constructs home and re-inscribes for himself a conceptual space imbued with memory. He bluntly confesses in the labyrinth chapter, "I had trouble just walking out of my door" (107), and, like the Minotaur, he cannot seem to leave. ${ }^{16}$ Yet even though he identifies with the Minotaur's entrapment, Johnny can also be seen as Theseus in search of a Minotaur and the "inner" house offers Johnny-as-Theseus self-knowledge when seeking the house becomes his remaining purpose, a weak yet important example of seeking to learn to dwell. Rather than an idealization that he never hopes to aspire to or another prison-type construct in which to isolate himself, the labyrinth as home (in the form of the house on Ash Tree Lane) offers Johnny a means of anchoring his sense of self while he discovers his burgeoning agency as a dweller and home-maker.

In an alternate interpretation of the labyrinth myth, Helmut Jaskolski suggests that instead of killing a beast, "Theseus penetrates the mystery of the Minotaur" in "a triumph of self-knowledge" (58), and Danielewski also includes such an interpretation of the labyrinth story in order to illuminate the role of home in the construction of self-concept. For example, the explorers venture in, Theseus-like, to solve the Cretan (now Virginian) problem, but Tom and

${ }^{16}$ Hayles points out that "The Minotaur" is an anagram for "O Im he Truant" (798) which marks Johnny as the Minotaur figure. 
Holloway also encounter themselves as "Mr. Monster" or "beast." Additionally, as Josh Toth points out, "Navidson and Truant seem to recover the possibility of fulfillment via a process of outwardly postmodern self-return" (189). The emphasis on self-knowledge in this re-telling reveals ways in which the mythical narrative of the labyrinth and Minotaur offers a meditation on more than seeking and finding. This ancient story is reinvented to again encompass internal as well as external transformations relating to identity, belonging, ethical imperatives, personal responsibilities, rights or restitutions, and other considerations that directly relate to questions of home and the process of continually learning to be at home.

The moments of self-awareness that Navidson and Johnny experience upon re-encountering their own narratives are symbolic instances suggestive of Heidegger's meditative thinking — not simply moments of their lives flashing before their eyes but the opportunity to see their lives in a new light. Nicoline Timmer even calls Johnny and Navidson facing their repressed issues or fears a "therapeutic aspect" (288) of encountering their own narratives. Both characters are creating documents that primarily memorialize their own lives under the guise of larger projects. Then, Navidson finds himself lost in the "inner" house with only a book titled House of Leaves while Johnny encounters musicians who have read his compiled and edited text online. Following the encounters, Navidson and Johnny begin to reflect on their environments, agency, and commitment to home-spaces, the people who fill them, and to themselves. Meditative thinking cannot guarantee any kind of poetic dwelling, but it is necessary for its very possibility, yet while Navidson seems to assimilate this idea, Johnny tries to resist it. The impulse to consider their sense of home and "place in the world" in a meditative manner has Navidson burning pages in order to read in the darkness of the "inner" house (465), while for Johnny the "flames all die" (493) when he willfully attempts to burn his manuscript in order to avoid thinking about it—even though he 
knows that not only the text, which already appeared online, but also the experiences that it represents cannot be erased. Johnny's resistance finally falters, and Katharine Cox suggests that he too experiences the "transformative qualities" (14) of the labyrinth structure. I agree because, even though his relation with the figure of the Minotaur initially serves as a coping mechanism for fears of abandonment, rejection, and loneliness, it transforms into a way to explore his issues with and desires for a sense of home. The mobilities required in this endeavour-from simply leaving his apartment, which he sometimes has trouble doing (107), to eventually deciding to seek out the Navidson house - help rather than thwart his attempts to "settle" in the many meanings of the term: to settle in a space, settle on a notion of home, and settle for less than an ideal. In the following section, I turn to the related ways in which technological mediation is shown to thwart but also facilitate home-making practices in House of Leaves by potentially compounding misleading information but also fostering exploration in ways that support the "therapeutic" and "transformative" revelations of a labyrinthine conception of home.

\section{The issue of technology: recording and reflecting (on) home}

In this section, I examine the ways that poetic dwelling is facilitated and obstructed by technology in House in Leaves and suggest that this duality demonstrates an important element of the unheimlich or unsettled nature of the idea of home that Danielewski proposes. In the colour edition of the book, the word "house" is consistently blue and by offering houses of paper "leaves" which suggest homepages through the traditional colour of the hyperlink, Danielewski indicates that home, too, is a dynamic composite of shifting characteristics that link multiple ideas and locations. This parallel with technology seems at odds with Heidegger's notion of technology as promoting calculative thinking, since "Heidegger sought to explain the unrelenting grasp that the 
technological mind-set has on us by arguing that when we humans came at last to see ourselves as living on a world, we had finally replaced any notion of dwelling with a rationalist, external, and objectified vision of existence" (Woessner 156). Yet, in House of Leaves technology is shown as capable of also mediating reflection and countering "a rationalist, external, and objectified vision of existence" (Woessner 156). Navidson and Johnny end up more self-aware after examining their experience of home and homelessness through book- and film-making, and their use of the Internet and digital recording technology are central to that. Brian W. Chanen notes that the narrators of the book "suffer in their labyrinths" because "[i]n a networked space of seemingly endless choice there is the real possibility of being lost" (171), but technology also helps these characters to relocate or reframe what seemed lost. By not only dwelling in but dwelling on the various home spaces that make up their labyrinthine notions of home through physical or virtual contact with the "inner" house, each is more at ease with the unheimlich aspects of home.

Heidegger's notion of das Unheimliche or "unsettledness" is an important element of Danielewski's house because this symbolic home shows how all homes have an element of homelessness and must include absences, especially on account of the calculative, commoditized, and replaceable understanding of home which is increasingly commonplace. In a section of Zampanò's manuscript that includes transcripts of Karen Navidson's interviews with people about the house in her husband's film, an interviewee offers the extreme opinion that "in the end it adds up to nothing" (361). Will Slocombe sheds light on such a claim when he argues that "House of Leaves is actually the figure of a homeless home" (90). Slocombe offers a cogent analysis of nihilism in the novel but in that effort delves rather narrowly into the text's fantastic metaphors, not balancing them with a more moderate or mundane relation to reality. For instance, Slocombe suggests that "[t]he House symbolizes absence and to live inside absence is impossible" (92), but 
in this view the deeply symbolic nature of this structure is a limited experiment rather than a means for expansive social commentary regarding identity and belonging. I propose that the absence in the house, rather than offering a potentially despondent meditation on nothingness, points to the absences that are a part of increasingly unheimlich experiences of home, or what Heidegger refers to as "the state of dwelling in our precarious age" ("Building Dwelling Thinking" 158), an age that has grown more precarious since he made that observation. Slocombe further claims that: "The space of the house within Heidegger's philosophy, as within House of Leaves, is delineated primarily by an ambiguous relation between dwelling and ourselves. We are at home in a space that is a home and not a home, a house within which we live and yet cannot live" (94). I argue that, alongside absence and destruction, cultivation plays a strong role in Danielewski's sprawling narrative through the characters' meditations and decisions to remember or rethink their sense of home as well as the very process of maintaining and reconstructing the narrative house through the various, multi-modal forms of art that the book incorporates. ${ }^{17}$

House of Leaves offers a contradictory position in regards to technology through its status as a compilation of mediations but also a pattern of expressing wariness regarding technological mediation and questioning the credibility of the information being transferred and transformed — examples of this include Navidson's purposeful editing of his documentary, the question of whether Zampanò ever saw this film, and Johnny's admission to having altered the text he found. The idea that technology can facilitate but also obstruct our commitment to learning to dwell poetically is most prominently explored in the novel through Navidson's film because at the

17 These include the book's central film, academic analysis, overly "creative" non-fiction from Johnny, original poetry, letters, as well as collages, photographs, drawings, and even the intertextual songs of Poe's album Haunted (2000), which is cross-marketed on the back cover of some editions of the book. Poe is the stage name of Danielewski's sister, Annie. For key links between the book and album, see Evans. 
heart of the documentary is a prototypical commodified home. A picture-perfect standalone house with a spacious yard (an image reinforced through the Polaroids of such houses in Appendix II on page 572, several of which also appear on the spine of the American edition of the book), initially fulfills the Navidsons' requirements for home. In fact, intimations of the comfort and placid bliss that such house imagery evokes are central to the setup of Navidson's documentary. According to Zampanò, The Navidson Record film begins "with Will Navidson relaxing on the porch of his small, old-style heritage house" as well as "pristine glimpses of the Virginian countryside, the rural neighborhood, purple hills born on the fringe of night" (9). Yet, it is "the house itself, an indefinite shimmer, sitting quietly on the corner of Succoth and Ash Tree Lane, bathed in afternoon light" (18) that eventually offers the greatest contrast with the "inner" house, as the "indefinite shimmering" and "afternoon light" are juxtaposed with the solid emptiness and darkness of that physics-defying space. This contrast—manifested in the same place—epitomizes the unheimlich aspects of home that dwelling poetically attunes us to and, in this ways, helps us address and manage home's alien unsettledness rather than ignore or internalize it, as Johnny initially does.

The novel illustrates how technology can obscure but also reveal dwelling through film-making and editing, processes which offer the opportunity to re-imagine or falsify experiences of dwelling but also facilitate characters' self-reflection or meditative thinking. According to Paul McCormick, "Danielewski relies on the technological opportunities of new cinema to represent these characters' inter-subjectivity and to show the new human relations possible through this technology" (62). McCormick discusses Tom's video diary and Navidson's "careful editing" (62) as ways that technology offers more than convenience and ease. Tom is able to finally open up to his brother on camera and Navidson edits his films to offer poignant messages 
to his wife. In his enthusiasm for the primacy of technological mediation, Hansen goes a step further to claim that "the novel enacts a subordination of face-to-face relations between characters in favor of ever more highly mediated forms. For example, Karen and Navidson communicate best across the distance of media interfaces: they speak to each other through Hi-8 video diaries and learn more about one another (and themselves) from viewing their documentations of the other than from any form of direct contact" (614). The qualification necessary here is that the film, or what we know of it through Zampanò's exposition, cannot offer all of their direct contact and it is highly unlikely that their relationship is as a whole based more on this form of communication than more direct relations. However, such new avenues of communication and exchange offer keen examples of how recording technology can be a means to illumination, though never on its own or in and of itself. The rich commentary of the diaries and footage of the house illuminate the kind of home that is sought by those in front of the cameras or the editing suite. The contextualized interviews require a form of meditative thinking or deeper reflection, and Danielewski offers many examples including Tom's video diaries discussing "Mr. Monster" and the self-reflexive comments that Navidson records in an effort to shed light on a dark, confusing space that should be his "dream" home.

In his discussion of technology and re-mediation, Zampanò cites a claim that films are now either "rumpled or slick" (144), and I suggest that his analysis not only indicates that both modes of representation can distract from and hinder the meditative thinking needed to dwell but also sets up the fact that Navidson's film is an unheimlich amalgamation of these two in a ways that offers a poetic image and the possibility of poetic dwelling. Zampanò explains that the rumpled film emerged "as the recording time for tapes and digital disks increases, as battery life is extended, and as camera size is reduced, the larger the window will grow for capturing events as they occur" 
(144). The slick film, meanwhile, is "expensive, cumbersome, and time consuming" but also powerful since "[d]igital manipulation allows for the creation of almost anything the imagination can come up with" (144). These categories mirror the provincial and urban debate in which Heidegger's "small-time" rural preference is echoed by Zampanò's favoring of a low-budget, independent film. Zampanò reminds us that "The Navidson Record is not a Hollywood creation" (395) and so not to expect a Hollywood happy ending, yet the documentary does, in fact, seem to offer just that in some measure with its final shot of the family's new, happier neighbourhood and home, as Navidson and his son (on Halloween no less) set out to potentially confront some of the demons that incessantly haunted them on Ash Tree Lane.

The confluence of technology types in this rumpled and yet slick film suggests a middle ground that is fertile for learning to dwell: at the end, in that new place the Navidsons not only expect something other than an idealized home but are aware that they will have to make rather than simply buy or move into a home, and this distinction makes all the difference in what Heidegger calls "the plight of dwelling" ("Building Dwelling Thinking" 159). The move away from the slick city to a rumpled small town is not enough to nurture dwelling for the Navidsons and, like dwelling's settled yet also unsettled nature, Navidson's film is neither a predictable Hollywood genre feature nor a hotchpotch of home videos but its own artistic enterprise that combines elements of both. So, while technology does not strictly help Navidson or Johnny own or "find" home, it does help them see that their idea of home needs to be reassessed and that home requires not merely their presence but engagement. The difference between "seeking" home and "building" a more substantive example of poetic dwelling is what I will turn to in concluding my analysis of House of Leaves in order to show the important ways in which Danielewski addresses the issues of learning to dwell in the twenty-first century even as he hesitates to suggests ways of 
adapting to the mobility and technology that increasingly surround and propel us.

\section{Unheimlich: finding, seeking, repeating}

In the previous sections I argued that House of Leaves proposes the labyrinth motif as a means of understanding home — and what Heidegger calls dwelling — in a time when common practices of moving house and even moving internationally do not signal the beginnings or the endings of "finding" home but are a part of a larger pattern of flux as people move about with more frequency. I also discussed some of the ways in which the novel stresses but also undermines the uses and abuses of technology as it encroaches on more aspects of everyday life. Together, through these points I want to conclude by suggesting that Danielewski's labyrinthine conception of home presents not only a critique of both postmodern homelessness (through Johnny) and the idealized image of the "American dream" home (through the house on Ash Tree Lane and the Navidsons" initial vision for their life in it) but, more importantly, the notion of home in the novel relates the unheimlich "state of dwelling today" by taking up as well as mitigating Heidegger's concerns. Danielewski's first critique shows how in a world of flux and technological mediation we are not fully disconnected from places, and this is demonstrated by Johnny, who attempts to convince himself along with readers of his detachment while his obsessive discounting of the possibilities of home and fixation with the Navidson's house indicate otherwise. In regards to the second critique, Danielewski reveals that mobility and technology cannot make or even adequately imitate an idealized home. The Navidsons view the house that they now own as a commodity which, to reiterate Malpas' description of Heidegger's problems with technology and technological thinking, meets their criteria for productivity (Navidson will work in this house), reflects their consumer preferences (the imagery is a 1950s "home sweet home"), as well as utility (they seek to 
use the house in that they expect it to manufacture a sense of home for them, since they have struggled to connect with places and each other). While outlining his characters' attempts to escape from or escape into a sense of home, Danielewski employs the "inner" house, his poetic image of home, in order to demonstrate how the unsettled and unfamiliar, or unheimlich, aspects of home and home-making can actually facilitate more fruitful and reflective exploration of both a sense of home and homelessness. ${ }^{18}$

The unheimlich home, which includes a sense of "not-at-home(ness)," is showcased in House of Leaves through experiences of heightened disorientation, an excess of interpretive choices, re-mediated or sparsely verified information, and other qualities that point to the many ways in which home is always "unsettled" but not unmade or erased on account of this unfamiliarity or uncertainty. Finn Fordham calls the underground space of the "inner" house "at once natural and supernatural" (49). In this regard, it offers a poignant example of Heidegger's notion of the poetic image, able to shed new light on old ideas through its combination of the familiar and alien. The house offers an entry point for understanding the possibilities of poetic dwelling by existing as a dynamic work-in-progress that is altered by external forces as well as the psychology of those who attempt to claim it or make it a home. ${ }^{19}$ The house as a whole suggests Heidegger's notion of das Unheimliche since even after the actual house is moved into and made "homey," the unsettled "inner" space cannot be controlled or commodified in the same way-even the technology brought inside can be used with generally limited success. Danielewski illustrates the unsettled and unfamiliar through his sprawling, inconclusive, and layered narratives and while

${ }^{18}$ In an interview that Karen conducts about Navidson's film, she asks interviewees to describe the house and the answers include "Unheimlich-of course" (364).

19 Zampanò cites theories that "the horrors Navidson encountered in the house were merely manifestations of his own troubled psyche" (21) but clarifies that most commentators see his psychology as influential rather than causal. 
these are countered by the characters' need for a stable, safe home space—Navidson's "outpost" (23) and Johnny's "immutable" (xix) home - the resulting notion of home is a labyrinth that fuses the possibilities of trauma and domestic bliss. This duality is not as simple as confining trauma and nightmares to metaphoric dark cellar (as Gaston Bachelard does following Carl Jung) and cordoning off the upper level for everyday use and daydreams because bad things happen above ground too, and the dark expanse of the "inner" house fosters important insights for many characters as they give up "calculating" and quantifying the space and begin to meditatively think as they alternately lose and find their way inside it. In other words, in a more nuanced way Danielewski's natural and supernatural house illustrates Bachelard's claims that the "house is one of the greatest powers of integration for the thoughts, memories, and dreams of mankind" (6). Through direct contact but also indirect experience, this function of the house as an integrative force and space helps characters, who are willing, to learn to dwell.

The symbolic nature of the house has received scholarly attention since Bachelard's Poetics of Space, notably in The Architectural Uncanny by Anthony Vidler, which offers insights into the cultural relevance of the house as a symbol for the "uncanny" (the translation of das Unheimliche common in psychological discourse and Freud's notion of finding the eerie in the familiar rather than Heidegger's focus on being "unsettled"). ${ }^{20}$ Particularly relevant to Danielewski's strange house is Vidler's notion in his "Homes for Cyborgs" section that the modern metaphor of the machine-home has been replaced by the metaphor of something that is "at

${ }^{20}$ Vidler asserts that " $[\mathrm{t}]$ he house provided an especially favored site for uncanny disturbances: its apparent domesticity, its residue of family history and nostalgia, its role as the last and most intimate shelter of private comfort sharpened by contrast the terror of invasion by alien spirits" (17). This mixture of the foreign or alien is framed more positively by Heidegger through the enlightening or meditative possibilities of the poetic image, but the image that House of Leaves initially offers of home borders on sinister, akin to Vidler's description - and it is not surprising that this academic text is listed in Zampanò's footnotes (359). Ultimately, however, the image of home that the book presents lies been a haunted and idealized house. 
once prosthesis and prophylactic" (147). This idea could suggest Bachelard's integration in a new age but Vidler takes a darker view when he claims that the "'machine for living in' has been transformed into a potentially dangerous psychopathological space populated by half-natural, half-prosthetic individuals, where walls reflect the sight of their viewers, where the house surveys its occupants with silent menace" (161). In the novel, Navidson, his family, the crew, and even Johnny experience such a form of the technologically mediated "cyborg" Unheimliche: a sense of surveillance (the many cameras in the house) prevails as well as the need for micro-managing safety (the outpost home model). Zampanò even comments that with the discovery of the "inner" house "the Navidsons' home had become something else, and while not exactly sinister or even threatening, the change still destroyed any sense of security or well-being" (28). Through this melodramatic claim, Zampanò falls into the either "safe home" or "unsafe non-home" trap, since the house itself was always both, a point that information on the troubles of previous owners makes clear (21). What "becomes something else" is really the Navidsons' idea of home-first as something unheimlich in Freud's and Vidler's sense of uncanny before settling on Heidegger's notion of unheimlich as, for better and worse, unsettled. This "new" conception is in some ways more troubling than an idealized or outpost home but it is also a place where learning to dwell can occur when meditative thinking is finally fostered or in some ways demanded as characters confront their ideals of home (Navidson) or homelessness (Johnny).

Danielewski examines postmodern homelessness through Johnny, and critiques the apathy and lack of agency that it can mask. Johnny is largely unwilling to explore his own unheimlich sense of home, and resides in a tiny apartment in a building that provides him little besides a bit of storage space for himself and his things. He vehemently warns readers of the unheimlich nature of home in his introduction: "even in the comforts of your own home, you'll watch yourself 
dismantle every assurance you ever lived by" (xxiii). He also placates himself with the claim that others' "comforts" cannot guarantee more than a fleeting sense of peace and security because it is something he never seems to experience. The theme of comfort yet uncertainty is taken up again but in relation to Heidegger's writing as dwelling yet being unsettled. Zampanò cites a passage in which Heidegger connects das Unheimliche to being "not-at-home" in a perpetuating cycle in which once familiarity is reached, the individualization of that familiarity makes it unfamiliar again. Johnny's footnotes on this passage instantly resist the idea—as he surmises, "Which only goes to prove the existence of crack in the early twentieth century. Certainly this geezer must of [sic] gotten hung up on a pretty wicked rock habit to start spouting such nonsense" (25). Yet, in that same footnote — and "[c]razier still" (25) according to Johnny—he admits that the passage starts to make sense. Johnny may not be sure what parts speak to him but he comments that Heidegger's idea of "das Nicht-zuhause-sein [not-being-at-home]" is "definitely true" (26).

Danielewski's critique of postmodern conceptual homelessness is increasingly clear not only as Johnny's self-involved whining about not feeling at home becomes increasingly superfluous but also as this character finally stops feigning disinterest and reclaims some agency as a home-maker. Johnny, who continually battles mental instability, begins to conflate the narrative of the house with his own, at one point realizing: "suddenly I find something, hiding down some hall in my head, though not my head but a house, which house? a home, my home?, perhaps by the foyer" and in the same train of thought he even attempts to locate for himself "beyond the property line, theirs, mine; what used to be my home" (506). The structure of "which," "a," and "my" home demonstrates not only a growing specificity but also a claiming. The question marks highlight the impossibility of a static kind of precision when thinking about home, while the vague "which" is followed by "a" home and finally a claim is made through the 
possessive. The unclear "property line" suggests that Johnny knows that his own claim on the Navidson house is tenuous at best, yet he still becomes more motivated to find the actual house and the ancient structure it rests upon. Through this goal, he seeks to compensate for his general lack of connections to places and people. By finally reflecting on having had homes ("what used to be my home"), he begins to see that home, as conceived through Heidegger's sense of dwelling, involves a process of continually building rather than the wistful notion of stumbling upon or being born into an ideal space.

Through Will Navidson's investigation of what home means and Johnny Truant's parallel exploration of conceptual homelessness, House of Leaves demonstrates that in the postmodern push towards multiplicity, detachment, and leaving, the notion of home is not obsolete but actually suggests an increasingly necessary anchor. Although the compasses that Karen buys are essentially useless in the "inner" house because "the house defies any normal means of determining direction" (90), there is an element of direction or anchoring that Danielewski's house as a whole still offers: as a kind of mobile centre, and a space from which to set out and invariably return to in inconspicuous as well as more explicit ways which are concealed but also revealed through technology. Johnny's conditional threat to his boss before leaving town, "I'm going to burn your life down" (411), even uses the house, or more precisely the physical and conceptual association of home, as a metonymy for an individual, and in doing so underscores the still important link between places and people that home-makers continue to incorporate into their own notion of dwelling, as Heidegger describes it in "Building Dwelling Thinking." Although home can be unwelcoming or unsettled, Danielewski's characters eventually begin to mitigate this unheimlich aspect through meditative thinking. Johnny, for instance, is initially stuck on "what used to be my home" (506), but his meditations on home and homelessness help him to integrate 
that knowledge into what his home has become and could be. Through the course of the novel, then, both Navidson and Johnny are exploring their labyrinthine constructions of home and eventually learning to dwell—by building on a sense of dwelling by thinking about "which," "a," “my home?” (506). 


\section{Chapter 3: Homecoming in Neil Gaiman's Neverwhere}

In Neverwhere, Neil Gaiman not only examines the epistemological and ontological problems of not (quite) knowing home and a broader sense of postmodern conceptual homelessness, but also explores modes of adapting to both of these alienating circumstances. Although House of Leaves presents a more in-depth exploration of these interrelated issues, Gaiman's work more explicitly challenges the apathy and helplessness which Danielewski uncovers in his novel's catalogue of failing home-makers who only begin to take up learning to dwell at the conclusion of the novel. I suggest that Gaiman is able to take the next step in the way he theorizes home in Neverwhere by, first, acknowledging the sometimes overwhelming task of feeling at home amidst mobility, technological mediation, and what feels like rampant change, and, then, revealing strategies for rooting and anchoring in these conditions. Like Johnny or Navidson, Gaiman's protagonist, Richard Mayhew, struggles to feel at home even though in London he has a fairly well paying job, fairly comfortable flat, and in between has time to spend with his controlling girlfriend. Only after he becomes trapped in a quite different London does Richard explore his own agency as home-maker in a more decisive way. While the "inner" house similarly "traps" Johnny and Navidson, rather than being a reader or observant explorer like those two, Richard is transformed from a less than willing peripheral participant to a central figure in a small group's quest to reclaim their sense of home and through it, their claim on a place in the world. Through Richard's shift from passive drone to active agent as he expands the bounds of what home can look and feel like, Gaiman demonstrates a means of mitigating the effects of a technological world of increasing updates, upgrades, and flux. 
The 1996 novelization (which is what I refer to unless otherwise indicated), television mini-series, and 2007 graphic novel adaptation of Neverwhere all chronicle Richard's opportunity to re-evaluate his expectations of and commitment to what he considers home as he wanders the maze of the regular city of London, or London Above, and the labyrinthine underground networks (mapped through the London Underground) of the fantastic London Below. The two Londons mirror each other in the manner of a carnival mirror: London Above is the regular place of tourist attractions, overflowing pubs, and "possessors," while London Below is a magic-filled world of the dispossessed "who live below and between, who live in the cracks" (97). Richard discovers this other world after offering to help Door, a girl he finds bleeding on the street. His decision to "see" and help a dispossessed person has the unwanted consequences of people in London Above no longer "seeing" him, as though he too has fallen through the cracks of society. The novel then follows Richard's quest to return to his old life, yet he ultimately realizes that it is in this other London that he is able to dwell while in London Above he was thoughtlessly going through the motions.

Significant for Richard's discovery are the fantastic mobile and transformative homes which he encounters, particularly Door's family home which consists of rooms and locations that are not linked by geography but her family's ability to create and open "doors" to disparate places. Yet, even though the house should be a safe haven that only family members can enter and navigate, Door's parents and siblings are brutally murdered while she is away. Her quest to find those responsible is what puts her in Richard's path and, feeling responsible for his eventual invisibility in London Above, she not only allows Richard to join her small group but promises to try to help Richard eventually return Above. The medieval and Victorian influences of London Below collide with the rat race of a late capitalist London Above as well as the power struggles in 
both spaces, and Gaiman importantly concludes with the possibility of Richard sustaining his own version of Door's house in London Below - a conceptual composite of rooms and spaces connected by and through him rather than their proximity.

Gaiman, although firmly rooted in the fantasy genre no matter which medium or age group he writes for, is a notable example of an internationally popular and best-selling author writing about magical worlds and modern sorts of myths. He initially garnered critical attention for writing the comic series, The Sandman (1989-1996), and several of his book projects have also been turned into films - these include Stardust (2007) and Coraline (2009)—as well as graphic novels. Neverwhere itself was initially a project that Gaiman co-wrote for a six-part BBC mini-series (1996) before deciding to write the novel to better represent his vision for the story, which was adapted into a graphic novel a decade later by Mike Carey with illustrations by Glenn Fabry (2007) - depicting certain visuals in ways reminiscent of the television series but generally distancing its style from that work — and the story has even been adapted for the stage. Although scholarship is sparse on Gaiman and this particular narrative, popular publications such as The Neil Gaiman Reader edited by Darrell Schweitzer (2007) and Neil Gaiman and Philosophy edited by Tracy L. Bealer, Rachel Luria, and Wayne Yuen (2012) offer a mixture of scholarship and commentary. Articles and chapters written on Neverwhere frequently focus on its depiction of literal homelessness through an underground city of people who have become invisible (see Beaudry for an analysis of this metaphor in terms of human rights and Ekman for a comparison to Megan Lindholm's Wizard of the Pigeons). The rich metaphors that Gaiman weaves into his urban fantasy are also explored in scholarship that focuses on the roles of architecture and technology in the text (Jenkins) and the metaphor of transport (Howie). In Neverwhere, Gaiman explores 
mobility and technology through the metaphor of magic in London Below. ${ }^{21}$ And, like Heidegger's notion of dwelling, the alternate world Below presents much more than a superficial means of embracing old modes of rooting. My argument is that in Neverwhere Gaiman overtly considers diverse home-making attitudes and practices - the seemingly traditional, novel, as well as amalgams of the two - through this magical and thus "other" lens and the poetic images London Below offers in order to present Heideggerian insights regarding poetic dwelling in a highly technological and "calculative" world.

In contrast to the theme of "losing" and "seeking" home that is at the heart of House of Leaves, ${ }^{22}$ Neverwhere more distinctly frames the rediscovery of the significance of home as a deeply personal, lifelong process of "homecoming." In my analysis of the written and visual adaptations of this story, I show that Gaiman's narrative elevates the idea of home by marking it as a locus through which meditative thinking about formative experiences — of both stability and mobility_necessitates the returning to elemental questions that the idea of home raises for the home-maker regarding self-concept and belonging. To this end, Gaiman foregrounds various modes of leaving as well as returning to (both places and ideas) in his meditation on homecoming by examining the convergence of familiar, strange, old, and new in the fantastical setting which he calls London Below. While Danielewski’s “inner” house embodies fundamental contradictions and paradoxes that define home (such as stability and shifts or protection and danger), Gaiman's metaphor of London Below and Door's house offer a more integrative space to which one returns

${ }^{21}$ In her analysis of the book Jenkins claims that "fantasy is now responding to digital technologies which equally affect our conception of journey and narrative" (41); see Friedman's comparison of science fiction and fantasy genres for an eloquent introduction into the technology/magic metaphor more broadly.

${ }^{22}$ Both Johnny and Navidson choose a new place in Virginia in an attempt to distance themselves from problematic former homes - even going back to the historical origins of the United States rather than their own histories. 
even though it can never be an impenetrable fortress. Nonetheless, as an imperfect, emotionally-laden archive of good and bad memories, I suggest that Door's house as well as the conceptual home that Richard learns to construct over the course of his ordeal serve to model dwelling in spite of but also through technological mediation, faster transit, and more convenient digital communication.

In the following sections, I will examine how Neverwhere defines home-making through a process marked by exploration, discovery, and agency, and I suggest that this view presents an important alternative to the isolation (or exploration as observation) and a predominantly passive endeavour that House of Leaves reveals to be potentially debilitating in regards to an individual's construction of home. First, my focus will be on Gaiman's depiction of dwelling and homecoming, and then I will discuss how he presents the influences of technology on home-making, particularly the mundane ways in which it can promote rather than impede the meditative thinking that poetic dwelling requires. Gaiman's narrative also illustrates an argument that Jeff Malpas makes regarding Heidegger's concept of dwelling, when he claims that we can work "to reorient ourselves to the proper place in which [we] find ourselves—-beyond this, however, there is no 'saving power' that we ourselves can exercise" (Heidegger and the Thinking of Place 69). In Neverwhere, Richard's homecoming is a process and not a singular event that solves all of his problems or answers all of his questions. In other words, his homecoming is this kind of "reorientation" towards thinking about and building home—in Heidegger's sense of both construction and cultivation — rather than the specific return which seems to engross him for much of the story. 


\section{Homecoming in "our precarious age"}

Throughout Gaiman's narrative of homecoming, Richard's notion of home evolves and this evolution, I suggest, is an intimate account of the protagonist's learning to dwell. In London Above Richard does not seem to think of home beyond the material comfort of his flat, and in London Below he nurtures an obsessive homesickness, a simplistic will to return to a now idealized place. After experiencing the extremes of taking a home space and its conceptual significance for granted and obsessing about it once it is "gone," he begins to discover a more complex understanding of homecoming through an engagement with his renewed questions of not only where but how he constructs his sense of home. Richard learns that home does not have to only imply his residence in London or the Scottish hometown that he eagerly left behind, and that it can be both and even other more meaningful places. Because Richard's quest in London Below revolves around finding his place in the world, Neverwhere presents an incisive illustration of Heidegger's understanding of dwelling as a kind of continual homecoming. In order to highlight the ways in which homecoming in Neverwhere illustrates poetic dwelling in a mobile and technological age, I examine the nuances of this term in Heidegger's work and the ways in which Richard thinks he can "come home" to his old life in London Above as well as the ways in which he learns to "come home" and dwell.

I argue that Gaiman illustrates Heidegger's sense of dwelling through Richard's journey of homecoming — seeking to return Above and then finding a way to return Below. Brendan O’Donoghue offers an extensive analysis of homecoming in Heidegger's work and in doing so illuminates the multi-scalar scope of Heidegger's sense of home as not only a space but the process of dwelling. O'Donoghue points to multiple means of coming home: to a house, a homeland, or “to what and who one is" (6). These three examples can be problematic if essentialized or limited to 
ownership, ethnicity, or a predetermined sense of identity that one is somehow born with (such as nationality or citizenship). Gaiman avoids such regressive traps and develops new ideas about homecoming by continually foregrounding his protagonist's growth and evolution, even as he rethinks or rejects previous notions of home. Similarly, O’Donoghue elaborates that Heidegger's sense of homecoming need not be limited to a first or originary house or homeland, since "homecoming is by no means a native possession, but is rather the farthest horizon of the human being's journey abroad" (371). This emphasis—away from ownership or origins and towards comparative experience - opens up the notion of "what and who one is" to the multiple allegiances, possibilities, and geocultural links which Gaiman depicts in Neverwhere through Richard's growing investment in the places, people, and ideas that construct his notion of home.

Richard's quest to return illustrates the sense of homecoming that O'Donoghue describes as coming home "to what and who one is" (6), not because Richard was destined to be a resident of London Below but because he chooses to commit to a place of his own accord-a home in and through which he understands himself and his narrative. O’Donoghue refers to John Moriarty’s Nostos to describe the conceptual aspects of dwelling: "For Moriarty, individuals are not housed or sheltered in houses made of bricks and mortar but rather they are sheltered in a master narrative or great story" (53). This idea is depicted in Neverwhere as Richard rejects a generic "master narrative" of the commodity home — which his central if small flat in London adheres to — in order to seek shelter in his own construction. Another example, Door's house in London Below embodies the notion of shelter in a narrative. In the graphic novel, she explains that in her family's networked home: "The memories are-woven into the walls. The house tells our story" (np). In contrast, the narrative that is supposed to house Richard in London Above hinges only on a socio-economic sense of belonging, as exemplified when he refers to a "Richard-Mayhew-shaped 
hole in the world that I used to fit so perfectly" (np). The "shaped hole," like a standardized dominant narrative, traps Richard well before he notices his passive compliance. O’Donoghue explains that we can experience a "falling out" (21) of this master narrative, and this is also an idea that propels the story in Neverwhere since characters in London Below have fallen through the cracks of society.

Although the plot of Neverwhere stems from the very real social problem of homelessness, Gaiman also uses that theme to explore the postmodern (over)emphasis on conceptual homelessness and the distance or invisibility that this too can engender. Richard's falling out and between the cracks includes a poignant moment in which he feels dispossessed and invisible in his own apartment in London Above. A couple comes to view his apartment and the woman quickly confirms, "It's just what we want," but qualifies this with, "Or it will be, once we've made it homey" (63). She only means redecorating in a preferred or familiar way but her comment suggests the utilitarian outlook that Richard himself embraced until he found himself unhomed. Richard's plaintive "I live here" (64) is lost on the inadvertent intruders, and in another tactless blow, the couple comments about the "rubbish" in the place while all Richard is able to do is meekly claim that it is not garbage: "It's my stuff" (63). Through this scene Gaiman underscores that Richard continues to think of home as a possession and shortly after this unexpected imposition he decides to find Door, the girl he saved, in hopes of an easy solution to the troublesome development. For Richard, London Above remains "a world of safety and of sanity" (123) and his homesickness for it continues up until his eventual return. By then, however, Richard finds no comfort in the old home even after all the nostalgia and homesickness that motivated him to return. Once he returns, he is able to see his old home in a new and less favorable light, but to get to this point Richard must make his way through a labyrinthine world and an actual ancient 
labyrinth in London Below.

As in House of Leaves, the labyrinth motif is important in the underground world of Neverwhere, and Gaiman suggests the labyrinth as a metaphor for understanding the stability and mobility of home through an emphasis on the notion of homecoming. With the emphasis on the need to return — by wandering back but also by wondering and reflecting—Gaiman effectively replaces more quantitative question of "finding" home (that motivate and haunt the protagonists of House of Leaves) with more qualitative explorations of "homecoming." Gaiman draws on the Minotaur myth by initially depicting Richard as a Minotaur-type, a trapped outsider even among other outcasts, but the character is forced by circumstance to take on the role of Theseus, not only by searching for those responsible for the murders of Door's family but also as the slayer of a creature named the Beast of London Below. Like Johnny, Richard initially dreams of the Minotaur but rather than being the Minotaur, in Richard's dream he kills the Beast which lives in a literal labyrinth, "one of the oldest places in London Below" (304). This Beast is highly territorial and all animal - whether bull, boar, or bear-like is left open and in the graphic novel it appears as somewhat prehistoric or even alien. It also represents potentially all-encompassing psychological traumas: "In his dream [...] there is nothing left in the world but the Beast, its flanks steaming, broken spears and juts of old weapons prickling from its hide" (217, my emphasis). In the story, Richard and company are trapped in the labyrinth while the Beast inherently knows the space as his own, yet after it wounds Door's bodyguard, Richard is instructed to use her spear to kill the Beast, and when the Beast again attacks Richard is able to face his fears of unworthiness and fulfills the task set to Theseus in the myth. Richard's ordeal is increasingly defined by his own agency through exploration and discovery, as he finds himself adapting to his circumstances instead than cowering from change. 
Like Danielewski, Gaiman offers an unheimlich Minotaur-Theseus amalgam in order to illustrate the unsettled aspects of dwelling — the beast and prince melding by both conquering and being conquered. Richard is told to "touch the Beast's blood...to your eyes and tongue" (315) in order to help him get through the labyrinth by knowing the space as the Beast did. After doing this, Richard "ran straight and true through the labyrinth, which no longer held any mysteries for him" (316) yet he continues to traverse the roles of beast and hero, as an outsider with inside information who straddles belonging in his past and potential home. Like Johnny, Richard experiences moments of merging with the Minotaur figure, feeling less than human and thus unworthy of claiming and sustaining a home - at least until he is forced to face this belief during his ordeal. In a pivotal moment in which Gaiman underscores the home-maker's agency in being able to dwell and feel at home, Richard is brought to the brink of suicide on the Blackfriars subway platform after encountering various hallucinations of family and friends who tell him to give up, reminding him that he is lost and insisting that he will never regain control of his life, and, moreover, that his life is worthless. He nearly succumbs but finding a bead from a homeless girl he had met earlier helps Richard realize that his agency has been largely dormant and that he can choose to passively accept the taunts or not. More than other strange encounters in magical London Below, this ordeal pushes Richard to really consider dwelling, as existing since he found himself on the brink of suicide. This jarring experience (more than his initial invisibility in London Above) together with the different articulations of home that he encounters in London Below, open up for Richard the possibility of learning to dwell. It is to the many examples of poetic images in Neverwhere that I turn to next.

\section{The issue of mobility: poetic images in London Below}

Richard is better able to learn to dwell in London Below because building for Heidegger 
involves a form of claiming, not in the sense of ownership but in acknowledging a responsibility to cultivate. Cultivation is a part of everyday life amidst the mobility and stability of London Below not simply because of the city's culture of bartering and recycling (rather than consumption and disposal) but more generally because ownership seems to include responsibility in that economy. Even the historical connections of lineage that are foregrounded Below are based on responsibility and cultivation, rather than aristocratic rights or ownership. In these ways the poetic image of a global city illustrates the cultivation as well as construction that are essential aspects of building and dwelling for Heidegger because without cultivation constructions will crumble, decay, and disappear. That this responsibility is more noticeable in London Below than in London Above may initially seem surprising since most of dispossessed London Below suggests a feeling of mobility and haphazard stability, yet residents Below embrace a sense of overarching territoriality—one that Gaiman depicts as a process of de- and re-territorialization rather than homelessness - and this more established form of connection helps sustain the emotional "comforts" of home rather than physical luxury. Alice Jenkins calls the residents of London Below "the dispossessed, the homeless and the hopeless" and describes the city as a "a viciously hierarchical, squalid society whose highest communal achievement is a kind of carnivalesque shared degradation at the monthly Floating Market" (39) but, in my view, there is quite a lot of hope Below and the space is arguably no more "viciously hierarchical" than its sister city Above. What Gaiman manages to bring to life through his fantastical, sometimes carnivalesque setting is a combination of the familiar and alien, an exemplary poetic image, through which Richard is able to re-evaluate his ideas of home and "reorient" (to echo the term Malpas uses) himself as he rethinks home as a process of homecoming that affects him in deeply formative ways.

Such poetic images or new and unconventional depictions of home-whether of complex 
networks or simple burrows - offer insightful alternatives to the dominant imagery of the relatively pristine standalone house. Eric Paul Meljac's examination of poetic dwelling as well as the care and kindness it involves exemplifies the expansive nature of Heidegger's concept through an analysis of J. M. Coetzee's Life \& Times of Michael K and Franz Kafka's “The Burrow," and several of his observations are relevant to Gaiman's work. for instance, Meljac argues that in both of these texts "the act of building the burrow becomes an intellectual exercise rather than simply a domestic act" (70), and this is what makes Coetzee's and Kafka's burrows not only strange homes but poetic images of home. The homes in these texts are literal holes in the ground and yet show the possibilities of dwelling poetically through "the invocation of not only care, but of charis, the creation of beauty, and more specifically, the beauty of dwelling in a home" (72) - whether the home is a burrow or luxury flat. When Richard decides to return to London Below at the end of Neverwhere, he is expressing his own invocation regarding the beauty of dwelling in that place.

Because Richard and his companions keep moving, he does not identify a specific location with his home Below and yet he constructs a conceptual "burrow" there, one that suggests what Meljac calls "an intellectual exercise" (70) and it signals an emotional link as well as Richard's agency through the act of claiming or self-assertion. Meljac concludes that Heidegger's poetic dwelling "seems incompatible with the commodity-driven housing and entertainment markets that dominate his (and our) contemporary culture" (72), and, similarly, Gaiman's melding of old world magic and new world technology offers a more nuanced critique of the role of commodities and entertainment in the construction of home, without being dismissive of either old or new ways. Meljac's analysis demonstrates how care and meditative thinking can transform a hole into a home as Coetzee's and Kafka's protagonists thoughtfully invest their time, efforts, and emotional attachments, and I similarly suggest that in Neverwhere Richard shows the agency and adaptation 
central to such an intellectual engagement with poetic dwelling and its possibilities in a commodity-driven, technologically-mediated age. Richard finds the kind of beauty that Meljac points to, even in the grime of an underground space full of landscapes and people that are not familiar to him and yet filled with more possibilities for home-making than the comfortable but bland commodity he had claimed Above.

While the homes in London Below are nowhere near ideal, many of these amalgams of a medieval or magical past shed light on distinctly modern problems. The mobile connectivity of London Below, the floating market, and Earl's Court subway car offer new ways of imagining "mobile" homes through new depictions (or poetic images) of what "home" can be conceived as. Earl's Court, the subway car that contains a court, can be read as a metaphor for what home has become when convenience is prioritized. Even with essentials and a few gadgets packed, there is still a good reason why Door and Richard do not elect to stay in Earl's Court when the Earl invites them to embrace this type of home-making. Its hypermobility and small space combine to create something only particular (in this case quite eccentric) dispositions can handle. The invitation is politely declined and, instead, the Earl bestows upon Richard the honour of "the freedom of the Underside" (344). This gesture seems empty since Richard has been wandering quite freely up to that point, but through the declaration Gaiman underscores that the freedom to move about or relocate is easily taken for granted in an increasingly mobile age (I will examine the privileges and problems of mobility in more detail in chapter four). While Richard initially seems sure that everyone else in London Above lives and prioritizes as he had, it surprises him that in London Below people are more invested in their homes without any overt patriotic rhetoric. While he may not have examined his attachments to place previously, in London Below Richard finds himself exposed to an understanding of home based on cultivation and learning rather than ownership, and 
his own differentiation between the two makes a tremendous impact on his sense of home.

The floating market is another example of Heidegger's understanding of cultivation as a part of building, wherein aspects of home are not always replaceable and need to be cared for and maintained. The market is a communal extension of home for the people of London Below but also the safest place there, since breaking the market peace treaty incurs severe punishment at this essential trading and meeting ground. The market itself, which Richard claims "was loud, and brash, and insane, and in many ways, quite wonderful" (109), offers him an odd mixture of a world before money and after online shopping. London Below has no paper currency but deals in gold or any exchange that is deemed sufficient by both parties-Richard exchanges his handkerchief for information, for example, though he might have gone to a stall offering dreams or garbage. Yet, somehow, as with the vast virtual shopping mall online, everything can be found at this market. ${ }^{23}$ This re-imagining of both past social conventions and modern practices does not valorize personal interaction or online efficiency but instead serves to question the motivations and norms regarding the goods and services that are sought. For example, amidst services that include the seemingly worthless and criminal, Richard hears the yells from an arms stand: "Defend your cellar, cave, or hole!" (110). The selling tactic works because all kinds of home are worth defending in London Below — not only gated communities or the abstract homeland — and this suggests something other than a calculative view of establishing worth. The merchant is not initiating a literal call to arms but offering a reminder that home, even the shabbiest burrow (such as those that Meljac analyzes in Coetzee's and Kafka's works), requires an active engagement, not just buying, renting, and storing while coming or going. The emphasis that Gaiman is placing on cultivation is clear if the

${ }^{23}$ Garbage being "sold" at the market also suggests clichés concerning people's garbage and treasures but, even more so, when the vendor yells, "Crap, tripe, useless piles of shit. You know you want it" (110), he could very well be referring to the usefulness of any number of things that shops and malls have on offer. 
merchant's marketing is compared to Richard's response to the "occupation" of his apartment in London Above, where he did not seem to think that the flat was worth defending since he only meekly contested the eager couple's claim to the space.

Finally, the most poignant example of a poetic image of home is Door's house with its physically scattered yet connected rooms, which like London Below itself also suggest the structure of a labyrinth. In the BBC series, a small budget limited the visual scope of rendering this fantastical space but in the second episode Door returns to a space of off-white walls and pillars with paintings and photographs hanging everywhere, even from the ceiling. A decorative stairway and more contemporary looking pillars offer another mix of old and new as Door's house takes London Below's mobile connectivity to a new level of being networked and labyrinthine. The house is a kind of fortress but, more importantly, a rich metaphor for how home can anchor identity without imposing distinct physical limits. Door's house is a network of rooms, and as is explained in the novel, "Door had no idea where any of the rooms of her house were, physically. Her grandfather had constructed the house, taking a room from here, a room from there, all through London, discrete and doorless; her father had added to it" (80). The lack of doors was not a problem but a safety precaution and privilege because Door's family members were "openers" (171) and able to not merely open but "create doors where there were no doors," "unlock doors that are locked," and even open those "that were never meant to be opened" (323). What this house offers as an identity marker is flexibility but also connection to people and places, time and place. Memories "are imprinted in the walls" (81). In a more revealing manner than posed or vacation photographs in frames, the memories that the walls store include unplanned moments and even the murders of Doors family.

While Door's house is not the idyllic home that the idea of linked rooms anywhere in the 
world might suggest, it does offer a glimpse of the possibilities of investing in a home: this particular household has not only built but cultivated a home through intellectual and emotional investment. The house represents an archive of experience that not only integrates but mediates and re-mediates identity in ways that facilitate meditative thinking regarding a home-maker's sense of dwelling and belonging. The deeply personal, emotional side of home is also vital to Heidegger's notion of poetic dwelling as Adam Sharr explains when he points out that place for Heidegger goes well beyond the material and visual since "[w]e reach for an appreciation of the reality of the place and what it means to us emotionally by experience" (63). Sharr further argues that, according to Heidegger, our conceptualizations of place include "a place's memorable qualities, memorable events that happened there, memorable people associated with it, even memorable fictions we have made up about it" (63). The fact that Richard's senses and feeling about home are muted in London Above but assault him in various ways in London Below, offers another reason for his choice of the latter as the place to "come home" to. In London Below "memorable qualities" abound and I want to next turn to the ways in which technology is shown to impede such emotional connections and forms of engagement with dwelling in the calculative culture of London Above but can also help reveal dwelling in London Below.

\section{The issue of technology: never here, never there, virtually home}

Through the imaginative scope of London Below, Gaiman does not merely recreate the social relations of barter societies and feudal-like allegiances but is actually looking ahead and shedding light on new networks, instant communications, and emerging practices that diminish the necessity of rooting in a single place. The magical technology that Gaiman depicts includes rats and rat-speakers, incredibly reliable pigeons that are not only passenger pigeons but can take 
special instructions, surprisingly efficient transit that moves or appears in unexpected ways, and even audio-visual recording technologies such as Door's father's holographic diary. During his travels in London Below and his contact with these strange modes of mobility and communication, Richard discovers that in a world of quickly changing technologies and priorities, home can still anchor the individual—even through speedier, multiplying, mediated, or re-mediated memories and experiences. Mobile phones and computers (which the television series foregrounds in many shots of London Above, particularly when they fail him as Richard struggles to meet a deadline or make a reservation) are missing Below, yet the functions of these tools are not. Gaiman de-familiarizes and alienates his protagonist from technologies, such as the telephone, which he does not know the inner workings of, and replaces them with animal communication techniques that he also does not understand. The magical technologies Below, I want to suggest, reveal to Richard that while technology and technological thinking are an integral part of his sense of home, they do not define the idea, and in this section I investigate the different relations to technology that the inhabitants of London Below establish as well as the dependencies on (or automatic, unthinking relations with) technology that the inhabitants are able to subvert.

Heidegger's major concern with technology is that it can overpower less quantitative, meditative thinking, and Gaiman illustrates this concern through Richard's technology-rich but unmeditative life in London Above. Since the fantastic space below the familiar consumerist metropolis is an allegory for the possibilities of a life that balances calculative and meditative thinking — constructing and preserving are privileged over consuming and replacing — through London Below Gaiman outlines the possibilities of future change rather than a proscriptive return to the past. ${ }^{24}$ O'Donoghue elaborates on Heidegger's sense of conceptual homelessness by

${ }^{24}$ Gaiman, after all, satirizes most of the feudal and Victorian penchants of his secondary 
suggesting that "modern technology suppresses other non-technological forms of disclosure" (226). For Heidegger, both calculative and meditative thinking are necessary but the latter is, as O'Donoghue points out, being stifled. Richard finds himself in the midst of this kind of suppression while he is surrounded by gadgets in his apartment and at work-in the BBC series, for instance, he juggles multiple phone lines and a mobile phone which interrupt and delay him rather than save time. In London Below, new forms of knowledge sharing, including a "rat" messaging system ("rat speakers" relay messages through the rats that travel in and between the Londons) and these magical technologies do not conceal or commodify Being to the same extent because the connections that the technologies used in London Below foster help maintain rather than distance users from a sense of home and a deeper engagement with dwelling.

In Neverwhere, fantastic elements illuminate relations to technologies that are embedded in menial practices and are thus no longer very noticeable, yet which taken together play a central role in everyday functionality, from increasing means of personal communications to the accessibility of global media. The modes and means of knowledge sharing are significant in fantasy beyond the utilitarian uses of the Internet, for instance, and information flows are diversely reframed in the genre, as Neverwhere exemplifies. Door's house, which Jenkins refers to as "hypertextual geography" (41), truly embodies the abstract possibilities of increased speeds and the accessibility of physical mobility as well as the virtual means of connecting to other "rooms" that might be a few time zones away. The way that the house showcases connectivity through Door's family's talent or magical skill integrates the often isolated physical and virtual experiences of mobility. If Door's house is taken as a model of a twenty-first century home- a necessarily imperfect model as the tragic fate of the family reminds us - then it demonstrates a

characters - from the mad Earl to the underhanded Marquis. 
mode of home-making that is adapted to rather than dictated by the scope and embedded nature of modern technology. Gaiman's text illustrates an agency rather than subservience that fosters Heidegger's sense of poetic dwelling. Such agency is required to use technology and think calculatively without becoming so immersed that all our thinking becomes automatic, in which case poetic dwelling is impossible.

In their analysis of new media, Jennifer Bay and Thomas Rickert rightly stress that Heidegger's argument is not about demonizing technology but rather finding better ways to relate to it, and Gaiman's allegorical technology of organic matter and simple materials similarly does not demonize high tech cybernetic tools but seeks to show the more basic uses and abuses of a technologically defined life. Door's father's diary, for example, presents a new-old hybrid and a more meditative relation to technology in London Below. Door and the Marquis need to physically find it as though it were a book but it is an audio-visual projection. The diary is something that Portico kept for himself, not to replace or mediate interaction but as a means of reflecting upon and potentially sharing his ideas should something happen to him. In the television series the machine that recorded Portico's diary entries looks like something from the 1950s with strange pumps and pastel colours. In the novel, "[t] he whole mechanism looked rather like a combined television and video player might look, if it had been invented and built three hundred years ago" (96), and includes a brass horn and wooden ball to offer an amalgamation of the electrical, mundane, and magical. Both visuals combine nostalgia with efficiency in a device that a powerful man trusted to use as a specific tool. Portico was able to engage in meditative thinking through his use of the diary rather than succumb to calculative thinking regarding the number or efficiency of entries amassed, number of people viewing them, or other quantitative distillations. Moreover, this diary was an extension of the poetic dwelling Portico engaged in through his intricately networked home space. 
Similarly, Bay and Rickert claim that there can still be "a sense of home in places, even those that—being mobile, dynamic, and/or virtual—are seemingly the antithesis of what makes a place" (217), and this is a fair assessment that a narrative like Neverwhere showcases by depicting the possibilities of dwelling poetically in an increasingly mobile and digital world by using technology in ways that hinge on the quality of interchange and life, not simply quantity or convenience.

Finally, while Bay and Rickert mention "the sense of ease [technology] cultivates" (234), they do not explore the impact of the thoughtless or automatic ease that Heidegger describes. Gaiman, however, poses questions regarding this impact by destabilizing the purposefulness or necessity of everyday technologies that speed things up and alternately slow their users down by further isolating people or replacing human contact with screens. In examining Richard's invisibility in London Above, Stefan Ekman points out that "[e]ven the machines of the natural domain ignore him" (68) and this includes the tube ticket machines and an ATM. Gaiman describes that Richard's coins "went straight through the guts of the machine and clattered into the tray at the bottom" (57) and with the ATM "[s]omewhere in the depths of the machine something grumbled and growled" (66) before a sign notified Richard that his card was not valid. That these machines can reject his existence in much the same way that people do signals a status that is not often attributed to technology — both examples personify the machines by referring to their "guts" (57) or describing vocalization as "grumbled and growled" $(66) .{ }^{25}$ Once the convenience of technology that Richard is used to is denied, he is forced to rethink rather than act in an automatic fashion. In London Below, however, machines (like the Earl's vending machines) are tools rather than potential agents and people remain integrated into the networks of transit and communication without resorting to full or near-full computerization. To return to Heidegger's terms from "The

${ }^{25}$ This idea of machine agency is the premise of media archeology. See Wolfgang Ernst's Digital Memory and the Archive (2012). 
Origin of a Work of Art," in London Below technology remains "handmade" to some degree—for example, the rat speakers practice a talent or art for which they are valued - while in London Below technology represents equipment that also happens to have the power to leave us as helpless as Richard when something goes wrong. ${ }^{26}$

In my final example of the differences regarding the use of technology in the Londons, I want to turn to the question of time because it helps me to develop the idea of modern dwelling as something that takes time, even in a culture preoccupied with "saving" time. Richard notices that time-related technology fails him Below when his digital watch is "completely blank" (108). Yet, the Marquis, who keeps a pocket-watch that he finds in Door's father's study, seems satisfied with the efficiency of that watch. This does not indicate a preference for or the superiority of mechanical over electronic technology, and time neither slows nor stretches in London Below in a way that the digital device cannot adjust to. What Gaiman reveals through these symbols of time is that in London Below time exists for its inhabitants as a finite thing that passes and not as something that can be saved through faster or more convenient technologies. Upon noticing the blank screen Richard thinks that the batteries may simply be dead but then "thought, more likely, time in London Below had only a passing acquaintance with the kind of time he was used to" (108). Richard's digital watch, like his various phones in the office, symbolizes a way of amassing technology to save time with the outcome of also — and potentially even more so-wasting it. Richard is less productive and further delayed because of phone interruptions and his manic time-checking during and even after work, but in London Below he assesses his time in a more qualitative manner, a practice that is important for him in learning to dwell.

${ }^{26}$ Had Richard encountered the ATM issue prior to meeting Door, for instance, he might very well have had strong words for the bank or machine representative at some far-away call centre, someone who for him would only represent a drone in a system - one which exists and continues to grow by favouring calculative thinking. 
Richard's transformation over the course of the narrative illustrates how meditative thinking, as Heidegger explains, "demands of us not to cling one-sidedly to a single idea, nor to run down a one-track course of ideas" and "demands of us that we engage ourselves with what at first sight does not go together at all" ("Memorial Address" 53). Although Richard initially "clings one-sidedly" to his need to return no matter the cost, he eventually begins to see things "together," in a large part by being exposed to and increasingly more open to other approaches to dwelling and relating to the world, approaches that are rooted in multiple and dynamic ways to potentially distant groups of places and people. The chaos of life Below begins to not only make sense to Richard but holds a new appeal. Through Richard's initial alienation and later wish to embrace this different London, Gaiman's novel reveals that the "quickness" of life through expedient transit and communication technologies breeds misconceptions regarding what home can still mean in the digital and mobile twenty-first century and the kinds of dwelling that the notion of home can cultivate but also integrate in meaningful ways, much like Door's house. Gaiman also shows that home can be made or built in unexpected places and unpredictable circumstances. Furthermore, his work complements the depth of Danielewski's examination of the idea of home and conceptual homelessness through its breadth of depictions of relations and practices that help individual home-makers to integrate the multi-sensory, multi-locational, and multi-scalar dimensions of home.

\section{Unheimlich: unexpectedly at home}

Through the term unheimlich, Heidegger stresses an awareness of our unsettledness and what causes or exacerbates this kind of partial sense of homelessness—-something that can motivate us to take up the question of how we dwell and seek to learn to dwell. To understand 
home as inherently unheimlich means to willfully expand the concept beyond common associations of nostalgia or comfort and explore the multifaceted, dynamic concept as a framework for identity, belonging, and all manner of homely and unhomely, welcome and unwelcome, as well as familiar and strange elements. In the previous sections I have attempted to demonstrate the ways in which Gaiman's uncanny double city also illustrates an exemplar unheimlich home, which supports meditative thinking and what Heidegger calls poetic dwelling. To conclude my examination of home on the individual scale, I want to return to the notion of homecoming that I began with in my analysis of Neverwhere. Not only the fact that Richard returns to London Below but even the way in which he returns is highly evocative of the kind of home that Gaiman models as a dynamic network capable of incorporating the ephemeral nature of the mobile and virtual into something that feels stable and can anchor even the most initially hesitant home-maker (Richard, for instance). Like Danielewski's labyrinth motif in House of Leaves, Gaiman's central metaphor of a networked house in a networked city foregrounds multiple paths and places, but what he also manages to show is the ability of other home-makers-people who, unlike Door, did not grow up in such a house — to build and explore this kind of multi-scalar dwelling.

When he decides to return to London Below, Richard draws the outline of a door and when the Marquis de Carabas appears to fetch him, they "walk back into the darkness, leaving nothing behind them; not even the doorway" (370). Even if Richard never comes back to London Above, the way he returns Below echoes Door's magically connected house of rooms in various places and suggests that he too can construct such a conceptual home, integrate self-concept, and root his sense of belonging through it. Door has a family penchant for "opening doors" and the ability to live in such a house, but Richard also finally discovers a composite sense of home that does not 
need to be exclusive in terms of locations and firmly delineated physical or political borders. His homecoming, first Above and then Below, is precarious in certain ways, but this no longer causes him anxiety or an obsession with going back in time to another place. Instead, Richard renews a commitment to learning to dwell through self-reflection and the eventual decision to return where he thought that he could never be at home. It is in London Below that he learned to do what Heidegger describes as "stand and endure in the world of technology without being imperiled by it" ("Memorial Address" 55), and through his imaginary London, Gaiman suggests that it is possible to discover and foster places in which dwelling can still be poetic rather than supplanted by technological automation.

Upon returning to London Above, Richard discovers a home devoid of meaningful connections; in it he finds that he is not able to, as Heidegger puts it, "attain to dwelling" ("Building Dwelling Thinking" 143). His assumed sense of belonging is distinctly missing and he is apathetic in response to this unexpected lack, thinking, "I really don't want anything. Nothing at all” (368). "Attaining” suggests action or an agency which Richard only begins to claim when he realizes that being more fully responsible for what happens in and with "home" is a continuous process. He does not unpack the boxes of his things that were brought out of storage from the time during which his apartment was rented out without his permission. He eventually asks his co-worker and friend, "Do you ever wonder if this is all there is?" and elaborates, "Work. Home. The pub. Meeting girls. Living in the city. Life. Is that all there is?" (364). Although Gary seems quite happy in this understanding of dwelling - a calculative view of work, a commodity home space, and so on - for Richard it is no longer enough. Upon his return Richard only finds disappointment because he was not dwelling in Heidegger's sense in his apartment in London Above; he was merely staying there. Richard's journey, from the materially comfortable rat race to 
a much different race for meaning — of learning to dwell—offers a cogent example of attentive dwelling because being at home involves a sense of continually cultivating and more purposefully thinking about home. In the graphic novel Richard feels that he returned to "a space I didn't fit any more and couldn't make myself comfortable in. Like a coffin made to measure for a man slightly shorter than me" (np), and the sense of being taller than before (when the "coffin" did seem to fit him) suggests that he has grown figuratively and is learning to dwell.

In London Below Richard is exposed to more kinds of homes (including the poetic images that I discussed earlier) which might very well exist in some form Above but did not fit Richard's framework of home while he was still there, and I suggest that the poetic images which Gaiman fills Neverwhere with serve to reorient our expectations - like Richard's — regarding the idea of home, what it means, as well as where it begins and ends. The floating market is on the impermanent or homeless end of the spectrum, while the subway car of Earl's Court serves as an intermediary transit home, and Door's house is the ultimate custom-made fortress. Each of these includes downsides: the floating market is an ephemeral place, Earl's Court is a confined space controlled by unpredictable whims of a mad man, and Door's house ends up a deadly trap for the family. But home is never merely "sweet" and it could not be a nexus for poetic dwelling otherwise because the kind of dwelling which Heidegger extols necessitates growth and change, neither of which is familiar and comfortable, as Richard discovers.

I want to conclude with a final, telling example of the poetic images of home that Gaiman ingeniously incorporates into his fantastic city. In a street in London Below that Richard encounters towards the end of his ordeal, a plaque proclaims that it is the home of "The Royal Society for the Prevention of Cruelty to Houses" (285). This suggests that home-makers have, in fact, been cruel to their houses and homes by degrading them to commodities, rather than spaces 
that through their meanings and conceptual weight accumulate and safeguard memories and personal histories. Even more interesting is the sign just below with directions that read, "Down Street. Please knock," and when Richard can't figure out what this means, he asks, "You get to the street through the house?" (285). It is explained to him that, actually, "The street is in the house" (285), and such innovative ways of thinking about the physical and conceptual spaces as well as scales of home offer even richer poetic images that can facilitate learning to dwell by uncovering insights through the alien elements of these images. Home, as a multi-scalar and porous concept, can be full of overlaps and inversions which shed light on the home-makers and communities that are constructing and preserving particular home spaces. Size and time lived in a location need not take priority, as Gaiman points out through this street located inside a house. Which spaces, rooms, buildings, and areas shape an individual's home are chosen and require a level of reflection, and this is why a city in which he has spent considerably less time can become more of a home for Richard even after his years in London Above and childhood in Scotland (although these other places are still central to his idea of home as older "rooms" linked in a house such as Door's). By questioning the new and old boundaries of home, Gaiman shows that our notions of dwelling can expand and contract in ways that are more reflective of changing home-making practices on personal, communal, social, global, or any combination of these geocultural scales.

By the end of Neverwhere, where exactly Richard will call home remains uncertain, but we know that he is rethinking the idea and will likely continue to do so no matter how many "Londons" he visits. Home, as the crux of dwelling, seems possible somewhere here or almost there, even if it is ultimately "neverwhere" as Gaiman proposes because it must be unheimlich and un-home-like or unsettled in some ways. This paradox only makes learning to dwell that much more important for Heidegger, and what the two literary texts that I have analyzed in Part I 
demonstrate is that our role as dwellers does not disappear when dwelling is commodified or ignored (instead, this leads to personal and social problems for many of the characters) while the results of rethinking dwelling help formerly inactive home-makers gain their bearings, discover a dynamic conceptual centre, and integrate the emotionally charged relations that they have with places. In both House of Leaves and Neverwhere characters experience transformations through the fantastic spaces that they encounter and begin engaging with home-making more deeply. In House of Leaves Johnny compulsively seeks to finish editing a manuscript about a supernatural house, while Neverwhere's Richard "fell through the cracks" (127) of society and seeks to find his way back from an underground city that strangely mirrors his own. Both the unlikely editor and the unlikely hero navigate complex textual or underground labyrinths and help reveal the labyrinthine nature of home. Although Johnny only begins to reflect on dwelling and embrace his agency in home-making by deciding to look for the house about which he reads, Richard offers a more decisive choice to not simply "find" home but to understand "finding" as homecoming. So while Danielewski's narrative delves into the psychological issues of exploring home amidst postmodern conceptual homelessness and ends with hints of its characters learning to dwell, Gaiman demonstrates that the labyrinthine, networked home can, in fact, be understood through a sense of continued homecoming - a merging of mobility and stability, and what Heidegger calls poetic dwelling. 


\title{
PART II: Home on an interpersonal scale and the economics of
}

\author{
mobility
}

For lack of a better term a windswept spirit.

- Anne Carson, Nox

To settle. Settled. Settling. To fix or resolve definitely and conclusively; to agree upon (as in time or conditions). To place in a desired state or in order. To furnish with residents. To quiet, calm or bring to rest. To stop from annoying or opposing. To cause (dregs, sediment, etc.) to sink or be deposited. To dispose of finally; close up. To decide, arrange or agree. To come to a rest, as from flight: The bird settled on the bough. To gather, collect or become fixed in a particular place, direction, etc. (Of a female animal) to become pregnant; conceive. To become established in some routine, especially upon marrying, after a period of independence or indecision. To apply oneself for serious work. To settle for; to be satisfied with: To settle for less.

- Steven Sherrill, The Minotaur Takes a Cigarette Break 


\section{Chapter 4: Bauman and "liquid modernity"}

In the first chapter, I examined Heidegger's philosophical approach to the importance of learning and dwelling, an approach that was deeply influenced by the post-war technological changes that he observed reshaping modernity. In this opening chapter of Part II, I turn to the work of Zygmunt Bauman whose project, I argue, complements and updates Heidegger's foundational work on dwelling by considering the social context of a global economy as well as the multifaceted impacts of increased mobility. Half a century after Heidegger outlined a cultural shift from dwelling in our environment to viewing the world as a divisible resource in "Building Dwelling Thinking," Bauman's writing focuses on the socio-historical conditions of the new millennium-a time marked by an abundance of technology and consumption that for much of the world greatly exceeds the influx of innovation and consumer goods that followed World War II. While Heidegger alludes to problems regarding commitment and consumption in his analysis of the shift from dwelling as Being to indicating the "activities" of taking up space, Bauman foregrounds these same issues in the context of what he calls liquid modernity. His term describes a cultural and economic context which followed solid modernity, an era that put stock in stability, production, and tangible goods or "hardware." Liquid modernity, which began to emerge in the later parts of the twentieth century, is characterized by frequent change, consumption, and promoting tangible as well as intangible goods or "software." I find the notion of liquidity so compelling because the new and increased "flows" of the twenty-first century continue to promulgate the characteristics of liquidity's flux and flows. Together, Heidegger's vital philosophical insights regarding dwelling and Bauman's more contemporary social critique allow me to illuminate what is at stake when 
home is not seen as a conceptual tool—as an anchor and integrative space that fosters

reflection - but understood as an object, resource, and, more specifically, an asset that can be "liquidized."

What Bauman's work helps me do with Heidegger's ideas is move beyond the scale of the individual home-maker and onto the scale of community and relations, particularly because Bauman focuses on the ways that mobility and a global economy are affecting norms regarding communal engagement as well as the means of maintaining relations to people and places. The notion that dwelling no longer defines Being, which Heidegger takes as his starting point in "Building Dwelling Thinking," offers a rich context for Bauman's critiques of a modern culture of flows and disposability that favours the quick benefits of replacing over the more abstract, long-term benefits of preserving and constructing, or what Heidegger calls "building." Furthermore, I suggest that Bauman's twenty-first century critiques regarding consumerism and commitment also enrich Heidegger's critique that, even though both kinds of thinking are necessary, calculative thinking is stifling meditative thinking. In other words, the consumerist thinking of late capitalism, most concerned with quantifiable results, increasingly suppresses forms of qualitative thinking that concern meaning, relations, and commitment. The continuing shift from meditative to calculative thinking normalizes socio-economic prerogatives and priorities, such as the rights of ownership and the "uses" of land, which deeply impact notions of home since calculative thinking propagates a conception of the commodity home-more residential good than space of meaning-making.

In order to examine the commodification of home on the scale of relations and exchange, I specifically focus on the culturally and globally reconfigured economics of mobility. What I mean by this is the economically facilitated or induced international mobility of people, products, and 
practices as well as the intra-national, regional, and even local mobilities that create webs (for individuals, families, and communities alike) of increasingly multiple origins and destinations. Bauman's work helps me to frame this approach through his dichotomy of tourists, who are mobile and model consumers, and vagabonds, the "flawed" consumers whose existence remains unnoticed as liquid modernity is increasingly marked by a preoccupation with what Bauman calls "shopping around." The tourist and vagabond offer expansive metaphors through which to begin mapping the possibilities of home-making and mobility in a liquid modern world. Moreover, Bauman's concept of liquid modernity offers a lens through which the question of home signals a very specific problem within the theoretical promise of postmodern multiplicity (as well as postmodern conceptual homelessness), most notably because liquid modernity includes the realities of vagabonds for whom multiplicities are not often feasible options.

Like Heidegger did mid-century, Bauman observes in the late twentieth century a shift in which the possibilities of engagement fail in the face of consumerist instrumentality. In my analysis of a film and novel in this part, I explore the traces of this historical shift by seeking out ways that these texts inscribe tensions between commitment and consumption as well as model ways in which they can co-exist. The complex relations to people, objects, and places depicted in these works allow me to unpack the disruptive ways in which a consumer market level understanding of "buying" home obscures the personal and communal meanings that are integral to "building" home. I argue that the late capitalist emphasis on buying is an imperative concern because it limits legitimate home-makers to those who can afford to make such a "purchase" or "investment" but also, more broadly, because it severely limits a home-maker's agency. The commodified home undermines the engaged making that the concept of home requires in order to function as more than another physical shelter, particularly in a world constantly reshaped by the 
mobility of faster communications, farther imports, and more frequent migrations. Although previously "natural" assumptions about home as predominantly origin or legacy may have largely been debunked by the rise of postmodern ideas, I argue that the multiplicity or liquidity of what and where home might be has also diluted the idea of home, and this is a side effect that is in some ways inevitable but can also be offset. Bauman's project is aimed at offsetting these problems and in Does Ethics Have a Chance in a World of Consumers? he makes clear that a return to a previous form of solid modernity is not what his critiques advocate: "The question is not how to turn back the river of history but how to fight against its pollution by human misery and how to channel its flow to achieve a more equitable distribution of the benefits it carries" (75).

In chapters five and six I deal with two primary texts: M. Night Shyamalan's The Village (2003), a genre film which centres on a "safe" gated community, and, Nicolas Dickner's Nikolski (2008), a postmodern novel that sanguinely explores the openness of a globally mobile world. Both texts tackle questions relating to equity, ethics, and responsibility by exploring where home is "made," how, by whom, and through what kinds of relations. They do this in ways that illuminate Bauman's sense of liquid modernity but they also suggest new means of addressing the instabilities and uncertainties of its flows and flux. In fact, in The Village an idealistic attempt to "turn back the river of history" fails, while Nikolski explores other roles that function between the tourist-vagabond extremes and new means of "distributing" home that demonstrate the benefits of an expanded sense of the idea. Together, these works show that a more inclusive rather than exclusive understanding of home does not hinge on the multiplicity of residences but rather a sense of commitment to the multiple, interlinked scales of home.

In my analysis of these texts in chapters five and six, I utilize Bauman's concept of the tourist and vagabond in order to investigate the ways in which strangers, foreigners, or nomads and 
natives, locals, or settlers are constructed — and construct themselves — through the economics of mobility in these two very different creative works. Each fruitfully demonstrates but also problematizes Bauman's opposing life strategies, particularly Nikolski which offers less polarized and more transformative examples of home-making in liquid modern times. These two texts explore the ways that commitment can occur not just in spite of but also through mobility, and in doing so, they shed light on the three core elements of home that I am investigating: the stability of dwelling, the mobility of modern life, and the multi-scalar nature of home. In The Village Shyamalan depicts extreme pessimism in regards to the possibility of home being stable amidst liquidity. The community in the film attempts to go back in time not simply to 1897 but to "solid" modernity, with its more rigid social expectations and seemingly more predictable though notably isolated way of life. I suggest that the unsustainable nostalgia at the heart of Covington Woods community and ideology impedes an understanding of home as a multi-scalar construct that mediates mobility and stability. Consequently, the village elders in effect replicate the problems of unanchored and commodified home-making in liquid modernity, just under the guise of a former era. In Nikolski, a novel which offers a rather optimistic look at the freedom to "explore" the world as home but also manages to uncover ways that home can still be stably constructed in liquid modernity, Dickner, I argue, reveals the ways that the multi-scalar home can be integrated in a "complex map" that is influenced by global consumerism and the effects of a mobility divide but,

nonetheless, includes a sense of stability through "roots" that are not immutable but multiple and flexible, along with the mobility and "routes" that are equally integral to constructions of home.

\section{Introduction: liquid modernity, flows, and flux}

Bauman's characterization of liquid modernity and the globalizing twenty-first century 
shed light on the nature and significance of the interpersonal relations that can "make" home because these relations are facilitated as well as impeded by forms of liquidity. In order to demonstrate the relevance of his ideas, I will first examine the idea of liquid modernity and Bauman's overall project as it relates to postmodernity and identity, and then delve into an analysis of consumption more specifically by looking at the significance of the rhetoric and practices relating to "liquefying" assets—-such as houses and other physical homes—which my texts also critique. The gated community at the heart of The Village, on one hand, and Nikolski's protagonists searching for "the one" home while they drift, on the other, show different ways in which Bauman's work challenges the emerging trend of "shopping around" not only in general but shopping around for home specifically. The elders in the first work decide to settle for buying and distinctly "decorating" the Covington Woods area to suit their preferences. The three protagonists of the second text initially continue their "shopping" search when they cannot find a home that suits them, but what is more interesting about Dickner's work is that it shows how practices of "shopping around" can also be fruitful in a non-commodifying way by fostering exploration and an openness to new possibilities rather than procuring "the one(s)." Finally, I examine how Bauman's metaphors of the tourist and vagabond reveal significant material and socio-economic obstacles to home-making through the ways in which they position strangers. Here again the novel and film enrich Bauman's ideas in very different ways: Shyamalan's film shows how a fear of strangers debilitates those who seek to make a home, while Dicker's novel foregrounds the ways that his home-makers identify as strangers in a way that helps them to explore new modes and locations for home-making.

Bauman offers emergent views of what he eventually calls liquid modernity first in Modernity and Ambivalence (1991) and then Postmodernity and its Discontents (1997). His 
interest in developing this term has spanned several books: Liquid Modernity (2000), Liquid Love (2003), Liquid Life (2005), Liquid Fear (2006), Liquid Times (2006), 44 Letters from a Liquid Modern World (2010), and Liquid Surveillance (2013). I find the shift that he outlines from solid to liquid modernity valuable for understanding the epistemic shifts regarding commitment, community, and changing conceptions of home, particularly over the last twenty years. Liquid modernity not only offers a rich metaphor but the solid/liquid distinction is also less ambiguous than modernity and postmodernity. Additionally, by sidestepping the "post" of periodizing concepts like postmodernism, Bauman's notion of a liquid/solid dialectic avoids a teleological notion of history, with one period overcoming or surpassing another. ${ }^{27}$ Bauman insists that the liquid and solid metaphors offer an imperfect dialectic and this, I think, is vital since even in liquid modernity home is an idea mired in nostalgia and connected to ideas that seem "solid" or are associated with perceptions of solid modernity. His scientific metaphor draws on the processes of matter passing from one state to another under particular conditions, and this offers a dynamic way of understanding historical processes through complex sets of conditions as well as their effects. As my analysis of my primary texts shows, home can neither mirror the imaginings that we have of solid modernity — as attempted in The Village — nor be a concept that functions in a completely liquid world—something Nikolski examines through variously nomadic characters. So, even if solid modernity suggests traditional rooting while liquid modernity appears to offer the freedom of

27 In an interview with Simon Dawes, Bauman elaborates on the "dialectical bond" (132) of solid and liquid. He explains that "it was the quest for the solidity of things and states that most of the time triggered, kept in motion and guided those things' and states' liquefaction; liquidity was not an adversary, but an effect of that quest for solidity" (132). I take this to mean that our search for bigger or faster or better remains linked to finding something "solidly" so, rather than persisting in a loop of consumption or liquidizing assets for the sake of consumption itself. In the interview, Bauman also refutes any claim of global synchronization when it comes to experiencing the effects of liquidity, which is another reason that the liquid metaphor works well with my sense of the multi-scalar home-some locations and socio-geographic scales are more liquid than others. 
infinite routes, the fact that the characteristics of these modernities overlap and form a dialectic remains important for my understanding of home as integrally constructed through an amalgam of roots and routes, both of which can seem "solid" and "liquid."

I contend that Bauman's dialectic offers a rich framework for examining the connections and relations that help construct notions of home because his metaphor, in terms of physics even, is most concerned with the question of relations or "bonds"- whether these are sustainable and to what degree they are malleable. He opens Liquid Modernity with the Encyclopedia Britannica definition of "fluidity" and emphasizes that, in comparison to the "bonding" of solids, fluids "neither fix space nor bind time" (2) because they are not bound to a shape or specific space and not susceptible to the fracturing or decay of the passing of time to the same degree as solids. His other associations with the concept of fluidity include lightness, weightlessness, mobility, and inconstancy, all of which further suggest an ambivalent relation to flux. Solids, meanwhile, are more difficult to move or "melt" and include "the bonds which interlock individual choices in collective projects and actions" (6). So, if solid modernity suggests a stable and rooted life, liquid modernity is marked by the flows of changing routes and the uncertainty of where they might lead. While these distinctions align the solid and liquid metaphors with that of roots and routes, respectively, it is important to be able to problematize such an opposition by suggesting that an expanded view of roots and stability along with an added emphasis on routes and mobility more accurately define home, a concept which must be fluid in order to reflect our increasingly mobile realities but is far from "liquefied."

One reason that Bauman's work is still valuable, particularly for questions regarding identity and belonging, is his contention that liquidity furthers commitment avoidance. By promoting the convenience of replaceability, disposability, and the increasingly central role of 
consumption in everyday life, liquid modernity has critical implications for the commitment that a notion like home requires. In The Postmodern Condition, Jean-François Lyotard points out that "each [self] exists in a fabric of relations that is now more complex and mobile than ever before" (15), an assessment that remains accurate; yet, writing in the 1970s, Lyotard was rather optimistic about the communicative and thus connective possibilities of people existing as "nodes" in increasingly large and accessible networks. Since Liquid Modernity, Bauman's project has highlighted the imbalance of the breadth of networks relative to the depth of communication and the connections that are being created or maintained. In one letter from 44 Letters from a Liquid Modern World, Bauman contemplates the case of a young girl who sent 3,000 text messages on her mobile phone in one month. This excess - messages instantly received and probably just as quickly forgotten in order to make room for the flood of more - is captured by the liquidity metaphor more so than by postmodernity, which conventionally celebrates multiplicity. The idea of home, while immeasurably enriched by the notion of multiplicity in discourses of immigration and others, can become overly fractured by a continued emphasis on change, and Bauman's notion of liquidity helps me to frame the ways that the spaces of home are commodified in an increasingly liquid market and that home, as an idea, is "diluted" through twenty-first century consumerism.

Bauman suggests that through the consumerism of liquid modernity, connections themselves become secondary to the act of seeking and acquiring them, and this is the issue of commodification that The Village and Nikolski take up. According to Anthony Elliot, Bauman wants to stress that “'relationships' are increasingly replaced by the activity of 'relating,' 'connections' are increasingly replaced by the activity of 'connecting"” (58). ${ }^{28}$ This same pattern

28 This shift has also been examined by writers and researchers in regards to social media, notably by Zadie Smith in "Generation Why" (2010) and Sherry Turkle's Alone Together (2011). More directly concerned with home, Marjorie Garber similarly describes such a disconnect for 
occurs at the intersection of identity and belonging, and the activity of "home-making," or what Heidegger calls dwelling, is replaced by searching for, consuming, and replacing or wishing to replace "homes." Because I want to further explore the extensive role that consumerism plays in liquid modernity, in the sections that follow, I turn to how the tourist and vagabond life strategies that Bauman proposes disrupt community building in this context—what can easily be a shopping spree for the tourist amounts to window shopping for the vagabond. Most significantly, neither the tourist nor vagabond seeks a conception of home that suggests Heidegger's sense of dwelling, and this is precisely the kind of deeper engagement with place that Bauman argues is missing in a liquid modern world of commitment-avoiding consumers.

\section{Critical issue 1: commodification and "shopping around" for home}

In Liquid Modernity Bauman uses the phrase "shopping around" (74) to describe the liquid modern approach to objects, skills, and relationships. Although he does not mention home, "shopping around" for home is a quintessential practice in a globally connected liquid modern world that is increasingly affected by what I have referred to as the economics of mobility, or the perceived cost and time benefits of moving and replacing rather than investing in the preservation of not only home spaces but the allegiances as well as sources of support and responsibility that they signified. Tony Blackshaw describes Bauman's notions about consumer society and its impetus to "shop around" by linking liquid modernity to a sociality "that is knowledgeable but is incapable of contemplating itself, and which asks no questions because it allows consumer culture to provide all the answers" (Zygmunt Bauman 33). This lack of reflection parallels Heidegger's

affluent home-owners: "We build exercise rooms instead of exercising, furnish libraries instead of reading, install profession kitchens instead of cooking" (5). 
concerns regarding decreased meditative thinking. A society concerned with what is being consumed rather than with how, why, and with what potential consequences suggests an imbalance of calculative thinking. What this means is that mobility can so loosen connections to the places that signify home so that the idea is flattened; home becomes a kind of basket of goods and services that can be haphazardly thrown together, each of which is easily replaced elsewhere. Calculative thinking and consumerist conditions can shift home spaces and their meanings until they are no longer differentiated from other forms of shelter or spatially conceived identity markers, such as places of work.

I now want to examine the effects of commodification, hyperconsumption, and the ways that privileging mobility can-although it does not have to-undermine the role of home. Bauman's concept of liquid modernity is the context within which I seek to show that "buying" is now displacing a sense of "building" home. Further to the similarities of Heidegger's opposition of meditative thinking and calculative thinking to Bauman's binary of commitment and consumption, the two thinkers propose learning as an important missing link in our potential for poetic dwelling and equity, respectively. Bauman's concerns with social justice supplement Heidegger's existential ideas because they amend a philosophical concern about oneself and one's world with the place, role, and quality of life of the other. Heidegger's emphasis on learning—which he stresses through our elemental need to "ever learn to dwell" ("Building Dwelling Thinking" 159) and which I examined in chapter one-is open enough to include questions of equity on larger communal scales and so I suggest that this kind of learning is being channeled when Bauman suggests that long term learning is consistently undermined in liquid modernity: "swift and thorough forgetting of outdated information and fast ageing habits can be more important for the next success than the memorization of past moves and the building of 
strategies on a foundation laid by previous learning" (Liquid Times 3, original emphasis).

Heidegger's insistence on a need to "ever learn to dwell" is incisively depicted by Bauman in his analysis of social norms and strategies regarding employment, in a time when an apprenticeship model of building on skills over time is replaced by the ebbs and flows of malleable and more easily replaceable labour dependent on increasingly fickle market trends. In a cultural context in which learning is replaced by a greater need to quickly adapt, home is similarly characterized as provisional and replaceable, each instantiation forgotten like "outdated information." Heidegger's and Bauman's social critiques highlight the ways in which home no longer functions as a cumulative construct, and what I seek to demonstrate through Bauman's work as well as the theoretical work of my primary texts is that such a cumulative construct is even more important in an increasingly mobile age.

A market-driven society offers a very simple and increasingly socially-accepted means of belonging: consumption. Bauman insists on questioning a consumerist sense of freedom and belonging in much of his later work by exploring ethics and suggesting that commitment and responsibility still have their place, even in societies increasingly defined by liquidity and liquid relations. Some critics, however, take Bauman's critique as an oversimplification of consumerism. Mark Davis, for instance, argues in Freedom and Consumerism that Bauman depicts "postmodern society as one dimensional consumer culture" (46). As Blackshaw effectively clarifies in a review of that book, Bauman's argument is that "it is not our love of shopping that's really the crux of the problem, so much that we mistake the endless cycle of buy-use-throwaway as freedom" (127). This use-and-throw-away or replace-with-new consumerist sense of freedom is importantly reflected in ideas of home: if mobility and consumer choices suggest freedom, then attachments to places and any preservation of home limit such freedom. The film and novel I treat here engage 
with this very idea from opposing ends of the spectrum - a disregard for freedom in favour of a stable home in The Village, and an exploration of freedom that actually leads to fruitful construction of home in Nikolski. Another way in which Bauman problematizes the liquid modern association of freedom with consumption is through the question of responsibility. In Globalization, he suggests that the freedom to leave is also a freedom to evade consequences. This waning responsibility particularly applies to those who "move in" only to leave a ravaged landscape when benefits or profits have been maximized from a place that signifies home to other people. He claims that "[m]obility climbs to the rank of the uppermost among the coveted values - and the freedom to move, perpetually a scarce and unequally distributed commodity, fast becomes the main stratifying factor" (2). For Bauman, our growing desire for mobility now suggests that there is "[n]o need to engage if avoidance will do" (11), and I will turn to the forms as well as results of such commitment avoidance in the following sections.

The relation of the liquidity metaphor to capital is particularly important because it elucidates the way in which tangible assets, like houses or other living spaces, are increasingly valued for their financial value and convenience. An incentive to physically leave homes behind increases along with, even more importantly, the incentive to not emotionally invest in them since they are likely to be replaced. Fredric Jameson relates consumerism to identity, describing a "hyperindividuality that effectively decenters the old individual subject by way of individual hyperconsumption" (Seeds of Time 31). I suggest that this process of decentering also occurs at the level of home. This is not to say that home has a singular or static center but that its conceptual layers can integrate various times and spaces into a coherent narrative that speaks to what Heidegger describes as dwelling, or what I understand as a personal but also relational notion of home. Bauman alludes to the emergence of this kind of hyperconsumption when, in dialogue with 
Riccardo Mazzeo, he claims that: "Fullness of consumer enjoyment means fullness of life. I shop, therefore I am. To shop or not to shop, this is the question" (On Education 89). The emphasis on consumption leads Bauman to consider identity as not only an increasingly utilitarian commodity but also essentially unstable, and this, I argue, is another factor of the precarious state of the notion of home. Bauman makes clear that he is looking beyond the cosmopolitan mobility of jet setters and the elite, is aware of the limited choices of many migrants, and even more attuned to those whose political status or national paperwork does not offer mobility or the means through which to "choose" it, and these are all important concerns in terms of how home can be constructed —in fact, these concerns form integral points of tension in The Village and Nikolski.

Building on Bauman's work, I underline the importance of responsibilities based on allegiances and presence, or sustained relations (across distance, even when virtual) which cannot be discarded like used goods. Shyamalan and Dickner illustrate the need for such allegiances - needs so important that in The Village they are fulfilled through deception and in Nikolski they are interconnected through a complex map that inscribes the allegiances that make up Dickner's characters' conceptual homes. But before turning to my analysis of these two works, I want to examine the role of strangers in liquid modernity and the influx of people not only crossing borders but also city limits and streets that lead into welcoming or unwelcoming territories. In addition to its commodification, the second critical issue that Bauman's notion of liquid modernity crystallizes in relation to conceptions of home is the problematic figure of the stranger who moves but is unknown, potentially unwanted, and often feared in a cultural climate that already consists of so many unknowns and fluctuations. Through the many forms of mobility it fosters, Bauman argues that liquid modernity produces two kinds of strangers-tourists, who may easily traverse a void of connections to place, and vagabonds, who may only seek mobility 
because they are tethered to specific place(s) by economic and political circumstances—and it is to the tourist's and vagabond's difficulties in constructing home that I turn to next.

\section{Critical issue 2: the modus vivendi of a stranger}

Mobility is vital to ideas of home, most directly through the social categories of "settled" natives or locals and "unsettled" nomads or strangers. ${ }^{29}$ This seemingly old-fashioned binary remains relevant through the assumptions regarding rights and privileges that it implies—natives and nomads are not only still used as categories within communities and states but are each expected to play by different rules (something Part III's discussion of home and hospitality treats). Bauman points out that the native/nomad question can be presumed irrelevant only by tourists, those privileged enough to move freely, consume at will, and potentially become "locals" where they choose through economic means. To illustrate this important dichotomy, he outlines the tourist and vagabond "life strategies," and through them highlights what I see as a kind of mobility divide in regards to home: some people are able to move freely calling "home" wherever they can afford, while others are limited to specific locations by the socio-political realities of their place of residence or employment. The nuances of Bauman's metaphors infuse the native/nomad binary with an economic layer that complicates origins and legacies in late capitalism since both figures show how old markers of home can now be monetized, owned, and consumed. Furthermore, as he explains in Does Ethics Have a Chance in a World of Consumers?, liquid modern strangers are

29 Stephen Muecke offers an incisive example of the problems and incongruous understandings of these categories when he points out "that a migrating class of European people came a vast distance, completely unsettling themselves, to arrive in Australia and call the locals "nomads"' (Benterrak et al. 20). More broadly, Frantz Fanon similarly problematizes the notion of the native by explaining that "it is the settler who has brought the native into existence and who perpetuates his existence" (36). 
"people who, precisely because they are unfamiliar and thus unpredictable and suspect, are vivid and tangible embodiments of the resented and feared fluidity of the world" (38).

The tourist and vagabond figures operate in ways that showcase concrete shifts in modes of living in liquid modernity, specifically through the mutually reinforcing possibilities of increased mobility and the economic impetus to consume not only goods but places. Mobility—and the strangers it "produces" when former locals arrive at new destinations - is not a liquid modern force since solid modernity also included everyday mobility, regional trade, and globe-spanning migrations. Bauman explains the elusive reason for the liquid modern value of mobility: "being on the move - searching, looking for, not-finding-it or more exactly not-finding-it-yet is not a malaise, but the promise of bliss; perhaps it is bliss itself" (Globalization 83). Yet, even as he describes this endless search, which suggests a kind of nomadism, Bauman takes issue with the term nomad being applied indiscriminately. Instead, he proposes a distinction between two variations of nomads: the tourist, who is out to gather (or consume) sensation, and the vagabond, who would be a tourist but is denied the tourist's privilege and choices. Because there are more and less privileged tourists and vagabonds, I understand Bauman's metaphors as populating a spectrum rather than firm distinctions of desired or denied itinerancy.

Bauman's binary is particularly useful for unpacking the ways in which the economics of mobility result in a provisional rather than ongoing and engaged sense of home. In "From Pilgrim to Tourist—or a Short History of Identity," Bauman begins to chart the effects of an economically-derived shift from former values of stability and durability to patterns of commitment avoidance, which points to a commodification of home through a shift from dwelling in to consuming places. Within the scope of my project, this change represents a vital impediment to constructing home in ways that respond to liquid modern values by being dynamic and evolving 
yet must also in some measure reflect the "solid" values of stability and durability in order to maintain meaningful connections for the home-maker. Bauman's outmoded "life strategy" from solid modernity, the pilgrim, helps to demonstrate the shifts in thinking about and "investing" in ideas of home from this solid modern strategy to the liquid modern strategies of the tourist/vagabond. The pilgrim life strategy is untenable amidst the under-determination or free-floatingness of liquidity and a global economy that keeps people as well as objects in flux. Consequently, Bauman explains that while it made sense in solid modernity for the pilgrim to wait, internally seek, save for the future-and, I suggest, to engage with home-making to a greater extent but also while conceptualizing the roles and norms of the idea more rigidly—in a liquid modern world savings are uncertain and so the pilgrim's accumulation, connections, and concern with the big picture seem fleeting, easily devalued, and less meaningful. For Bauman, the pilgrim of solid modernity has transformed into the tourist in an era increasingly defined by ambivalence and forms of social engagement that are ultimately linked to consumption. If the pilgrim-vagabond binary for solid modernity rested on having a destination or not, the liquid modern tourist-vagabond distinction makes choice the thing worth "having."

The tourist has the explicit choice of various potential homes along with a perennial option of a return and this overabundance undermines the conceptual work of home through what I see as a constant trial-period type of dwelling. Bauman describes the tourist as a "conscious and systematic seeker of experience," more particularly "the experience of difference and novelty" (29). His search, I argue, unlike that of the pilgrim, fosters a detachment to home that can be extensive when "consuming" places or the qualities of home (including comfort, privacy, or welcome) supersedes more engaged knowledge of and connections with home. A marked feature of the tourist life strategy that Bauman also mentions is the dual pull of homesickness but also 
"home-boundedness" (31), conflicting afflictions that pit an attraction to home and "a dream of belonging" (30) against a repellence to home through the fear "of being tied to a place and barred from exit" (31). In the uncertainty of liquid modernity, homesickness and home-boundedness both generate anxiety about not finding home again or being trapped by it, but mobility can defer dealing with either issue by offering the tourist distraction. Furthermore, the tourist always has an exit strategy or "well marked escape routes" (29). Tourists have the financial and political means to extricate themselves from undesirable locations but their focus on the freedoms of mobility diminishes the relevance of these important routes-which can actually shape conceptions of home as a kind of central node-into single use "escape routes."

The vagabond figure is equally essential in understanding the forms of conceptual homelessness that are becoming emblematic of liquid modernity. Vagabonds do not have the privilege of choosing a "destination" home and are either literally homeless or tethered to a home that they have little or no control over. In "From Pilgrim to Tourist—or a Short History of Identity," Bauman explains that the vagabond was also a problem of solid modernity because unlike the pilgrim, who was "predictable" with a set destination, the vagabond's movement was "erratic" and open to change when "other places beckon" (28). Although "beckoning" romanticizes vagabond mobility, Bauman also points to the darker side of the potential lure of new places: vagabonds can "wake up to find the places (places in the land, places in society, and places in life), to which they 'belong,' no longer existing or no longer accommodating" as "neat streets turn mean, factories vanish together with jobs, skills no longer find buyers, knowledge turns into ignorance, professional experience becomes liability, secure networks of relations fall apart and foul the place with putrid waste" (29). These are the kinds of changes that tourists fear as well and, consequently, distance themselves from committing to places as homes in order to avoid the risks 
of such events and the chance of also becoming a "flawed" consumer of mobility.

Bauman's insistence on the possibilities of the tourist becoming a vagabond (and the implicit, if rarer, possibilities of the vagabond becoming a tourist) suggest a dynamic relation between the poles. The commitment avoidance is clear at the ends of the continuum that Bauman sets up: the tourist chooses not to commit and the vagabond is never given a choice but rather is forced to make do with immobility or conspicuously limited economic mobility. Vagabonds enjoy the choice of mobility when this is profitable for tourists, often when manual labour or childcare is "outsourced" (this would include Mexican field workers or Filipino nannies in North America, or their Eastern European counterparts in Western Europe). In Globalization, Bauman indicates that tourists "put the bitter-sweet dreams of homesickness above the comforts of home" (92) while vagabonds are tied to "the waste of the world which has dedicated itself to tourist services" (92), yet there is overlap between the categories. In "Tourists and vagabonds," Bauman explicitly points to the shifting and intertwined nature of the types that he is observing. He concludes that essay by suggesting that "we go on moving, the tourists and the vagabonds, the half-tourists and the half-vagabonds that we have become in the postmodern society of relentless consumption" (26). The "half" categories offer a range of more and less privilege, "a continuum from tourists to vagabonds" (Best 318). How this continuum can shed light the idea of home and new home-making practices on the scale of interpersonal relations and community building is my focus in the following section.

\section{Conclusion: a modus co-vivendi despite liquidity}

In the social context of liquid modernity, home primarily exists as an "exit strategy" for those privileged enough to be tourists or an ephemeral dream for vagabonds who are forced or 
unable to move. Through this exit strategy or potential dream, both figures seek to mitigate risks of loss and dissatisfaction with home by not committing to "building" the idea but wishing to find and "buy in" elsewhere. Bauman's examination of interpersonal relations and commitment avoidance in this era highlights our growing fixation with managing uncertainty and risk - the risk of losing jobs, partners, friends, status, or a home, community, and sense of belonging. Akin to the diversification of an investment portfolio, scattered or replaceable homes with backups or exit strategies incur smaller risk. Moreover, an emergent culture of leaving mitigates such risks of loss but also facilitates increasingly transitory, hotel-like homes. Yet, as I argue and show through examples in my primary texts, home still contains the potential to connote more and connect home-makers on individual, relational, and social scales. Shyamalan's film shows the limitations of the tourist and vagabond strategies and echoes Bauman's critiques, while Dickner's novel goes a step further by demonstrating that the two types which Bauman has usefully generalized can be adapted to a modus co-vivendi that includes more "solid" but still "liquid" relations and is thereby more stable but also flexible.

I will build on Bauman's insights on liquid modernity's increasingly mobile interpersonal, spatial, and material relations by exploring home-making and homelessness in the following chapters in texts which examine the challenges of being at home while continually adapting to change and fast-paced flows. For Bauman, a defining mantra of the liquid era for both the tourist and vagabond is "do not commit yourself too strongly to people, places, causes-you cannot know how long they will last or how long you will count them worthy of your commitment" ("Pilgrim" 25), and both The Village and Nikolski contend with this notion in disparate ways by forcefully rejecting or testing the new possibilities and losses that mobility involves. These works reveal some of the ways in which commitment avoidance increasingly undermines the benefits of 
thinking about and investing (time and effort, not simply money) in home even though the social impetus of what I have referred to as the economics of mobility supports a perception that "savings lose value fast, and the once-vaunted 'cultural capital' tends to turn in no time into cultural liability" ("Pilgrim" 25). Shyamalan and Dickner explore a notion that home is similarly a liability or an unprofitable kind of investment, but rather than a reason for discarding the idea, this troubling sense of home is what spurs characters in The Village and Nikolski into a search for new spaces and modes that spur or nurture home-making.

Finding one's place in the world and "localizing" oneself predominantly through consumption undermines a sense of home as a meaningful locus which nurtures ethical imperatives and forms of support as well as responsibility because consumption quantifies home, transforming it into a basket of goods or properties that are defined by their market value. In the next two chapters, I examine this pattern within the scope of liquid modernity and the economics of mobility in my primary texts. My aim is to reveal the non-traditional stabilities that Bauman's dialectic of solid and liquid modernity allows but on which he does not focus in his critique of relations in liquid modernity's changing material realities, new technological mediations, and other flows or mobilities. I will analyze depictions of collective life, mobility, consumerism, and their connections to home-making, alongside the notion of figurative homelessness in a highly mobile era of flows and virtual interconnectivity. Bauman maintains that "mobility means the ability to escape and evade" (Globalization 125), and such escapism and evasion is illustrated in the context of tourists and vagabonds as more and less privileged consumers of goods and mobilities in both The Village, with its estate funding and general escapism, as well as Nikolski, through the intense mobility that transforms the novel's protagonists' lives.

I chose these texts for their opposing depictions of the "quest for solidity" (Bauman qtd in 
Dawes 132), which remains the core of Bauman's solid-liquid dialectic. The Village contends with liquid modernity through isolation and an imitation of the "inner" mobility of the truth-seeking pilgrim, while Nikolski depicts exploration and outward movement. In spite of this major difference, both texts offer contemporary examples of different kinds of tourists and vagabonds in less extreme terms than the global elite, on one hand, and refugees, on the other. Consumerist clutter and waste become the texts' secondary or background themes as the community in The Village and the half-siblings and cousin in Nikolski explore old and new homes without the goals of amassing material wealth. Through the opposing themes of isolation and exploration in the context of consumer society, these works shed light on the immediacy of Bauman's observations regarding interpersonal relations in liquid modernity and pose new questions about the possibilities of home-making and community amidst "liquidity." These texts neither valorize nor disparage the strategies that Bauman theorizes through the tourist and vagabond. Instead, they show some of the important ways in which Bauman's strategies highlight the ubiquity of mobility in modern life (whether welcome or not) but also the inability of that mobility to supplant the need for the idea of home.

My main question is what kind of home tourists and vagabonds can "build," as "buying" increasingly describes the liquid modern means of dwelling. Bauman's writing suggests that this is a spectral home of marketing dreams but no salient realities, and such a home is, in fact, cleverly illustrated in The Village through the community's extreme response to and attempted denial of mobility—even the smaller levels of mobility, like regional trade, which were vital even during solid modernity. This ghost of a home that is emblematic of solid modernity is not the only possibility of dealing with liquid modern fluidity, however, and Nikolski offers examples of the kinds of homes that tourist and vagabond-like individuals can build by still forming relations to 
places and communities. In its overlapping narratives, the novel maps conceptual homes that are, in fact, built despite frequent personal mobility and the increased mobility of others. The protagonists are largely successful in mapping their conceptual home because, even as nomadic locals, they adopt the self-reflection that Heidegger's sense of dwelling requires and an engagement with place which allows for preservation as well as the integration of new and old experiences of home - rather than the purchase of a ready-to-use(-and-replace) commodity home. Dickner charts how his characters remain the creators and cartographers of their conceptual homes and not merely consumers. In doing so, he suggests emergent modes of meaningful home-making and commitment in spite of the economics of mobility. To account for this emphasis on agency and engagement, I ultimately expand Bauman's life strategies in order to reveal the significance of the middle space between the tourist and vagabond, strategies that Dicker depicts through protagonists whom I characterize as "passersby" and "pirates." Faster communication, transportation, and the ability to sometimes not merely transport but translate a sense of home the world over, I argue, allows these half-types to more fruitfully integrate home into a kind of “complex map." 


\section{Chapter 5: "Roots" and stability in M. Night Shyamalan's The}

\section{Village}

The Village, written and directed by M. Night Shyamalan and released in 2004, investigates our nostalgic penchant for idealizing the past and previous ways of life. I explore this work as a counter-narrative of mobility in relation to Mark Z. Danielewski's House of Leaves and Neil Gaiman's Neverwhere with their emphasis on understanding home as movement through labyrinthine spatial and conceptual constructs as well as an existential search for homecoming. The Village depicts the extremely limited mobility of a secluded (or trapped) community created for the very purpose of escaping the flows of an increasingly liquid modern mode of life. While the film shows a radical reaction to the emphasis on change and flows that define liquid modernity, this community symbolizes an escape, a fiction that cannot be made "solid." Shyamalan depicts a curiously commodified home through this made-to-order village and how the elders' fears of the instability and uncertainty of mobility — embodied in the vilified figure of the stranger - undermine the ideals of the community in irreparable ways. The Covington Woods village is actually a gated community, a kind of home that cannot accommodate multiple geographic and cultural scales and is neither porous nor dynamic. Not only is the community's unity really a meticulously controlled uniformity, but the elders' emphasis on one bounded location, one ideology, and one kind of home-making (the kind that is constantly modeled by them publicly) sets up this expensive experiment for failure since the sense of home that grows from such singularity breeds conformity, a quantifiable and utilitarian mentality that Heidegger describes as calculative thinking, and more of a commodified ready-made-product than a 
meaningful idea. By undermining the agency of the home-maker, the kind of homogeneous and inflexible home forced into life in the Covington Woods community cannot be expected to last even if the elders keep fabricating events and history in order to sustain its artifice.

The film opens with a shot of the backs of several heads covered in plain hats, an angle that positions the viewer as a member of this crowd, looking on and presumably sharing the grief of the man shown kneeling by a small coffin. The gathering turns out to be the funeral of a child, Daniel Nicholson, whose tombstone bears the date 1897. The funeral—a formalized ritual of familial and communal interpersonal relations — continues with an outdoor meal during which the leader of the community, Edward Walker, makes a brief, somber speech and asks, "Did we make the right decision to settle here?" Although the bereaved father squeezes Edward's hand to answer in the affirmative, this initially rhetorical question remains vital throughout the film as various characters wrestle with their village's limited location and rigorous isolation. Not long after Edward's speech, howls resonate across the fields in a reminder of the danger that looms beyond the village. The grand revelation of the film is not that the howling creatures in the nearby woods are a farce invented by the village elders to keep everyone else inside but that on the outside, beyond the forest and a large perimeter wall, it is more than a century later. The Covington Woods community is actually situated in the Walker Wildlife Preserve, a sprawling property "protected" from the twenty-first century and financed by the Walker estate.

For Bauman the concept of liquid modernity describes the contemporary socio-economic condition, one that is marked by increased insecurity and uncertainty through more frequent social and financial flows. The fluidity of interpersonal relations, social conventions, political and geographical allegiances, and increasingly mobile as well as anonymous lifestyles of urbanized and technologically mediated life can improve quality of life but this liquidity, Bauman contends, 
also makes everyday concerns such as community building, economic stability, and questions of physical safety problematic. The solution to-or, more precisely, escape from - the problems of liquid modernity that the community in The Village embraces takes the form of lifestyles which imitate the historical trappings of solid modernity. The film's mise en scène suggests the life of early American settlers, and the placid landscape as well as tightly-knit community that are depicted imply that the "solid" connections of a previously more sedentary life somehow harbour a cure for the growing insecurities and uncertainties of the late twentieth and twenty-first centuries. The issues that I focus on in my analysis of the film are mobility and interpersonal relations, or more specifically questions regarding the control of mobility and the related concern that more flexible relations are inevitably more tenuous. Both issues have broad ethical implications which Shyamalan investigates through the competing moral agendas of the elders and the remaining community members, particularly a younger generation of children who have no knowledge about the actual outside world. Even though the elders' communal vision engenders relations that appear to be stable and inflexible, these relations are quite tenuous since they require constant control and misinformation as the elders need to reinforce a kind of "re-solidifying."

Shyamalan's The Sixth Sense (1999) was a film that gained the director the most critical acclaim and financial success but many of his later films, including Unbreakable (2000), Signs (2002), and The Village (2004) were expected to offer a similarly shocking conclusion and never quite lived up to those expectations, potentially because the "twist" became an expectation. The Village has received some scholarly attention. Chapters from Critical Approaches to the Films of M. Night Shyamalan, in additional to a number of articles on The Village, treat the topics of communal deception (Fowkes, Weinstock) as well as political control through narrative (Collier, Jordan and Haladyn). Coates et al. focus more particularly on a reading of the creatures in the 
woods as Native Americans - they point to parallels with early American descriptions of "howling wilderness; inarticulate, violent dwellers in the forest" (358) — but also suggest that the film offers a much broader historical commentary on American myths of community over time. Additionally, Slavoj Žižek offers some incisive remarks about the myths of family, community, and capitalism in The Village. Somewhat surprisingly, that scholarship rarely mentions home or the kind of home that the Covington Woods community attempts to establish since the question of settlement from Edward's opening speech is the basis for the film and since home, particularly on the interpersonal scale, is implicitly related to the communal dynamics and power hierarchies depicted in the film. Miriam Jordan and Julian Jason Haladyn explain that "[t]he elders construct a fictional existence of innocence within a romanticized simulation of the past to escape the predations of the contemporary world" (175). In contrast, I suggest that the predations that are being escaped are not simply the violence that alters each elder's life prior to the founding of the community but a more abstract sense of the malicious nature of liquid modernity as the cause of uncertainty and insecurity in their lives and notions of home.

The elders' choice of settling in a space unmarked by the technology and ecological waste of liquid modernity represents a reaction to the various forms of insecurity that Bauman describes, along with a romanticized reinvention of solid modernity. Shyamalan highlights timely parallels by suggesting that the elders' initial resettlement coincides with the era of the Vietnam War, while their contemporaneous "outside" world is marked by the threat of twenty-first century terrorism. However, the film's scope in this regard is not limited to a literal physical insecurity or global violence. Instead, this community represents a vehement reaction to the modern insecurity of committing to people, places, practices, or ideas — a reaction compounded by a liquid modern sense of depreciation and devaluation that Bauman describes as having overtaken a previous 
cultural emphasis on saving and stability, but the elders seek to recreate this latter world of stability without considering the inequalities and problems of solid modernity. Although Bauman's project suggests stepping away from consumerism, which invokes solid modernity since the economic conditions for consumerism did not exist to impact people broadly, such a step back does not require nostalgically regressing, and this idea is implicit in Bauman's understanding of a solid and liquid dialectic. The film's ambiguous conclusion, through the sheer impossibly of sustaining the fiction that the elders must work increasingly diligently to uphold, demonstrates that liquid modern problems cannot be solved with the perceived solutions of solid modernity.

\section{The Covington Woods settlement as an escape}

The Village demonstrates many of the issues that Bauman outlines in his discussion of community — both the ideal that the elders seek to emanate and the problems that they wish to escape from by constructing their outlier of solid modernity. In Liquid Modernity Bauman describes a shift in how we understand belonging and communal identity in liquid modern times: "The community of the communitarian gospel is a home writ large (the family home, not a found home or a made home, but a home into which one is born, so that one could not trace one's origin, one's 'reason to exist,' in any other place): and a kind of home, to be sure, which for most people these days is more a beautiful fairy-tale than a matter of personal experience" (171). This "fairy-tale" is what the elders seek to enact since theirs is a strange life of pretend and "playing house" with no concern for the rest of the world or the consequences of the community's complex agoraphobic ideology. In this film, Shyamalan illustrates Bauman's ideas about an “ideal community" as "a compleat mappa mundi: a total world, supplying everything one may need to lead a meaningful and rewarding life" (172). It is a vision of community as "an island of homely 
and cosy tranquility in a sea of turbulence and inhospitality" (182) that becomes the root of the problems in Covington Woods because in order to seek tranquility the elders attempt to ignore what they see as the causes of violence: greed and the enmity of strangers. To this end they reiterate that money has no place within the village — even though it funds its very existence — and suggest that only strangers bear ill will — even though so much of crime is perpetrated by people who know their victims, which is also the case with the stabbing that occurs in the film.

Violence changed the elders' lives and initially brought them together at a group session for grief counselling, after suffering a loss that made each adult question who they might trust on various geographic scales of home: inside their home (Edward's father was shot in his sleep by a business partner who then hung himself), on their street (another elder's sister was raped, killed, and left in a dumpster three blocks away from her home), and their hometown or city (Alice Hunt's husband was mugged and his body was found in the river). Although the crimes that touch their lives are not limited to particular centuries or urban spaces, the elders feel that they can isolate themselves from senseless violence by limiting and monitoring the people they live amongst — people they can trust because no one is a stranger. The liquid modern world, as Bauman describes it, includes contact with more and more strangers through urbanization, mobility, and technology. To symbolize the dangers of strangers and temptation of greed, the elders invent mysterious creatures in the woods who must be appeased, and they hope that what they see as benign fear can ensure that real malice will be kept at bay.

Shyamalan undermines the binary of solid and liquid modernity that the elders construct by inverting and overlapping the associations of the two through double metaphors and expedient juxtaposition. For instance, Edward tells Ivy, his blind daughter, that he intended to save her "from the darkness" of the rest of the world when modern medicine might have actually saved her sight. 
The dual significance of darkness subverts the elders' claims that good things and light belong to solid modernity while bad things and darkness are somehow tied to liquid modernity. A more general example of the film's dualities is the innocence and safety sought through manipulation and a denial of insecurity and crime inside the village. When a man disrupts the elders' meeting to announce that Lucius Hunt is hurt, he says, "There's been an accident," as though multiple stab wounds are likely to be accidental. However, the tranquility of the town and the antiquated, blunt way of speaking that the villagers have embraced, also manage to suggest an innocence, even to the extent that such a brutal, underhanded crime would actually be unthinkable and so understood as an accident. Even the somber opening funeral scene is immediately balanced with a pastoral collage of sheep placidly herded, communal work efficiently underway in a greenhouse, and two young women congenially sweeping a porch. At the end of this collection of scenes, full of colour and soft light, the girls spin in circles with their brooms, mock dancing as they work, but before the rustic whimsy becomes truly excessive one of the girls stops abruptly and the mood shifts back again. A bright red flower growing off the deck frightens the girl in a moment that mirrors the startling howling during the funeral dinner. The offending flower is quickly ripped out by the roots and buried before the young women return to their menial task, and it is soon revealed that for the community in Covington Woods everything unsavoury or dangerous is easily identifiable through the colour red because it attracts the creatures, while yellow is the safe colour that explicitly marks the village border. The elders vilify strangers and the materialistic outside world, which is only referred to as "The Towns," but cannot expunge crime and conflict from their distinctly marked boundaries: Noah Percy stabs Lucius Hunt because he is jealous that the other man will marry Ivy Walker, and so a kind of greed manifests without the presence of symbolic money or visible material wealth. 
For the villagers, Covington Woods is a haven that represents a direct contrast to the anonymous and barbaric urban spaces of "The Towns." Viewers only glimpse the world outside the community through the Walker Wildlife Preserve ranger station which Ivy visits in an effort to get medicine for Lucius' infected wounds. She convinces her father to break the rules (more precisely, to find a convenient loophole since only the elders took an oath never to leave the village) and after a tense journey through the woods Ivy, who has been told that the creatures are not real but not that her home's temporal setting is similarly a fiction, encounters a soft spoken ranger and convinces him to get the supplies on her list - telling him that her name is Ivy Elizabeth Walker seems to help convince the startled man. That this stranger is willing to help Ivy and risk his job to do so undermines the stories that Ivy has heard all her life about the people and kinds of life beyond the village but she seems too overjoyed with his response to consider the implications. Conversely, the scene at the station illustrates the commitment avoidance and utility of liquid modern relations when the ranger's colleague (played by Shyamalan) says, "Can I give you some advice? Don't get into conversations." The sentiment of avoiding relations is precisely what the village elders seek to counter and a mark of liquid modernity that Bauman summarizes through his comments on the need to move on efficiently without engaging because engagement risks further encumbrance or delay. This short scene conveys the problems of fluid social bonds and the ambivalence that increasingly defines relations in liquid modernity, but, importantly, it does so through only one of the rangers, while the other man is partially responsible for saving Lucius' life.

The elders wish for the residents of Covington Woods to embrace the mythic sense of community that Bauman describes in Community as a place where "we are safe, there are no dangers looming in dark corners" (2). For the elders, whether this ideal was ever possible is made secondary to the fact that liquid modernity offers a "community-hostile reality" (3), which makes 
the supposed safety of an idealized community even more appealing. However, as Bauman argues, the "price" for community "is paid in the currency of freedom" (4), and this is explicitly depicted in The Village as group safety trumps individual autonomy should anyone, as Lucius does, wish to venture past the boldly demarcated border. Bauman's observations that the more safe the inside appears, the more wild the outside will seem (117) is shown through Edward and his fellow elders' stories of the towns which they - the sole source of information about the outside and the past — choose to tell in decidedly negative terms. The sacrifice of individual freedoms and control of information in The Village serves to draw attention to what Bauman calls the "existential insecurity" and "ontological uncertainty" (146) of liquid modernity that is usually overshadowed by more immediate worries regarding "the threats to the safety of streets, homes and bodies" (146). The elders focus on the latter through the myths and rituals that they establish, such as the symbolic boxes that remind them of their loved ones' brutal deaths and the sacrifices of food that

they throw to the creatures in order to supposedly mollify them. Yet, throughout his film Shyamalan is also deftly showcasing these existential and ontological concerns by depicting a desperate reaction to liquid modernity's mobile dangers and fluid unknowns.

\section{The issue of commodification: buying stability in a liquid modern world}

I now turn the ways that The Village illuminates the critical issues that Bauman's work raises about home in liquid modernity: first, the ways that late capitalism commodifies home and, then, the ways in which mobility produces strangers. Although the culture of the Covington Woods community appears to accurately simulate life in a rural place and removed time, I argue that it has been bought in order to offer a particular kind of tourist destination-a literal home away from (the liquid modern) home. Frederic Jameson's description of the postmodern era as 
marked by diminished historicity as well as growing economic dimensions helps me to show that The Village illustrates the collusion of the economic and cultural, even as its central characters attempt to hide the economic dimensions of their community behind a utopian hotchpotch of stereotypical small town, settler culture. In "Notes on Globalization as a Philosophical Issue," Jameson characterizes postmodernity as "[t]he becoming cultural of the economic, and the becoming economic of the cultural" (60), and this duality opens up new avenues of cultural belonging through economic means, while also leading to an economic overhaul in which Jameson suggests the "new electronic trade routes tirelessly plied by commerce and finance alike" (56) overshadow the routes or mobilities that can meaningfully link people to places. Since cultural and economic flows run in and out of each other, this aspect of postmodernity is central to Bauman's concept of liquid modernity. When Jameson asks, "What human relations might be without commodification, what a life world without advertising might look like, what narratives would model the lives of people empty of the foreign bodies of business and profit" (Seeds of Time 74), he is articulating the concerns that Bauman places at the heart of his critique of liquid modernity: a culture of "shopping around." Although The Village explores what it might mean to isolate relations along these lines, it does so with some very crucial fine print since an industrial fortune is needed to attempt this communitarian project of renewed relations and the rejection of money, commodification, and profit.

Money is notably missing inside the Preserve but on the outside it pays rangers, ensures border maintenance, and funds the diversion of planes over the area. Visually, the village looks like a recreated living space from an ethnographic museum or a "pioneer village" somewhere on the east coast, in areas such as Ontario, Massachusetts, Virginia, as well as Pennsylvania, where the film was shot and where, as behind-the-scenes DVD footage shows, cast members learned to 
chop, bake, and "make do" at a local pioneer site. When telling Ivy about her grandfather's murder, Edward explains, "Money can be a wicked thing," and he is insistent on this point, ignoring the fact that money has facilitated the very existence and isolation of this community. So even though he insists, "You do not know of money; it is not part of our life here," money is actually a very significant part of Ivy's life, especially if she is heir apparent to the Walker trust. The lack of money inside the preserve represents another historical incongruence since the older eras and their settler communities that are being replicated belonged to a money economy and functioned through networks of production and trade. It is unlikely that the villagers, as adults, can attain the level of craftsmanship of woodwork, metallurgy, masonry, and so on of artisans who previously apprenticed for a significant portion of their lives or required more complex tools and natural resources than those which appear to be available in the village. For instance, even though there is abundant wood and wool in Covington Woods, it is unclear where replacement glass for windows or the dyed cloth for the women's voluminous dresses come from. So while the self-generated communal entity is presented as an organic social collective, it is actually a complex construct that is deeply marked by the economics of mobility in that only those privileged with access to economic means can attempt to reject the mobility of liquid modernity.

The community is essentially an example of a gated community through the controlled mobility coming in and out as well as the high level of consumerism or financial investment needed to create and maintain the space. This particular community is being paid for by the Walker estate and made according to imagined historical specifications which blur eras as well as the mythology of American settlers over a long history of migration. The material reality of this village suggests an anti-consumerist stance, yet as scholars who are wary of vilifying consumer culture, like Grant McCracken, would argue, a penchant for Birkenstocks by the environmentally 
conscious is still a consumerist penchant (5). Ultimately, the furnishings and objects in the village are either expensive antiques or costly imitations. The elders' preference can be explained by Janelle L. Wilson's research on nostalgia and material objects. Wilson explains that "[s]ome collectors associate antiques with a period of time that is somehow 'better' than the present” (114), often calling a time they have no firsthand knowledge of as "more simple, more safe" (115). This is precisely the association that the elders invoke as the community's limited material wealth—and lack of shops or sites of production - is used to suggest the benefits of "more simple, more safe" and materially uncluttered living.

The community's isolation is, in effect, not a freedom but a controlled dominance and the elders' rhetoric of freedom — supposedly a freedom from violence and the fear of violence — veils a purchased escapism. I will further explore the nuances of this escapism in relation to Bauman's tourist type in the following section but want to conclude my analysis of the modes of commodifying home that are at play in the film by addressing the response to the economics of mobility which is being depicted: essentially, the elders pay to avoid the flux associated with mobility while on a kind of extended vacation. The home that the elders create remains a mirror of Edward's plan, even when he chooses to amend it — a pattern which makes it that much less likely that the community could continue without him. Collier goes so far as to claim that the elders are guests on the Walker property (286), and Edward's savvy in persuading everyone to his views is even evident in the final scenes of the film when the elders are told that Ivy has returned after killing one of the creatures. The other elders know that this was really Noah because both he and a hidden costume are missing, but Edward consoles the grieving parents by assuring them that Noah would receive a proper burial and his death would not be in vain since the other villagers would be told that the creatures actually killed him. In an echo of his initial rhetorical question about 
settlement, Edward explains that Noah has offered the elders a means of continuing the deception, quietly adding, "If that is something we still wish for." The use of "we" is again generous but the elders slowly rise in order to show Edward their humble and customarily silent support. His rule "appears to be something resembling a benign dictatorship" (Collier 286) but perhaps the title of CEO is better fitting for the founder and main investor of "The Walker Wildlife Preserve" and the extremely exclusive resort in the middle of that property.

The elders intend to instantly "return" to a time when communities were formed with stronger links but they do not consider that the communities being imitated also included rigid social norms and hierarchies, which end up replicated with Edward at the helm. While the former group therapy members' wishes to speak more plainly and live more simply may be admirable, their blind rejection of liquid modernity only leads them to recreate a problematic social experiment which assumes that people are fully controllable "variables.” Along these lines, Žižek asks:

is the point of The Village not precisely to demonstrate that, today, a return to an authentic community in which speech still directly expresses true emotions, etc. - the village of the socialist utopia — is a fake which can only be staged as a spectacle for the very rich? The exemplary figure[s] of Evil are today not ordinary consumers who pollute [the] environment and live in a violent world of disintegrating social links, but those (top managers, etc.) who, while fully engaged in creating conditions for such universal devastation and pollution, exempt themselves from the results of their own activity, living in gated communities, eating organic food and taking holidays in wildlife preserves. (46)

Such privilege is illustrated after Edward inquires about Lucius's health and is told that there is only a little hope for the younger man's survival because infection has set in. Edward's follow-up question is, "If there were no limitations, what could be done?" This offhand inquiry is shocking to the other elders because the village has been constructed through self-imposed limitations. Normally such a question would suggest financial limitations, but this is not the case for the 
wealthy benefactor. His ideal community is gated and includes the internal stratification of privileged tourists and a younger generation of vagabonds. Moreover, the community's denial of mobility and commodification veil the mobility-obsessed and materialistic nature of the project.

\section{The issue of strangers: "those we [actually] don't speak of"}

In this section, I turn to a related deception by examining the ways in which these tourists' and vagabonds' fears of strangers nurture a superficial semblance of bygone "country values" in order to cover up the communal agoraphobia and "mixophobia" on which their escapist community is based. The elders' commitment to safety through isolation appears to be a symptom of what Bauman calls "mixophobia." In Collateral Damage, he describes "mixophobia" as something that "manifests itself in a drive towards islands of similarity and sameness amidst the sea of variety and difference" (64), and I want to illustrate the power of this idea to define home by looking at it in the context of Bauman's liquid modern life strategies of the tourist and vagabond, strategies which seem to seek out the mobility that helps to create a "sea of variety and difference." What is most compelling about the ways that the villagers exhibit "mixophobia" in their gated community is that it foregrounds another of the important dualities that Shyamalan fills his film with. The villagers call the creatures in the woods "those we don't speak of" but the creatures themselves not only stand in as manifestations of the physical dangers outside of the community but also represent the ontological dangers of strangers, visitors, and anyone not vetted by the elders or born in the village. This symbol for strangers succeeds in nurturing and naturalizing "mixophobia" in this gated community. According to Bauman, the "lucky few who have bought themselves into a closely guarded 'gated community' pay an arm and a leg for 'security services': that is, for the banishment of all mixing" (65), and this price has been taken care of by Walker 
family money. Bauman further explains that the need to be "secure from danger" is more precisely a need "to be secure from the daunting, harrowing, incapacitating fear of insecurity" (66, original emphasis), a fear which Shyamalan illustrates through the paranoid need of the elders to isolate themselves and their children from the outside world, even as the lies they must tell escalate. Homes created in an atmosphere of "mixophobia" are "piles of compact private cocoons suspended in a social void" (65) because such isolationism cannot foster a composite, multi-scalar sense of home which is open to change and forms of mobility. The social void and the elders' inability to deal with mobility and change over time are reasons why the fate of the community is bound to be a form of self-destruction.

Although the elders situate the notion of "roots" and stability at the centre of their own historically ambiguous narrative, Shyamalan shows that their denial of mobility and "routes" undermines the home that they meticulously construct. Roots, I argue, remain integral to understanding home on an interpersonal scale in liquid modernity and even in the backward-looking, traditionalist endeavour depicted in Covington Woods prove to be intimately linked with "routes" because movement foregrounds the notions of growth and transplantability that are already inherent in the root metaphor-these "settlers" have transplanted themselves. I suggest that the elders represent tourists who are not so much at home in Covington Woods as they have created a "destination" for themselves, a strange kind of resort reminiscent of an extended trip to a pioneer village. During their stay, they pretend to be more than settlers and conceive of themselves as locals, mainly through their commitment to remaining in the space over time as well as keeping other members willingly inside through oaths and the deliberate mis-education of the younger generation. The fact that the elders have what Bauman calls the tourist "exit strategy" back to life in real-time America— which they know about and could function in—cannot be 
discounted through their oath to stay. The privilege of the elders in a global context is quite staggering since their freedom of mobility and financial means are vast, and they could move to the countryside, to another state, or even to another country, but want a home that is safe, placid, and predictable in a very specific, mythic way. The paradox is that they had these three things in Philadelphia as wealthy professionals. The only events that did not fit that paradigm were the violent deaths of their loved ones, tragic occurrences that were not recurrent dangers for this particular group. Yet, rather than addressing their issues at home, they created a more manageable escape — smaller, full of like-minded or mouldable people, and isolated —in order to escape from their pasts, their grief, as well as the uncertainty and "sea of variety" of liquid modernity.

Although Edward knows who killed his grandfather, since the former business partner hanged himself in the same house, other elders do not reveal having learned who attacked and killed their family members. The unknown perpetrators of these crimes serve to legitimize the "stranger danger" and "mixophobia" that the ideology of the community rests on. The social norms of accepting strangers have relaxed in many ways as mobility has increased and yet other locals can be strangers because they are many, mobile, and often unknown. Dennis Smith, in his analysis of Bauman's sociology, suggests that liquid modern strangers "remain at hand like neighbours, while remaining distant and unknown like aliens" (161). The sense of alienation in knowing fellow locals as fellow strangers is a result of increasingly liquid relations and can deeply impact community and notions of belonging. Yet, the elders do not seek to eradicate the idea of strangers and their danger. Instead, they turn to fear mongering and vilify the idea of strangers through the monster image of the shadowed woodland creatures stalking the village, making strangers an imperative concern for each villager. The larger rather than smaller role of the stranger in the community illustrates that even a privileged tourist's escape from liquid modernity 
can never be complete. In fact, through the fear that the elders instill in their children and each other, insecurity and violence not only affect but define life in this supposedly "solid" community.

On the other end of the spectrum, the younger generations in the village are essentially vagabonds, created through what Bauman calls "[e]nforced localization” (Globalization 93) - they have no money, no paperwork, and limited access to knowledge of where they could go. With no means of support or consumption - unless the Walker girls or others have access to the Walker trust - the children exemplify "flawed" consumers of liquid modernity. Even if they knew that they could leave, if they were allowed to choose, there would be a whole new way of life to deal with along with the knowledge that their parents have intentionally misled them. The kids are made helpless by their obsessively protective parents as well as by the extent of the fear that the creatures, drills, and communal scaremongering has fostered. Ultimately, what Shyamalan shows is that the fear of the creatures is a real and looming part of the younger generation's everyday lives in much the same way as the risk and violence of liquid modernity is for their parents. The younger kids look terrified when the nefarious creatures seem to be entering the village, and even the older children are genuinely scared-Finton Coin exudes fear during his shift on the watchtower and the girls who panic at the sight of the red flower also exhibit a visceral reaction to anything related to the creatures. All of the physical and psychological means of keeping the children inside the village in effect make them into liquid modern vagabonds.

Shyamalan's genre film, a more psychological than violent horror, deftly juxtaposes the supposed safety of a space with the idea of not being able to leave it, as the haunted or dangerous house is expanded to accommodate a village and the family at risk becomes a community. According to Bauman, we are "moved by the horror of being bound and fixed" ("Pilgrim" 26), and Shyamalan's subtler themes examine conflicting feelings of being homesick or homebound as his 
tourist figures, the elders, continue to mediate these dueling feelings even as their homesickness for a safe, idealized space turns their seemingly benign gated community into a malignant "mixophobic" regime. Bauman claims that questions about why the tourist persists in a perpetual search for novelty stem from being "[h] aunted by the spectre of exclusion" (Identity 47, original emphasis), and this kind of haunting is also depicted in The Village through the violence that forever altered the elders' lives and left them feeling excluded from a formerly "safe" home space. I argue that the experiences of fear, horror, and haunting in the film suggest a warped ghost of solid modernity. Immersed in their ideal home "destination," the elders are tourists who want to believe that they can keep all unknown and unsavory elements outside their borders, but the fact that ignorance makes victims of the younger generation remains secondary to the elders' obsession with safety and the "stranger danger" that consistently undermines the utopian intentions of the increasing unstable community. Bauman suggests that a "drive towards a homogeneous, territorially isolated environment may be triggered by mixophobia" (64), and the village community is emblematic of this very drive, since the elders are determined to vilify strangers by taking a fear of otherness to its isolationist extreme and demonizing all others as brutal creatures. These strange creatures can be trained or appeased through concessions of space and food, just like the elders have been through the creation of their community. Or, as Fowkes suggests, the monsters that the elders manufacture increasingly become illusions even for the elders as they notice "that the monster is within" (85).

\section{The gated community as an unsustainable "ideal"}

The image of solid modernity that the village projects is structured in a way intended to counter the insecurity and incessant flows of liquid modernity. There is, of course, a middle 
ground of adapting some solid ideas for liquid modern circumstance, but the elders are unwilling to explore such possibilities. For Coates et al. "[v]iewers have, like Ivy, criss-crossed the border separating fantasy from reality only to choose between two versions of blindness: the self-blinding project of exclusionary communalism and the blinding light of self- and communal undoing" (371). The extremes of either living in communal hypocrisy or dissolution are assumed by the elders as the only options because they have vilified not only strangers through the creatures in the woods but mobility itself to a point where it can either be fully embraced (with dire consequences) or completely denied. Bauman's comments in Globalization help to explain the disinclination of engaging with the mobilities and change inherent to ideas of home that the elders take to an extreme: "In the era of time/space compression [...] 'home,' though as always attractive, tends to be enjoyed most in the bitter-sweet emotion of homesickness" (121). It is this homesickness for an ideal which is safe and stable that blinds the elders enough to condone deception in the name of innocence, tether their children to their settlement in the name of community, champion "mixophobia" as an ethical choice, and pretend to eschew material culture in a space that is funded by industrial wealth. To conclude, I want to consider what The Village reveals about liquid modern conceptual homelessness and its uncertainties, and suggest that Shyamalan continually undermines the elders' regressive project in order to demonstrate a need to begin questioning the possibilities for community-making in the twenty-first century rather than re-mythologize the past.

Although the elders set out to ignore the multiple scales through which home is constructed in liquid modern times, Shyamalan reminds us of this multi-scalar and composite nature of the idea of home through the conflation of time periods and historical myths used to manufacture a foundation for this religiously, ethnically, and politically homogeneous settlement. The elders' attempt to pick the "best" of various eras and stories in order to create a seemingly singular 
"authentic" moment attempts to veil the multiple histories and ideas that are being sutured. The attempt at a non-religious, ethnically homogeneous, and supposedly classless American community embraces the country's past extremely selectively—eradicating the influences of religious persecution as well as tolerance; erasing the histories of Native Americans, slaves, indentured servants, and immigrants; and pretending that there is no wealth-based hierarchy which places Edward on top, the other elders in the middle, and remaining community members at the bottom. The film's significant periods include 1897 (the date on the tombstone), the beginning of the Spanish-American War, seventeenth-century Puritanism with pious intent yet no doctrine and an emphasis on simple styles of dress as well as speech, and instead of 1960s American idealism, a 1970s disillusionment with modernity (Coates et al. 363). The film's conflation of historical periods - and the global forces at play in each of them — suggests that the notion of home on the scale of a community is constructed through diverse networks, which include everyday interaction but also shifting allegiances and reconfigured histories. By unraveling the elders' fabrication but also investigating the aspects of community that do seem to flourish, Shyamalan explores ideas of home and reveals a construct that cannot be homogenized or "unmixed" from the influences of various scales, forces, and social restraints such as historicity or inordinate nostalgia.

The reactionary home in Covington Woods is set up to fail because the existence of this community is highly unlikely without continued complicity and even more manipulation. Collier takes issues with the film's outwardly ambiguous conclusion by claiming that it "validates the village's arbitrarily selective rejection of modernity and its unequal power structures" (290), but this is an overly literal reading which assumes that maintaining the status quo is possible and that Edward—both a brilliant dictator and revisionist—will perpetually be able to plan a cover-up. Shyamalan's hints at shifts in thinking of the younger generation also challenge the possibility of 
maintaining the existing conditions, particularly if Ivy and Lucius will lead the community as the elders plan. It is Lucius who initially wants to leave and risk his safety to get medicines, and other villagers might want to leave to see what or who else is out there-particularly after Ivy returns unscathed and successful by not only getting the medicines but defending herself against one of the creatures. Would the elders exile such a person or attempt to force him or her to stay? The film opens with the elders at the funeral of one of their children and closes with the group at another's sickbed but Shyamalan does not suggest a full circle through this, since, unlike Daniel, Lucius will live, and, more importantly, the outside world — like some distant planet-has been revealed as habitable rather than derelict and dangerous. This information thwarts the "mixophobia" that the village is founded on by offering tangible proof of good things existing in the previously only vilified "Towns." Ivy's experience with the young ranger-a sympathetic stranger-only reinforces such a shift in thinking for the heir apparent of the community. ${ }^{30}$

The Village not only shows that a community frozen "as is" is not sustainable and that mobility and flux are inevitable, but that liquid modernity is a "state" of social, political, and economic modalities or priorities, not the cause of hardship and human folly. The film's ending leaves many questions unanswered about the fate of the community as change seems imminent. Will the elders let others potentially die now that an exception has been made? Their isolation requires constant work and while the ending sees both generations temporarily placated — the elders have silently supported Edward and Ivy has returned to her betrothed - the future is uncertain for the Walker Wildlife Preserve tourists and vagabonds. Even though Ivy's final words are "I'm back," it is important that she says this to Lucius rather than the elders because she does

${ }^{30}$ Ivy says to the ranger, "You have kindness in your voice, I did not expect that," and is further surprised when he does not take the gold watch she offers as payment for the medicine. Even though he initially thinks the payment might be a joke, he has no qualms about helping strangers in need. 
not declare her support for their means of community building. Shyamalan also gives no indication that this independent and thoughtful heroine would perpetuate the system that her bereaved father created. The temptation may be there but Ivy, having lived without choice as a vagabond, might not take the opportunity to be the privileged tourist type like her father because she knows that her very idea of home and community is at stake in this move. She expresses this knowledge when she tells her father that she feels sorry for him and the other elders who cannot truly be at home and of a community that they constantly manipulate and seek to control. Even as Shyamalan depicts a reaction to the feeling that liquid modernity fosters a "community-hostile reality" (Community 3), his film suggests that regressing to an old reality is as troubling and he draws attention to the need to find new ways of thinking about the kinds of community that are possible in liquid modernity, ones that can invert roots and perhaps use the networks of "routes" for exploration rather than imposing isolation and "mixophobia."

Shyamalan depicts a bizarre enactment of homesickness for an "antique" ideal in order to raise questions about what it is that we seek in communities and homes in a mobile "glocal" era, and his film proposes that it is not the imagined "traditional" organization of social life that we are homesick for but a sense of belonging and attachment to place(s). In The Need for Roots Simone Weil expresses sentiments that are shared by the elders when she claims that "in our age, money and the State have come to replace all other bonds of attachment" (99), but her solution is not what the elders enforce when they ignore money and buy their way out from state control. Instead, while Weil disparages "this disease of uprootedness" (44), she maintains that "[e]very human being needs to have multiple roots" (43, my emphasis). These multiple roots include place, profession, and so on, which implies a multi-scalar sense of belonging. The elders, however, have limited and homogenized the community members' roots in order to create a singular construct that binds 
everyone tightly but cannot do so permanently. Despite the attempt to create more meaningful connections and re-establish more traditional roots in Covington Woods, the final product eerily manifests the problems of liquidity through similar fears regarding insecurity and uncertainty, and rather than nurturing equality, the community recreates the same two social groups of liquid modernity—privileged tourists and trapped vagabonds.

The Village undermines regressive nostalgia by depicting a meticulously manufactured home as an isolationist reaction to flux and mobility, and the text to which I turn in the next chapter, Nicolas Dickner's Nikolski, goes further in that it illustrates some of the new possibilities of home-making on a communal and relational scale. The three protagonists each undertake a broader exploration of how our "routes" impact "roots," and in doing so engage with the solid and liquid dialectic rather than falling into either extreme. In Nikolski, I will argue, Dickner illuminates the potential of commitment and home-making in liquid modernity by showing that mapping the trajectories as well as scales of home can offer a fuller understanding of not only the "where's" but the "ways" through which experiences of mobility change how we dwell because we are, as Heidegger suggests, dwellers above all else, even in liquid mobility. 


\section{Chapter 6: "Routes" and mobility in Nicolas Dickner's Nikolski}

Nicolas Dickner's Nikolski is essentially a novel about the process of continually rethinking, seeking, leaving, and making home through time and in new spaces. One of the protagonists, Noah, has academic interests that are described as "issues of relocation, traditional territories and identity" (209), and these speak to the themes of the whole novel as they show the relations of places and self-concept that the idea of home can integrate in an increasingly mobile world. The novel demonstrates ways in which home can be understood as a complex map that is able to relate mobility, place, and identity. Dickner depicts a multi-scalar notion of home by proposing that individuals can establish meaningful links to places and communities in liquid modernity through the notion of a "complex map." This is a map that not only includes a spectrum of intimate geographies and larger abstract regional associations but also geocultural, socio-political, and economic dimensions because it incorporates the networks of places that redefine an individual's idea of home in personal, interpersonal, and social contexts. The map that Dickner narrativizes in order to explain each main character's sense of identity and belonging offers a direct contrast to the kind of static home that is signified by a bound geographic space in The Village. This contrast is important because instead of the elders' reliance on stasis and control to maintain stability (which Shyamalan undermines without offering possible alternatives), Dickner's process of mapping suggests new means of fostering forms of stability and commitment to community by adapting to rather than escaping from a world of flux and flows.

In this chapter, I argue that Dickner's multi-scalar mapping of home brings together the theoretical concerns raised by both Heidegger and Bauman in a way that offers a cogent example 
of what I call liquid modern poetic dwelling. My analysis of Nikolski builds on the importance of mobility to ideas of home that I began exploring through the labyrinth motif in House of Leaves (chapter two) and a quest of homecoming in Neverwhere (chapter three). In the previous chapter, I examined The Village as a counter-narrative in which mobility is rejected and argued that the failed escape from the problems of liquid modernity depicted in the film points to a need to understand home as something defined by mobility. The economics of mobility-the confluence of forces that promote mobility—make migrations (frequently multiple and even circular) as well as the trade and the travel of ideas vital to how home is increasingly fragmented; however, what Dickner demonstrates is that understanding home as an idea that traverses various locations and scales can be a source of integration. Nikolski also shows that mobility is central to notions of home because of the ways that home-makers navigate this complex and deeply personal idea through memory (a movement through time) as well as comparisons of cultural ideals and other imagined homes - those we temporarily "inhabit" as guests of another person's or character's home.

For me, Dickner's innovative mapping of home incorporates the reflection that Heidegger argues is imperative to dwelling even in the circumstances of liquid modernity, which Bauman characterizes through change and the metaphor of fluidity. This expansive map requires meditative thinking, more than the quantitative coordinates of a representation of land, and must be fluid because it is "made" over the course of a home-maker's life. The three main home-makers in Nikolski are the cartographers of their sense of home and the process of mapping assists them in discovering the "powers of integration" (6) of the house that Bachelard theorizes. Furthermore, they do not simply find a physical "corner of the world" (Bachelard 4)—a kind of Covington Woods - but map multiple "corners" and on different scales in order to construct a more 
meaningful anchor, one that is capable of reflecting the multiplicities but also commitments that define their distinctly liquid modern forms of poetic dwelling. The book's theme of exploration makes the relation of mobility and stability central to each of the three narratives in Nikolski, while suggesting that home-makers find people and places that shape their sense of home in ways that can be as and even more formative than the traditional origins epitomized by a phrase like "blood and soil." In liquid modernity, familial and national ties take on less rigid forms — not only through multiple marriages and multiple citizenships but the very ways in which a culture that can be eloquently described as "liquid" facilitates changes in "states" that do not require the "either/or" delineations of solid modernity but spill over into "and/or" overlaps in liquid modernity. The looser ties and commitment avoidance that Bauman critiques in his writings on liquid modernity are re-imagined in Nikolski in this "and/or" manner as a way to redefine not only familial and national bonds but forms of committing to places and people that can yield a map of poetic dwelling.

I argue in this chapter that Dickner illustrates new forms of home-making and commitment to community through mapping and the notion of constructing a "complex map," an idea that I build on by suggesting that it offers a very apt means of conceptualizing the multi-scalar liquid modern home. The novel begins in 1989 and spans a decade during which its protagonists rethink home by travelling but also re-contextualizing their past mobility and that of others close to them. Throughout the book, traditional expectations in regards to rooting are undermined, beginning with each character's non-traditional upbringing, "broken" homes, and scattered family. The novel highlights the potential for family and community amongst strangers through the idea that strangers may be closely connected without even knowing it. Dickner interweaves the narratives of three protagonists who are unaware of their links: the unnamed narrator of his own chapters, this 
narrator's half-brother, Noah, and their first cousin, Joyce. Linking the three is Jonas Doucet, absent father to the boys and a maternal uncle that Joyce never met. Though related, each protagonist has a very different experience of a stable and/or mobile home. The first protagonist, the unnamed narrator is initially as immobilized by the comfort of the familiar as his mother, who was a travel agent but only ever "travelled" by reading travel guides, yet by the end of the narrative he decides to travel the world. Noah sees mobility as a norm following his childhood spent on the road in a trailer but seeks to settle, only leaving Montreal when he finds out that he has a son with a former girlfriend and following her to South America before eventually returning with the child to Montreal. Unlike the pendulum that her cousins swing between, Joyce's experience of mobility is less extreme in its fluctuations. Her childhood is spent in one place but she leaves to half-settle in Montreal before fleeing potential prosecution for computer piracy. Unlike The Village, Nikolski is global in its reach, discussing suburbs, decayed urban centres, sparse islands, and even liminal spaces of transit - the exotic and the banal, distinct places and those that seem "placeless." The geographic scope of the novel includes all of Canada as well as international locations, not for the sake of exoticism but as a testament to the complexity of genealogies and migration histories.

There has been some scholarship on this novel, which was published in French in Québec in 2005 with an English translation following in 2008. The English edition was a Canada Reads book for 2010 and garnered more critical and popular acclaim when it was featured on the radio as well as in libraries and bookstores across Canada. Scholarship on the novel focuses on diverse topics, including dumpster diving (Bates), conceptions of "heartland" and "hinterland" in Francophone Canada (Sing), as well as legitimacy and the notion of family (Saint-Martin). The novel's translator, Lazer Lederhendler, describes the work's themes as the "construction and constructedness of identity" but also "genealogy and heritage" and "interconnectedness, both 
visible and secret" (41). What Lederhendler points to is the way that Dicker not only depicts dualities but incorporates competing forces and priorities, and this is one of the reasons that his novel is able to offer innovative answers to questions about navigating home's stabilities and mobilities. Claudine Fisher focuses on the "triptych motif" in the novel, yet she similarly highlights Dickner's ability to integrate dualities by calling the novel a "tale of intimacy and estrangement" (1188). Laurence M. Porter takes a historical approach to the text and traces the novel's structural links to older works, including Herman Melville's Moby Dick, and explores its theme of Acadian diaspora. Although he mentions homes and homelands, Porter does so without discussing the relevance of the theme of home-making directly. However, his observation that each protagonist offers a different reaction to reconstituting a fractured identity—-"passivity, rebellion, and renewal" (308) — sheds light on the characters' experiences of home: initially the bookseller is passive, Joyce rebels, and Noah attempts a renewal on his own and then with his new family.

All three main characters are shown to fluctuate between stasis and mobility, and while the novel hints at each characters' potential success in constructing home, it offers no "solid" guarantees since Dickner diligently avoids offering a blanket solution to the questions of home, identity, and community. What he focuses on in order to investigate the three concepts is a changing approach to territoriality since mobility more frequently alters our relations to places. Through its alternately immobilized and itinerant characters, Nikolski explores the different kinds of networks and communal connections possible in liquid modernity and conjures new means of representing and understanding home through the complex (multi-scalar) map. In the following sections, I examine how Nikolski reframes the commodification of home and the figure of the mobile home-maker as a sometime stranger in liquid modernity. In order to build on Bauman's 
tourist-vagabond binary, I investigate the kinds of "life strategies" that Dickner depicts and conclude by demonstrating the significance of understanding the liquid modern home as a kind of map which helps home-makers manage the mobilities of people, objects, and ideas that surround them and infiltrate but do not have to inhibit constructions of home.

\section{Uprooting nostalgia in liquid modernity}

In Nikolski the protagonists initially search for home as though it could be "found," but the unnamed narrator, Noah, and Joyce do not seek novel experiences like the tourist-types that Bauman describes, and what their stories ultimately offer are narratives of endeavours to map a meaningful sense of home. I see the difference between "finding" and "mapping" as analogous to "buying" and "building," with the former terms suggesting an act or event and the latter a process. The home-making process which Dickner depicts showcases the impact of ideas of home on subjectivity not only through self-reflection (something I explored in Part I) but also through emerging or re-emerging interpersonal connections and the sense of community that they foster. Mapping incorporates other people, places, and social forces into the already labyrinthine idea of home, and the characters in Nikolski manage to seek out connections, explore old and new roots, and become a part of communities that they choose and are chosen by. Dickner also highlights the role of home in mediating experiences of mobility and stability as characters contend with dreams of having as well as escaping their roots. For example, Joyce seeks to "elude the clutches of her family tree" (60) but feels a deep void in her life because of her missing mother figure. Noah, similarly, sees Chipewyan elders haunting the trailer (22) but beyond this connection to his mother's roots, feels that “[ $\mathrm{h}]$ is family tree was, like everything else, a transient thing that receded with the landscape" (28-9). The novel, I suggest, explores the impact of mobility in order to 
explore the ways in which the idea of home is still fruitfully rediscovered, reconstructed, and reconstituted in liquid modernity.

Dickner explores territory and territoriality through new modes of claiming and commitment. Noah is the character who has idealized the idea of a fixed home the most because roads defined his childhood sense of home. Yet, Dickner problematizes this ideal when Noah discovers that settlement is not as straightforward as it seemed. Instead, he feels at home in different places and different scales in Montreal in a way that echoes his feeling of territoriality when, while relieving himself on the side of the road, he felt that a passing car "was encroaching on their territory, as if Route 627 actually ran through their bathroom" (20). Noah feels connected to the spaces he inhabits, even if in transit, because even this provincial highway offers him a familiar landscape that is part of the multi-scalar home that he constructs during his time living in the trailer. ${ }^{31}$ Arizna, an international student at Noah's university, complicates the concept of territoriality for him by invading his part of the library but also claiming that territory is not simply geographic and bounded or quantifiable. She claims, "Above all, territory is a matter of identity" (131), and such a view implicitly demands an understanding of home as more than physical space, and as an idea mired in questions of belonging that cannot be answered through ownership and purely economic or nostalgic links. Arizna is expressing the link that Heidegger points to when he defines dwelling as what we do and who we are, and her claim illuminates the problems that Bauman is critiquing in liquid modernity by undermining the notion that because of mobility territoriality does not matter.

Dickner reframes the problem of increasingly ambivalent or quantifiably economic

31 This example does not contradict Heidegger's comments in "Building Dwelling Thinking" regarding the road not being a truck driver's dwelling because the latter suggests a replacement of home with other spaces, in this case those that relate to work. For Noah, the road becomes an extension of his dwelling because he and his mother live in a trailer. 
relations to territory through a focus on personal experience and the concept of the complex (multi-scalar) map. This idea is first described when Noah gets a job delivering groceries by bicycle in Montreal, and he begins to explore "a complex map of the area, at once physical and cultural" (99). His perception of such a map is influenced by his mobile past and childhood, and while he resides in Montreal's Little Italy, the rest of the city, province, and so on also affect how he amalgamates and understands home. For Noah, home is initially a stable and utilitarian concept because he thinks that by moving into a fixed address his sense of home can finally be stabilized. However, it keeps shifting and he discovers that one address or even two dimensions are not enough to explain this map: "he would need a mobile, a game of Mikado, a matryoshka or even a series of nested scale models" (99). The shifting perspective that "zooms into and out from a local, personal position: Canada, Québec, Montreal, Little Italy, an apartment, a room, a bed, a thought” (Lederhendler 41) becomes an integral aspect of the novel's interwoven narratives of protagonists who not only physically move but are deeply affected by the mobility and "liquidity" that surround them. They understand their home as something that exists on multiple scales, and it is after discovering this expansive approach to such mapping that, "For the first time in his life, Noah is starting to feel at home" (Dickner 99). The significance of this feeling is immense as Noah is truly learning to dwell and committing to places and communities.

The novel models constructing ideas of home in liquid modernity by incorporating mobility without letting it undermine a sense of stability. For Fisher "the theme of home clashes with that of the outside world bringing back the constant dichotomy of motionlessness opposed to the desire for freedom" yet she points out that "Noah is the happiest when both home and freedom are embraced at once" (1196). It is this combination of stability and mobility that is foregrounded by Dickner in order to re-imagine a sense of rooted yet fluid home-making. Fisher eventually 
suggests that all of the main characters in the novel "strive to find a balance between their desire to belong and their longing to escape" (1198), and I also see this as the central point of the novel since Nikolski investigates more practicable contemporary solutions to addressing the uncertainties and instabilities of liquid modernity. Dicker reframes commodification as well as the notion of strangers in his novel in ways that show that poetic dwelling can flourish in liquid modernity, and it is to the issue of commodification and strangers that I turn to in the following sections. I suggest that the forms of rejection of materiality and openness to strangers that Dickner depicts facilitate an understanding of home as a complex map that incorporates meaningful relations and is inclusive by not limiting home to locations, market values, and a potentially stifling familiarity and stasis.

\section{The issue of commodification: mobile identities, garbage, and memories}

The forces of liquid modernity are adapted to and redirected in Nikolski, particularly in terms of the extent to which mobility and consumerism affect but do not define home-making for the novel's protagonists. Dickner demonstrates that while economics and nostalgia deeply affect constructions of home, objects themselves cannot define home, even in an increasingly consumption-oriented cultural context. According to Bauman, "our culture of speed, instantaneous satisfaction and instant waste disposal" (Wasted Lives 127) overwrites the meanings with which such objects (or spaces) could be imbued. Grant McCracken criticizes the tendency of making consumerism "an all-purpose explanation for the ills of contemporary life" (3), describing consumer goods as "one of our most important templates for the self" (3). Rather than focus on the quantity of objects flowing through the liquid modern economy, McCracken suggests that these

goods "capture the meanings with which we construct our lives" (4). Nikolski explores both the 
wasteful and meaningful ways in which objects can fill a home space and link to other aspects of the idea. Dickner challenges consumerist views of garbage by uncovering more than a mass of unwanted refuse. He does so by presenting three special talismanic possessions that are depicted in the novel as symbols of home- - linking past and future, or roots and the possibilities of new routes. His dual view of goods as commodities but also repositories of meaning helps me to expand upon the contrast of "building" and "buying" that I have used to distinguish Heidegger's ideal of dwelling from the liquid modern approach to literal home-owning. I argue that by mediating these extremes Dickner begins to show ways in which poetic dwelling is possible in consumer-oriented liquid modernity.

In Nikolski characters reassess the belongings they or loved ones leave behind, trade or resell books, and even find historical information as well as viable computer parts in garbage dumps. Through these everyday experiences and jobs or hobbies, Dickner incorporates a practical approach to consumption that speaks to McCracken's points but also foregrounds the modern over-consumption which Bauman writes about. The protagonists, somewhat radically, have few truly valued possessions, and they rethink garbage rather than ignore the increasing waste produced by consumer society and a culture of disposability. For instance, Joyce sees garbage collected from a Montreal food store and is initially "spellbound by all the waste" (71) and "sense of abundance" (71, original emphasis) that she never witnessed in the remote fishing village of her childhood. In Consuming Life, Bauman explains that consumer society "devalues durability" and "is unthinkable without a waste-disposal industry" (21). Joyce, however, is surprised but ultimately not impressed by capitalist excess and she continues skirting consumerist norms. When she desires a working computer, for instance, she ends up assembling several from parts taken from office building garbage dumps. What Bauman calls a "civilization of excess, redundancy, 
waste and waste disposal" (Wasted Lives 97) is at odds with the stability that is the goal of many home-making practices, yet Nikolski shows that liquid modernity can still foster home-making. Joyce and her cousins do not amass and dispose of home spaces but continue exploring new alternatives and routes to building home — assembling and mapping rather than simply consuming it.

Dickner's treatment of commodities seamlessly highlights both their disposability and their significance as means of symbolizing connections, memories, and personal as well as cultural meanings. Two scenes illustrate this dynamic when the narrator empties his mother's house after her death and Noah cleans out his room in Montreal when he moves. In the first instance, as the narrator sorts through his mother's possessions, he finds himself wondering "how many garbage bags would be needed to hold the countless memories my mother had accumulated since 1966" and he admits to being "fearful of underestimating my mother's existence" (5). Yet, the initial sense of value in physical quantity is quickly supplanted by the feeling that his mother could not be "reduced to a pile of disconnected artifacts" (7), which suggests the significance of non-material links without undermining the symbolism of meaningful objects. In the second instance, Noah experiences a similar situation with his own possessions when he decides to follow Arizna to Margarita Island and help raise his son. Noah finds himself "squeezing the contents of his room into plastic - thirty cubic metres of universe divided into garbage bags whose fate he determines by labeling them Trash, Recycling or Salvation Army" (192), and what is most striking about his efficiency is that he intends to "leave the room just as he found it five years ago" (193). He came to it with only a backpack and seeks to leave no trace when, of course, the room can never be the same - not for him. When he returns with his son, this Montreal room in his friend's apartment leads him to wonder, "How can so many memories be contained in such a cramped room?" (279), 
which suggests that even without those things the space is full of meaning. Dickner illustrates with these two scenarios that while commodities can store meaning, they are ultimately disposable in ways that their meanings, whether of the devoted mother or a young man's first experience of independence, are not.

Dickner explores mobility and materiality through the talismans of each of his protagonists, which are not consumer goods but odd, distinctly old, quasi-gifts. The compass, the narrator's talisman, symbolizes the process of locating and mapping home, and supplements the physical roots to people, particularly his father who sent it as a birthday gift but also his mother, who raised him. The fact that this compass “doesn't point exactly north" (12) but to a village called Nikolski, suggests that, like this narrator, everyone might have a different or shifting pole star or navigational pull; consequently, each map of home will comprise of different scales, points of reference, and unique legends or codes. According to Porter the narrator's compass "reveals only one meaning, a fixation on the unknown father" (306) because it points to the village where he died, and Fisher similarly only relates the meaning of the compass to the father, claiming that its shattering signals a "liberation from the father's gift" (1192). Yet, it is important to realize that this liberation is also from his mother's life, since she represents the opposite sedentary extreme, having settled in the Montreal suburbs and never traveled after her son's birth—while working as a travel agent, no less. Also significant is the fact that the narrator finds the compass again shortly after her funeral, while getting her house ready to sell. I suggest that it is only after the compass shatters that, without rejecting his parents or his past, he is finally able and willing to explore new routes as part of his home-making. Once the burden of the compass is lifted, he leaves Montreal in order to begin constructing a sense of home with more intent, realizing that he does not need to be vigilant about avoiding his father's itinerant life but also that his mother's sedentary lifestyle might 
not be right for him.

A compiled history assembled from different writers across time, Noah's book represents an amalgamated story instead of a singular one. He discovers the book in his mother's trailer and calls it "the Book with No Face" (30) on account of its strange combination of texts without clear identifying markers. His father initially leaves it in the trailer, and his mother gives it to him as almost an afterthought when he leaves for university. It is a memento from his parents, but it does not impact Noah as deeply as the compass does his half-brother. Nonetheless, after reading it Noah is changed: "Never again would he be able to separate a book from a road map, a road map from his family tree, or his family tree from the odour of transmission oil" (30). These multi-sensory connections suggest a multi-scalar sense of home that not only Noah begins to discover over the course of Dickner's novel. ${ }^{32}$ When this book finds its way to the used bookshop, the narrator points out that it is a "unicum" (284), or a one-of-a-kind text. Like the individually configured compass, this amalgam becomes a unique signifier, rather than an easily replaceable, mass produced object. The narrator clarifies that a unicum is not an anthology but linked fragments—_Debris. Flotsam and jetsam" (284)—which suggests platitudes about one person's garbage being another's treasure, something that actually commonly occurs in Nikolski. By ending up in the used bookstore's discount bin, the book becomes a specific example of sharing and reuse that undermines a consumerist value placed on new objects that can be purchased, owned, and discarded.

Lastly, Joyce's “antique sailor's duffel bag” (58) belonged to her beloved maternal grandfather, Jonas's father. The bag might have gone to Jonas but he left at the age of fourteen, and

32 The book combines three texts that align with each protagonist with "a study on treasure hunting," a "treatise on the pirates of the Caribbean", and "a biography of Alexander Selkirk, who was shipwrecked on a Pacific island" (284), since Noah is a treasure-hunting archaeologist, Joyce a virtual pirate, and the narrator a kind of castaway in suburban Montreal. 
after the grandfather died, Joyce "salvaged her own inheritance" (58). This bag represents for Joyce her goal of following the family tradition of piracy as well as a link to or means of reconnecting with her past elsewhere. She subsequently takes it with her on every journey: from under her bed to leave her hometown and attend high school, to run away to Montreal, when she goes to scavenge for computer parts around the city, and then to leave Montreal for the Dominican Republic. The duffel bag remains an import talisman for her during this quest of self-transformation and becomes so much a part of her that in two notable scenes the absence of the bag suggests Joyce being gone. In an eerie description of her apartment once she has left, the bag is listed as missing, and then, because the narrator frequently sees Joyce in the bookstore with the duffel bag, he notes the bag's absence: "Nothing has budged, but the old sailor's duffel is gone, the yellow raincoat is gone, Joyce has shoved off' (263). The duffel bag is something out of which Joyce can comfortably live, like Noah who arrived in Montreal with only a backpack, yet neither nomadic character seeks to just keep travelling as Jonas Doucet did.

For each of these protagonists, the concept of home and construction of the idea is more important than the value or status that a commodified space can represent. Rather than itinerancy or an endless escape, Noah and Joyce seek places which allow them to pursue ways of life that their fishing village or trailer did not, and while both characters accept that these first homes are a part of their understanding of home, they also demonstrate that those iterations of home need not define what their sense of home can or cannot be - something that the narrator similarly illustrates when he stops being trapped by his mother's and father's choices and he begins mapping his own sense of home. Dickner's characters offer counter-attitudes and glimpses into alternative worldviews, showing that in a decidedly mobile and commodified world home does not become fully replaceable and conceptually redundant. The potential of these views seems to stem from the 
ways in which the characters are able to remain minimally consumed by a monetized, global consumerism that favours liquid assets which are newer and less likely to be devalued. It is because these characters make choices to commit in various ways that they are not quite tourists nor vagabonds, and in the following section, I propose the pirate and passerby as emblems of more committed "life strategies" which include an emphasis on home-making and fill the gap between Bauman's hypermobile hyperconsumer and unwillingly immobile "flawed" consumer extremes.

\section{The issue of strangers: pirates, passersby, and "Applied Nomadology"}

Nikolski seems to be a novel about nomads, but I suggest that if its protagonists can be called nomads, then they are nomads who use mobility to try to understand ideas of home, settlement, and belonging. Bauman identifies two kind of liquid modern nomads based on levels of privilege: the cosmopolitan tourist is neutral and unfettered by allegiances, while the vagabond is denied the extensive choice of where and how to move but wants to explore new landscapes. The dimension that I see Nikolski adding to Bauman's types is the question of agency, and I propose the text's representation of the passerby and pirate "life strategies" as explorations of agency in regards to commitment and home-making within the socio-economic conditions of liquid modernity. In order to explore the passerby and pirate figures, I focus on the idea of "nomadology" as presented by Dickner and explored by his characters, particularly Noah, who first envisions a university degree in this strange field. Having to choose a major at university, Noah finds himself "looking for the Diploma in Applied Nomadology or the B.A. in International Roaming, the only disciplines for which he felt he had some talent, but there was no mention of any such degrees" (39). The mention of nomadology, more than just "roaming," proposes a need to more precisely study our migrations and the unexpected as well as logical routes and destinations that they 
involve. Nomadology, as a study of nomads or nomadic practices, suggests the need for a deeper analysis of the reasons for and means of migration, and each of Dickner's main characters studies alternatives in order to find his or her own mix of stability and mobility, not as hypermobile tourists or vagabonds whose mobility is limited but alternate types that are not only mobile and settled but chose to commit to places.

The passerby and pirate figures that are articulated in Nikolski and which I propose as complementary to Bauman's model are part-tourist and part-vagabond in a way that fruitfully fills the middle space of tourist-vagabond binary. In "From Pilgrim to Tourist—or a Short History of Identity," Bauman mentions two tangential life strategies along with the tourist and vagabond - the stroller or player — but he does not return to either figure in later writing. Dickner's passerby and pirate figures, I argue, not only demonstrate the breakdown of old but also the emergence of new home-making practices and relations. ${ }^{33}$ These types depict a level of commitment avoidance and ambivalent or self-serving goals similar to Bauman's extremes, yet the ways that the figures $d o$ commit to places and people in the novel suggest important counterpoints to a conception of rampant commitment avoidance in liquid modernity. My main contention in this regard is that Bauman refers to commitment as a static idea which was embraced in solid modernity and is avoided in liquid modernity, and I want to suggest that our understanding of commitment cannot remain the same across eras. The kinds of "rooted" and often pre-determined responsibility or engagement expected under solid modernity are impracticable in liquid modernity. Furthermore, we cannot revive the old kinds of commitment and the conditions that fostered them by returning to a time not affected by extensive, liquid flows - a point that The

33 The pirate figure is used by Dickner to anchor these practices in New World history, as pirates were disruptors of colonial trade routes and their transportation of goods and humans. For Joyce, who names her computers after historical pirates, the powerful figure is emblematic of the kinds of disruptive and subversive agency she seeks. 
Village insightfully demonstrates.

Noah's sense of nomadology is not the conceptual and inherently political notion coined by Gilles Deleuze and Félix Guattari, most notably since the diploma he imagines is in applied nomadology. ${ }^{34}$ In Noah's sense, nomadology refers to literal mobility, foremost, but without limiting the experience of mobility to the more extreme circumstances of international refugees or nomadic peoples. Noah is concerned with everyday life - his everyday life, especially, which includes a childhood defined by constant mobility—more than abstract philosophical approaches to institutionalized knowledge or social theory. Bauman's approach is similarly more focused on everyday life (as the term "life strategies" indicates) and he is wary of romanticizing nomads by ignoring the privilege of self-styled, cosmopolitan nomads. For Bauman, the term "nomad" has become overly fashionable and misleading because "it glosses over the profound differences which separate the two types of experience" (Globalization 87) of the tourist and vagabond. According to Martin Jay, Bauman's overarching project suggests that: "We are all nomadic extraterritorials, who restlessly transgress the increasingly porous boundaries left by solid modernity. We have learned to value transience over duration, and cope-more or less—with the erosion of even our sense of enduring individual selves" (98). This focus on "nomadic" tendencies in Bauman's work, nonetheless, also highlights the extent to which actual mobility-not just the broader sense of conceptual wandering — is shaping our lives both directly and indirectly, by

${ }^{34}$ Rosi Braidotti, whose work builds on Deleuze and Guattari's notion of nomadology, explains that "the nomadism in question here refers to the kind of critical consciousness that resists settling into socially coded modes of thought and behaviour" and reiterates that "not all nomads are world travellers; some of the greatest trips can take place without physically moving from one's habitat. It is the subversion of set conventions that defined the nomadic state, not the literal act of travelling" (5). This broad understanding of nomadic subjectivity can include Bauman's view of the pilgrim of solid modernity as well as the liquid modern tourist and vagabond who are physically pushed and pulled because all three figures are implicated in conceptual or physical flows. 
transgressing intra- and international borders and shifting our values to reflect new relations with mobility itself.

Each of Dickner's variously nomadic protagonists accepts mobility as central to their lives and embraces multiple roots - a sense of belonging shaped by past as well as present homes and lived experience. These characters are able to explore the expanded connections as well as freedoms offered by more mobile identities, and illustrate the middle ground that John Durham Peters theorizes in his analysis of nomadism, nationalism, and diaspora. For Peters nomadism suggests having no fixed home while nationalism delineates a specific home space, and he investigates this binary through the idea of being "homeless" and "home-full" (21). Bauman's figure of the tourist seems to exemplify the state of being "home-full" in the sense of possessing overabundance, and a luxury of being allowed to move freely from potential home to more of the same, and as with Bauman's vagabond, for Peters the seemingly homeless nomad suggests a defiance or avoidance of the state and society_-something that connotes a flaw or lack. Peters seeks to suggest a fertile middle ground between the home-full and homeless extremes, and he eventually settles on diaspora, which he views as existing conceptually between nationalism's “organic connection" and nomadism's "rootless liberty" (38). For him, diaspora is capable of accommodating the various shades of a mobile and yet rooted existence, and although Nikolski does not address diaspora as traditionally conceived (through mass and relatively permanent immigration), the diasporic mobility of the various half-Doucets depicts the dynamic experiences of the "organic connections" and "rootless liberty" that Peters describes. The non-traditional diaspora in the novel, I suggest, is depicted by the passerby figures who are less privileged tourists (not quite "home-full") and the pirate figures who are more privileged vagabonds (not quite homeless). 
Nikolski does include characters who represent the extremes which Bauman theorizes, and this is important in establishing the spectrum that the protagonists then fill out by populating the middle space through new "strategic" configurations. Even Dickner's tourist and vagabond include a twist on Bauman's stock figures. The global elite is represented by Arizna but she uses her family's money in activist endeavours, and the vagabond is represented by a Montreal homeless man who serves as a reminder that the tourist's privilege is denied to individuals in prosperous areas of the world as well. In several moments a "vagrant wearing a Maple Leafs hockey tuque" (77) peripherally enters the novel and even though the recurrent tuque suggests it is the same man, this is neither denied nor confirmed. City rivalries being what they are, a Toronto Maple Leafs hat in Montreal might be more quickly traded or discarded for another and the vagrant's defining attribute is also more noticeable for being distinctly out of place. In the final appearance, when a "vagrant wearing a Toronto Maple Leafs hockey tuque pushes a grocery cart loaded with his harvest of empty bottles" (186), the irony of such an inedible and meager yet perhaps sufficient "harvest" reframes the lack of material wealth in the protagonists' lives as still being more than adequate. Most importantly, the literally homeless figure undermines the romanticized view of conceptual homelessness and foregrounds some of the rigors of a nomadic life. Through these extremes and the more moderate main characters, the novel tracks the impacts of the interactions of diverse people in potential home spaces that are altered through mobility and the diverse changes that mobility inevitably brings.

Another reason that the novel's pirate and passerby resonate with Bauman's life strategy framework is that they share characteristics with the stroller and player, Bauman's original extra two life strategies. Yet, by filling out the tourist-vagabond spectrum rather than merely offering tangential ideas of overlapping strategies, the pirate and passerby are able to fruitfully 
problematize Bauman's extensive sense of liquid modern commitment avoidance. Nikolski's narrator is a passerby, or less privileged tourist, and life seems to pass by as he observers instead of engaging with his surroundings. Bauman's notion of the stroller similarly includes an emphasis on pleasures without attachments, a "psychical out-of-reachedness" ("Pilgrim" 27), and a level of commitment that Bauman finds comparable to watching television. ${ }^{35}$ Yet, while passersby might not wish to form permanent attachments, they value them and commit in their own ways. The narrator's life suggests an overarching detachment—first in a suburb of Montreal where, like his mother, he learned to rely on books as a means of experiencing life and then downtown working in a bookstore in which he keenly observes his customers - but not to the extent of a tourist. Even though his engagement seems minimal, the narrator is actually quite devoted to the used bookstore and makes an effort to find a worthy replacement once he does decide to see more of the world and "pass by" on a grander scale. The passerby figure's higher levels of agency and commitment include observing and "learning" a place rather than merely experiencing its novelty (the tourist's modus operandi).

Joyce, meanwhile, represents the pirate figure, one that flourishes in liquid modernity's flows as well as global, economic interconnectedness. Because she has more privilege and agency than a vagabond type, she is able to insert herself into a new landscape, taking or "looting" what she requires. As her computer piracy suggests, the pirate figure need not steal goods but can also copy, borrow, and adapt things and ideas. The link that the role has to Bauman's additional strategy of the player is less direct than the stroller to the passerby but worth mentioning. The player, Bauman explains, functions through "moves" ("Pilgrim" 31), like in chess or another

35 The stroller figure that Bauman describes is closely related to the flaneur, a figure theorized by Walter Benjamin and taken up by Anne Friedberg who proposes the shopping mall as "a site for flânerie and for a mobilized gaze instrumentalized by consumer culture" (12). 
game, as well as "moving away." The strongest link to the pirate here is that players can "“cut their losses' and start from scratch" ("Pilgrim" 32), something that Joyce seems to do on several occasions. Yet, she does not "start from scratch" and even "cutting" her losses is a hard won opportunity. While the player has an ambivalent relation to winning, the pirate demonstrates a more active agenda and deeper intent. Less privileged than the tourist and passerby, in order to escape the confined role of the vagabond, the pirate must fight for and maybe even steal the right to more mobility—or even any mobility at all.

Lastly, Noah draws both of these figures of nomadology together; he was a passerby as a child traversing western Canada with his mother, a kind of pirate on Margarita Island, and fluctuated between these two positions when in Montreal. Over the course of his travels, Noah keeps learning to mediate his experiences of mobility with his expectations of stability, never feeling fully rooted or afloat while he continues to understand the "roots" that connect him to people as well as places and the "routes" that are available to him. In one instance, Noah recalls driving past a schoolyard in his mother's trailer as some of the kids "gazed yearningly at the road" (37) and "[w]ith their fingers threaded through the grid, the captives envied the nomads" (37). But Noah is familiar with what the romanticized nomadic life can entail as well as what it misses. So if the road symbolizes endless possibilities and a sense of freedom for the other children, for him "the road was nothing but a narrow nowhere" (37). His constant mobility does not allow for interpersonal relations or community beyond the enclosed space of his mother's trailer, and it is not surprising that, when Noah finally arrives in Montreal, he is not picky about where he settles — he is fully focused on simply settling somewhere. Looking at a newspaper he "points arbitrarily" (78) to an ad for a room, but quickly enough he also learns of the difficulties of settling as it becomes increasingly clear for him that home involves more than a stable residence. 
The two types of nomads that Bauman theorizes, the tourist and vagabond, offer a paradigm for understanding mobility in the twenty-first century, and this is a paradigm that Dickner's novel enriches by exploring new ways of relating to home amidst the flows of liquid modernity and integrating multiple kinds of home spaces. Yet, the two additional types that I theorize on the basis of my reading of Dickner's novel add to the possible subject positions available to home-makers in liquid modernity, and the passerby and pirate are able to anchor themselves in spite of the economic and social fluctuations of this era. By problematizing and overlapping Bauman's types in order to depict more moderate experiences, Nikolski shows that the notion of home is a mixture of choice and circumstance, constructed through moments of staying and leaving. I want to further suggest that "mapping" describes the conceptual work of integrating different experiences and expectations of home, and that in Nikolski this integration occurs through a "complex map" (99), which I understand as a personal conception of the multi-scalar home. In the following section, I suggest that the agency of the pirate and passerby "life strategies" as home-makers comes from their ability to see home not as the tourist's exit strategy or the vagabond's trap but as a complex map comprising of various dimensions and scales.

\section{The liquid modern home as a complex map}

In this final section, I want to develop the notion of the complex map that Nikolski proposes into a more comprehensive conceptual framework that includes Heidegger's idea of poetic dwelling as a goal within the conditions of what Bauman calls liquid modernity. This conceptual tool integrates a personal, multi-scalar map of a home-maker's "roots" and "routes," by offering an immersive, virtual, four-dimensional cartography which grows and adapts. Not merely a clear-cut, flat visual representation, it includes overlapping geographical and cultural scales as well as a 
matrix of sensory and landscape memories - from the links contained in material objects to smells and sounds as well as familiar topographies like flatlands or cityscapes and specific rooms, buildings, or streets. Such a map of home is an expression of dwelling and learning to dwell, and constructing it meaningfully requires self-reflection, or what Heidegger calls meditative thinking. In Nikolski partial narratives of its characters' complex maps of home are offered through its overlapping stories of their mobilities. In this way, Dickner models emergent home-making practices as his characters explore and re-evaluate the increasing diversity of ideas of home in liquid modernity. In previous chapters—chapter two particularly—I proposed the labyrinth as an insightful metaphor for understanding home on an individual scale, and I want to now suggest that transforming the labyrinth into a complex map maintains that metaphor's sense of discovery and continual movement (in space and time), while also foregrounding the relational nature of home-making since maps are constructed through relations.

Because sounds, sights, and smells as well as objects play a vital role in the links that each character's complex map of home includes, bodily experiences and memories forge this mental construct. The narrator, for instance, claims, "It's impossible to confuse the subdued murmur of Mallorca with the resonant roll of Greenland's prehistoric pebbles, or the coral melody of the beaches of Belize, or the hollow growl of the Irish coast" (3) and that "there's no mistaking the shores of the Aleutian Islands" (4). He is a recluse in the parts of the novel that are recounted yet these claims offer a glimpse into the travels this narrator eventually undertakes. While going through his mother's things, he asks, "Since when do diesel engines imitate breaking waves?" (4) and eventually calls this sound the "[d]ubious poetry of the suburbs" (4). The wave-like sounds from childhood form links to the later experiences, connecting them to a past home. Noah offers a similar comparison that is also visual, when, "Gazing at the sea, he once again experiences the 
dizziness one feels on the great plains of Saskatchewan. The monotone roar of the waves is reminiscent of the wind in the barley fields" (221). This kind of landscape memory is superimposed on new places and, I argue, becomes a part of the complex map of home. In another example, for Joyce the smell of fish blood is "so familiar" (71) that when she smells it on her hands after a day of work in the Montreal fish store, "[w]ith her eyes closed she can almost believe she is back in her father's kitchen" (74). The sensory memories offer more ways of linking to a conceptual, composite home, further revealing that links to home do not need to be marketable commodities which are rented or owned but are created through mental and physical experiences of home spaces.

The body, a kind of ultimate and inescapable home, mediates and stores the memories of home and experiences that a multi-scalar, immersive map can integrate. Several scholars have explored the relation of body and home. In Home Bodies, James Krasner considers the role of touch in the ways that we experience home, and although he seems to want to take the phrase "feel at home" literally, his book — part scholarship but also part memoir —investigates some of the ways in which our physical engagement with home spaces is "interwoven with emotion and memory" (190). Similar ideas, not limited to touch, are explored by Margaret Morse in "Home: Smell, Taste, Posture, Gleam." Morse focuses on sensory associations with home and argues that even if the idea is not loaded with meaning, it maintains an abundance of sense memories, such as a "fortuitous and fleeting smell, a spidery touch, a motion, a bitter taste" (63). She suggests that home is "an evocation that is of this sensory world" (63) and can incite Proustian moments. Flashbacks or involuntary memory, I argue, are only some examples of the sensory memories that can be mapped conceptually as the idea of home is continually (re)constructed.

In Nikolski the feelings of home that memories generate- things the characters feel 
viscerally and "in their bones"- are often recounted in order to explore larger ideological questions about what home could and does mean for each character. Noah, for example, investigates the figurative sense of being steady on land and lost at sea. He thinks he is "stepping onto solid ground" (91) once he leaves his mother and her trailer, but while posting her a letter to General Delivery he feels that "the ground is slipping out from under him" leaving "nothing but rolling waves, choppy seas and dizziness" (91). This unexpected reaction helps Noah realize that home cannot be perfectly stable, comfortable, or unchanging, whether he is on the Island of Montreal or Margarita Island. He does not succumb to a happenstance kind of existence that for Bauman epitomizes liquid modernity, but he also eventually stops seeking refuge in an idealization of the rigid stabilities of solid modernity.

Rather than protecting themselves from mobility as the characters in The Village attempt to do, the protagonists of Nikolski embrace mobility, and the resulting three narratives suggest a kind of nomadology through their explorations of competing needs to remain, leave, and sometimes return. The narrator expresses a prejudice based on the nomad's lack of stability and physical permanence when the ad seeking his replacement in the bookshop includes the stipulation, "Nomads need not apply" (280), yet mobility is not demonized in Nikolski beyond this rather practical concern of finding longer term labour in an economy that increasingly rewards career drifters. Other motifs, such as recurrent mentions of fish migrations and food chains all serve as reminders of the everydayness of mobility—even if more traditional forms of migration like transhumance are supplanted by a norm that seems faster, more frequent, and even fleeting. Although Adrian S. Franklin claims that "[i]n a more mobile, more networked, connected and extra-territorial world, the paradox at the centre of Bauman's work is that the social bonds that can now be created (and even proliferate) are looser, weaker" (344), Nikolski shows that commitment 
to people and places can still flourish. If social bonds are looser, they can also be more flexible. If they are more easily broken, they can also be more easily made. Noah's relationship with Arizna and Joyce's opportunity to live with Maelo's grandmother are examples of both changes.

Similarly, the technical innovations that impact the accessibility of transport and consumer goods affect the stability and formerly assumed permanence of the idea of home, but they also influence new relations that can be incorporated on a more expansive map of home. Unlike a single house, address, or region, which in and of itself cannot adequately describe a sense of home for people in a mobile era, the complex map incorporates the multiple locations and scales that define home and dwelling in the twenty-first century.

In Nikolski, notions of home cannot be left behind, discarded, or replaced by another object, address, or idea. Even the narrator's decision to travel, introduced in the outset of the novel but foregrounded throughout the chapters in which he seems to be hiding in the sanctuary of the bookstore, does not suggest a means of escaping a confined life and leaving a home behind. The travels are his own way of continuing to "make" and map home by building onto what he has already experienced and discovered. He will undoubtedly miss the bookstore and Montreal, but the narrator explains: "it's more important for me to find my own road, my own little providence" (282). After years of seeing books travel through the shop, he is able to fulfill a formerly buried need to explore his “own road” (282). Through this character's candid first-person account as well as the stories of Noah and Joyce, Dickner illustrates in Nikolski the ability of home-makers to adapt to the changes of liquid modernity—such as consumerism, an emphasis on moving on, and increasingly ephemeral connections. The contrived look backwards of The Village proves to be a disaster, but Nikolski's look ahead shows new ways of dealing with mobility without enforcing or ignoring interpersonal relations and community (as the Covington Woods elders enforce and as 
Bauman suggests we increasingly ignore). The novel's protagonists manage to sustain their own stabilities by constructing complex maps of home which help them to integrate experiences from past homes, present circumstances, and what they seek from home in the future. These immersive maps can address conceptual homelessness and facilitate community building in ways that singular or static notions of home cannot, and this multi-scalar way of mapping home is something that I will continue to examine in my analysis of social norms and hospitality in the final part of this dissertation. 


\title{
PART III: Home on a social scale and the politics of (hostile)
}

\author{
hospitality
}

Here is where I fault myself, for my lazy trick of deferral that allowed me to believe I could actually locate my own framework in someone else's building.

- Sara Sulari, Meatless Days

And so we sail toward cities, streets and homes Of other men, where statues celebrate

Brave acts played out in peace, in war; all dangers End: green shores appear; we assume our names, Our luggage, as docks halt our brief epic; no debt Survives arrival; we walk the plank with strangers. - Sylvia Plath, from "Channel Crossing” 


\section{Chapter 7: Derrida and "hostipitality"}

Home, as I have shown throughout this dissertation, cannot be limited to a physical location — such as a building, neighbourhood, city, or nation — and is being defined in new ways. The idea is defined as a geographical but also cultural construct (Blunt and Dowling 2006), as a “territory" shaped by global media (Morley 2000), and as an ideal that is devalued by being framed as a financial investment or status symbol (Ronald 2008). All of these perspectives on home are important because they reveal how the concept is constructed within a social context that is deeply marked by the political forces of cultural globalization and the economic structures of late capitalism. Most home-makers are (multi)national citizens and global consumers, and their ability to be citizens and consumers is increasingly linked to their ability to stimulate production through consumption, a role that Bauman sees as supplanting long-standing social ties or ethical imperatives to other, proximal but also distant, home-makers.

To step into the debates on the shifting symbolic and material role of home, I began this dissertation by turning to philosophy and Heidegger's critique of viewing the world as a "resource," teasing out the way he offers poetic dwelling as an alternative to modernity's alienating effects. Heidegger's notion of dwelling, as I demonstrated, occurs principally at the scale of the individual, and is thus divorced from economics or politics. To address this lacuna, I turned to consider interpersonal and communal scales by examining home-making in light of Bauman's distinction between the "tourist" consumer and the "vagabond," who is a flawed consumer. These subject positions are integral to Bauman's conception of liquid modernity, a notion that describes how consumerism and globalization nurture the many flows and instabilities 
that directly impact the economic and political contexts within which home is constructed. What I argued, in some ways contra Bauman, is that Heidegger's form of home-making as dwelling is still possible in liquid modernity. Because liquidity supports fluidity and change, it can also nurture new forms of commitment and new modes of "making" home through meditative thinking and learning to dwell. Now I seek to analyze the social context — at the larger scale of towns, cities, and nations - in which home is constructed in order to develop new ideas about the multi-scalar home as a means of poetic dwelling in the mobile, technologically mediated, and consumer-oriented twenty-first century. I turn to poststructuralist theory as a way to examine the ethical and political questions of the ontology of home, and show how societal norms and practices can enrich a sense of home but also constrict conceptions of what, where, and when home may or may not be "made."

I propose that the most significant practice that defines dwelling in a social context is encompassed in the deceptively benign term "hospitality." To examine this concept, I draw upon Jacques Derrida's deconstruction of the notion of hospitality—developed in various shorter works including an 1997 Le Monde interview which was translated and reprinted in the journal parallax as well as the book Paper Machines (2005), an article based on a 1997 paper that Derrida presented entitled "Hostipitality" (2000), as well as Of Hospitality (2000) written as a kind of distanced dialogue with Anne Dufourmantelle, and On Cosmopolitanism and Forgiveness (2001). Derrida turned to hospitality late in his career, while also considering issues such as citizenship, cosmopolitanism, migration, and friendship, which emerged from reflections on the paradoxes of his own experience, as a Sephardic Jew from Algeria — an outsider occupying a central position in French philosophy. Derrida's examination of hospitality and, through it, the notion of home, links the acutely contemporary issues of "guest" workers, immigrants, and refugees, to the Greco-Roman constructions of hospitality and belonging by focusing on the relationships between 
the host or master and the hostis, guest, or foreigner. These relationships, Derrida contends, are always a question of ethics. In On Cosmopolitanism and Forgiveness he explains that:

Hospitality is culture itself and not simply one ethic amongst others. Insofar as it has to do with the ethos, that is, the residence, one's home, the familiar place of dwelling, inasmuch as it is a manner of being there, the manner in which we relate ourselves to others, to others as our own or as foreigners, ethics is hospitality; ethics is so thoroughly coextensive with the experience of hospitality. (15-16, original emphasis)

The ways in which Derrida unites hospitality and ethics underscores the importance of power in this social practice, since power relations are not reciprocal nor amenable to calculation and veil violence as well as forms of hostility for both hosts and guests. Hospitality maintains inequality, particularly when welcome is attributed to an act of generosity and kindness (charity rather than hospitality), and Derrida problematizes the term in a way that frames the social forces which construct and permeate the protective thresholds of "home," both physically and ideologically, as imperative ethical concerns.

Derrida proposes two issues that are critical for a rethinking of home through the term "hostipitality," which combines hostility with hospitality. First, he challenges the kind of categorical thinking that delineates hosts and guests. Second, he also draws attention to the more nuanced and often mutually exclusive relationships between public and private hospitalities. "Hostipitality" reveals the inextricability of the hostile and hospitable, and is not only significant for understanding the home-maker's social welcome to others but also the relations of welcome that occur outside of the immediate home space and contribute to the internalized feeling of being welcome that underlies Heidegger's notion of dwelling. In Colonial Fantasies, Meyda Yeğenoğlu claims that "[i]f the Hegelian economy works by making the subject recognize himself in the other, Derridean deconstruction makes the subject recognize the other in himself or herself" (9), and this difference is reflected in hospitality. A Hegelian subject can imagine being a guest but 
what Derrida's inversion suggests is the importance of a subject recognizing others as hosts. There is a shift in power in the latter position, and acknowledging this shift is key to my questions of what kind, where, and when home may or may not be "made."

Although Derrida is indebted to Heidegger for the term deconstruction, his deconstruction of hospitality enriches Heidegger's notion of dwelling in important ways by adding to "learning to dwell" the need to learn to navigate the realities of hostility as well as welcome. Additionally, Derrida's "hostipitality" challenges Bauman's binary, rooted in economics, of the (welcome) tourist and (unwelcome) vagabond "life strategies" or identities that significantly impact an individual's levels of choice regarding mobility and what kinds of home(s) can be claimed or bought. While Bauman's binary is useful on its own as a means of discussing global mobility and inequality, Derrida's notion of "hostipitality" develops a rich middle space that can illuminate the ways that the tourists' privilege can also restrict their sense of welcome to purely instrumental economic transactions, while the lack of privilege of the vagabond might still generate forms of social welcome for these "flawed" consumers. Bauman's insights on global privilege, consumerism, and the flows of liquid modernity helped me to investigate the complexities of commitments to home in the twentieth and twenty-first century, and by tracing the way two films relate the notion of "hostipitality" to the increasing flows of late capitalism, I seek to demonstrate that poetic dwelling in liquid modernity is possible not because globalization makes the world more "open" or "hospitable" but because, as my analysis will show, an understanding of home as multi-scalar and defined by "hostipitality" allows home-makers to navigate and even reconfigure the uncomfortable, "bitter" aspects of what has been mythologized and commodified as "home sweet home."

Derrida's understanding of hospitality is vital to the new conception of home that I argue 
cultural texts showing as a labyrinthine, multi-scalar map based on personal, interpersonal, and social relations that is radically marked by experiences of hospitality and hostility. After fleshing out the significance of Derrida's work in this area, in the final two chapters of this dissertation, I will unpack the nuanced relationships between welcome and hostility in the possibilities of liquid modern poetic dwelling in my analysis of two films that not only challenge stock conceptions of outsiders and guests but also critique the ways in which the publicly enacted social norms of hospitality can veil very different private experiences of being (un)welcome in a "new" or "old" home. Lars von Trier's Dogville (2003) and Wolfgang Becker's Good Bye, Lenin! (2003) illuminate the ways in which mobility, technology, and consumerism have dramatically altered the forms and "values" of hospitality as well as the ways in which hospitality marks home-making as a distinctly inclusive or exclusive endeavour. I will show how the two films take up his questions and help to further develop insights into some of the possible ways of conceiving of the ideal home in relation to agency, power and ethics at the present time.

\section{Introduction: deconstructing hospitality}

The notion of welcome - of an implied comfort, security, and stability — is crucial to an understanding of the idea of home, particularly if home is understood as an idea that can foster poetic dwelling in spite of this reality. Yet, like home, hospitality is increasingly a superficial construct, a gesture or symbol of intentions, generosity, or obligations. ${ }^{36}$ For instance, the

${ }^{36}$ In 2011 a new journal, Hospitality \& Society, was launched in order to address "a missed opportunity to infuse hospitality studies with critical significance and to bring the concept of hospitality to bear on some of the most pressing social, cultural and political questions of our time" (Lynch et al. 3). The editors mention Derrida's work in their introductory editorial and delve into the concept by describing disciplinary definitions and approaches that are diverse and include sacred obligations, etiquette, cultural forms, technology (Internet "hosting"), citizenship, and 
expression "make yourself at home" suggests welcome as a feeling of comfort, while veiling what is implicit: "make yourself at home in $m y$ home" with the secondary condition that "you" cannot make this your home. There are many examples of perverse hospitality—from the story of the Cyclops in Homer's Odyssey to the tale of Hansel and Gretel recorded by the Brothers Grimm to classic and contemporary horror films with a haunted house motif—but Derrida's work goes beyond foregrounding the dangers that underlie hospitality or a false hospitality. I argue that an understanding of his "hostipitality" can help shape how we conceive of not only host and guest categories, but the notion of home itself.

Derrida's sense of hostile hospitality, or "hostipitality," focuses on the contradictions that influence how home is made, claimed, or denied and it is these points of tension that I want to focus on as I continue to explore the social nuances of the process of "building" and "learning to dwell" in the decidedly labyrinthine networks and home spaces of liquid modernity. In Of Hospitality Derrida proclaims that "the problem of hospitality $[\ldots]$ is always about answering for a dwelling place, for one's identity, one's space, one's limits, for the ethos as abode, habitation, house, hearth, family, home" (149-150). This claim translates Heidegger's notion of dwelling into a social context, positing hospitality as the means through which individuals can be home-makers, not as solitary thinkers but as members of the households, communities, and societies in which they give or receive and deny or are denied various forms of welcome. In this section, I explore the complex and contradictory process of deconstruction and the dual views of hospitality as alternately economic or ethical in order to suggest that deconstructing rather than simply critiquing the commodification of hospitality is essential to rethinking home as a multi-scalar construct amidst

human rights. One of their key findings, however, is that the discourse is dominated by business studies and the hospitality industry's concerns of providing food, drink, and shelter. Consequently, hospitality is all too often reduced to economics, with the terms "host" and "guest" describing economic agents who participate in commercial exchanges of commodities and services. 
increased mobility and consumerism.

In "What is Deconstruction?" Nicholas Royle suggests a less traditional but very useful definition of deconstruction: "not what you think: the experience of the impossible: what remains to be thought: a logic of destabilization always already on the move in 'things themselves': what makes every identity at once itself and different from itself: a logic of spectrality: a theoretical and practical parasitism or virology: what is happening today in what is called society, politics, diplomacy, economics, historical reality, and so on: the opening of the future itself' (11). Royle reveals that the last phrase comes from Derrida and "the opening of the future" signals the forward-looking nature of deconstruction — of taking apart past understandings in order to find new potential in the ways that they can be destabilized and reconfigured. It is this aspect of deconstruction that is particularly salient for my analysis of the notion of home. Earlier I demonstrated how the idea of home cannot be excavated or recovered from past iterations and myths. Even with his criticism of liquid modernity, Bauman rejects such an idea, and in chapter five, I argued that M. Night Shyamalan's The Village illustrates the problems of a backwards-looking impulse that stems from the nostalgia of home. Accordingly, I sought to theorize new means of home-making which suggest "the opening of the future," particularly through the "complex maps" of home that Nicolas Dickner narrativizes for his protagonists in Nikolski. In these final three chapters, I want to use the deconstruction of hospitality as a means to further illuminate the ways that mobility and stability are mediated by the complex hostilities and welcomes that shape notions of home, identity, and belonging.

Deconstruction describes a "tension with the unpredictable and unforeseeable" (Royle 4), yet it is well suited for rethinking home amidst the uncertainty and insecurity that for Bauman is so central to the cultural and socio-economic reality of liquid modernity because it problematizes a 
"solid" vision or template of home. Because deconstruction seeks out a "reinscription or transformation of the basis on which the opposition functioned in the first place" (5), an understanding of what can and cannot be home through forms of (un)welcome has much to gain from the practice of deconstruction. Jonathan Culler, in his preface to the 25th anniversary edition of On Deconstruction, describes the deconstruction of texts as "a teasing out of their warring forces of signification and an interrogation of the pieties and principals that these texts insightfully engage" (np), and this is the approach that I take. The "pieties and principals" of generous hospitality and comfortable home are unmasked as I treat these films as complex negotiations of passive and active home-makers and "unsettled" homes. Similarly, Mark Wigley claims that deconstruction "is an appropriation of structures that identifies structural flaws, cracks in the construction that have been systematically disguised, not to collapse those structures but, on the contrary, to demonstrate the extent to which the structures depend on both these flaws and the way in which they are disguised" (42). The hostile side of hospitality is precisely such a flaw or crack that importantly defines the welcome of not only unknown strangers and known neighbours but every home-maker.

Derrida was greatly influenced by the work of Emmanuel Levinas and suggested that with Totality and Infinity Levinas "bequeaths to us an immense treatise of hospitality" (Adieu to Emmanuel Levinas 21, original emphasis). Yet, rather than privilege the "other" as Levinas does, or privilege the "self" as Heidegger does, Derrida mediates the approaches of these two important philosophers in a way that relates the self and the other through the impossibility of absolute hospitality — one cannot offer the other unconditional welcome without asking for anything in return or suggesting stipulations - which can, however, function within the constraints of everyday life as a potential balance of sharing with others and also protecting oneself in order to be able to 
share with others in the future. Because Heidegger frames his concerns in relation to the individual dweller, Derrida's emphasis on ethics offers an important supplement - a focus on the self that includes the other in the process of learning to dwell. ${ }^{37}$ So, while Heidegger's work offers philosophical insights on ideas that are "other than ethics," I take the time in this chapter to consider the ethics of what Heidegger terms dwelling through Derrida's work on hospitality.

For Derrida, hospitality is an aporia, a paradox or puzzle that cannot be solved and necessitates doubt. In On Cosmopolitanism and Forgiveness he calls the unconditional and conditional understandings of an aporia "irreconcilable but indissociable" (45), because if we only forgave the forgivable, then the idea of forgiveness, for instance, would lose meaning. The notion of hospitality would similarly unravel if welcome was extended only to "insiders"-from within the household, homeland, and so on-who are already welcome. Derrida elaborates on two of the rights that hospitality signifies: "the right of a guest to be entertained," which is given by hosts, and "a right of resort," which is a basic human right because people are inherently "entitled to present themselves in the society of others by virtue of their right to communal possession of the earth's surface" ("Hostipitality" 5, original emphasis). The latter idea suggests the underlining ethical claim of home-making as a practice made possible through the right of resort, a shared right to be at home in the world. However, the politics of welcome increasingly obscure this right by naturalizing a stable division of hosts and guests that are characterized as home-makers and interlopers, respectively. When hospitality is understood as an aporia — as "hostipitality" — the categories of hosts and guests prove to be neither natural nor stable but intertwined in contentious power relations, complex economies of quantifiable and incalculable mutuality as well as overt and

${ }^{37}$ Christina Howells suggests that "Derrida considers Levinas to be wrong in his belief that Heidegger subordinates ethics to ontology" (126), calling "Heidegger's attempt to 'think the Being of beings' [....] other than ethics, but not a subordination of ethics; rather, Derrida argues, ethics would be impossible without it, for it conditions respect for the other as other" (126-7). 
covert hostilities.

\section{Critical issue 1: designating "guests"}

Derrida's view of hospitality suggests a dynamic and intricate relation between the host and guest, and sheds light on the complex maps through which home-makers can integrate divergent experiences of home — of being welcomed and being able to extend welcome (or not). In this section, I investigate the political and increasing economic inflections of the ideas of hosts and guests and what "giving place," as Derrida terms it, might entail for "foreigners" as well as "locals." Hospitality includes the possibilities of a host or guest shifting into the roles of hostage or parasite, and a partial inversion that Derrida emphasizes is if " $[\mathrm{t}]$ he one inviting becomes almost the hostage of the one invited, of the guest, the hostage of the one he receives, the one who keeps him at home" ("Hostipitality" 9). The host, then, is not necessarily immobile or in full control of the physical and social space, while the guest is not without agency even while at the mercy of the host. ${ }^{38}$ Derrida's description of a parasite as "a guest who is wrong, illegitimate, clandestine, liable to expulsion or arrest" (Of Hospitality 61) suggests danger and violation, which also underscore the tensions inherent to "hostipitality" and notions of home. Drawing on the linked etymology of hospitality and hostility, Michael Marais even suggests that in some cases a "host becomes a hostis, that is, a stranger, unto herself" (276), and such a dramatic transformation highlights the consequences of figurative homelessness if a home-maker, without an anchor, is unable to dwell and construct home. The texts that I analyze in the next two chapters explore the host/guest binary through a range hospitalities. For example, the residents of Dogville leech off Grace's free labour

38 In Politicizing Ethics in International Relations: Cosmopolitanism as Hospitality, Gideon Baker examines inhospitable guests in his discussion of colonizers and conquerors and offers new insights into the notion of hostile hospitality. 
and can be seen as parasitical hosts, while Alex usurps his mother's role as host in their home, making her a quasi-hostage.

Derrida distinguishes between the impossible ideal of "absolute hospitality," and hospitality as a practice of selfless sharing of one's person, one's space, and everything that this encompasses. Unlike its absolute form, hospitality as a practice is understood as conditional, yet the social practice of hospitality can and should strive towards aspects of the "absolute" welcome of both self and other. In Of Hospitality, Derrida describes absolute hospitality as "open[ing] up my home...to the absolute, unknown, anonymous other, and that I give place to them" (25, original emphasis). His idea of "giving place" is important to my understanding of home since belonging extends beyond tangible claims, and "giving" place suggests relations marked by welcome and inclusion, an incalculable relation between people who may be hosts or guests for a time but are all home-makers as well. Although Derrida calls home that "which makes hospitality possible," he also underscores "the violation or impossibility of home" (Of Hospitality 65). The contrast between exchanges based on giving, on one hand, and violating, on the other, is my focus in analyzing the ways in which characters are made to feel "home safe" or "under house arrest" in both Dogville and Good Bye, Lenin!. Rhetorical games and local propaganda can veil the superficial or deeply hostile realities of "giving" hostipitality, and the hospitality that is initially presented in the films as "giving place" works to conceal a conceptual and physical violation. Yet, as both films demonstrate, through dramatic failure in Dogville and a complicated success in Good Bye, Lenin!, an understanding of "hostipitality" can ease this tension since Derrida's amalgamated term sustains contradictory and shifting roles for "hosts" and "guests."

Von Trier's and Becker's films show ways in which a sense of "hostipitality" can also undermine the cultural and national myths about hospitality through a political rhetoric that 
predetermines whose and what kinds of welcome are to be expected and encouraged. In Postcolonial Hospitality Mireille Rosello examines the conception of immigrants as guests and argues that it is "surprising that the metaphor of hospitality should seem so appropriate: does someone who works for a private corporation today feel as though he or she is a 'guest' of the firm?” (9). What Rosello underlines here is how the idealized conceptions of the relationship between states and people who enter them conceal the instrumentalizing terms of their relationship, even when these terms are very familiar under capitalism's cultural logic. Rosello points out how, when the related concepts of parasitism are invoked under this same banner, the hostilities underlying such a conception of immigration become more readily apparent. Importantly, Rosello also suggests the need for conceptualizing new forms of hospitality, arguing that "ideally, the proliferation of new types of journey should correspond to different types of hospitality: migrants, the members of diasporas, jet-setters, business travelers, refugees, asylum seekers, commuters, tourists, delocalized workers, powerful and powerless travelers, all need to receive or grant hospitality" (vii), and these are all elements for which my work seeks to account.

An emphasis on the vacillating nature of (both giving and receiving) welcome also facilitates an understanding of home as a dynamic identity anchor that changes not only when a home-maker physically moves but continually on account of larger flows and shifts in the social norms of welcome. Jennie Germann Molz and Sarah Gibson’s volume, Mobilizing Hospitality, focuses on literal and figurative mobilization because "the contemporary global condition is perhaps best understood through metaphors of scapes, flux, flow, mobility and liquidity" (1). Building their case through the compelling terminology of Arjun Appadurai, Manuel Castells, John Urry, and Bauman, the editors come to the same conclusion as Rosello: "[ $\mathrm{t}]$ he plethora of different journeys in today's mobile world has thus led to a diversity of hospitalites" (2). What interests me 
most about this approach to the question of hospitality is that the scope of the volume includes chapters on backpacking and couch surfing as well as the Internet and commercial tourism. This focus on different forms of mobility helps Molz and Gibson gesture towards rethinking home in an era that produces so many new hospitalities. They claim that "what constitutes home depends very much on the way hospitality is imagined, performed, offered, or denied" (11).

I argue that Derrida's concept of "hostipitality" offers a cogent lens through which to conceive of home as not only shaped by experiences of welcome and hostility but also, as my analysis demonstrates, that how we imagine home can in turn shape what Rosello as well as Molz and Gibson insist are diverse forms of hospitality. The multi-scalar notion of home, I suggest, mitigates the potential duplicity of hospitality as an increasingly economic and political social practice (a public welcome that masks private rejection) while facilitating an understanding of "hostipitality" - not necessarily hostile but potentially so through the power relations that are always involved in "giving" place and being welcomed.

While Molz and Gibson gesture towards the sense that the host/guest relation occurs in equally important mundane ways on a regular basis within, around, and away from home, this is often missing in the emerging discourse on hospitality. These relations occur between the "native-born" or self-proclaimed local, the legal or illegal alien (to use American terminology), as well as the unhomed, exiled, or nomadic home-maker. Mustafa Dikeç's claim that hosts and guests not only change but "are held in tension" (237) points to an ongoing process rather than isolated events, and this is a fruitful way of framing the binary. Although Dikeç concerns himself with larger scales of national discourses, this observation is relevant to experiences on smaller scales since every time a "new" person comes or goes, to whatever extent they are perceived as foreign (from a different neighbourhood, town, coast, or country) and every time someone is invited into a 
home, forms of hospitality take place. Dikeç highlights the larger impact of such meaningful yet mundane nuances when he claims that "[h]ospitality is not about the rules of stay being conditioned by a duality of host and guest with unequal power relations leading to domination; it is about a recognition that we are hosts and guests at the same time in multiple and shifting ways" (239). According to Dikeç, Derrida proposes an understanding of the two identities as "mutually constitutive of each other" (239), and this mutually constitutive aspect of the welcoming/welcomed dynamic forms the core of the social scale of my understanding of home as an idea defined by mobility and stability, with home-makers who are hosts and guests.

\section{Critical issue 2: the scales and politics of home}

As I discussed in the previous section, "hostipitality" reframes the categories of host (owner/nation) and guest (non-owner/immigrant) from a clear opposition to categories which are mutually constructed — even potentially destructive because of their deep link—and, in this section, I turn to the broader implications of conventional associations of home-makers as home-owners and hosts, while home is categorized as primarily and predominantly a private space that is individually constructed and privately owned. As Derrida's work suggests and I will show in my analysis of the films, social norms and the public sphere cannot be restricted to social and political discourses about a region or "homeland," because the social scale of home is not only regional or national but a pervasive part of the idea on all scales through the various forms of formal and informal welcome that occur on and between them. In proposing a multi-scalar understanding of home, I suggest that home (as household, hometown, homeland, and amalgam of geocultural scales) mediates and integrates private and communal experiences of welcome and hostility. 
In addition to blurring categories of guests and hosts, "hostipitality" facilitates a way of thinking about various other binaries that are important to an understanding of home as both mobile and stable across multiple scales. These binaries include several that Judith Still suggests, such as "those between self and other, private and public, inside and outside, individual and collective, personal and political, emotional and rational, generous and economic - these couples that overlap each other's territory without any one exactly mapping another" (4). The metaphor of mapping that Still uses offers a way to consider such binaries in new, interrelated ways. The relations between these categories then take precedence over their delineations or presumed stabilities: the self and other are co-determined, the private influences the public and vice versa, and "hostipitality" can be mapped between and over the generous and economic because although it is often presumed to be either-a generous social practice or economic service—Derrida demonstrates that this idea is much more than an act of welcoming or commodifying welcome. Derrida uses deconstruction in order to illuminate the ways in which conventional associations limit how we make meaning and internalize cultural norms. In the case of hospitality, connotations of the self, private, inside, individual, personal, emotional, and generous hospitality have obscured the important roles of the other, public, outside, collective, political, rational, and economic all of which frequently veil hostility when discriminatory social norms have been used to justify this other side of hospitality, especially in relation to categories such as class, race, gender, and sexuality. Guest workers selectively or temporarily welcomed in foreign countries, residents deemed unsuitable for quasi-gated communities, and individuals rejected from or oppressed within households, all offer examples of the complexity that Derrida foregrounds in proposing "hostipitality."

Derrida specifies that "the phenomena that interest [him] are precisely those that blur these 
boundaries, cross them, and make their historical artifice appear" (Monolingualism 9), and the value of Derrida's work to my argument is that he not only seeks to show the artifice of boundaries but uncover new ways of thinking about the ideas that these boundaries seek to contain. When Derrida finds it difficult to slot himself into a linguistic and regional "identity," he asks, "What taxonomy should I invent?" (Monolingualism 13), and I argue that the films which I will analyze similarly suggest new taxonomies for home and hospitality. In my analysis, I show how both films not only incisively demonstrate the artifice of a private and public divide for hospitality and home, but von Trier and Becker also suggest the need to seek new ways of thinking between or beyond the binary, and Becker even depicts a multi-scalar approach. The need for "invented" taxonomies that Derrida suggests can be extended from speakers to dwellers as a crucial feature of the multi-scalar home that conventional, static iterations of home cannot accommodate. I have argued in previous chapters that the multi-scalar home is labyrinthine (chapters two and three) and cannot be pinpointed but needs to be mapped (chapters five and six), and in the next chapters I demonstrate that this conception of home can incorporate conventional as well as "invented" taxonomies. In doing so, the multi-scalar home affords home-makers flexible ways of navigating and integrating the locations, regions, groups, and other customary social categories that relate to home in a liquid modern era of re-mediation, hybridities, flows, and flux.

I turn now to two additional ideas which seek to work within the private/communal and hostile/hospitable binaries and, in doing so, demonstrate the significance of the political stakes of home through its social construction. These ideas are Tyson Lewis and Daniel Cho's notion of the "dirty" home as a collective construct that can remedy the alienating effects of understanding home as private property in late capitalism, and bell hook's notion of "homeplace," which suggests an even more fruitful means of resisting oppressive social norms and dehumanizing practices by 
constructing home in order to reclaim subjectivity.

The crossing or blurring of boundaries that Derrida suggests in his deconstruction of hospitality illuminates Lewis and Cho's concept of the "dirty" home, an idea that seeks to undermine the conventional, idyllic "purity" of home. Lewis and Cho base their concept on Frederic Jameson's application of the literary idea of "dirty realism" to architecture and space. According to Jameson, "dirty" in this sense signifies "a collective built space, in which the opposition between inside and outside is annulled" (The Seeds of Time 155), and this emphasis on annulling distinctions of inside/outside and private/public is a way in which the notion of the "dirty" home gestures towards Derrida's conception of "hostipitality." The "dirty" home is individually as well as collectively constructed and mediates fantastic expectations (Utopian welcome) and horrific fears (violent hostility) which Lewis and Cho attribute to the alienation that results from the ownership of home spaces in late capitalism. They offer an interesting argument that speaks to a very specific conception of home since their economic focus limits home-makers to home-owners. They argue that as private property, "home seems now to be a useless cultural artifact that no longer contains any semblance of a political motive; it has been sanitized of politics" (81), and this claim speaks to some of the issues that I examined in chapter four in my analysis of Bauman's work on tourists, vagabonds, and consumerism in liquid modernity —in other words, economics "sanitizes" the politics of home by transforming home into a "liquid" asset which is sold as part of a business transaction, an understanding that obscures, as Bauman or Derrida suggest, a political practice that "tourists" or "hosts" can participate in and "vagabonds" or "guests" are restricted from. Ultimately, the alternative that Lewis and Cho offer addresses the tourist's or host's alienation from home without considering the home-makers who are not home-owners. Yet, in spite of their narrow critique, Lewis and Cho do emphasize politics, arguing 
that rather than an owned physical space that constructs individual identity through its materiality, "if the home were made into a space for collective identity, then it may serve as a place for political struggle" (71). In order to examine the idea of political struggle — what Lewis and Cho examine as a potential for a "bourgeois home" (87) - I next turn to the work of bell hooks, who offers a more deliberate articulation of the political struggle that can and, in fact, has been fostered in the past through the construction and cultivation of the idea of home.

By focusing on the hostile aspects of hospitality, Derrida is formulating a means of countering hostility by acknowledging and understanding rather than ignoring or submitting to it, and this approach is incisively illustrated by bell hooks in her association between home and resistance. In "Homeplace: a site of resistance," hooks explores "that feeling of safety, of arrival, of homecoming" (41), which she associated with coming to her grandmother's house but did not generally feel as a girl because of the hostilities of racism. For hooks, "a homeplace, however fragile and tenuous" (42) includes the potential of "recover[ing] ourselves" (43) even amidst oppression. She contends that black women could resist in and through the "homeplace" by "making homes where all black people could strive to be subjects, not objects" (42). Such a view enriches Heidegger's concept of dwelling by demonstrating that home-making is not only a human essence but an essence which dehumanizing forces and circumstances may seek to suppress but cannot destroy. In describing how her mother sought to counter a culture of white supremacy, by cultivating a "homeplace" that "affirmed our beings" (46), hooks offers a vivid example of how the "private" home importantly relates to the "public" sphere in the very ways that such a "homeplace" can both resist and work to change inhospitable social norms and hostile ideologies.

Together, "hostipitality," the "dirty" home, and "homeplace" suggest diverse ways of reconfiguring home and "inventing" taxonomies of home which, instead of standardizing a 
template, support the "building" or "mapping" of multi-scalar physical and conceptual dwelling that can reflect and inform a home-maker's dynamic self-concept and social identity. In a time when global media increasingly infiltrates the home space and the public flows "inside," the notion that the home can cultivate ideas that resist and impact social norms "outside" is a vital example of the porous nature of the public/private distinction and the socio-political implications of ideas of home. The relation of public and private that home mediates makes the notion of home an important site of maintaining or modifying individual as well as group identity. Moreover, the idea of resistance through the construction of home infuses politics into the "dirty" home and recovers the idea of home for hostages and guests alike, as the female leads in Dogville and Good Bye, Lenin! exemplify in quite different yet profound ways. In their films, von Trier and Becker depict the impact of the artificial opposition of private and public on social relations by showing seemingly isolated home spaces locked in a rhetoric of "us" (insiders) versus "them" (outsiders), only to dismantle these divisions by exposing the shifting nature of such seemingly rigid labels and the permeable nature of home: distinctions between inside and outside blur, the public invades and shapes the private, and the private similarly reshapes public spaces, practices, and ideas.

\section{Conclusion: recovering home through "hostipitality"}

Derrida's notion of "hostipitality" importantly insinuates economic self-interest, political strategies, and human caprice into what is usually perceived as a noble practice. Even though hospitality is often framed as something essentially positive through links to generosity or good will, Derrida draws our attention to the far-reaching social implications of a mundane practice that is marked by need and greed, as well as the potential for mutuality. What makes Derrida's idea particularly compelling is the way in which he evaluates but does not overstate the economic shift 
of commodified or calculated hospitality: "This is the double law of hospitality: to calculate the risks, yes, but without closing the door on the incalculable, that is, on the future and the foreigner" (“The Principle of Hospitality" 6). The duality of economic and ethical, or "calculated" and "incalculable," concerns that he points out serves to foreground the differences between rhetoric and the practical effects of how hospitality is enacted, especially in the context of economic globalization. For instance, while markets seem to function "without borders," there are large numbers of people more commonly confined by those same borders, yet the former fact obscures the latter when globalization is discussed. ${ }^{39}$ I suggest that Derrida's view of hospitality transforms a conventional view of the material home with a host who owns and controls "his castle"- however large or small — into a concept that always refers to "dirty space" because it is constructed privately but also by external forces and home-makers who fluctuate in the roles of hosts and guests on multiple scales.

The notion of incurring a debt for hospitality and being welcome commodifies hospitality in ways that change the nature and impact of the practice. In Economy of the Unlost, Anne Carson suggests that "[c]ommodification marks a radical moment in the history of humanity. People who use money seem to form different relationships with one another and with objects than people who do not" (17). Even when money does not change hands, von Trier and Becker show that analogous modes of calculating what is owed through time and effort also significantly change relations. Carson elaborates that a commodity "is a quantity of value that can be measured against or substituted for other such quantities" (18) and this definition echoes Heidegger's critiques of calculative or technological thinking and the ways in which the ease of substituting diminishes the meaning of objects and ideas. Unlike a physical structure, home and the welcome that the notion

39 Scholars, including Bauman and Rosello, have offered broader critiques of this disconnect. 
implies is inextricably altered when quantified. Bauman's claims regarding liquid modern commitment avoidance and Derrida's insistence that hospitality be understood as more than a calculated political or commercial act, propose a challenge of rethinking the ethical responsibilities of social relations, not by looking back on views of commitment and hospitality in the past but to seek new ways of conceptualizing both—ways the literary and cinematic texts that I have studied suggest might include mapping commitments in an inclusive understanding of welcome that does not privilege the subject position of a distinct, economically and politically defined "host."

Bauman argues that liquid modernity nurtures not only flows and fluidity but also consumer culture and the convenience or disposability of modern commodification, and such commodification, I suggest, produces a sense of home which includes only an initial feeling of welcome (through the invitation to buy). Its material dimensions increasingly mark home as a marketable object, the hospitality industry seeks to commodify the intangible aspects of home, and in these cultural and socio-economic conditions "[h]osts are reconfigured as proprietors, guests as customers, houses as restaurants and hotels" (Shryock, "Thinking about Hospitality" 415). An economic view of hosts and guests is critiqued by von Trier and Becker through the ways in which both directors foreground the impossibility of fiscally valuing the ethical forms of hospitality. In Dogville, Grace can never seem to "pay back" the townspeople and, in Good Bye, Lenin!, Alex feels that he can never go far enough to pay off a debt to his mother for protecting his childhood at her own personal cost. These debts seem to come with compounded and rising interest rates, which might makes sense in an economic conception of hospitality but is shown by both filmmakers as directly opposed to an ethical understanding of the term. In an ethical view, literal reciprocity and debt cannot be quantitative but, rather, the "welcome" that the two female protagonists of the films 
receive (Grace in the new town and Christiane in her own home) raise questions about quality of life rather than quantifiable debts.

Derrida distills the importance of thinking about mobility and the experiences of welcome that it generates by reminding us that "there is no culture or social bond without a principle of hospitality" ("The Principle of Hospitality" 6). The ever-presence of hospitality in various forms is a reason why understanding its hostile dimensions and their effects on quality of life are crucial. Suggesting that the (un)familiar essence of hostipitality continually re-emerges through our contact in and beyond the home, Derrida posits "the other as the nearest neighbour," and embraces the paradox as "[u]nheimlich" (Monolingualism 37). This claim regarding distance within proximity and vice versa describes the "dirty" home which enmeshes the private and public dimensions of home. Similarly, reiterations of hospitality as "togetherness" that have been culturally inscribed through rituals and familiar images "also open up the possibility of doing togetherness differently_ of imagining inside and outside, stranger and friend, self and other, host and guest in new, radical and potentially dangerous ways" (Lynch et al. 14). The element of danger is vital to "hostipitality" since it suggests both risks and benefits, which Derrida claims hospitality cannot guarantee mitigating or increasing, respectively. Ultimately, the possibilities and overtones of hostility in "hostipitality" describe the relations that occur in "dirty spaces" and mark the notion of the multi-scalar home.

Lewis and Cho suggest the notion of the "dirty" home in an analysis of the fantastic and horror genres because these often frame home as an ideal or the opposite, respectively, and the narratives of home that I analyze in the following chapters innovatively employ more mundane forms of fantasy (creating fake newscasts about a kind of socialism that never existed) or all too common horrors (Grace's abuse). The characters in the films learn to recognize their agency in the 
process of learning to dwell and the requisite agency in helping to "build" rather than "buy" or "buy into" others' delineations of home. Such agency is most evident in Grace's eventual rejection of a town that she had adamantly hoped would epitomize home but also in the fact that Christiane's final days are spent in a home that her son finally recognizes as hers rather than something fully within his control. In both films, ideals of safety seamlessly transition into representations of a prison-like home in ways that illustrate the workings of "hostipitality." Each work also articulates and visualizes aspects of the "dirty" home in all of its privately-public horror and glory. Depictions of the "dirty" home—which include Grace's positive and negative experiences in Dogville as well as the city of Georgetown, and Alex's various Berlins (East, West, unified, as well as a re-imagined East) — exemplify the polyvalent nature of home as an identity anchor. The films, in short, reveal the process of learning to dwell as something that must occur as a part of a home marked by "hostipitality" rather than in distinctly positive or negative extremes. As these two films and the other works I have analyzed show, a home-maker not only experiences a multi-scalar home but also continually learns to integrate the scales by "giving" and violating place while conceptually "building" and mapping a sense of home.

In "Hostipitality" Derrida points out the breadth of issues implicated by "the historical, ethical, juridical, political, and economic questions of hospitality" (3), yet after outlining the far-reaching concerns that impact "questions" of hospitality, he offers the disquieting answer that, we, in fact, "do not know what hospitality is" (6). This bold statement is not an accusation but a way to stress that "hospitality is not a concept which lends itself to objective knowledge" (7). The difficulty in discussing this concept in concrete ways - much like the idea of home-is where creative works come in, offering windows into subjective experiences that range from blatant hostility to conditional but welcoming hospitality. As Heidegger argues, we do not merely build 
dams or find acceptable caves; dwelling makes us human because we emotionally invest in places and, through them, engage with the world. Both of the films that I turn to in the following chapters centre on the right of their protagonists to be at home and question other characters' rights to the same only when they impede the protagonist's home-making by feigning welcome or abusing their power in "giving" place. What these films cogently demonstrate is that home cannot be neutral, even when its myths and conventional imagery reiterate a comfortable, convenient, and consumable idea. In illustrating many of the paradoxes of Derrida's understanding of hospitality, each film affirms a home-maker's agency in rejecting not only dominant views that may not reflect their reality but also the domination of others and ideologies which reiterate a homogeneous vision of home space, hometown, and homeland. 


\section{Chapter 8: Welcome as house arrest in Lars von Trier's Dogville}

Written and directed by Lars von Trier, Dogville was released in 2003 following the Danish filmmaker's success with Dancer in the Dark (2000) and planned as part of a trilogy titled "Land of Opportunities" which so far has only included the sequel Manderlay (2005). Dogville is frequently categorized by critics as a European critique of American self-indulgence or, more broadly, a scathing picture of human hypocrisy, but my interest in the film stems from the way in which von Trier depicts hospitality and why it fails to produce a cogent understanding of home. Dogville, like the other texts I treat here, is a work about the possibilities of "making" home as well as impeding the construction of a notion of home, and von Trier demonstrates the impossibility of home-making if home is understood as a static thing to which only a select group of people have the right. In Dogville the role of the conceptually homeless vagabond figure belongs to Grace. Like Johnny Truant in House of Leaves and the children in The Village, who represent ignorant outsiders or victimized innocents, Grace represents an outsider who contends with feelings of being unworthy of "building" her own idea of home and allows others to dictate in what ways and to what extent she can feel at home. In Danielewski's book, Johnny's tragic childhood leads him to believe that a sense of home is beyond his means. In Shyamalan's film, the Covington Woods second generation blindly trusts the elders to keep defining home. Grace does both, feeling unworthy of home while trusting the residents of middle-of-nowhere Dogville to decide when and how she might be at home in their town.

By presenting an allegory about the politics and power relations of hosts, guests, and the social norms of claiming home, von Trier's Dogville challenges the notion that good intentions and 
generous gestures compensate for the rejection and dehumanization of a feigned or duplicitous hospitality. Grace, a young woman, flees the city of Georgetown and arrives in Dogville, an isolated town, where she is offered shelter but at an ever rising price. Under the guise of welcome and protection, the townspeople manipulate and abuse her, until they finally betray her by contacting the gangsters from whom she ran. But Grace is revealed to be a mobster heiress, and in the final scenes of the film, she orders the complete destruction of her "hospitable" captors and their town. The isolated setting of the film bears a thematic link to Shyamalan's The Village, yet the community in von Trier's film is more open to outsiders in as much as their isolation is geographic, with mountains obstructing transit, rather than perimeter walls offering concealment. Yet, Dogville is also a kind of Covington Woods through the power of its de facto elders-the economic elite of the depression-era town, including a retired doctor, his ambitious son, and the owner of the only shop. Von Trier is even more overtly critical of the hypocrisy of these "elders" than Shyamalan is, going further to challenge communitarianism and myths of communal harmony. He also undermines Grace's assumptions of "small town values" as being morally superior to those found in urban spaces, and through his depiction of hostility and hospitality invites us to rethink the rampant blurring of ethical and financial "values" at the turn of the century.

There is an extensive body of scholarship and popular writing on von Trier, his films, his manifestos about filmmaking, and even Dogville itself. Books on von Trier include The Cinema of Lars von Trier: Authenticity and Artifice by Caroline Bainbridge (2007) and Lars von Trier by Linda Badley (2010), while the fifth volume of the Dekalog series, On Dogville, edited by Sara Fortuna and Laura Scuriatti (2012), offers a collection of articles about Dogville. Articles on the film take varied approaches to the work and focus on diverse themes, such as integrity (de Gaynesford), arrogance (Fortuna), the gift (Nobus), and religious questions of salvation and 
sacrifice (Mandolfo) or hospitality (Bradatan). Some scholars make a point to counter anti-American readings of the film by suggesting that it is actually about a disappointed love of America (Elbeshlawy), or claiming that "Grace embodies a non-personal entity" and thus the film "relates the workings of this entity in a completely abstract and general situation" (Dell'Aversano 68), or proposing that Dogville is depicting neither American nor universal conditions but actually "relat[ing] the identity of European audiences" (Staat 84). Although Dogville is distinctly embedded in American and European culture, I focus on the overarching questions that von Trier poses about home and the decisions to "defend" it, particularly when it may not be under threat. The film investigates these questions through the actions of the people of Dogville, who believe that they are protecting themselves and their home when they treat Grace first hesitantly, then condescendingly, and, finally, maliciously.

Late in the film, the narrator announces, "Dogville might be off the beaten track, but was hospitable nonetheless," and it is the film's powerful critique of this ideology that imbues naïve conceptions of home that I wish to uncover and further develop in dialogue with Derrida. Through Dogville, I argue, von Trier offers an allegorical exposition of welcome, by depicting the pretense, as well as the subtle and even violent violations of home that seem to lie outside of the scope of hospitality but are a part of what Derrida describes as "hostipitality." Dogville demonstrates how Derrida's more complex understanding of the aporias at the heart of the social relationships between host and guest or foreigner-in which the vectors of power and control can run both from host to guest, since the host must maintain some control over the guest but also must relinquish mastery and claims to ownership in order to be genuinely hospitable, and the guest similarly must abide by the host's rules for if they take over by force they too are rupturing the code of hospitality — might offer a more fruitful sense of the possibilities and limits of welcome for 
home-making on the social scale.

I have suggested that Derrida's work on "hostipitality" destabilizes the ideals of hospitality by replacing an understanding of this term as a simple gesture of generosity and kindness with a nuanced understanding of hospitality as a dynamic practice steeped in power relations, and Dogville depicts the importance of understanding these power relations since they can destroy the possibility of dwelling, as von Trier very literally depicts. The town is un-home-like and unwelcoming because a select group of people can redefine at will what "makes" a social space a home. An understanding of home as multi-scalar and marked by "hostipitality" and "dirty space" is distinctly outside of the scope of the dualistic worldviews that are maintained by the townspeople in the film, and von Trier uses the dualism to foreground problematic views regarding the "rules" of home-making — who can be at home when and where — and (hostile) hospitality today. In this chapter, I begin by examining the ways in which place is "given" (through welcome) and home is "violated" in the film, then move on to outline the simplistic sense of divisible public and private scales that the film in effect challenges, and conclude by demonstrating how the rigid view of home which the town represents is presented as untenable since no one is at home in Dogville.

\section{Public and private hospitality in Dogville}

Throughout Dogville, von Trier undermines the division between public and private that we typically take for granted. He does this by exposing the perverse conceptions of hospitality and home that upholding such a division fosters. For instance, the opening shot of the film captures the town from above and rather than rooftops or walls, buildings are distinctly outlined in white in the style of a floor plan. As a result of this set design, in the wide shots viewers literally see "through" the town, yet the transparency is misleading. After Grace is offered shelter in the abandoned mill, 
the townspeople diligently watch her through their invisible walls while she remains disinclined or wary of staring back. Grace represents the passive female object Laura Mulvey describes in her theory of the gaze: "the silent image of woman still tied to her place as bearer of meaning, not maker of meaning" (58). Often looking down or warily towards someone, Grace, as an outsider, is not allowed to "make" meaning or make a home as she awaits the townspeople's decision and approval. Brian Michael Goss offers a unique reading when he questions Grace's innocence by proposing that she feigns her idealism in order to improve her chances of getting protection from the townspeople. Goss seeks to "call into question whether Grace is as enamored with the town [...] or simply attempting to insinuate herself into it for the protection it affords" (137), and this reading is interesting in that it suggests for Grace the same kind of underhanded, private intent that the townspeople harbour along with a public story which proclaims good intentions and self-sacrifice. Yet, whether her innocence is performed or authentic, Grace only becomes a maker of meaning at the end of the film as the "un-maker" of this duplicitous home space. Her change in status is significant because it illustrates the shifts between hosts and guests that Derrida outlines, but only through inversion. The film's disastrous end demonstrates that notions of hospitality and home based on binaries cannot flourish: Grace goes from being powerless, chained guest/hostage to an all powerful, ruthless host, and, ultimately, no one can be at home in the town of Dogville.

In order to subvert the connotations of generosity and good will that the townspeople refer to but do not enact, von Trier charts the town's initial hesitant hospitality, its transformation into a hostile hotbed of abuse, and its end result as a scorched piece of land that may not be figuratively or literally hospitable to living organisms for some time. According to Linda Badley, "in starkly conceptual terms, [the film] presents identity as the subject's relation to community" (103, my emphasis), and I argue that such a relation is problematized by von Trier when he depicts identity 
both for the community of insiders and the lone outsider as something manufactured by the community through a kind of groupthink, or based on consensus and conformity. Although the film depicts a figuratively "dirty" home built on lies, this is not the "dirty" home that for Lewis and Cho includes the collectivism of Jameson's "dirty space" and the permeability of the public and private. The stark division that the residents maintain impedes a sense of home that is formative, capable of anchoring a sense of belonging, and a potential place in which we "recover ourselves" (hooks 43). Instead, Grace regresses, is put in her place whenever she begins to feel anchored in the town, and does not resist her oppressors until her vengeful retaliation at the end. All the while, the townspeople publicly insist that even in hard times their home is "sweet," and relegate their bitterness and anger to private moments of verbally and physically abusing Grace-moments which are then publicly ignored because the townspeople wish to seem publicly hospitable even if, privately, they become increasingly hostile.

Rather than being open, the town is full of open secrets as well as rigid social mores, and Grace's welcome is affirmed in words but not otherwise. From the very beginning of the film, von Trier exposes the town's rhetoric of hospitality as only intended to uphold the facade of public good will and forthrightness. Rather than being "good and honest" (in Tom's words), most residents are living private lies or open secrets, a pattern that foreshadows the duplicity of Grace's initial public welcome. An omniscient narrator explains, when Grace first arrives, that "she hadn't chosen Dogville from a map or sought out the township for a visit, yet Tom felt right away she belonged," and through a sense of belonging to a place that seems so open—seemingly "without walls" - von Trier lays the groundwork for the dualities and double standards that the residents, along with Grace, perpetuate in order to keep up the facade.

An example of this duality and disconnect between words and actions is the first resident to 
meet Grace. Tom is a writer who dreams of the prestige his works will garner but never actually writes more than two words, and instead operates as the orator or secular pastor for the town. Tom calls his rhetorical technique "illustration" even though he gives examples by talking instead of illustrating through actions. Dany Nobus observes that Tom's "illustrations" serve "to radically deny the possibility of provocation and to interpret every provocative occurrence [...] as a further illustration of what is already known," and the result is twofold: "that belief turns into conviction and that Dogville becomes ever more dogmatic in the affirmation (and acceptance) of its perfidious core" (35). This movement between belief, conviction, and dogma, I argue, is also highly pertinent to the film's articulation of "hostipitality." Tom's insistence on interpreting events and actions as illustrations of what is already known represents the kind of thinking that leads to static understandings of home within which there can be no dwelling. That the townspeople refuse to amend their conception no matter what changes they face or what promises they made only further reinforces the contagious power of this rigidity.

Other townspeople internalize lies about their place in the community in the hopes of being publicly acceptable and inadvertently supporting the dominant social structure of the community, which arrives at consensus through the threat of public exclusion. Ben, a truck driver, tells Grace, "I'm in the freight business - the road's my home" in order to explain the fact that he has no house in Dogville, only his truck's garage. Grace also visits Jack, a blind man who has an obsession with light and a rich vocabulary with which to describe it at different times of the day in order to compensate for his blindness, which everyone in town knows about. Even when Jack finally admits his blindness to Grace, he says, "So please go and let me be that on my own." Both Ben and Jack construct a private existence around their lack of engagement with the community as though this is their preference and not a form of ostracism. If Ben and Jack's experience of the community forces 
them to take measures to conceal what the town might consider shameful, others, like Tom or Vera and her husband are involved in the construction of the town's public sphere. These figures all put on deceptive public faces. Tom represents himself as a "doer" but he only talks about doing, and Vera and Chuck represent themselves as generous, genial hosts and employers even though both simmer with hatred and hostility. Grace, for her part, continually refrains from judging the residents' public personae and incompatible behaviour because, as a newcomer, she feels (and is reminded by residents) that she is not a "local" or "insider" and so has not been granted the privilege to judge them. These examples of private shame and public grandeur illustrate the perceived safety of the "private" as well as the social pressures of a public sphere and belonging to it, and the disconnect that Dogville highlights is important for the larger ethical questions that von Trier raises because even though everyone pretends to welcome Grace publicly, her new neighbours treat her with more and more hostility and contempt.

I argue that von Trier positions Grace as a generic home-maker, privileged in some ways but not in others, in order to depict her inability to learn to dwell in Dogville not because of her own initial naïveté or passivity but on account of the townspeople's Janus-faced dispositions and binary thinking, which Grace also takes up. Grace destabilizes the private and public or "us" and "them" divisions around which the townspeople function by reminding them of their promise of welcome when they abuse her. Scholars have described her "as a cinematic metaphor for an ironic god" (Bradatan 58), an avatar for the gift of the grace (Badley 107), as well as duplicitous (Goss 137). They have also spoken about her fall from grace, as she is dehumanized by being chained like the town dog (Chiesa 16) or objectified as she "is slowly rationalised and dismembered into a series of functions and tools" (Scuriatti 12). Together, this diversity of readings suggests a multifaceted, "everyman" quality that Grace possesses as a home-maker seeking to find her place in the world. 
The only certainty that von Trier offers at the end of the film is that while Dogville deeply affects how she conceptualizes home, she cannot be at home there. In the remaining sections of this chapter, I will explore in more detail the nuances of Grace's categorization as (perpetual) guest in Dogville, as well as the way in which the town's literally invisible walls maintain a problematically static and singular sense of home that is controlled by the leaders of the town and does not shift or evolve-not even when Grace herself usurps power.

\section{The issue of guests: "giving" Grace "place" (and keeping her in it)}

In the this section, I focus on Derrida's notion of "giving" place through the invitation of welcome as an ideal of hospitality and the violations of home that underlie the hostile aspects of hospitality in Dogville. I identify three levels of this relation that are depicted in the film: a deceptive rhetoric of welcome, the use of cheap labour as a symbolic gesture of thanks, and an outright disregard for human rights. In the film, each level feeds into the next as von Trier keeps the question of home trapped between the townspeople's insistence that they are "fully" at home and Grace's hope that she might one day be as well. The increasingly economic-based politics of belonging in Dogville redefine norms regarding obligations between people, predominantly through deeply entrenched distinctions between the "true" resident and guest. Grace's eventual re-emerging sense of agency clashes with the townspeople's selectively collective mentality, which was mercenary and self-serving but never acknowledged as such. The townspeople feel protected by their "insider" status, since they agree that Dogville is their rightful home, one that Grace is not allowed to or encouraged to claim. Grace, for her part, initially refuses to question or resist this limitation, and her idealism as well as the townspeople's consistent rhetoric facilitate her transformation from being marginally "home safe" beyond the city into a very literal form of house 
arrest. The two notions of hospitality — as a social ethics and an industry — collide as Tom attempts to obscure what amounts to his exploitation of her cheap labour with his suggestion of a kind of mandatory gift or gesture of thanks that Grace should volunteer.

In order to critique the ways in which home, hospitality, and community are "valued," von Trier shows the power of the public facade of welcome which sanctions the private mistreatment of Grace, and this is the first level of the imbalance of "giving" place and violation that von Trier reveals. All of the townspeople aim to sustain their physical homes in difficult times but abide by a flexible ethical code that demands a modicum of honesty and fair treatment only to people who have lived in Dogville for an unclear span of time. When Grace does offer to help the townspeople in return for letting her stay in town, the insistence that what she can do is not what they "need" instantly devalues her contributions, as well as her "worth" to the community as an individual seeking to be at home there. Von Trier explores Derrida's notion of "giving" place but Grace illustrates the ways in which the townspeople aim to keep her "in her place," not as someone at home in Dogville but as a perpetual interloper and guest. In a telling exchange, the shop owner, Ma Ginger, chastises Grace when she attempts to take a shortcut between the older woman's gooseberry bushes. Even though everyone else goes this way, Ma Ginger explains, "Dear, that's right. They’ve been living here for years. You haven’t been here that long." Like Ma Ginger, the residents claim that time, rather than their choice, keeps Grace on the outside, and I will turn to the nuances of this rhetoric in my discussion of Dogville's public scale of home-making in the following section.

Place is "given" to Grace, seemingly graciously at first, yet Dogville’s hospitality is marked by the history of this practice as well as its increasingly economic underpinnings. Mark W. Westmoreland offers a historical overview of hospitality, highlighting its associations with the law 
and noting that it "has been reciprocal, engaged in an economy of exchange, even an economy of violence" (2). This judicial and economic context may seem like a contrast to the ethical question that Derrida explores, but Westmoreland suggests that "to challenge the aporia of hospitality" Derrida also "invites us to challenge our ideas on sovereignty and immigration" (9), which, of course, circles back to questions of law and economics. In On Cosmopolitanism and Forgiveness Derrida explores the notion of cities of refuge and condemns the increasingly popular idea that immigrants should not expect economic gain (he is specifically discussing France but the critique has broader relevance), claiming that "[t]his distinction between the economic and the political is not, therefore, merely abstract or gratuitous: it is truly hypocritical and perverse; it makes it virtually impossible ever to grant political asylum" (12). Von Trier takes up a similar critique with Dogville as a kind of "small town of refuge," which ultimately succumbs to economic considerations that make offering Grace asylum—even though she is promised it—impossible.

From the outset, rather than being offered a legitimate means of paying for housing and food once she settles, Grace's hospitality is quantified and bound to an unspoken contract, and this marks the second level of imbalance as Grace transforms from guest to guest worker. It is Tom who initially suggests that she offer to work and the townspeople give her pay-what-you-can wages, with which she is even able to begin buying a rather ugly set of figurines to decorate her sparse living space in the abandoned mill. Yet, since Grace needs protection and the townspeople claim not to need anything from her, they hold the upper hand in negotiating the host/guest conditions and so their "contract is highly asymmetrical and made under duress" (Goss 136). The price of protection goes up within a free-market framework, and when the police come to replace the "missing" poster of Grace with a "wanted" one, the previously settled contract goes up for renegotiation even though Tom learns that Grace is wanted in connection with bank robberies that 
she could not have committed because she was in Dogville at the time. Her innocence is not an issue deemed pertinent to the new "contract," and the town's economics-based hospitality is explained to Grace by a somewhat flustered but mostly pompous Tom: "From a business perspective, your presence in Dogville has become more costly because it's more dangerous for them to have you here. Not that they don't want you. It's just that they feel there should be some counterbalance, some quid pro quo.” Although Grace cannot help but compare this mercenary logic to that of city gangsters, her deep need to see in Dogville an idyllic shelter allows her to overlook the striking similarities. Even Tom's feigned alliance with Grace, when he uses the word "they" rather than "we," is not questioned by Grace while he justifies the actions of a collective which he represents.

While Grace continues to hope that she will earn insider status, the final level of violation occurs as she is still allegedly "given" place by the townspeople. However, rather than learning to dwell in Dogville, she can only learn to get by_first by getting through her double day of "volunteer" work and eventually enduring psychological and physical abuse from her hosts-turned-captors. When Chuck confesses to wanting to turn her in because she refused to kiss him, a resigned Grace timidly tells him, "I treated you unfairly." Following her meek apology and unspoken plea not to turn her in, Chuck rapes Grace whenever she works in his orchard, and Grace's only reaction is to grow more detached, living in a prolonged state of shock that results from the contrasting homey expectations and brutal realities of her life in this town. Her dream of home transforms into a nightmare as not only her labour but her body becomes a part of the economy of Dogville. During her attempted escape, Ben refers to "tak[ing] due payment" when he rapes her in the truck bed before returning her right back to the town. Her previously eager agreement to the contract regarding her welcome is followed by passivity during the 
renegotiations, and, finally, no contract as Grace is chained following her attempted escape.

Through these social but ultimately economic "contracts," Grace's relationship with the townspeople transforms from one between guest and hosts to being between servant and employers to being between prisoner and self-appointed guards. Her subordination continues, but Grace still cannot seem to prove herself worthy of "insider" status, even as she continues to feel that she ought to continue offering concessions to the townspeople who are truly "at home" in Dogville.

Throughout the film von Trier undermines a conventional understanding of hospitality by depicting the enmity that Derrida examines as the potentially "hostile" side of the "host" and the broader tensions between hospitality and hostility. Together the three levels of violations problematize altruistic associations with welcome and show the ways in which larger and larger impositions on "guests" can become naturalized. Derrida's observation "that perhaps no one welcomed is ever completely welcome" ("Hostipitality" 5) is dramatically illustrated by von Trier in ways that seek to provoke reflection through the townspeople's rhetoric of welcoming Grace and their incongruent actions as they bully and abuse her. Additionally, the host and guest binary links to hostility when another notion of "host" is considered: an organism infected by a parasite. Yet, even if the argument is made that the host-parasite relationship can be symbiotic, the "parasite" is never on equal terms - as the term's negative connotation suggests. I suggest that, in attempting to make a home in the town of Dogville, Grace undergoes the categorical transformation in her hosts' eyes from "guest" to "parasite" as the town's hospitality becomes predominantly hostile, and this rhetorical shift serves to justify her unconscionable treatment.

While the host-parasite relation is generally invoked to conjure the relationship between victimized benefactor and its unscrupulous beneficiary, Derrida's work illuminates the social ramifications of the metaphor, since both hosts and guests can act parasitically in different ways 
and to different degrees. The etymology of parasite means "one who eats at the table of others" $(O E D)$ which brings the biological aspect of gaining sustenance to the realm of social norms and hospitality—or "hostipitality" more precisely. The metaphorical "table" is in the purview of the "others" and no labour, gifts, or spirit of sharing can amend the situation for Grace. When she sits with the townspeople at the Fourth of July celebration, she is greeted with kind words but inevitably put back in her place at "the table of others." Von Trier adds another layer to the discussion that connects the issues the film is working through to Derrida's understanding of hospitality as an aporia, since Dogville shows that parasites take sustenance from their host but hosts must also take it from something else.

Dogville's self-proclaimed hospitality is actually nothing of the kind but, rather, a form of publicly acknowledged charity that masks parasitism — and what is crucially important is that it is not Grace who is the parasite. She initially asks for assistance, for concealment and sanctuary, but the townspeople "take" from Grace, not only her work and her body but also a perverse moral justification for the supposed goodwill with which they "feed" their communal harmony. The parasitical relationship depicted in Dogville also depicts Bauman's liquidity as a function of capitalism. In the Bauman chapter, I suggested that it is still possible to dwell within liquid modernity under certain conditions, conditions that mitigate modernity's instrumentalizing relationships and the alienation they wreak, particularly through the commodification of home and the de-politization of identity in relation to home when the latter is an investment, commodity, or status symbol. When home is assigned a market value or a price, it becomes more object and less formative conceptual space capable of integrating systems of belonging. In Dogville von Trier also suggests that when a price is set on home and belonging, then dwelling in Heidegger's sense is moved into the control of some (hosts, tourists, home-owners) and out of reach for others (guests, 
vagabonds, non-owners), which results in a power dynamic that fosters hostility, not welcome.

\section{The issue of scales: invisible walls and the social order of Dogville}

In this section, I explore the town's pretense of welcome to their "guest" by turning to the ways in which this welcome is solely contrived on a publicly constructed scale of home. Indeed, the film relentlessly erodes the individual and interpersonal scales of dwelling and co-habiting in order to draw attention to the impact of naturalized social constructions of home and communal consensus. The literally invisible walls in Dogville uphold a social order that is inhospitable to dwelling in Heidegger's sense - the townspeople's calculative thinking and growing abuses of Grace make meditative thinking on her part impossible since she cannot reflect upon a home that she can neither construct nor cultivate in any meaningful way. The mise en scène in Dogville offers a sparse theatrical set of outlined but invisible walls in an enclosed space with no natural lighting. There is a suggestion of openness, but only within the context of the artifice of inclusion and the stifling nature of a manufactured interiority. The film's setting is a key means of depicting the public/private divide, since the whole town is located inside a large enclosed space yet, on the set, there are only sparse frames where some walls would be but no actual rooms for characters to hide away in. The entire town becomes the private space while its residents have no private corner to claim individually.

Through the film's "Brecht-meets-Our-Town stage design” (Badley 102) von Trier also foregrounds people, their words and actions, and the ideas — particularly regarding hospitality - that are being (mis)represented. In order to shed light on the same constructions of communal harmony, von Trier employs Bertolt Brecht's practice of de-familiarization by not veiling the constructed nature of the film — not only through the theatrical set, but also the narrator, 
and titled “chapters" of the film. Thorton Wilder's prop-less play Our Town (1938)—in which actors must mime opening doors, shelling peas, and so on-is not only copied but politicized in Dogville. When von Trier's characters close doors, the sound effect underscores the action since other characters and viewers can see through the door, which is not merely missing from the set but no longer a threshold that marks private space.

The invisible walls of Dogville maintain a social order that renders the individual, interpersonal, and social scales of home indistinct and the way the private scales of reflection and relations are trumped by those of the public has serious ethical ramifications. Von Trier, I argue, uses the stage-like quality of his mise-en-scène and the invisible walls to show how superficial transparency can be a form of controlled surveillance, since the townspeople self-police in public but act however they like when with Grace because they know that the publicly proclaimed welcome does not extend to private actions. This panopticon has one prisoner and a community of prison guards who turned a blind eye to each other's crimes while branding Grace a danger. The "unified front" of the townspeople represents the power of the public sphere to suppress individual action, and von Trier insightfully depicts this power as a form of oppression that results from an "us" and "them" view of home wherein "ours" is to be kept safe from "them" and never shared.

Von Trier also represents the public sphere as a force that nurtures uniformity. Brunella Antomarini suggests that the townspeople in the film are similar to one another partly because "the lack of walls prevents them from having a personality on their own" (41), attributing their indistinctness to the maintenance of the social system through the townspeople's inability to create their own-subsystems. In the film, even if the residents believe in the town's public facade and feel at home in the social scale of the town, on the more intimate scale of personal space or household they remain wary of constructing "sub-systems," knowing that other townspeople might be 
watching and keen to offer censure for purported disloyalty. The townspeople are bound together by a fear of being ostracized, and their lack of initiative and independent thinking further suggests that they are truly locked into the groupthink and static social order of the town. As an entity in which the public sphere and social scale subsumes everything else, including the personal scale, the town remains a publicly constructed homogenizing place that can foster only one kind of belonging —one that is ultimately unethical.

In a pivotal scene during Grace's failed escape, von Trier offers a bold reminder of the persistent invasions of private space that consistently occur in Dogville. When Grace is curled up with apple crates in the back of Ben's truck, a cloth covering the truck bed becomes semi-transparent, as though mimicking the town's invisible walls. The murky transparency of the cloth signifies the futility of her concealment and foreshadows the fact that everyone in Dogville already knows of the attempted escape. Wim Staat claims that "Dogville only seemingly accepts the stranger into the community as it grants no claim rights to Grace, and no freedom to obey the law that she, as a member of a sovereign community, would have given to herself. Grace remains a foreigner, never at home in Dogville" (89). For Staat, the town's "[t]ransparency turns out to be veiled" (89), and he points out that when Grace is being raped on multiple occasions inside the mill, her supposed home, the townspeople are able to see her-just as they did when she first moved in - but choose not to see what is happening.

Through these voyeuristic visuals of invisible walls and semi-transparent covers, I suggest that von Trier subverts the division between the private and public in order to reveal the importance of, on one hand, its constructed nature, and, on the other, the impossibility of equating the power relations and supplementary roles of the two spheres. There is an obvious need to conceal the fact that in the surveillance culture of Dogville, the community dictates all terms for interpersonal and 
individual identities, experiences, and belonging. All of the townspeople become complicit in this concealment by perceiving the transparency between private and social realms as a positive thing rather than an invasive and manipulative one. The fact that the town is a parasitical entity thus forms the very basis for the lies around which the town functions. In the context of the film, where the interpersonal is merely a conceit for larger and calculated forces at play, hospitality can only be a simulacrum, a veil concealing exclusion, hostility, and a gaping ethical void.

The publicly constructed vision of Dogville, which is reiterated by the town leaders at town meetings - to which Grace is never invited - is shown by von Trier as a deeply problematic, homogenizing template for home. Even though Grace is passive for most of the film, her escape marks her as a non-conformist and the townspeople use that attempt to rationalize implementing an “escape prevention mechanism" that chains Grace by the neck and includes a bell to signal her every move. Von Trier utilizes his sparse set to shift the context of the film set's black floor and walls as the town becomes Grace's prison, the townspeople her prison guards, and her room in the old mill a panopticon-type of cell. Although Grace initially seeks to grow roots in Dogville, these roots are transformed through her passivity and the townspeople's manipulation into an imposed link once she no longer chooses to feel connected to this place. Rather than being rooted, she is literally tethered and chained. Tom's father, the retired doctor, explains the town's rationale for the “escape prevention" punishment, telling her, “Grace, we don't like doing this. We don't have much of a choice if we're to protect our community." For the townspeople defending their home, even from the unlikely threat that Grace herself represents (particularly after so much time has passed), takes precedence over former promises as the idea of protection nullifies hospitality. ${ }^{40}$

40 Nikolaj Lubecker claims that Grace "is not a simple victim" (159, original emphasis) because she had a choice of calling her father for aid, but this logic only applies to her initial stay and disregards the fact that she believed that her father would not react kindly to finding her after 
Dogville depicts ways in which questions of protecting the home are often publicly distilled into two distinct sides with nothing in-between. In the context of a threat, all questions of belonging become secondary to the binary which becomes a means of controlling who can be at home through two options on one scale - the inside ("us") and outside ("them"). Von Trier highlights the ease with which this rhetoric translates into everyday concerns when, during the final town meeting, Tom is asked directly, “Are you for us or against us?" He must answer cautiously for his answer will either secure his place on the inside, or potentially reposition him as an enemy "them," likely to be dehumanized and "consumed" as Grace has been. Tom attempts to choose both positions but his later claim, "I've chosen you," said to Grace while she lies in bed chained to a metal wheel, is false, contrived, and fully embedded in the foul private/public doublespeak of his town. Grace's silence upon hearing the declaration suggests that she is unwilling to dignify the absurd assertion and unable to justify the town's understanding of "choice," which always boils down to the public facade and only supporting "us."

Idealism and naïveté, on one hand, and greed and manipulation, on the other, are the overarching themes of the film, but at the heart of Dogville and its dual themes is a stifling definition of home that mythologizes the idea and limits home-making to those who publicly embrace that myth. Von Trier shows that this understanding makes the town a superficial home for the townspeople until, in the end, Grace conquers the space, only to then reject it as a home entirely. Von Trier demonstrates with her coup a dialectical pattern of binaries and their inversions: the public trumps private until Grace's private vision of Dogville dominates and decimates the townspeople's public facade. I suggest that the public and private divide in the town is maintained because neither the townspeople nor Grace seek to explore the overlaps of these scales and to

their last confrontation and would likely kill her. 
uncover the hypocrisy at the heart of the town's offer of welcome. Instead, von Trier's brutal conclusion portrays one of Derrida's potentially hostile outcomes of hospitality: Grace, the guest, takes her hosts hostage. These hostages have no chance of escaping, just as Grace's escape attempt was doomed to fail.

\section{Home or not: a failure to conceptualize the multi-scalar home}

In Dogville, the private/public or inside/outside division is visually collapsed and conceptually undermined by the townspeople's violent maintenance of such a distinct separation, revealed in Chuck's succinct description of the town as "rotten from the inside out." Through this decidedly negative image of concealed spoilage and decay, von Trier suggests that, through a focus on the public image or myth of the town, its residents stop seeing the damage that is up close and increasingly commonplace. What makes Dogville such a rich illustration of Derrida's "hostipitality," particularly in the ways that hospitality affects ideas of home, is that the film ultimately remains ambiguous as von Trier champions neither the rule of majority nor the plight of the underdog. "Siding" with Grace suggests a very frightening precedent in light of hate crimes and histories of human rights abuse through a demand that everyone-including children and all bystanders - implicated in unethical treatment be dealt this kind of Old Testament justice. Instead of weighing sides, von Trier is posing several vital questions about how such "rotting from the inside out" might be prevented and what can be done when home seems increasingly "rotten." Grace's solution is to eliminate the whole of the town and move on (or back, in this case, to the city) but this solution does not address the cause of the "rotting" problem - a problem which, I argue, von Trier shows as being rooted in the duplicities around which the social scale of home is constructed in the town since Dogville has no room for multiplicities, overlaps, or degrees of 
feeling "at home." Moreover, abuses of hospitality can just as easily happen in the city to which Grace returns, and, in fact, it is quite likely that Grace's father's mob syndicate is a similar "rot" that is spreading through that urban home space.

Through the film's unhappy ending, von Trier undermines notions of an idyllic and mythologized home, particularly small town charm and the conditional welcome of migrants. Grace waits for the home that will be but never is, hoping that the uncomfortable and unfamiliar elements will fade away, but she waits in vain until the townspeople finally put a stop to her waiting by contacting the gangsters. After this betrayal, Grace finds herself unable to justify the residents' actions, and she admits to the familiarity of such corrupt behaviour, which she once assumed was only characteristic of the city. She chooses her former sullied home with its more forthright allegiances rather than continuing her delusional trial in Dogville, and the voice-over narrator describes Grace's realization that the difference between people "back home" and in Dogville "had proven slighter than she'd expected." Grace, like the blind man who at long last admitted to being blind, finally admits to seeing. This revelation is made even more poignant by the fact that Grace tried not to pry or "see through" the townspeople's households and communal home but respected their walls - even as they disregarded hers by treating the mill as a public building and a prison rather than her home space. The narrator compares what Grace sees to "changes of light" which "previously so merciful and faint, finally refused to cover up for the town any longer," and I suggest that in this act of seeing, Grace, no longer passive and numb, reconstitutes her agency as a home-maker. Her meek self-preservation takes on a new form, as does her previously repressed anger, because while Grace had imagined a rural paradise full of calm and kindness with "good and honest" rather than greedy and corrupt people, the stoic calm of the town and its residents proves to be a facade. Grace appeared stoic and calm in an attempt to fit 
in but, finally, in a position of power with the support of her father's gangsters, she not only returns the townspeople's so-called hospitality with compounded interest but also justifies her actions through a lofty, self-serving logic about the greater good and making the right choice that perfectly mirrors the townspeople's. The narrator explains Grace's rationale: "If one had the power to put it to rights, it was one's duty to do so, for the sake of other towns, for the sake of humanity, and not in the least the human being that was Grace herself." In this problematic justification for mass murder, von Trier points to Derrida's distinction between the right of resort and the right of a guest. Grace is not vindictive because the townspeople did not want to treat her as a guest (entertain her and make her feel well cared for or welcome) but because she was denied a universal right of resort. This denial was an act that sought to dehumanize Grace and, in her mind, undermined the humanity of the townspeople. What makes von Trier's film such an important work on the notion of home is that although Grace appears to be a "winner" in the battle to control Dogville as she drives away from the burning town, Dogville remains a narrative that ends with no winners since no one is or likely will be at home in this place.

In Dogville von Trier illustrates various combinations of the roles that Derrida describes in his examination of "hostipitality": Grace, the guest, becomes a hostage (but is labeled a parasite), and takes her initially welcoming hosts hostage. In an analysis of the religious themes of the film, Costica Bradatan refers to Derrida and explains that in Derrida's sense "hospitality is not only my way of accepting the other into my world, but—more importantly—it validates and strengths my own acceptance into the world" (72). For Bradatan, the residents of Dogville perverted the idea of hospitality and by doing so "seriously undermined the conditions of their own living there. By turning Grace into a hostage and enslaving her, they enslaved themselves. Their dramatic extermination in the end is only a metaphor for a suicide" (72). I would not go so far as this, since 
Bradatan's reading denies Grace agency even at the end when she renounces the possibility of welcome in Dogville. Instead, I suggest that in the final scene von Trier illustrates the problem of hospitality when conventional understandings connote an inherently positive practice, founded on a host's presumed kindness or generosity. The townspeople's skewed view and an economics-based understanding of hospitality, von Trier shows, lay the groundwork for a rhetoric of "giving" place that the townspeople continue to invoke while justifying their violations of Grace's trust, labour, body, and basic human rights.

Anthropologist Andrew Shryock incorporates Derrida's work into his research on the Bedouin understanding of the roles of host and guest, explaining that "[a] new politics of belonging built on these concepts will ultimately fail us because host and guest meet in a social space that is not really 'home' to either" (49), and the film interrogates the role of the other in the "making" and "un-making" of home by depicting the spectrum of Derrida's concept of hostipitality from forms of welcome to hostility. Von Trier presents a town which divides those who have rights and those who have none according to an "us" and "them" logic, and, in doing so, protects hosts at the cost of destabilizing home through the constant "trespass" of another. The presence of a guest makes a home space un-home-like yet this is the state that the residents of Dogville perpetuate by making Grace a permanent guest. For Derrida, there is no "full" host or "complete" guest but since the two are kept in tension they form an aporia that needs to be rethought and problematized. Dogville demonstrates the problems of rigid host/guest categories and I argue that the multi-scalar home offers a way to rethink the binary, since within such a conceptualization of home the quasi-host and -guest can feel at home and "make" home in different ways on multiple scales.

In Dogville, the townspeople offer a public facade of hospitality, but Grace remains an 
"outsider" and guest until the farce of her welcome includes town leaders calling her a threat and parasite, cleverly seeking to take advantage of their "small town" hospitality. Ultimately, the publicly sustained "us" and "them" distinction results in no one being at home—not the paranoid, greedy hosts, nor the former guest who ends up orchestrating the demise of her former captors. Unlike Dogville, the film that I examine in the final chapter, Wolfgang Becker's Good Bye, Lenin!, distinctly depicts multiple geographic and political scales that suggest various, shifting "us" and "them" binaries as well as changing public and private histories of what was once East Berlin. I argue that the film problematizes hospitality with more fruitful results since Becker's characters think beyond a division of the private and public and seek alternate means and modes of home-making. Good Bye, Lenin! not only depicts hostility and hospitality through a more nuanced relation between the shifting roles of hosts and guests, but in the film this binary is even mediated through perceived mutuality and a sense of co-habitation. In addition to offering a sustained critique of various dualities of home as stable and yet mobile, Becker's film reveals the ways in which a conception of the "dirty" home and Derrida's notion of "hostipitality" can facilitate the "building" and multi-scalar "mapping" of the idea of home in ways that foster Heidegger's sense of learning to dwell on an individual, relational, and social scale. 


\section{Chapter 9: "Home safe" in spite of hostility in Wolfgang Becker's Good Bye, Lenin!}

In Wolfgang Becker's Good Bye, Lenin!, Alex Kerner not only re-imagines East Germany after the fall of the Berlin Wall but uses the thought experiment of re-writing history as an opportunity to think meditatively about what it means to dwell and to offer welcome (to himself and others) in a world of flows or what Bauman calls liquid modernity. Becker's film was a blockbuster in Germany in 2003 and an international hit that offered a lighthearted but layered reconciliation of Americanized and Soviet-influenced memories and grievances, well over a decade after the fall of the Berlin Wall. The major thematic concern of the film is nostalgia, particularly "Ostalgie" or "Ostalgia" from the German word for "east," and this has garnered comparisons from scholars to other films about Eastern Germany (the GDR), including Leander Haussmann's 1999 Sonnenallee (Jozwiak and Marmann), Hannes Stöhr's 2001 Berlin Is in Germany (Kapczynski), and Florian Henckel von Donnersmarck's 2006 The Lives of Others (Creech). Yet, even within the historical context of its setting in former East Berlin, Good Bye, Lenin! transcends its socio-political moment and geographical bounds in the ways that the film theorizes the political stakes of shifts in the meanings of home and the roles of home-makers in making these meanings.

I argue that Becker deliberately charts a multi-scalar kind of home by emphasizing the overlaps of public, or social and communal, as well as the private or individual scales when his protagonist, Alex, reconstructs a no longer existing city and nation inside his ill mother's room. Becker investigates what Derrida terms the "giving" and violation of place as Alex invents an East 
Germany for his mother, Christiane, who was an idealistic socialist but in a coma during the fall of the Wall. After being told by her doctor that a shock will likely result in another heart attack and death, Alex intentionally leaves Christiane in the dark about not only the precarious state of her health but the dramatic political change that has taken place in her country. Over the course of the film, the complexity of Alex's well-meaning fiction escalates until his charade finally comes to an imperfect yet mutually cathartic end when Alex idealistically re-imagines the opening of East German borders for Christiane, who is by then aware of the lengths to which her son has gone to in order to protect her from further physical and emotional pain. In this chapter, I will analyze the ways in which, through the innovative retroversion and the introversion that it ultimately fosters, the film depicts what Derrida terms hostile hospitality or "hostipitality" in order to explore the complex experiences of being (un)welcome that are central to the idea of home. Neither Alex's constructed fictional home nor the Kerner family's constructed lived home is ever wholly (un)welcoming. Instead, the ways in which hospitality and hostility shift from within and from without the historically isolated apartment underscore the salience of the politics of dwelling not only on conventional scales of household or hometown/homeland but also through other emergent forms, modes, and means of multi-scalar home-making that may not match one such category.

In my analysis of the social scale of home, I chose two character-driven yet overtly political films (Dogville has been criticized for being anti-American and Good Bye, Lenin! for promoting an uncritical view of East Germany) because, with such a personal yet also social focus, both films reveal important links and disconnects between the private and public facets of hospitality and its impact on constructions of home. Although the historical, cultural, and political context of each film is vital to its meanings, these aspects have been amply represented in the scholarship on the films. My focus here is more philosophical since I analyze them as representative of concerns that 
run throughout twenty-first century texts from different nations. Such an approach frames this dissertation's inquiry into the collusion of the personal and social politics of claiming and maintaining home, not only physically but conceptually.

There are significant differences in the ways Dogville and Good Bye, Lenin! sort through the aporia of hospitality. Von Trier's Dogville exposes a kind of trap wherein public constructions of a welcome home overwrite the needs and experiences of individual home-makers, who are treated with hostility in the service of supposedly harmonious communal living. At stake in the film is the fact that when the public interest and private interests are at cross-purposes, a kind of contemptuous duplicity can erupt that makes it impossible to dwell. This conflict between an economic public interest and private interests is also critiqued by Bauman's analysis of consumerism, as national or "global" economic concerns regarding growth trump the increasing inequity of the allocation of the qualitative benefits of modernity. In contrast, when Becker's Good Bye, Lenin! investigates "hostipitality” on various scales, including Alex’s family, his neighbourhood in former East Berlin, the city as a whole, as well as national and even international discourses, he is able to illustrate how diverse and networked the relations of seeking and being welcome can be. For example, the newly open borders and prevalence of national media depicted in the film are important symbols and precursors to changes in international mobility and access to global media, both of which continue to shape the bounds of what home means.

Scholarship on Good Bye, Lenin! generally focuses on history, memory, and nostalgia, as well as the material culture, media, and technology that can memorialize and inscribe facts as well as fictions into both history and memory. Jennifer M. Kapczynski contends that the film "perpetuates the very myth that it has worked to discredit—at once sending up and serving up nostalgia" (89), but I suggest that the film's whimsical depiction of nostalgia offers a means of 
softening the political upheaval and familial drama that lie at the core of the film. Furthermore, Alex's nostalgia is Ostalgie but also the more basic nostalgia for childhood, a remembered "simpler time." The footage of Alex as a child depicts a carefree boy who admires his mother, and his sense of a public home in East Germany with a mother who seems to support the regime overwrites his private experiences of having been abandoned by a father who fled to West Berlin. Alex learns much later that his father actually left thinking that the family would follow him and that it was Christiane who was too afraid of losing her children to attempt to follow her husband as planned. Becker scatters other jarring encounters with reality and revelations of lies throughout the film in order to draw attention to the hostilities that can underlie the best intentions and professed forms of welcome in individual cases and within their socio-political contexts.

Daphne Berdahl offers a fruitful approach to Becker's use of nostalgia when she claims that the film explores a nostalgia for "the vanished state" (185), depicting "lost possibilities and critiques of the present" (182), and I will illustrate in this chapter how Becker additionally depicts new possibilities in his critique of the present in regards to the idea of home - not only as state or "homeland" but also other geocultural scales such as household, neighbourhood, and an emerging European community. In the following sections, I will show how, rather than an ideal home that is superficially nostalgic, singular, and unsustainable, Good Bye, Lenin! offers a visual narrative in which Alex learns to reassess and resituate the relations and experiences of his complex map of home. To show how the film elucidates the personal as well as political stakes of home, I explore the film's depiction of problematic hosts and guests - including Alex and Christiane but also West and East Germans more broadly. I then consider how Becker depicts various geocultural scales and reframes modes of being at home in or between them. The value of Becker's film to my argument is that it demonstrates how understanding home and history through distinct public narratives and 
private accounts must be secondary to the inevitable blur and overlap of the private and public. Ultimately, I suggest that home is presented in Good Bye, Lenin! as a notion constructed through experiences of "hostipitality" and "dirty space," because it is individually yet collectively constructed on not only private or public but multiple geographical, as well as cultural, economic, and political scales.

\section{Public and private histories in Good Bye, Lenin!}

Dogville and Good Bye, Lenin! both reveal the cracks which emerge when a division of the private and public home is enforced, yet, while von Trier's film concludes with the destruction of a spurious home, the result in Becker's film is Alex's rethinking of home through and beyond these categories or scales. Alex reframes the relation of the public and private through a reconfiguration of home as a multi-scalar idea that is individually and collectively constructed, and in this chapter I investigate the transformation that Becker charts as Alex shifts from passive son to self-appointed "master" of the home when his mother is ill and, finally, to a more self-aware and reflective home-maker who seeks to map his own conceptual dwelling rather than imitate an impossible ideal for himself or others. Like Richard Mayhew in Neverwhere or Ivy Walker in The Village, Alex goes on a kind of quest that helps him to rethink home: where it is, how it anchors him, and why it remains so important. Alex discovers a new city (like Richard in Neverwhere) and passes through a seemingly impossible border (like Ivy in The Village), but his journey is also distinctly temporal, immersed in history and explicit social forces. These additional dimensions to Alex's labyrinthine quest are important because, like the "complex map" that Nicolas Dickner describes in Nikolski, Becker's protagonist is also navigating the idea of home by plotting a multi-dimensional, immersive, and dynamic cartography of home. 
Becker meshes the problems of the past with those of the present, the good with the bad, and the re-remembered with the re-forgotten. For instance, as Nick Hodgin points out, a young Alex is enthralled by the space launch on television in the opening sequence while his mother is being interrogated by the Stasi, the East German secret police, and so the film "begins by acknowledging the best and the worst of the GDR" (105). I suggest that Becker depicts such juxtapositions throughout the film, critiquing Eastern and Western political ideologies and their forms of hostile hospitality, since the re-imagined socialism that Alex concocts for his mother and finds himself wishing to believe in epitomizes his idealism and a humanist impulse rather than a potential political platform. The way Becker depicts Ostalgie suggests a model for the analysis of the uncertain and commodified flows of liquid modernity and a nostalgia for the more predictable stabilities of what Bauman calls solid modernity. Bauman's concept of liquidity can help to account for the re-emergence of a longing for something past in a world of flows and future-oriented concerns. In The Future of Nostalgia Svetlana Boym calls nostalgia "the incurable modern condition" (xiv). This is not to say that nostalgia or Ostalgie always describe an unhealthy fixation with or idealization of the past, and Boym usefully suggests that a kind of reflective nostalgia exists which "reveals that longing and critical thinking are not opposed to one another, as affective memories do not absolve one from compassion, judgment, or critical reflection" (49-50). I argue that since Becker neither celebrates socialism's triumph (Alex's narrative of German socialism is fake, after all) nor erases the characters' rights to feel nostalgic about their former experiences of home, Good Bye, Lenin! can be said to offer a critically reflective nostalgia in place of a purely naive or sanitized longing. The Kerner family's experience of the GDR dramatizes the kind of complexity that Boym accounts for since positive memories can occur within repressive contexts. 
In showing home as built by the home-maker's agency as well as collective life and external forces, Becker critiques individualistic as well as political oversimplifications of the idea which strip home of its dynamic, formative, and integrative qualities. The film depicts Alex's and Christiane's gradual transitions in thinking about home as they struggle to appease family and community by upholding an idealized view of their home in spite of larger personal and political troubles. Christiane does this when she outwardly embraces socialist ideals after her husband leaves her and their kids to escape to West Berlin, and Alex follows suit when he re-imagines German socialism for his ill mother. Becker shows that a division between the public and private is unstable but also that the overlaps of the two can be fruitful since, in the case of the latter episode, such overlaps instigate a re-emergence of the characters' sense of agency as home-makers: Christiane faces her past and finally becomes less accommodating to even Alex's overly-idealized brand of socialism (which kept her uninformed and in her room), while Alex comes to terms with his family's and country's past. Alex begins to develop his own sense of home rather than deferring to what he believes are his mother's ideas regarding home, ideas which she instilled in him as a child while attempting to protect him for the harsh realities of both his broken home and a repressive government.

Becker even undermines "us" and "them" binaries through Christiane herself since she remains difficult to politically situate in the political binary of socialism and capitalism. Critics often describe her willingness to blindly support socialist dogma, but there are several indications that she is, at best, ambivalent about the regime. According to Caitlin Manning and Julie Shackford-Bradley, Christiane "represents a generation who believed in socialist ideals and had to blind themselves to the betrayal of their dreams in order to survive" (42), while Timothy Barney describes the film as "the story of a woman's intense devotion to the socialist state circa 1989" 
(134). However, Christiane's breakdown after a visit from the Stasi regarding her husband's defection and her later confession that she was too scared that her children would be taken away if her attempt to get official paperwork garnered the wrong attention provides evidence to the contrary. One can argue that Christiane is motivated by fear and unhappiness rather than mere blind devotion. Anke K. Finger proposes a more nuanced reading of Christiane's political beliefs and her practical motivations, suggesting that Christiane's "only method for securing the future of her children - not to speak of her own — was to become as loyal to the system as possible, at least on the surface; otherwise, she, Alex, and Ariane would have had to suffer the constant stigmatization of having contact with the West and of having produced a traitor within the family" (54). Further support for such a reading is the fact that Christiane's practical motivations are ultimately not very politically successful. Despite her commitment to "comrade" neighbours and "young pioneer" schoolchildren, she is demoted at the school on account of her unwillingness to compromise the socialist ideals which she chose to follow in her own way rather than the Party's.

Because the film depicts political transition and a redrawing of borders, Becker is able to explore the conflicts between private and public visions or iterations of home beyond specific political ideologies or geographies. Alex's well-meaning familial ruse, on one hand, and the socio-political propaganda of Soviet-era communism, on the other, shed light on the private and public fictions that continue to have a deep impact on constructions of identity and home in late capitalism and liquid modernity. In the film, Christiane becomes a guest in her own home and, in the larger sense, East Germans are shown as outsiders or newcomers to Western culture and capitalism, no longer hosts but guests in a unified Germany, where norms, systems, and goods that are familiar to West Germans are embraced. These various experiences of private and public hostility illuminate the scope of Derrida's concept of "hostipitality" in innovative and unexpected 
ways since Becker shows how a tension between hostility and hospitality occurs through, as well as in spite of, local and global flows of (un)welcome people, products, and ideas. Rather that privilege an optimistic vision of welcome or a pessimistic depiction of hostility, the film offers a third solution in which ideas of home are reframed in order to integrate multiple scales for home-makers who experience the positives as well as negatives of "hostipitality."

For Timothy Barney, “Alex’s desperation [...], while absurd, makes sense as an unselfish tribute to mom's devotion" (146), and, indeed, Becker seems to offer a simple depiction of a devoted son who plays host for the sake of Christiane's good health, but Alex's devotion masks deeper feelings of guilt. It is also shadowed by a perception of reciprocity, which impacts the terms of his hospitality. As a child, Alex is shown in home videos to be obedient and dutiful, even more so after he witnesses his mother's mental instability (the breakdown following her husband's desertion), and as an adult, he seeks to keep Christiane safe from physical harm and emotional pain, just as earlier she did for him in spite of his father's desertion. Alex finds that he must keep escalating his charade of a sociality Germany, from showing Christiane news reports from the past to fabricating new ones that resemble current events and finally scripting and filming a complete alternate history of socialism in Europe. Yet, much like Tom and the townspeople in Dogville, he uses his mother's needs as the justification for initiating and continuing the ruse of a segregated Berlin, and his "generosity" in this grand and increasingly time-consuming effort is largely selfish. He feels guilty for instigating his mother's heart attack and coma because he did not tell her about his involvement in anti-government activity, and she had the heart attack right after seeing him in a group of protesters. In that pivotal scene, Alex is shown struggling but unable to reach her as police load him into a truck with other protesters, and he has further guilt when he learns from her doctor that her coma was a direct result of CPR being administered late. To cope with his sense of 
responsibility, Alex invents an artificially safe and familiar home for his mother and since this is exactly what Christiane did after her breakdown, it seems that Alex wishes to reciprocate the kind of welcome and comfort that he once felt at home. Yet, as I will demonstrate in the following sections, Becker's mirroring of the mother's and son's coping strategies and problematic constructions of home show that hospitality and home cannot be quantified or equated in this manner of indebtedness and calculative thinking.

\section{The issue of guests: "giving place" in an imagined home}

In this section, I explore the unconventional situation in Becker's film of Alex offering hospitality to his mother in a home that was and presumably is hers. I investigate the shifting economic meanings of the "guest," which Becker critiques through both the historical moment of German unification and the Kerner family drama of misplaced loyalty and indebtedness. Christiane initially set the parameters or a template for Alex's private construction of home and this leads to his inventive response to protecting her. Because Alex segregates his private and public understanding of home, for much of the film he latches on to his association with the ready-made personal and social construct that his mother exposed him to rather than attempting to build his own sense of home. Ultimately though, his charade (like his mother's) comes to an end and, in the remaining sections, I want to examine the impact of this conclusion on the notions of home that the film proposes.

More than anything or anyone else, Christiane defines Alex's private associations with home, and her influence puts a decidedly positive spin on difficult events, an approach that Alex later studiously recycles. The images of home video footage and postcards at the beginning and end of the film are marked by Christiane's enthusiasm for making her two children's lives happy even 
in troubling circumstances. She is shown smiling brightly and even her gestures in these clips suggest a warm and supportive parent. Alex's admiration for her as a child seeps through the lens in the grainy segments as well as his covert looks as an adult when she watches the news segments of the world he has imagined specifically for his mother. Yet, as Oana Godeanu-Kenworthy points out, "[t]he referent of her world, the outside reality, disappears; at the same time, it is Alex who now holds the monopoly on opinion that the Party used to have" (170). In producing the ideal East, Alex perpetuates lies very much like Christiane's about his father running off with another woman and the socialist propaganda with which he grew up. While Alex's "giving" place escalates from requesting that his mother stay to ensuring that she does not leave, he even replicates the East German oppression of limiting Christiane's mobility. The Berlin Wall has fallen and not only does Christiane not know that she could attempt to leave the city without facing prosecution but she cannot even leave the four walls of her room without special permission that seems unlikely to ever be granted.

Even though he takes more and more liberties with the newscasts of his re-imagined socialism, Alex also loosens his hold on the role of host as Christiane recovers, and through this transition Becker begins to reaffirm the role of home as what bell hooks calls "homeplace," or a site of resistance where subjectivity and agency can be "recovered." Christiane, for her part, reclaims more of a host role before she can be made into a hostage in her home. She makes an unsanctioned trip outside the building, and following a newscast about the opening of the wall for those in West Berlin and an influx of "refugees" escaping the capitalist rat race, Christiane wants to volunteer to house one of these refugees by sharing their cottage or her own room once she is in the hospital after a second heart attack. Notably, this willingness to welcome others presents a stark contrast to the scene in which Alex "welcomes" himself into the home of someone who escaped East Berlin 
(but might come back at some point with the country unified) in order to find products and packaging that Christiane will recognize. The two situations contrast the ways in which Christiane wants to share and truly "give" place, while Alex is happy taking it from strangers as well as his mother, unaware of his own parasitical behaviour.

Good Bye, Lenin!, I suggest, offers a meditation on the central questions that Derrida poses in "Hostipitality": "does one owe hospitality, and is that the right word when it is a question of welcoming - or being made welcome" (4). In the film Alex feels that he owes his mother this expansive mirage because of the happy childhood which she helped construct for him by also selectively focusing on positive ideas, reframing political problems, and in many ways mis- or not informing her son about the socio-economic realities that surrounded him. However, the ethical core of "giving" place, as Derrida argues, cannot include a sense of paying debts or settling scores. What makes the seemingly reciprocal practice even more complex is that there are important power dynamics at play, such as in this case when a person can explicitly manage "reality" for another. Although Alex is returning the favour, so to speak, the major difference with Alex's welcome to Christiane is that, while she is recovering from illness, she is not a child. His benign lies, omissions, and misrepresentations take on an added weight since, by manufacturing an old familiar context for her, Alex is denying his mother agency in regards to how she might be at home privately and publicly in the new political context. His intentions and actions present a contrast to the top-down model depicted in Dogville, since his socialism is not Party-mandated but Christiane's lack of agency stalls the idealistic effort.

As Alex plays host and Christiane patiently plays the role of convalescent-guest, I argue that Becker critiques social but also increasingly economic forms of hospitality inside their Berlin flat. Alex's efforts make Christiane feel more and more like a guest (almost to the point of being a 
hostage) and less at home since she is "given" place graciously but only if she submits to strict rules, otherwise she might end up back in the hospital. When Derrida examines "the most used words in the code of hospitality, the lexicon of which consists of the words 'invite,' 'welcome,' receive "at home," he points to the implications of control when these terms are used "while one is 'master of one's own home' and of the threshold" (6). In Good Bye, Lenin! Alex is the "master" who seeks to ensure that Christiane does not leave the bounds that he has determined. His offer of hospitality, welcoming his mother (back) into her apartment and East Germany, usurps her role as host because Alex is, like the former government, claiming control over the symbolic and material networks of "household" and "homeland." This comically depicted but increasingly perverse situation showcases some of the nuances of well meaning but also selfish and self-serving "hostipitality," as the re-imagined home that Alex creates for his mother offers him comfort (as well as control). He acts like a helpful concierge in a hotel bringing his mother rare delicacies, yet only he decides what decor, products, and information can fill the space — ensuring his sister's new belongings are not seen by Christiane, telling his mother that she is eating East German food, intentionally breaking her radio, and so on. Alex, for his part, starts to thrive in the role of "host" and "master" for Christiane until, with some outside intervention, he begins to contextualize the hostile nuances of the experience of home that he is manufacturing. Ultimately, only when Alex allows Christiane and himself to participate in both roles of host and guest, Becker shows that he is able to reclaim the role of home-maker for himself.

The instances of "giving" place and violations of place that are depicted in Good Bye, Lenin! suggest better intentions and certainly include less brutality than those in Dogville, yet Becker's film also showcases a slippery ethical slope as Alex takes more and more liberties in order to make a recovering Christiane feel welcome and "at home" in the apartment, city, nation. 
His devotion seems clear as he goes to some trouble to replicate the East German decor of her room and "gives" Christiane the place that he thinks she needs. However, as in Dogville, the rhetoric of offering hospitality shifts from a kind of coddling towards explicitly conning. Becker distracts his audience with tender moments, comedic gags, and socialist kitsch in order to make this shift from helpful son to controlling host almost seamless. Initially, Alex tells a seemingly benign lie about where Christiane fainted but soon this once very active single mother of two is forced to indefinitely remain in bed in her room. Unlike the treatment of Grace in Dogville, Alex's treatment of Christiane never includes physically keeping her inside the space. However, his manipulation is depicted by Becker as a form of hostility when his modus operandi increasingly resembles the oppressive regime which Alex is "reforming" retrospectively in his newscasts. Alex might continue to have better intentions than the residents of Dogville but his treatment of Christiane marks her as an "outsider" to unified Berlin as well as a secondary citizen who is not privileged enough to deserve information or choice.

Even with similar patterns of increasing hostility, there are two important contrasts between the situation in Dogville and that in Good Bye, Lenin!. First, Good Bye, Lenin's Christiane take matters into her own hands without anyone's assistance once she has the strength to leave the apartment. And, secondly, in her case, others refuse to go along with Alex's increasingly ridiculous and oppressive plan and intervene. Alex's sister and his girlfriend both try to talk him out of the charade, and this is very different from the kind of public consensual collusion that results in Grace's entrapment and abuse in Dogville. When talking to him does not seem to help, they talk to Christiane. Alex ultimately agrees to end socialism in Christiane's simulated Germany, and by the end of the film, Becker shows that she is no longer a guest in her home but a co-host. This shift is clear when the family takes a trip to their cottage as per Christiane's own wishes and she sits with 
everyone in the garden, no longer a hostage in her own bedroom. For his part, Alex becomes cognizant of the increased hostility of his hospitality and recognizes his mother's right to navigate and build a sense of home in her own evolving ways. Because of this shift in thinking, a multi-scalar sense of home becomes possible and is shown as capable of integrating conflicting experiences and allegiances for both characters.

\section{The issue of scales: inside out and outside in}

What makes the film such a successful articulation of a conceptual model of home-making in a modern world and how to dwell in it has to do with the way in which it posits home as something that is constructed and reconstructed through public and private spheres—not fixed but fluid, neither imposed on people from above as in The Village and Dogville, nor merely imagined bottom-up from within an imaginary web of affective identifications as in House of Leaves and Neverwhere. Good Bye, Lenin! does offer up nostalgia but always as an idealistic construction, an ultimately naïve concept that is explicitly linked to Alex's childhood, both when his mother manages to distract Alex from his broken home and when he seeks to childishly imitate her by concealing what he fears she would feel was a "broken" nation. More importantly, the film offers "a subtle and convincing deconstruction of Ostalgia as a general phenomenon"

(Godeanu-Kenworthy 163, my emphasis), and I argue that Becker critiques Ostalgia and the hostilities of life in socialism as well as capitalism in order to more broadly deconstruct the relationship between home and hospitality associated with interpersonal, communal, and national levels. In other words, Good Bye, Lenin! is not merely offering commentary on Berlin but investigating the socio-political shifts that constantly "unsettle" home and yet also foster a need to, in Heidegger's words, "ever learn to dwell” ("Building Dwelling Thinking" 159). 
Becker's deconstruction of home uncovers several ways in which publicly or privately nostalgic visions of home impact the possibilities of dwelling, possibilities that adapt to rather than neutralize social and political change. He illustrates how older models of making and maintaining a sense of home can be conventionally re-inscribed without being reassessed and shows how nationalized or communitarian rhetoric of harmonious co-habitation can support dominant practices in ways that de-politicize home-making when the dominant practices become naturalized ways of compliantly "making" home or submissively being at home. Home-makers who are not able to maintain these conventions and practices (like Grace in Dogville) or do not wish to (like Alex when he secretly attends protests) are excluded from claiming home-Grace is not a "true" Dogviller and Alex is a not a "real" East German when they critique their communities or advocate change and this social exclusion is an important impediment to their ability to (learn to) dwell poetically.

I argued in the previous section that, prior to being made a guest in her home, Christiane represented a standard for home-making on a private scale for Alex, and in order to show how this private home is also publicly constructed, in this section I will turn to Alex's childhood hero, cosmonaut Sigmund Jähn — the lauded public figure used to symbolize the public home in the East German context. Both the dutiful parent and national hero exemplify the "us" of the "us" and "them" binary, but Becker uses these conventional symbols of figures who imbue home with meaning in order to question the practicability of older modes of a nationally sanctioned, standardized notion of home. Good Bye, Lenin! shows that harmonious co-habitation has a side-effect of complacent or de-politicized home-making when the social scale of home infiltrates the smaller scales: East German citizens are meant to support and believe the Party, and Jähn epitomizes the success of this harmonious arrangement. 
Cosmonaut Jähn represents the public construction of home in East Germany and stands in for the missing father figure in young Alex's life. In the film's opening credits montage of childhood home video footage, Alex's father is heard only for a moment from beyond the shot but soon even the disembodied voice disappears, and Alex is shown glued to a TV set watching cosmonaut Jähn, who offers a "public" replacement for the now missing father figure in Alex's life. Young Alex even waves back to Jähn on the television screen, just like he waved to his father in the initial home video footage. While the western travels of Alex's father were condemned, Jähn's travels were fully sanctioned and nationally celebrated. Yet, rather than maintaining a stark division between the private and public father figure, Becker brings them together when Jähn (or at least a man who looks very much like him) turns out to be the taxi driver who takes Alex to finally visit his father in what was previously West Berlin. ${ }^{41}$ Most significant about this meeting between Alex and a man he thinks is his childhood hero is the way in which Becker correlates Alex's journey into this unknown part of Berlin and Jähn's into space, showing that both undertakings are not only explorations of strange and unfamiliar places but also demanding voyages of knowledge-seeking — of navigating a labyrinthine sense of home and learning to dwell. On the return ride, when Alex asks Jähn how it was “up there," the former cosmonaut quietly replies that it was "wonderful" but "very far from home," and the answer importantly eludes a division of intimate and national home spaces by focusing on distance in a subjective sense. Through the

${ }^{41}$ Scholars take various positions on the identity of Jähn and I think that this makes him an even more telling symbol of the social constructs that populate personal and national discourses of home. Some critics suggest that the character is an outright "imposter" (Cook 211), that he simply "bears an uncanny resemblance" (Creech 102), that he may or may not be the actual former cosmonaut (Berdahal 180), or that he is Jähn and the cosmonaut-turned-taxi-driver symbolizes the socio-economic fall of East Germans (Jozwiak and Marmann 785, Mazierska 195) as well as "the ensuing disappointment with what the West has in store" (Barney 142). Considering the fantastic twists and coincidences in the film, a formerly famous man driving a taxi and meeting Alex seems on par within the illuminating parallel structure that Becker uses to problematize divisions between private and public spheres. 
exchange Becker suggests that West Berlin might too seem "very far from home" for Alex even though it is the neighbouring half of his city and "wonderful" in its own unfamiliar way. The importance of this immeasurable kind of distance also undermines the notion that a static geographical space can adequately describe home.

In addition to reframing distances in relation to feeling at home, Becker brings the "outside" in and the "inside" out by depicting multiple, problematic "us" and "them" binaries. These include the film's setting — East and West end up unified — and the family history of the Kerners since the father (who is a "them" when Alex thinks he abandoned his family for West Berlin) was not the parent who ultimately divided the family. The Ostalgie and East German perspective that are central to the film also underscore the significance of multiple and marginalized points of view, rather than one fixed narrative. So while East Germans are historically the "them," generously welcomed into a (West) German "us," the film offers a Derridian deconstruction of this hospitality by examining the opposite welcome when Alex has to explain why "West" Germans are moving into their apartment complex in "East" Berlin. He tells Christiane that the borders have been opened but under vastly different circumstances and creates a news segment that announces that people from West Berlin are seeking to escape the rat race of capitalism. While the segment itself is ironic in a historical context, Christiane's insistence that they offer their cottage or a room in the apartment to help house some of these West German "refugees" suggests an exemplary kind of almost absolute hospitality that is neither satirical nor cynical but gestures towards the promises of a home that is not merely comfortable or harmonious but a site for agency, resistance, unconventional inclusion, and experiences of welcome.

Alex imitates the models that Christiane and Jähn represent for him while constructing his own vision of what home should be until he realizes that in order to "feel at home," in his changing 
cultural context and even his own skin, he needs to do more than imitate by constructing his own map of home. He begins this process in the way he reinvents the end of East German socialism for Christiane with Jähn's help as pretend-chancellor in the final newscast. Even though Alex writes and shoots the story for his mother, Becker depicts its creation as an exercise in meditative thinking about, first, the important role and seductive powers of ideals of home, and, second, about learning to dwell by reassessing the political change and personal trauma that Alex had experienced up to that point. The stoic yet personable "Chancellor Jähn" shares a vision of hospitality that Alex deems worthy of his mother's ideals: “Socialism isn't about walling yourself in. It's about reaching out to others and living with them. It means not only dreaming about a better world, but making it happen.” In writing this text for Jähn, Alex himself wants to collapse the inside and outside binary through which his mother sought to protect him (by focusing on the inside and their immediate home). Yet, even as Alex highlights "reaching out" and warns against "walling yourself in," Becker manages to ground the character's whimsy in the speech by showing Christiane in bed, "walled-in" but now in a hospital room rather than her home. In this final newscast, the reinvented "outside" only exists "inside" the room but the speech, as more than a final treatise for a budding political philosopher (or public relations specialist), gives Alex the opportunity to rethink his actions and the political agenda that he protested but then sought to re-imagine.

Through this pivotal scene, Becker shows Alex's realization that-well intentioned or not-he cannot control his mother's home in much the same way as a government could not control its citizens' experience of "homeland." Christiane watches her son dotingly, knowing that he has gone to great lengths just for her health and her happiness, while Alex looks a little heart-broken, aware that this re-imagined Germany will never exist. Yet, his idealism is not shattered but more grounded since he finally seems to be constructing a composite home rather 
than simulating an image of a "proper" home as an immaculate household at the private level or as an uncritically patriotic nation at the social level. Manning and Shackford-Bradley suggest that “the film shows us Alex's inevitable transformation, which is shaped by his greater awareness and flexibility" (43), and I argue that this flexibility is what will allow Alex to function in an increasingly liquid world without resorting to self-delusions and others' templates of home. The geopolitics of post-Wall Germany, the family reconciliation that begins with Alex's trip to see his father, and the sheer idealism of Christiane are ultimately shown by Becker to influence Alex without dictating to him the ways in which he should construct home. By demonstrating how Alex can learn to dwell when he stops imitating templates that simply replicate social and political norms, Becker depicts an engaged home-maker who is unable to reinvent his circumstances but can amend or can even, to use Derrida's phrase, invent his own (multi-scalar) taxonomy of home.

\section{Mapping the multi-scalar: rooms, neighbourhoods, cities, worlds}

Through the recreation of a social moment inside a private space, Becker's Good Bye, Lenin! not only challenges the construction of "public" and "private" versions or scales of home but produces a compelling argument against a notion of home that suggests only enclosure and exclusion, something that can be locked away or isolated because it is distinctly personal or psychological. Derrida's re-evaluation of hospitality as "hostipitality" offers an incisive method of rethinking the social relevance of home as a physical and conceptual space for assessing and potentially subverting socio-economic processes like commodification, as well as political rhetoric that claims to offer freedom yet does so very selectively. Additionally, "hostipitality" models a means of collapsing or integrating binaries that frequently inhibit the roles of home and, in doing so, positions the home-maker as both host and guest - embedded in rootedness and 
unsettledness of a home marked by das Unheimliche. In Good Bye, Lenin!, the geographically and temporally complex mapping of home which Alex undertakes demonstrates that a home-maker internalizes public constructions and constraints, but, more importantly, that a home-maker can resist succumbing to a social paradigm of how home is conceived, and can "recover" himself as hooks proposes in her discussion of homeplace. The map of home that Becker charts for Alex in Good Bye, Lenin! is a complex map much like the one that Dickner discusses in Nikolski (which I analyzed in chapter six), but Good Bye, Lenin! focuses on socio-political dimensions and public constructions of home in addition to more personal "mapping" or navigation of the idea.

Unlike the binary understanding of a public versus private conception of home that I explored in my analysis of Dogville, Good Bye, Lenin! shows how Alex's understanding of home shifts when he starts to integrate conflicting narratives about his family and nation, no longer sterilizing the idea for his ailing mother or himself. In both films, the heroines' experiences include identifying as an "us," being home safe, and offered hospitality, as well as being identified as a "them," thereby being under house arrest, and a target of hostility. Yet, in contrast to Grace's literal entrapment, Christiane's post-coma experience represents a more complicated kind of uncanny unsettledness. By depicting the disconnect between promises made to and the treatment of these heroines, von Trier and Becker reveal the role of "hostipitality" in constructions of home. Although Grace appears to tolerate the abuse and Christiane seems to tolerate the East German government, only Christiane addresses the problems that stem from this approach. So, while von Trier's brutal ending in Dogville leaves a stronger impression about the problems of "giving" place, Becker's last scene — also one of death as Alex shoots Christiane's ashes over Berlin with a firecracker — suggests a collapsed rather than an inversed and thereby re-inscribed binary. Alex has not lost or usurped the power to construct a private or public home but, instead, accepted the 
darker as well as liberating nuances of "hostipitality" in a composite and dynamic understanding of home that fosters learning to dwell amidst the political and economic uncertainties and insecurities of liquid modernity.

In my analysis of "hostipitality" in Dogville and Good Bye, Lenin! in these final chapters I have sought to demonstrate that idealized images and myths (such as the quaint small town and the socialist nation) undermine an ethical understanding of the rights of dwellers to engage with and maintain a sense of home that can nurture not only self-reflection but the potential for resistance, particularly when dominant ideologies become oppressive. The townspeople of Dogville and the East German regime both offer hospitality to Grace and its citizens, yet a welcome that prohibits leaving is a mark of hostile subordination. Derrida explains that, historically, feeling welcome and offering welcome to others are experiences within the purview of the host, who feels at home and thus can welcome others, yet his analysis of parasitical behaviour-hosts or guests becoming hostages or parasites - also offers important ways of destabilizing this assumption. Derrida's work suggests the power of newcomers to reframe home for everyone, and, while his concern is largely with immigration, I want to suggest that many other dimensions can emerge from the issues that I have been dwelling on — these include gender, sexuality, minority status, and disability, as well as literal homelessness, poverty, the norms of domesticity, and other circumstances and practices through which home-makers feel that they are not at home because of social expectations regarding citizens, families, communities, or society and the institutionalized practices and cultural products that maintain them. Grace migrates from the city to a nearby town and Christiane "comes from" East Germany when she wakes up in a unified Germany, without having to go anywhere; however, by presenting allegorical rather than merely literal immigration, both texts are highly relevant to the varied and overlapping dimensions of the ethical imperatives of hospitality. 
In the films, the private lies and public facades constructed to uphold binaries actually bring attention to these fluctuations. The impossibility of rigidly delineating a "pure" inside and outside is often alluded to, most explicitly through a metaphor like Dogville being "rotten from the inside out" (according to Chuck) and the paradox of the re-imagined outside world existing only inside Christiane's room. I suggest that the parallels that Grace and Alex seek, between the small town and big city or socialist "East" and capitalist "West," are used by both directors to depict a need to undermine such normative oppositions and the "sides" that they privilege: in Dogville Grace's life is hardly tranquil as the friendly small town locals act like city gangsters, and in Good Bye, Lenin! nostalgic communist kitsch is countered with what Alex calls a "gaudy consumer paradise."

I find the framework of what Lewis and Cho describe though their notion of the "dirty" home particularly illuminating for thinking about identity, place, and belonging because home as "dirty space" incorporates such oppositions rather than merely replacing or reproducing them. Dogville illustrates the traps of a simplistic or overly rigid conception of home as either/or and "there" or "not," and Good Bye, Lenin! builds on these ideas by concluding with Alex's acceptance of the "dirty" home built through personal agency and collective forces, as well as traumatic but also formative experiences. Moreover, by subverting conventional notions of a static and singular home, these films showcase some of the ways in which the multi-scalar labyrinthine home and its multi-modal, multi-sensory cartography can help home-makers learn to dwell and rethink who they are-by integrating where they are, where they have been, where they are going, as well as the (un)welcoming forces that help to nurture or transplant their "roots" and guide them onto new or once familiar "routes." Becker, in particular, demonstrates ways in which home-makers can still conceive of and aspire to Derrida's ethical ideal of absolute hospitality within an increasingly 
monetized socio-political landscape. This ideal, as these two character-driven yet overtly political films have taken it up, has helped me to reframe the economic dimensions of hospitality and condemn the quantification of a social practice that importantly mediates, mitigates, and can "make" people feel at home.

Von Trier and Becker show in their films that an investment-oriented or consumption-based model of home-making undermines dwelling as a human endeavour that cannot be reduced to monetary "value." In Dogville the townspeople expect to see "returns" for letting Grace stay and in Good Bye, Lenin! the material trappings of East German socialism work to cover up the harsh political reality of life in that time, creating a kind of false consciousness that enforces an ideology that flattens experience. Yet, because in Good Bye, Lenin! Alex accepts "hostipitality" with the inevitably hostile sides of hospitality-unlike the characters in Dogville who are shown as being unable to reconcile this aporia-Becker's film suggests a means of integrating rather than isolating experiences of being (un)welcome in a household, homeland, and on other scales of home. This is a political position, not in a way that is restricted to specific historical and political circumstances but, rather, is relevant to the experiences of individuals in the twentieth and twenty-first centuries from a wide range of geopolitical areas all shaped by liquid modernity. Von Trier and Becker illustrate in these works why it is important to consider how all home-makers - not just consumers of hospitality in the increasingly economic sense of the term or international migrants who too often experience hostile receptions - are faced with diverse conditions of welcome while "making" home, mapping its multi-scalar networks, and learning to dwell. 


\section{CONCLUSION}

When we renew our concern with homeplace, we can address political issues that most affect our daily lives.

- bell hooks

Lewis and Cho suggest that "[p]erhaps there is no more pressing social problem than the simple yet elusive question, Where do you call home?" (89). By highlighting ideas of home as pressing now and not "back then," my aim has been to unpack the socio-political, cultural, and affective significance of home. Home represents so much more than a residence, a geographical origin, or a sense of belonging delineated by birth, citizenship, or ethnic ties. Calling place(s) home demands agency because "Where do you call home?" asks for more than an address ("Where do you live?") or a point of origin (“Where are you from?"). To account for the increased mobility we see in the twentieth and twenty-first centuries, James Clifford goes so far as to suggest amending "Where are you from?" to "Where are you between?" (37), and throughout this dissertation I have argued that the conceptual, multi-scalar home is the constant "between." When a particular home space is claimed or left behind, a unilateral or unequivocal redefinition of home cannot take place. A change in residence or household, for instance, might not result in an equivalent change in the sense of homeland, and an idea of home can also shift without physical mobility — through diverse personal changes, shifting relations, and external forces. Together, questions about the "between" of home suggest the many ways in which home is attached to places, contexts, experiences, connections, relations, and is, in these ways, multi-scalar.

In my examination of home as a multi-scalar mapping of "betweens," I engaged with a variety of ongoing debates about identity, space/place, mobility, belonging in late capitalism, commitment and community, origins and ownership, as well as agency. Specifically, I focused on 
six inter-related critical issues. I began with the issues of mobility and technology because they describe the most important changes to the presumed and culturally inscribed stability of the idea of home, since we can "transport" aspects of home through digital image and communication technology. I then turned to commodification in order to problematize the increasingly utilitarian significations of home as investment, liquid asset, or hotel-like shelter. These three issues were significant for my analysis of the ways in which individuals who are denied home are categorized: as strangers (outsiders, nomads, physically unhomed or figuratively homeless, and others) and as guests (those who seem to be welcomed but not to truly "make" themselves at home). Finally, I concluded with the issue of scales and sought to bring together all of these issues by suggesting that, within a multi-scalar understanding of home, forms of mobility build rather than destabilize the idea of home, that technology and commodification can facilitate rather than replace the psychological and social significance of the idea, and that strangers as well as guests transform into roles which are actually integral rather than anathema to home-makers and their ability to construct, preserve, and continue learning to dwell poetically.

Through the diverse body of films and literary texts that I analyzed and the nuanced questions about home that they propose, I sought to demonstrate that a theorization of the many dimensions of the idea of home is absolutely vital in an increasingly mobile and globalizing age. Questions of identity, belonging, as well as rights and responsibilities have been highly debated in the postmodern and postcolonial era, yet amidst forced as well as voluntary mass migration and vast changes in how we move and communicate over large—previously staggeringly so - expanses, the notion of home has been largely overlooked in theory. Instead, discussions of home have been flat, relegated to national or familial sagas and to immigrant narratives rather than understood as central to the experience of modernity and, especially, liquid modernity. My aim in 
looking at texts from across North America and Europe that offer allegorical depictions of immigration and non-traditional familial narratives was to elucidate the broader significance of the idea and its global currency. In doing so, I sought to avoid exploring mobility and belonging through conventional tropes of a linear search to find "new" or return to "old" homes.

The works in my corpus importantly rethink and reframe templates of home as well as the agency of home-makers. Through my analysis of Mark Z. Danielewski's House of Leaves, M. Night Shyamalan's The Village, and Lars von Trier's Dogville, I showed that a conventionally static as well as nostalgic and increasingly economic understanding of home cannot flourish in a mobile and global era. In its stead, I showed that Neil Gaiman's Neverwhere, Nicolas Dickner's Nikolski, and Wolfgang Becker's Good Bye, Lenin! proposed a multi-scalar conception of home. Their alternative model, I argued, fosters inclusion rather than exclusion, exploration rather than isolation, and the agency of "building" (constructing and cultivating) home rather than "buying" land, property, or wall space.

The multi-scalar home: theorizing many sizes, relations, and modes

In order to examine the philosophical and sociological nuances of the notion of home and to ground my three scales, I drew upon the works of Martin Heidegger, Zygmunt Bauman, and Jacques Derrida. On the individual scale, Heidegger's work on dwelling offered me a rich foundation on which to begin recuperating the philosophical significance of home for human beings, whom Heidegger characterizes as $d w e l l e r s$ first and foremost. On the interpersonal scale, Bauman's work on liquid modernity presented twenty-first century insights as well as a cultural and historical context within which to look at the relations between dwellers and dwellings, people and places, and the flows and fluxes of increasingly itinerant or virtually mobile groups and 
individuals. Finally, on the social scale, Derrida's work on hospitality and its hostilities offered a fruitful lens for exploring the social constructions of welcome that infiltrate private and public notions of home. Together, through the theory as well as literary and filmic works that I analyzed, I offered a critique of the dominant static conception of home as something that can be quantified, replaced, and fully controlled. The home-maker's agency, the new forms of commitment it makes possible, and the confluence of public and private power relations these bring about are facets of home that a more updated, more complex, and more flexible conception can address. There are clear political stakes involved in this alternate, more dynamic idea.

On their own these theoretical works were insufficient as a lens through which to rethink home because they lead to discussions of flat or partial notions of home that are limited to one scale or dimension. Taken together, however, their theoretical insights, illuminated by my multi-scalar approach, offered a robust framework that is both flexible and can produce a more comprehensive understanding of home. This is a model of home through which individuals maintain social norms, collectives, and traditions but also resist, re-invent, and dream (to echo Bachelard's language) new norms, collectives, and traditions.

Poetic dwelling is possible in liquid modernity, and this is important because it not only challenges some of the principle tenets of postmodern and contemporary Marxist theory but also invites a reassessment of history and its effects. Tony Blackshaw suggests that Bauman "seeks in his sociology to express a poetic response to modernity in its liquid modern stage" ("Bauman's Challenge to Sociology" 82 , my emphasis) and, through my analysis of literary and cinematic works, I sought the same, modeling new approaches to thinking about poetic dwelling in the liquid modern era. I have shown how home-makers may learn to dwell amidst flows, flux, and increasingly economic local, intra- and international concerns when they bypass a framework 
based primarily on ownership in favour of one shaped by a multilayered sense of allegiances and experiences. Bauman himself gestures towards this understanding of home in Liquid Modernity when he draws on Derrida's and novelist Juan Goytisolo's ideas: “[r]ather than homelessness, the trick is to be at home in many homes, but to be in each inside and outside at the same time, to combine intimacy with the critical look of an outsider, involvement with detachment—a trick which sedentary people are unlikely to learn. Learning the trick is the chance of the exile: technically an exile — one that is in, but not of the place" (207, original emphasis). The distinction that Bauman makes between "in" and "of" is important in removing place of birth or an ancestral space as prime signifier of where and what can be thought of as home, since we can be "in" many places and co-create them, while being "of" a place suggests an essentialist position that limits home as well as individual and social identities.

A conception of home that spans scales can nurture meditative thinking and, through it, the engaged home-making that Heidegger calls poetic dwelling. Rosello claims that, along with the social sciences, literature and cinema offer "a parallel search for the signs of emerging patterns" by "invit[ing] us to think beyond what we already know, to dream up new paradigms" ("Wanted" 17), and my corpus of postmodern works redefines home as a concept that de-naturalizes what formerly were certainties by exploring new paradigms of navigating and mapping this labyrinthine idea. Together, these texts innovatively depict home as a space that shifts (the "inner" house in House of Leaves or Door's house in Neverwhere), an idea that cannot be manufactured and controlled (as depicted in The Village and Dogville), and a composite of places that can be reconfigured (the complex maps in Nikolski and the private-but-also-public home that Good Bye, Lenin! depicts). All of these texts foreground the overlaps that constitute home while exploring the idea's labyrinthine qualities, the networks that suggest a complex map, and the social context that 
infiltrates all scales of home.

\section{"Inhabiting" texts: the insights of literature and film}

I chose to analyze literary and cinematic works because the rhetoric and the imagery of home are intertwined but also integral to this complex, deeply emotional, and political idea. Literature (which I analyzed chapters two, three, and six) offered introspection and important insights into the thoughts and feelings of home-makers, while film (which I analyzed in chapters five, eight, and nine) offered insights on the bigger picture by depicting social and physical landscapes. Not merely theorizing the realities of post-war dwelling (Heidegger), the consequences of liquidization (Bauman), or the politics of economically derived welcome (Derrida), the literary and filmic texts illuminated richer, contemporary conceptions of home by refracting new ways of working within the realities of this post-war liquid modern hostipitality on multiple geocultural scales. My corpus depicted variously successful attempts at poetic dwelling and showed how the circumstances of late capitalism as well as its dominant socio-political norms affect but only sometimes impede the possibilities of poetic dwelling. Moreover, as Margaret Morse points out, "feeling at home is, in essence, a personal and culturally specific link to the imaginary" (63) and my primary texts helped me build on this claim through close readings and comparative analysis.

The central issue that I have taken up in light of an extensive history of home —one that archaeologist Jerry D. Moore describes as ten thousand years of "using our homes as templates of the cosmos" and of understanding homes as "rich frameworks for the construction of meaning" (223) — is that such frameworks are increasingly utilitarian, economic, and standardized. In fact, I have sought to undermine the notion of a template that instead of suggesting meaning-making 
broadly, outlines the "proper" goals and "desirable" homes for individuals as consumers—such a model is more explicit in House of Leaves with the Navidson's house, in The Village with the Covington Woods community, and in Dogville with the superficially quaint small town, but it also functions implicitly in Neverwhere with Richard's London flat, in Nikolski with the narrator's suburban childhood home, and in Good Bye, Lenin! with Alex's father's house in former West Berlin. Thus, while all of the texts aim to describe or redefine home, looming in the background is a conventional notion of home that is linked to the explicit goals of ownership and wealth that are encompassed by a generic experience that can be earned or is associated with values in increasingly quantifiable and economic ways.

The overarching themes of my pairings - the initial contemplative texts and the ones that then examine new ways of imagining home-were isolation and exploration, respectively. The first texts focus on the micro-home and isolating an individual (Johnny in House of Leaves), household (the Navidsons in House of Leaves), select group (in The Village), or a social history that suggests a community (in Dogville). Isolation is initially presented by Danielewski, Shyamalan, and von Trier as a means of saving or resurrecting home in a world that no longer values settlement. In House of Leaves characters attempt to create an "immutable" home or an "outpost" and grow obsessed with their immediate space as well as the related feelings of safety or belonging that they seek in the notion of home. In The Village a small community isolates itself in order to ignore global forces, but also manages to foster a paranoia that encompasses an adult extreme of "stranger danger" as well as a general distrust of others and otherness. Dogville similarly depicts the isolation of a community but through a more immediate us-versus-them or ours-versus-theirs brand of social home-making because a common enemy has not been mythologized and imagined but is marked by the arrival of an actual outsider. In different ways, 
these texts elucidate the obsessive elements of maintaining and protecting home that can turn it into a space of exclusion rather than integration and connection.

Because these works offer in-depth reflections on the problem of locating and sustaining a sense of home, I paired them with works which explored means of more actively managing the fear of loss, insecurity, and instability that were shown in the initial texts to be an important aspect of ideas of home. The second texts demonstrated the necessity of a more open, exploratory approach to the notion of home, and in Neverwhere, Nikolski, and Good Bye, Lenin! the private and public or micro and macro spheres of home consistently overlapped. Rather than merely reflecting on or reacting to the increasingly complex multi-scalar dimensions of home (as in the three initial works), the protagonists in Gaiman's, Dickner's, and Becker's works found that instead of being isolated by external forces or their own fears, they could learn to negotiate the scales and work to (re)position themselves through their own maps of home - maps that incorporate their "roots" and "routes" and thereby integrated stability with mobility.

The sense of home that emerges from my corpus is an idea that is continually reframed by a shifting dynamic of not only physical but psychological and social circumstances. The texts demonstrate that, even though fears of loss and entrapment as well as the possibilities of safety and belonging depend on external factors, the agency involved in constructing, cultivating, claiming, and committing to home is imperative - as evidenced by von Trier's destructive conclusion in Dogville and the constructive ending of Good Bye, Lenin!. I showed that the works in my corpus, together, theorized home as a space in which individuals (both alone and collectively) can keep learning to dwell poetically in liquid modernity. Furthermore, these works illuminate the larger social issues of privileged settlements, privileged mobility, and the subtleties of hostility and welcome that have for too long been overshadowed by two trends that I have treated here as 
postmodern problems of universalizing consumerist multiplicity and embracing conceptual homelessness.

\section{Postmodern problem 1: multiplicity as "owning” (multiple) home spaces}

My synthesis of theoretical concepts relating to home and my analysis of representations of home in primary texts revealed the importance of home as an integral concept without which individuals transform into consumers, by both buying and being commodities (or "resources" to use Heidegger's language). Recent popular and academic research on home is largely concerned with the materiality of home. Even the more personal and conceptual projects seem to result in “consumption” histories of home, such as Mary Gordon's Home: What It Means and Why It Matters (2010) or Bill Bryson's At Home: A Short History of Private Life (2010). Gordon's and Bryon's personal experiences do not suggest meditations on dwelling but a real estate hunt for a "dream house" and a historical account of architectural conventions, respectively. Scholarly works on home also focus on consumption and these works span disciplines: Grant McCracken (2005) discusses the marketing of the idea of home; Witold Rybczynski's popular architecture-based study, Home: A Short History of an Idea (1987), focuses on the notion of comfort and even opens with an examination of the Ralph Lauren Collection furnishing brand as a successful replica of traditional American “homeyness”; while Richard Ronald's (2008) urban studies research relates the trend of viewing homes as investments in the United Kingdom, across Asia, and in the United States. In Domicide: The Global Destruction of Home (2001), Douglas Porteous and Sandra E. Smith's critique this increasingly conventional view of home as an asset or consumer good view by examining the economic impetus to eradicate homes in order to make room for commercial or public projects. 
The novels and films in my corpus challenge the increasingly prominent relations of home and materialism by, instead, exploring its role for protagonists as a successful or failed conceptual tool which mitigates the mobility and liquidity of a globalizing, digitizing landscape. What my texts all highlight in very distinct ways is that in order to provide a means of connecting to a rapidly changing world, home needs to be conceptually claimed and built by the home-makers themselves because when another - a community, a government, or a corporation-dictates what and where home can be and how it can or cannot be rooted, then this is no longer home: it is Johnny Truant's nightmares and Will Navidson's unwieldy inner house, Richard Mayhew's lifeless flat in London (Above), an isolated village ruled by ignorance and fear, or the kind of burden that the Doucet brothers feel to settle in ways that their father never could (or perhaps did not want to). My final two texts, Dogville and Good Bye, Lenin!, most clearly illustrate the agency at the core of the politics of home. Grace cannot be at home in Dogville if the other residents control her sense of home and Christiane cannot feel at home in her apartment and city if Alex, like the residents of Dogville, can control her life within the space as well as her access to the outside world. Although both films depict the possibilities of home being a stifling and even terrifying trap, they more keenly demonstrate the freedoms of home - not the ideal that Grace awaits and Christiane is told exists, but a sense of the "dirty" home that could allow them to filter the public through a private lens and explore their place in the world that is built with rather than by others in a process that includes leaving and returning, as well as being welcomed and welcoming.

Because both suggest privileged positions (or possessions), an increase in mobility and secondary residences do not make the multi-scalar home an obvious transformation of the conventional singular home space. What I sought to show through a diverse corpus and home-makers of various attitudes and economic means is that a predominantly material and 
economic approach to the question of home in the twenty-first century is incomplete and highly problematic. Only Bauman's ideal type of the tourist can experience home in this way, while the less privileged vagabonds (as well as the pirates and passersby that I theorized in my analysis of Dickner's Nikolski in chapter six) cannot actually engage with home-making in such a way because their documents and bank accounts offer limited mobilities. Von Trier's Dogville would have been a very different story if Grace arrived with a suitcase of mob money but her lack of money (and the fact that she initially does not want to benefit from the illegal and brutal activities through which it was earned) transformed Grace into a more representative home-maker-one who cannot buy at will, move on a whim, or jet set wherever she pleases. In Good Bye, Lenin!, Becker similarly stresses the economic disparities of home-makers and this is most noticeable when Alex visits his father, a privileged homeowner, and is overwhelmed when he enters a space many times larger than his mother's compact flat.

\section{Postmodern problem 2: "homelessness" and the privileges of mobility}

Even though "the uncanny has become a widely used figure for the simultaneous homelessness of the present, and the haunting of the past" (Collins and Jervis 2) and modern individuals are often described as "in crisis, made homeless by the rootlessness of contemporary living" (Ainley 139), my primary texts show that notions of home and roots need to be rethought rather than mourned or presumed lost. Morley points out that "[i]mages abound of our supposedly de-territorialised culture of 'homlessness': images of exile, diaspora, time-space compression, migrancy and "nomdology"” yet "[t]he concept of home often remains as the uninterrogated anchor or alter ego of all this hyper-mobility" (2). Yet, mobility and what is emerging as "hyper-mobility" is not the opposite of a settled, static home because, as my texts repeatedly show, 
mobility is implicit in the construction of home in many ways-leaving childhood homes, other migrations and forces of change, the mobility of others, and a trend of shorter stays in one residence because of economic migration as well as a housing market model increasingly focused on "trading up" and investing in assets or lifestyles.

Instead, I have discussed the homelessness that is a part of rather than opposed to home. This is Heidegger's sense of das Unheimlich, since, as Nico Israel points out, "[d]welling, for Heidegger, already involves a kind of homelessness. For Heidegger this homelessness enables a degree of freedom to rethink being" (15). This notion was my starting point in looking at the individual construction of home - always also unsettled and changing. Another important aspect of promoting conceptual homelessness is the engrossing emphasis on the individual in modernity, particularly through the historical role of neoliberal thought and stress on individualism in the post-war era. Bauman delves into the patterns of liquid modernity in order to reposition the individual within a communal and social context. In this vein, I have focused on the ways in which the authors and filmmakers of my primary texts seek out the potential for rooting amid a self-oriented postmodern culture of starkly individual multiplicities even in an increasingly electronically "networked" digital age. The multi-scalar home, I demonstrated, is a significant conceptual network or map that serves to link individuals in flexible but also sustainable geocultural social webs.

I endeavoured to contextualize the pitfalls and possibilities of such communal and social webs by looking at Derrida's concept of "hostipitality" in Part III. For Derrida, hostile hospitality suggests the need to re-evaluate the rhetoric and gestures that obscure this important ethical social practice. Rosalyn Diprose eloquently summarizes the significance of this view of hospitality when she claims that it "is not a footnote to human existence: this responsiveness, this welcome, this 
openness is subjectivity; it is dwelling; it is the political" (69, original emphasis). My aim in this dissertation has been to demonstrate the significance of rethinking conventional models of home because dwelling is political in all of these ways, while conceptual homelessness works to erase the important political implications of who is welcome to make home, where, and when, and who can participate in the larger cultural constructions of collective, social, and global conceptions of an idea that cannot be pinpointed to one static location but requires a kind of map to be better understood. This map is expansive for contemporary dwellers or home-makers - not only the privileged tourists that Bauman writes about but also those who share more in common with the vagabond "life strategy."

\section{Expanding the paradigm: the global scale}

I have implied through my analysis of the stabilities and mobilities which define home that a cornerstone for the shift away from singular or stagnant notions of identity and belonging is the increasing cultural prominence of the globally situated home. A multi-scalar understanding of home includes a global scale and an investigation of this scale would offer new ways of conceiving of home through cosmopolitanism and cultural works that reflect the social conditions of multinational capitalism and the digital era. Home, after all, is an important site of cosmopolitan uprooting and connectivity. Future research can bring into dialogue work on globalization and identity from various disciplines and draw upon transnational literature and film. Even though ideological and physical markers of at-homeness - such as legitimated claims to cultural legacies and ownership of objects or spaces - continue to evoke the sense of a static or rigidly rooted belonging, forms of hybridity and multiple allegiances are increasingly acceptable and fruitful norms. Elisabeth Bronfen points out that "traces of dislocation inextricably inhabit any 
configuration of home" (24) and an examination of the global scale of home can shed light on not only overt dislocations but their traces and lingering impact.

The global scale of home also offers more ways to think about not only where one can "make" a home but also raises important concerns regarding power in an international context and whose ownership of places, regions, and the world itself sustains expectations regarding home and the rights that the notion of home implies. Joshua Mills-Knutsen suggests that Derrida's analysis of hospitality problematizes who the other, stranger, or foreigner is and invites us to ask, "Whose home is this anyway?" (532). Mills-Knutsen explores the encounter of the Pilgrims and Pequot, concluding that although the Pilgrim arrived as stranger to the land, the Pequot was "the other, judged as inferior and sentenced to death in order to make room for the hordes of Pilgrims to come" (532). A multi-scalar model of thinking about home can help to reframe the question of "Whose home is this anyway?" as one that cannot receive an explicit, incontrovertible answer but an implicitly emergent response that gestures towards a history of claims, power relations, and allegiances for individuals, intimate communities, and larger social groups.

New research can investigate how such power relations continue today and how hostile practices can be uprooted or re-routed in order to recover the ideas of "home" and international "welcome" not only for the tourist-type home-owner or the multinational corporate entity but for dwellers, whose right of resort - like the notion of home itself - is an ethical imperative and not a commodity. Ultimately, the relations between subjectivity, dwelling, and politics as well as the relations of hospitality on the individual, interpersonal, social, and global scales, highlight the stakes of a material template of home, on one hand, and conceptual homelessness, on the other hand. Both extremes facilitate inequality by undermining or delineating what, where, and when home can "exist" as well as who can construct or claim it, and so dwelling on home continues to 
offer important insights into larger questions of self-concept, social identity, and belonging.

\section{Further reading into the practices of home-making}

My humanities based study, which also touched on the important changes to the idea of home that works in communication studies (Morley 2000) and cultural geography (Blunt and Dowling 2006) have outlined, enriches the discourse on home by engaging with a broad scope of philosophical questions regarding dwelling and investigating the innovative depictions of the idea in art. My multidisciplinary examination draws on both the depth and breadth of ideas that literature and film can offer to how we think about home and how these ways of thinking can confine or constrict the notion as well as help transform it into a locus of agency and social engagement.

Because my examination has the large scope of a philosophical, geographical, and sociological understanding of home that is embedded in political and economic contexts, I have not been able to delve into more particular concerns. Since home "along with gender/sexuality, race, class, acts as an ideological determinant of the subject" (George 2), it can be fruitfully analyzed in relation to these ideological determinants. Examinations of political struggles to maintain material or cultural home spaces, the inequitable realities of national and global economics, and domesticity can all gain from an understanding of home as locations, scales, and various "betweens." Other topics are not limited to but can include questions of gender and sexuality on various scales of home, as well as class and socio-economic issues such as home ownership, affordable housing, actual homelessness, and gated communities - whether literally gated, isolated through other means, and even examinations of nations as gated communities. Investigations of the idea of home as constructed regionally and through race, ethnicity, religion, 
or political ideology will also offer new ways of understanding the integral paradoxes and artificial limitations that the idea of home can signify. I chose to examine broader scales but the meanings and relations of conventional delineations such as household, hometown, or homeland could also shed light on the complex scales on and through which home is constructed.

Additionally, new scholarship on immigration, diaspora, and mobility can explore home as a complex map rather than a location and in this way focus on labyrinthine journeys of homecoming rather than isolated acts of staying or leaving. This scholarship can build on Sarah Ahmed's critique of the conventional understanding of home and migration by challenging "the assumption that migration is necessarily a movement away from home" (16, original emphasis). Ahmed's claim highlights the ways that both stability and mobility define home through multiple locations and shifting relations. Another way of examining home as a constructive and relevant rather than destructive or antiquated idea is the approach that Evelyn Jaffe Schreiber undertakes in Race, Trauma, and Home in the Novels of Toni Morrison, when she examines “[h]ow Morrison's novels trace the success or failure to rebuild a self through home" (27). New studies of important international authors and filmmakers as well as those working in emergent genres and styles can re-contextualize the connection between "building” home (in Heidegger's sense of constructing and cultivating) and "rebuilding" self as a home-maker.

Whatever the geographic or disciplinary focus, the idea of home requires further research. bell hooks claims that in "renew[ing] our concern with homeplace, we can address political issues that most affect our daily lives" (48), and this idea offers an important practical foundation for new scholarship on the physical and conceptual spaces that make up home or "homeplace." The underlying political stakes of home have been the impetus of this dissertation and my examination of dwelling, the economics of mobility, and the politics of hospitality. Because the notion of the 
multi-scalar home is based on inclusion and shifts rather than exclusion and rights which are based on rigid conceptions of origins and ownership, it favours more hospitable relations or the possibilities of co-inhabiting in more productive and equitable ways. Political and social change hangs on the material and metaphysical experiences of being at home: people who feel at home anywhere can be apathetic or complacent, while those who are not at home are denied agency-a voice in local, regional, national, and global politics — even in regards to the decision of where and how they can live. The question of home, as I have framed it, is intended to further illuminate not only how our constructions of home are changing but also demonstrate why home remains the most important composite of spaces/places and ideas that we can "make" and know. 


\section{Bibliography}

Ahmed, Sara. Strange Encounters: Embodied Others in Post-Coloniality. London: Routledge, 2000. Print.

Ainley, Alison. “Luce Irigaray: At Home with Martin Heidegger?” Angelaki 2.1 (1997): 139-45. Web. 25 Jun. 2013.

Antomarini, Brunella. "Dogville, or the Arrogance of Grace: Notes on Cinema as Theatre." On Dogville. Ed. Sara Fortuna and Laura Scuriatti. London: Wallflower Press, 2012. 38-50. Print.

Bachelard, Gaston. The Poetics of Space. Boston: Beacon Press, 1994. Print.

Badley, Linda. Lars von Trier. Urbana: University of Illinois Press, 2010. Print.

Bainbridge, Caroline. The Cinema of Lars von Trier: Authenticity and Artifice. London: Wallflower Press, 2007. Print.

Baker, Gideon. Politicizing Ethics in International Relations: Cosmopolitanism as Hospitality. London: Routledge, 2011. Print.

Barney, Timothy. "When We Was Red: Good Bye Lenin! and Nostalgia for the 'Everyday GDR'." Communication and Critical/Cultural Studies 6.2 (2009): 132-151. Web. 7 Nov. 2013.

Bates, Catherine. "Sustainable Urban Foragings in the Canadian Metropolis: Rummaging through Rita Wong's Forage and Nicholas Dickner's Nikolski." British Journal of Canadian Studies 26.2 (2013): 191-212, 297. Print.

Bauman, Zygmunt. 44 Letters from the Liquid Modern World. Malden, MA: Polity Press, 2010. Print.

---. Collateral Damage: Social Inequalities in a Global Age. Cambridge: Polity, 2011. Print.

---. Community: Seeking Safety in an Insecure World. Cambridge: Polity, 2001. Print.

---. Consuming Life. London: Polity Press, 2007. Print.

---. Culture in a Liquid Modern World. Malden, MA: Polity, 2011. Print.

---. Does Ethics Have a Chance in a World of Consumers? Cambridge, Mass: Harvard University Press, 2008. Print.

---. "From Pilgrim to Tourist--or a Short History of Identity." Questions of Cultural Identity. Ed.

Stuart Hall and Paul Du Gay. London: Sage, 1996. 18-37. Print.

---. Globalization: The Human Consequences. New York: Columbia University Press, 2000. Print.

---. Identity: Conversations with Benedetto Vecchi. Malden, MA: Polity Press, 2004. Print.

---. Liquid Fear. Malden, Mass.: Polity Press, 2006. Print.

---. Liquid Life. Cambridge: Polity, 2005. Print.

---. Liquid Love. Malden, MA: Distributed in the USA by Blackwell Pub., 2003. Print.

---. Liquid Modernity. Malden, MA: Blackwell, 2000. Print.

---. Liquid Surveillance. Malden, MA: Polity, 2013. Print.

---. Liquid Times. Cambridge: Polity Press, 2007. Print.

---. Modernity and Ambivalence. Ithaca, N.Y: Cornell University Press, 1991. Print.

---. On Education: Conversations with Riccardo Mazzeo. Cambridge: Polity, 2012. Print.

---. Postmodernity and Its Discontents. New York: New York University Press, 1997. Print.

---. Wasted Lives: Modernity and Its Outcasts. Malden, MA: Blackwell, 2004. Print.

Bay, Jennifer, and Thomas Rickert. "New Media and the Fourfold." jac: a journal of rhetoric, culture, \& politics 28.1-2 np. Print.

Bealer, Tracy, Wayne Yuen, and Rachel Luria, eds. Neil Gaiman and Philosophy: Gods Gone Wild! Chicago, Ill.: Open Court, 2012. Print. 
Beaudry, Jonas-Sebastien. "Apologizing to a Rat." Neil Gaiman and Philosophy: Gods Gone Wild! Eds. Tracy Bealer, Wayne Yuen, and Rachel Luria. Chicago, Ill.: Open Court, 2012. 71-84. Print.

Becker, Wolfgang, dir. Good Bye, Lenin! X Filme, 2003. Film.

Belletto, Steven. "Rescuing Interpretation with Mark Danielewski: The Genre of Scholarship in House of Leaves." Genre: Forms of Discourse and Culture 42.3-4 (2009): 99-117. Print.

Bemong, Nele. "Exploration \# 6: The Uncanny in Mark Z. Danielewski's House of Leaves." Image \& Narrative 5 (2003): np. Print.

Benterrak, Krim, Stephen. Muecke, and Paddy. Roe. Reading the Country: Introduction to Nomadology. Liverpool: Liverpool University Press, 1996. Print.

Berdahl, Daphne. "Good Bye Lenin! Aufwiedersehen GDR: On the Social Life of Socialism." Post-communist Nostalgia. Ed. Mariia Todorova and Zsuzsa Gille. New York: Berghahn Books, 2010. 177-189. Print.

Best, Shaun. "Zygmunt Bauman: Personal Reflections within the Mainstream of Modernity." The British Journal of Sociology 49.2 (1998): 311-320. Print.

Bhabha, Homi. "The World and the Home." Social Text 31/32 (1992): 141-153. Print.

Blackshaw, Tony. "Bauman's Challenge to Sociology." Bauman's Challenge: Sociological Issues for the 21st Century. Eds. Keith Tester and Mark Davis. New York: Palgrave Macmillan, 2010. 70-91. Print.

---. "Book Review: Mark Davis, Freedom and Consumerism.” Journal of Consumer Culture 11.1 (2011): 125-127. Print.

---. Zygmunt Bauman. New York: Routledge, 2005. Print.

Blunt, Alison, and Robyn M. Dowling. Home. New York: Routledge, 2006. Print.

Borges, Jorge Luis. Labyrinths: Selected Stories and Other Writings. New York: New Directions Pub. Co, 1964. Print.

Borgmann, Albert. "Cosmopolitanism and Provincialism: On Heidegger's Errors and Insights." Philosophy Today 36.2 (1992): 131-45. Print.

Boym, Svetlana. The Future of Nostalgia. New York: Basic Books, 2001. Print.

Bradatan, Costica. "'I Was a Stranger, and Ye Took Me Not in': Deus Ludens and Theology of Hospitality in Lars von Trier's Dogville.” Journal of European Studies 39.1 (2009): 58-78. Print.

Braidotti, Rosi. Nomadic Subjects: Embodiment and Sexual Difference in Contemporary Feminist Theory. New York: Columbia University Press, 1994. Print.

Brick, Martin. "Blueprint(s): Rubric for a Deconstructed Age in House of Leaves." Philament 2 (2004): np. Print.

Bronfen, Elisabeth. Home in Hollywood: The Imaginary Geography of Cinema. New York: Columbia University Press, 2004. Print.

Bryson, Bill. At Home: A Short History of Private Life. Toronto: Doubleday Canada, 2010. Print.

Butler, Christopher. Postmodernism: a Very Short Introduction. Oxford: Oxford University Press, 2002. Print.

Capobianco, Richard. "Heidegger's Turn Toward Home: On Dasein's Primordial Relation to Being." Epoché: A Journal for the History of Philosophy 10.1 (2005): 155-173. Print.

Carey, Mike, and Glenn Fabry. Neil Gaiman's Neverwhere. Vertigo, 2007. Print.

Carson, Anne. Economy of the Unlost: Reading Simonides of Keos with Paul Celan. Princeton,

N.J: Princeton University Press, 1999. Print.

Chanen, Brian. 'Surfing the Text: The Digital Environment in Mark Z. Danielewski's House of 
Leaves." European Journal of English Studies 11.2 (2007): 163-176. Print.

Chiesa, Lorenzo. "What Is the Gift of Grace? On Dogville." Film-Philosophy 11.31 1-22. Print.

Clifford, James. Routes: Travel and Translation in the Late Twentieth Century. Cambridge, Mass: Harvard University Press, 1997. Print.

Coats, Lauren et al. "Those We Don't Speak Of: Indians in The Village." PMLA 123.2 (2008): 358-374. Print.

Collier, Patrick C. “'Our Silly Lies': Ideological Fictions in M. Night Shyamalan's The Village.” Journal of Narrative Theory 38.2 (2008): 269-292. Print.

Collins, Jo, and John Jervis. Introduction. Uncanny Modernity: Cultural Theories, Modern Anxieties. Basingstoke, UK: Palgrave Macmillan, 2008. 1-9. Print.

Cook, Roger F. "Good Bye, Lenin!: Free-Market Nostalgia for Socialist Consumerism." Seminar: A Journal of Germanic Studies 43.2 (2007): 206-219. Print.

Cox, Katharine. "What Has Made Me? Locating Mother in the Textual Labyrinth of Mark Z. Danielewski's House of Leaves." Critical Survey 18.2 (2006): 4-15. Print.

Creech, Jennifer. "A Few Good Men: Gender, Ideology, and Narrative Politics in The Lives of Others and Good Bye, Lenin!" Women in German Yearbook: Feminist Studies in German Literature \& Culture 25.1 (2009): 100-126. Print.

Culler, Jonathan D. On Deconstruction: Theory and Criticism after Structuralism. 25th anniversary ed. Ithaca: Cornell University Press, 2007. Print.

Danielewski, Mark Z. House of Leaves. New York: Pantheon Books, 2000. Print.

Davis, Mark. Freedom and Consumerism: a Critique of Zygmunt Bauman's Sociology. Burlington, Vt.: Ashgate, 2008. Print.

Dawes, Simon. "The Role of the Intellectual in Liquid Modernity: An Interview with Zygmunt Bauman." Theory, Culture \& Society 28.3 (2011): 130-148. Print.

de Certeau, Michel. The Practice of Everyday Life. Berkeley: University of California Press, 1984. Print.

de Gaynesford, Maximilian. "Integrity and Grace." On Dogville. Ed. Sara Fortuna and Laura Scuriatti. London: Wallflower Press, 2012. 81-96. Print.

Dell'Aversano, Carmen. "'Your Eyes Shall Be Opened and Ye Shall Be as Gods': The Director as Serpent in Dogville." On Dogville. Ed. Sara Fortuna and Laura Scuriatti. London: Wallflower Press, 2012. 67-80. Print.

Derrida, Jacques. Adieu to Emmanuel Levinas. Stanford, Calif: Stanford University Press, 1999. Print.

---. "Hostipitality." Angelaki 5.3 (2000): 3-18. Print.

---. Monolingualism of the Other, or, The Prosthesis of Origin. Stanford, Calif.: Stanford University Press, 1998. Print.

---. Of Hospitality. Stanford, Calif: Stanford University Press, 2000. Print.

---. On Cosmopolitanism and Forgiveness. London; New York: Routledge, 2001. Print.

---. Paper Machine. Stanford, Calif.: Stanford University Press, 2005. Print.

---. "The Principle of Hospitality." Parallax 11.1 (2005): 6-9. Print.

Dickner, Nicolas. Nikolski. Trans. Lazer Lederhendler. Toronto: Knopf Canada, 2008. Print.

Dikeç, Mustafa. "Pera Peras Poros." Theory, Culture \& Society 19.1-2 (2002): 227-247. Print.

Diprose, Rosalyn. "Women's Bodies Between National Hospitality and Domestic Biopolitics." Paragraph 32.1 (2009): 69-86. Print.

Ekman, Stefan. "Down, Out and Invisible in London and Seattle." Foundation 34.94 (2005): 64-74. Print. 
Elbeshlawy, Ahmed F. "Dogville: Lars Von Trier's Desexualized America.” Scope 10 np. Print. Ernst, Wolfgang. Digital Memory and the Archive. Minneapolis, MN: University of Minnesota Press, 2013. Print.

Evans, Mel. "This Haunted House: Intertextuality and Interpretation in Mark Danielewski's House of Leaves (2000) and Poe's Haunted (2000)." Mark Z. Danielewski. Ed. Joe. Bray and Alison. Gibbons. Manchester: Manchester University Press, 2011. 68-85. Print.

Fanon, Frantz. The Wretched of the Earth. New York: Grove Press, 2004. Print.

Finger, Anke. "Hello Willy, Good Bye Lenin!: Transitions of an East German Family." South Central Review 22.2 (2005): 39-58. Print.

Fisher, Claudine. "The Triptych Motif in Niksolski by Nicolas Dickner." The French Review 84.6 (2011): 1188-1198. Print.

Fortuna, Sara. "Dogville's 'Illustration': Ambiguous Images, Filmic Plurilingualism and Ethics." On Dogville. Ed. Sara Fortuna and Laura Scuriatti. London: Wallflower Press, 2012. 97-116. Print.

Fortuna, Sara, and Laura Scuriatti, eds. On Dogville. London: Wallflower Press, 2012. Print.

Fowkes, Katherine. "Four Films by M. Night Shyamalan: Oh, the Irony?" Critical Approaches to the Films of M. Night Shyamalan: Spoiler Warnings. Ed. Jeffrey Andrew. Weinstock. New York: Palgrave Macmillan, 2010. 71-87. Print.

Franklin, Adrian S. "On Loneliness." Geografiska Annaler: Series B, Human Geography 91.4 (2009): 343-354. Print.

Freud, Sigmund. The Uncanny. New York: Penguin Books, 2003. Print.

Friedberg, Anne. Window Shopping: Cinema and the Postmodern. Berkeley: University of California Press, 1993. Print.

Friedman, Avi, and David Krawitz. Peeking through the Keyhole: The Evolution of North American Homes. Montreal: McGill-Queen's University Press, 2002. Print.

Friedman, Ted. "The Politics of Magic: Fantasy Media, Technology, and Nature in the 21st Century." Scope 14: np. Print.

Garber, Marjorie B. Sex and Real Estate: Why We Love Houses. New York: Pantheon Books, 2000. Print.

George, Rosemary Marangoly. The Politics of Home: Postcolonial Relocations and Twentieth-century Fiction. Berkeley: University of California Press, 1999. Print.

Godeanu-Kenworthy, Oana. "Deconstructing Ostalgia: The National Past between Commodity and Simulacrum in Wolfgang Becker's Good Bye Lenin!" Journal of European Studies 41.2 (2011): 161-177. Print.

Gordon, Mary. Home: What It Means and Why It Matters. New York: Sterling, 2010. Print.

Gosetti, Jennifer Anna. "The Poetic Politics of Dwelling: Holderlin, Kant, and Heidegger." International Studies in Philosophy 30.1 (1998): 57-71. Print.

Goss, Brian Michael. Global Auteurs: Politics in the Films of Almodóvar, von Trier, and Winterbottom. New York: Peter Lang, 2009. Print.

Graulund, Rune. "Text and Paratext in Mark Z. Danielewski's House of Leaves." Word \& Image 22.4 (2006): 379-389. Print.

Greenfield, Lauren, dir. The Queen of Versailles. Evergreen Pictures, 2012. Film.

Hall, Stuart. "Cultural Identity and Diaspora." Identity: Community, Culture, Difference. Ed. Jonathan. Rutherford. London: Lawrence \& Wishart, 1990. 222-37. Print.

Hamilton, Edith. Mythology. New York: New American Library, 1942. Print.

Hamilton, Natalie. "The A-Mazing House: The Labyrinth as Theme and Form in Mark Z. 
Danielewski's House of Leaves.” Critique: Studies in Contemporary Fiction 50.1 (2008): 3-16. Print.

Hansen, Mark B. N. "The Digital Topography of Mark Z. Danielewski's House of Leaves." Contemporary Literature 45.4 (2004): 597-636. Print.

Haswell, Jonathan, dir. The Royal Opera: The Minotaur. Opus Arte, 2008. Film.

Hayles, N. Katherine. "Saving the Subject: Remediation in House of Leaves." American Literature 74.4 (2002): 779-806. Print.

Heidegger, Martin. “Homeland.” Trans. Thomas Franklin O’Meara. Listening 6 (1971): 231-8. Print.

---. "The Question Concerning Technology." Basic Writings: From Being and Time (1927) to The Task of Thinking (1964). Rev. and expanded ed. San Francisco, Calif.: Harper, 1993. 307-341. Print.

Heidegger, Martin. Discourse on Thinking. New York: Harper Perennial, 1969. Print.

---. "Building Dwelling Thinking." Poetry, Language, Thought. Trans. Albert Hofstadter. New York: Perennial Classics, 2001. 143-159. Print.

---. Poetry, Language, Thought. Trans. Albert Hofstadter. New York: Perennial Classics, 2001. Print.

Heller, Agnes. "Where Are We at Home?" Thesis Eleven 41.1 (1995): 1-18. Print.

Henson, Jim, dir. Labyrinth. Sony Pictures, 1986. Film.

Hodgin, Nick. "Aiming to Please? Consensus and Consciousness-raising in Wolfgang Becker's Good Bye, Lenin!" New Directions in German Cinema. Ed. Paul Cooke and Chris Homewood. London; New York: I.B. Tauris, 2011. 93-110. Print.

Hofstadter, Albert. Introduction. Poetry, Language, Thought. By Martin Heidegger. New York: Perennial Classics, 2001. ix-xxii. Print

hooks, bell. Yearning: Race, Gender, and Cultural Politics. Toronto, ON: Between the Lines, 1990. Print.

Howells, Christina. Derrida: Deconstruction from Phenomenology to Ethics. Malden, MA: Polity Press, 1998. Print.

Howie, Cary. "Means of Transport." Postmedieval 2.3 (2011): 329-338. Print.

Humphreys, Dewi, dir. Neverwhere. BBC TV, 1996. Film.

Hutcheon, Linda. The Politics of Postmodernism. London: Routledge, 1989. Print.

Israel, Nico. Outlandish: Writing between Exile and Diaspora. Stanford, Calif.: Stanford University Press, 2000. Print.

Jameson, Fredric. "Notes on Globalization as a Philosophical Issue." The Cultures of Globalization. Ed. Fredric Jameson and Masao Miyoshi. Durham, N.C: Duke University Press, 1998. 54-77. Print.

---. The Seeds of Time. New York: Columbia University Press, 1994. Print.

Jaskolski, Helmut. The Labyrinth : Symbol of Fear, Rebirth, and Liberation. Boston: Shambhala, 1997. Print.

Jay, Martin. "Liquidity Crisis: Zygmunt Bauman and the Incredible Lightness of Modernity." Theory, Culture \& Society 27.6 (2010): 95-106. Print.

Jenkins, Alice. "Tunnel Visions and Underground Geography in Fantasy." Foundation 35.98 (2006): 28-43. Print.

Jordan, Miriam, and Julian Jason Haladyn. "The Simulation of Evil in M. Night Shyamalan's The Village." Critical Approaches to the Films of M. Night Shyamalan: Spoiler Warnings. New York: Palgrave Macmillan, 2010. 175-188. Print. 
Jozwiak, Joseph F., and Elisabeth Mermann. “"The Wall in Our Minds?' Colonization, Integration, and Nostalgia.” The Journal of Popular Culture 39.5: 780-795. Print.

Kapczynski, Jennifer M. "Negotiating Nostalgia: The GDR Past in Berlin Is in Germany and Good Bye, Lenin!" The Germanic Review 82.1 (2007): 78-87,89-100,111. Print.

Krasner, James. Home Bodies: Tactile Experience in Domestic Space. Columbus: Ohio State University Press, 2010. Print.

Le Corbusier. Towards a New Architecture. New York: Dover Publications, 1986. Print.

Leach, Neil. "Forget Heidegger." Scroope: Cambridge Architecture Journal 12 (2000): 50-59. Print.

---. "The Dark Side of the Domus." The Journal of Architecture 3.1 (1998): 31-42. Print.

Lewis, Tyson, and Daniel Cho. "Home Is Where the Neurosis Is: A Topography of the Spatial Unconscious." Cultural Critique 64 (2006): 69-91. Print.

Little, William. "Nothing to Write Home About: Impossible Reception in Mark Z. Danielewski's House of Leaves." The Mourning after: Attending the Wake of Postmodernism. Ed. Neil Brooks and Josh Toth. Amsterdam: Rodopi, 2007. 169-199. Print.

Lübecker, Nikolaj. "Lars von Trier's Dogville: A Feel-bad Film." The New Extremism in Cinema: From France to Europe. Ed. Tanya Horeck and Tina Kendall. Edinburgh: Edinburgh University Press, 2011. 157-168. Print.

Lynch, Paul et al. "Theorizing Hospitality." Hospitality \& Society 1.1 (2011): 3-24. Web. Malpas, Jeff. Heidegger and the Thinking of Place: Explorations in the Topology of Being. Cambridge, Mass.: MIT Press, 2012. Print.

---. Heidegger's Topology: Being, Place, World. Cambridge, Mass: MIT Press, 2006. Print. Mandolfo, Carleen. "Women, Suffering and Redemption in Three Films of Lars von Trier." Literature and Theology 24.3 (2010): 285-300. Print.

Manning, Caitlin, and Julie Shackford-Bradley. "Global Subjects in Motion: Strategies for Representing Globalization in Film.” Journal of Film and Video 62.3 (2010): 36-52. Print.

Marais, Michael. "Coming into Being: J. M. Coetzee's Slow Man and the Aesthetic of Hospitality." Contemporary Literature 50.2 (2009): 273-298. Print.

Massey, Doreen. For Space. London: SAGE, 2005. Print.

Mazierska, Ewa. European Cinema and Intertextuality: History, Memory Andpolitics. New York: PalgraveMacmillan, 2011. Print.

McCormick, Paul. "Houses of Leaves, Cinema and the New Affordances of Old Media." Mark Z. Danielewski. Ed. Joe. Bray and Alison. Gibbons. Manchester: Manchester University Press, 2011. 52-67. Print.

McCracken, Grant David. Culture and Consumption II: Markets, Meaning, and Brand Management. Bloomington: Indiana University Press, 2005. Print.

McGinn, Daniel F. House Lust: America's Obsession with Our Homes. New York: Crown Business, 2008. Print.

Meljac, Eric Paul. "The Poetics of Dwelling: A Consideration of Heidegger, Kafka, and Michael K." Journal of Modern Literature 32.1 (2008): 69-76. Print.

Mills-Knutsen, Joshua. "Becoming Stranger: Defending the Ethics of Absolute Hospitality in a Potentially Hostile World." Religion and the Arts 14.5 (2010): 522-533. Print.

Molz, Jennie Germann, and Sarah Gibson, eds. Mobilizing Hospitality: The Ethics of Social Relations in a Mobile World. Aldershot, England: Ashgate, 2007. Print.

Moore, Jerry D. The Prehistory of Home. Berkeley: University of California Press, 2012. Print. Morley, David. Home Territories: Media, Mobility, and Identity. New York: Routledge, 2000. 
Print.

Morse, Margaret. "Home: Smell, Taste, Posture, Gleam.” Home, Exile, Homeland: Film, Media, and the Politics of Place. Ed. Hamid Naficy. New York: Routledge, 1999. 63-74. Print.

Mulvey, Laura. "Visual Pleasure and Narrative Cinema." Feminism and Film Theory. Ed.

Constance Penley. New York: Routledge, 1988. 57-68. Print.

Naficy, Hamid, ed. Home, Exile, Homeland: Film, Media, and the Politics of Place. New York: Routledge, 1999. Print.

Nobus, Dany. "The Politics of Gift-Giving and the Provocation of Lars von Trier's Dogville." Film-Philosophy 11.3 (2007): 23-37. Print.

O'Donoghue, Brendan. A Poetics of Homecoming: Heidegger, Homelessness and the Homecoming Venture. Newcastle: Cambridge Scholars, 2011. Print.

"Parasite, N." OED Online. Oxford English Dictionary. Web. 6 Nov. 2013.

Pelevin, Viktor. The Helmet of Horror: The Myth of Theseus and the Minotaur. Toronto: Knopf Canada, 2006. Print.

Peters, John Durham. "Exile, Nomadism, and Diaspora: The Stakes of Mobility in the Western Cannon." Home, Exile, Homeland: Film, Media, and the Politics of Place. Ed. Hamid Naficy. New York: Routledge, 1999. 17-41. Print.

Poe. Haunted. Atlantic, 2000. CD.

Pöhlmann, Sascha, ed. Revolutionary Leaves: The Fiction of Mark Z. Danielewski. Cambridge Scholars, 2012. Print.

Porteous, J. Douglas, and Sandra Eileen. Smith. Domicide: The Global Destruction of Home. Montreal: McGill-Queen's University Press, 2001. Print.

Porter, Laurence M. "Mending the Acadian Diaspora: Strategies of Remediation in Nicolas Dickner's Nikolski." University of Toronto Quarterly 81.2 (2012): 297-312. Print.

Pressman, Jessica. "House of Leaves: Reading the Networked Novel." Studies in American Fiction 34.1 (2006): 107-122,124-128. Print.

Ronald, Richard. The Ideology of Home Ownership: Homeowner Societies and the Role of Housing. New York: Palgrave Macmillan, 2008. Print.

Rosello, Mireille. Postcolonial Hospitality: The Immigrant as Guest. Stanford, Calif: Stanford University Press, 2001. Print.

---. "'Wanted': Organs, Passports and the Integrity of the Transient's Body." Paragraph 32.1 (2009): 15-31. Print.

Royle, Nicholas, ed. Deconstructions: a User's Guide. New York: Palgrave, 2000. Print.

Rybczynski, Witold. Home: a Short History of an Idea. New York: Penguin Books, 1987. Print.

Saint-Martin, Lori. "Bastards, Legitimacy and New Families in Contemporary Québec Fiction1." The American Review of Canadian Studies 41.2 (2011): 125-137. Print.

Schreiber, Evelyn Jaffe. Race, Trauma, and Home in the Novels of Toni Morrison. Baton Rouge: Louisiana State University Press, 2010. Print.

Schweitzer, Darrell. The Neil Gaiman Reader. Holicong, Pa.: Wildside Press, 2007. Print.

Scuriatti, Laura. "Dogville and the Problem of Objectification." On Dogville. Ed. Sara Fortuna and Laura Scuriatti. London: Wallflower Press, 2012. 8-21. Print.

Shamsie, Kamila. Kartography. London: Bloomsbury, 2002. Print.

Sharr, Adam. Heidegger for Architects. London: Routledge, 2007. Print.

Shastri, Sudha. "Return to the Beginning: House of Leaves by Mark Danielewski." Atenea 26.2 (2006): 81-94. Print.

Sheehan, Paul. "Postmodernism and Philosophy." The Cambridge Companion to Postmodernism. 
Ed. Steven Connor. Cambridge, UK: Cambridge University Press, 2004. 20-42. Print. Sherrill, Steven. The Minotaur Takes a Cigarette Break. New York: Picador, 2002. Print.

Shryock, Andrew. "Hospitality Lessons: Learning the Shared Language of Derrida and the Balga Bedouin." Paragraph 32.1 (2009): 32-50. Print.

---. "Thinking About Hospitality, with Derrida, Kant, and the Balga Bedouin." Anthropos 103.2 (2008): 405-421. Print.

Shyamalan, M. Night, dir. The Village. Touchstone Pictures, 2005. Film.

Sinnerbrink, Robert. "Ereignis, Technology, Art: Poetic Dwelling in the Later Heidegger." Literature and Aesthetics 16.1 (2006): 81-94. Print.

Slocombe, Will. "'This Is Not For You': Nihilism and the House That Jacques Built." MFS Modern Fiction Studies 51.1 (2005): 88-109. Print.

Smith, Dennis. Zygmunt Bauman: Prophet of Postmodernity. Malden, MA: Blackwell Publ., 1999. Print.

Staat, Wim. "Dogville Characterized by The Grapes of Wrath: European Identity Construction through American Genre Conventions." Framework: The Journal of Cinema and Media 48.1 (2007): 79-96. Print.

Still, Judith. Derrida and Hospitality: Theory and Practice. Edinburgh: Edinburgh University Press, 2010. Print.

Tijmes, Pieter. "Home and Homelessness: Heidegger and Levinas on Dwelling." World Views: Environment, Culture, Religion 2.3 (1998): 201-213. Print.

Timmer, Nicoline. Do You Feel It Too?: the Post-postmodern Syndrome in American Fiction at the Turn of the Millennium. Amsterdam: Rodopi, 2010. Print.

Toth, Josh. "Healing Postmodern America: Plasticity and Renewal in Danielewski's House of Leaves." Critique: Studies in Contemporary Fiction 54.2 (2013): 181-197. Print.

Trier, Lars von, dir. Dogville. Zentropa Entertainment, 2003. Film.

Veel, Kristin. "The Irreducibility of Space: Labyrinths, Cities, Cyberspace." Diacritics 33.3/4 (2003): 151-172. Print.

Vidler, Anthony. The Architectural Uncanny: Essays in the Modern Unhomely. Cambridge, Mass: MIT Press, 1992. Print.

Weil, Simone. The Need for Roots. London: Routledge, 2002. Print.

Weinstock, Jeffrey Andrew, ed. Critical Approaches to the Films of M. Night Shyamalan: Spoiler Warnings. New York: Palgrave Macmillan, 2010. Print.

Westmoreland, Mark W. "Interruptions: Derrida and Hospitality.” Kritike 2.1 (2008): 1-10. Print.

Wigley, Mark. The Architecture of Deconstruction: Derrida's Haunt. Cambridge, Mass: MIT Press, 1995. Print.

Wilder, Thornton. Our Town: a Play in Three Acts. New York: Coward-McCann, 1938. Print.

Wilson, Janelle L. Nostalgia: Sanctuary of Meaning. Lewisburg: Bucknell University Press, 2005. Print.

Woessner, Martin. "What Is Heideggerian Cinema? Film, Philosophy, and Cultural Mobility." New German Critique 38.2 (2011): 129-157. Print.

Wrathall, Mark A. How to Read Heidegger. New York: W.W. Norton, 2006. Print.

Yeğenoğlu, Meyda. Colonial Fantasies: Towards a Feminist Reading of Orientalism. Cambridge, U.K.: Cambridge University Press, 1998. Print.

Young, Iris Marion. Throwing Like a Girl and Other Essays in Feminist Philosophy and Social Theory. Bloomington, Ind: Indiana University Press, 1990. Print.

Žižek, Slavoj. "The Family Myth in Hollywood.” CINEPHILE 3.1 (2007): 42-6. Print. 